\title{
Mechanisms of atrial paralysis due to atrial fibrillation : an integrative study in man and goat
}

Citation for published version (APA):

Schotten, U. (2003). Mechanisms of atrial paralysis due to atrial fibrillation : an integrative study in man and goat. [Doctoral Thesis, Maastricht University]. Universiteit Maastricht. https://doi.org/10.26481/dis.20030925us

Document status and date:

Published: 01/01/2003

DOI:

10.26481/dis.20030925us

Document Version:

Publisher's PDF, also known as Version of record

\section{Please check the document version of this publication:}

- A submitted manuscript is the version of the article upon submission and before peer-review. There can be important differences between the submitted version and the official published version of record.

People interested in the research are advised to contact the author for the final version of the publication, or visit the DOI to the publisher's website.

- The final author version and the galley proof are versions of the publication after peer review.

- The final published version features the final layout of the paper including the volume, issue and page numbers.

Link to publication

\footnotetext{
General rights rights.

- You may freely distribute the URL identifying the publication in the public portal. please follow below link for the End User Agreement:

www.umlib.nl/taverne-license

Take down policy

If you believe that this document breaches copyright please contact us at:

repository@maastrichtuniversity.nl

providing details and we will investigate your claim.
}

Copyright and moral rights for the publications made accessible in the public portal are retained by the authors and/or other copyright owners and it is a condition of accessing publications that users recognise and abide by the legal requirements associated with these

- Users may download and print one copy of any publication from the public portal for the purpose of private study or research.

- You may not further distribute the material or use it for any profit-making activity or commercial gain

If the publication is distributed under the terms of Article $25 \mathrm{fa}$ of the Dutch Copyright Act, indicated by the "Taverne" license above, 


\section{Mechanisms of Atrial Paralysis due to Atrial Fibrillation}

An Integrative Study in Man and Goat

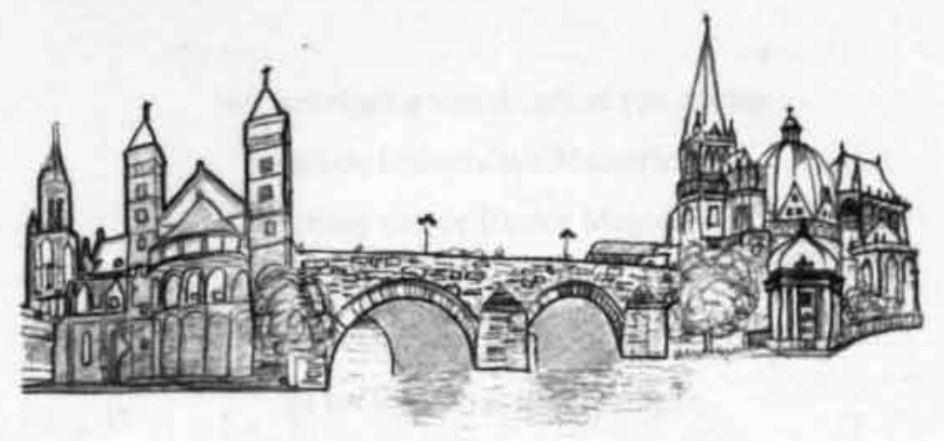

Ulrich Schotten 



\title{
Mechanisms of Atrial Paralysis due to Atrial Fibrillation
}

\author{
An Integrative Study in Man and Goat
}

\author{
PROEFSCHRIFT
}

ter verkrijging van de graad van doctor aan de Universiteit Maastricht, op gezag van de Rector Magnificus,

Prof. Dr. A.C. Nieuwenhuijzen Kruseman, volgens het besluit van de College van Decanen, in het openbaar te verdedigen

op donderdag 25 september 2003 om 16.00 uur

door

Ulrich Schotten 


\section{Promotores}

Prof.dr. M. Allessie

Prof.dr. P. Hanrath (University Hospital Aachen)

\section{Beoordelingscommissie}

Prof.dr. H.J.G.M. Crijns (voorzitter)

Prof.dr. U. Ravens (University Dresden)

Prof.dr. H.A.J. Struijker Boudier

Dr. D. van Wagoner (Cleveland Clinic Foundation, USA)

Prof.dr. G.J. van der Vusse

This study was supported by the Academy of Science of North-Rhine Westfalia, Germany, the Dutch Organization of Scientific Research (NWO program grant 90217097), and the European Union (Marie-Curie Fellowship QLGA-CT-2000-512 36).

Financial support by Medtronic, Biosense Webster, FMI GMbH Föhr, Sonometrics Inc, and the Stichting RESCAR Maastricht for publication of this thesis is gratefully acknowledged. 


\section{Contents}

Chapter 1 Introduction 7

Chapter 2 Cellular Mechanisms of Depressed Atrial Contractility in Patients with Chronic Atrial Fibrillation

Circulation 2001:103:691-698

Chapter 3 Atrial Fibrillation-Induced Atrial Contractile Dysfunction:

A Tachycardiomyopathy of a Different Sort

Cardiovascular Research 2002;53:192-201

Chapter 4 The L-Type $\mathrm{Ca}^{2+}$ Channel Subunits $\alpha_{1 \mathrm{C}}$ and $\beta_{2}$ are not Downregulated in Atrial Myocardium of Patients with Chronic Atrial Fibrillation

J Mol Cell Cardiol 2003;35:437-443

Editorial by Timothy J. Kamp \& Jason D Foell:

L-type $\mathrm{Ca}^{2+}$-channels in Atrial Fibrillation: Wallflowers or a Vanishing Act

J Mol Cell Cardiol 2003:35:427-431

Chapter 5 Electrical and Contractile Remodeling during the First

Days of Atrial Fibrillation go Hand-in-Hand

Circulation 2003;107:1433-1439

Chapter 6 Effect of Atrial Contractile Remodeling on Compliance and Size of the Fibrillating Atrium

Submitted

Chapter 7 The Role of Atrial Dilatation in the Domestication

of Atrial Fibrillation

Prog Biophys Mol Biol 2003;82:151-162

Chapter $8 \quad$ General Discussion

Electrical, Contractile and Structural Remodeling during Atrial Fibrillation

Cardiovasc Res 2002;54:230-246

Summary

Samenvatting

Nawoord

List of publications

Curriculum vitae 



\section{Chapter 1}

\section{Introduction}

Historical Overview

Potential Mechanisms of AF-Induced Atrial Contractile Dysfunction Clinical Relevance

Excitation-Contraction Coupling in the Heart Aim of the Study 


\title{
Historical Overview
}

Cardiac arrhythmias are the most frequent abnormalities of cardiac function and through the centuries palpitation of the pulse has become the act most commonly associated with the medical profession. Already since the times of Galen (131-201) it is part of any physical examination (Figure 1). William Harvey (1578-1657), the ingenious discoverer of blood circulation and founder of modern physiology, provided the physiological rationale for this diagnostic tool by linking the pulse to the rhythmic pump activity of the heart.'

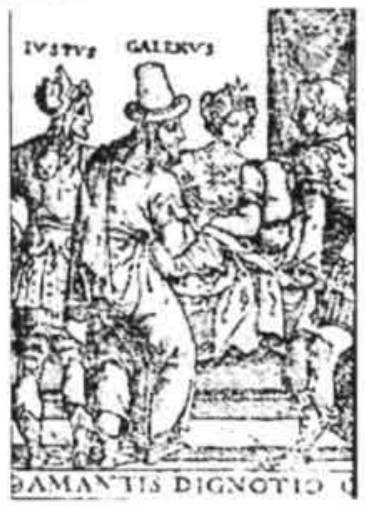

\begin{abstract}
Figure l
Galen (131-201) making a diagnosis of love sickness in a young woman who seemingly suffered from severe physical illness. On closer examination. Galen found no organic pathology and identified the real cause of her somatic symptoms: a hidden love interest. Sudden irregularity of her pulse served as crucial diagnostic clue.

Opera ex sexte Juntarum editione, Venice, 1586.
\end{abstract}

It is no surprise that at the end of the $19^{\text {th }}$ century the clinical syndrome later recognized as atrial fibrillation (AF) was first described in patients having a "conspicuously irregular arterial pulse", which was attributed to "delirium cordis" ${ }^{2: 3}$ "The first insight into the mechanisms of the "pulsus irregularis perpetuus" was provided by the Scottish physician James MacKenzie in $1902 .^{4}$ In tracings of the jugular pulse during AF he found that the "ventricular form of venous pulse" was very common, while the atrial component of the jugular pulse was lost. Cushny noticed a striking similarity between sphygmographic tracings from patients with irregular heart beat and pulse tracings of dogs with fibrillatory contraction of the auricles. For the first time, the irregularity of the pulse and fibrillation of the auricle were suggested to represent one clinical entity. ${ }^{5}$ At that time it was already known that cardiac contractions are caused by electrical impulses $^{6}$ and in 1903 the Dutch physiologist Willem Einthoven presented the prototype of the first string galvanometer as a tool to record electrical activity of the heart. ${ }^{7}$ The first clinical electrocardiogram displaying $\mathrm{AF}$ was published in $1906 .{ }^{8} \mathrm{~A}$ few years later Rothberger and Winterberg, ${ }^{9}$ and Lewis ${ }^{10}$ established uniform criteria for the diagnosis of AF: total irregularity of the ventricular cycle (R-R-intervals), absence of discrete atrial activation ( $\mathrm{P}$ waves), and irregular fast oscillations of the baseline.

Interestingly, apart from terms highlighting the irregularity of the heart beat during $\mathrm{AF}$ like "pulsus arrhythmicus", "pulsus irregularis perpetuus"," or "chronic arrhythmia", 12 already in 1902 MacKenzie suggested the term "paralysis of the auricle". ${ }^{4}$ Although he already recognized the loss of atrial contractility during $\mathrm{AF}$, MacKenzie assumed that atrial paralysis was due to loss of coordinated atrial activation. It should take another 60 years until the disappearance of intrinsic atrial contractility during AF was described for the first time.

William Harvey had already noticed that the atria function as a sort of pump transporting blood into the ventricles: "... But this especially is to be noted, that after 
the heart has ceased to beat, the auricles however still contracting, a finger placed upon the ventricles perceives the several pulsations of the auricles, precisely in the same way and for the same reason, as we have said, that the pulses of the ventricles are felt in the arteries, to wit, the distention produced by the jet of blood. And if at this time, the auricles alone pulsating, the point of the heart to be cut off with a pair of scissors, you will perceive the blood flowing out upon each contraction of the auricles. Whence it is manifest how the blood enters the ventricles, not by any attraction or dilatation of the

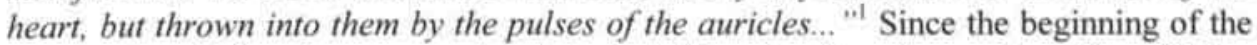
past century it has been appreciated that atrial contraction is capable of modifying ventricular filling. ${ }^{13: 14}$ However, only in the early 1960 s two important clinical developments largely stimulated research on the hemodynamic role of the atrial contraction: (1) the availability of an implantable pacemaker capable of maintaining the normal sequence between atrial and ventricular contractions in patients with atrioventricular block ${ }^{15}$, and (2) the ease and relative safety with which AF and other arrhythmias could be converted to sinus rhythm with the use of external electric countershock by synchronized capacitor discharge. ${ }^{16}$ In 1961 Eugène Braunwald demonstrated that in patients with atrio-ventricular dissociation atrial systoles which are appropriately timed make significant contribution to ventricular filling by elevating ventricular end-diastolic pressure and volume thereby increasing the force of the subsequent ventricular contraction. ${ }^{17}$ In contrast, ventricular contractions which were not preceded by appropriately timed atrial systoles may have lower ventricular enddiastolic pressures and volumes and therefore are weaker (Figure 2).

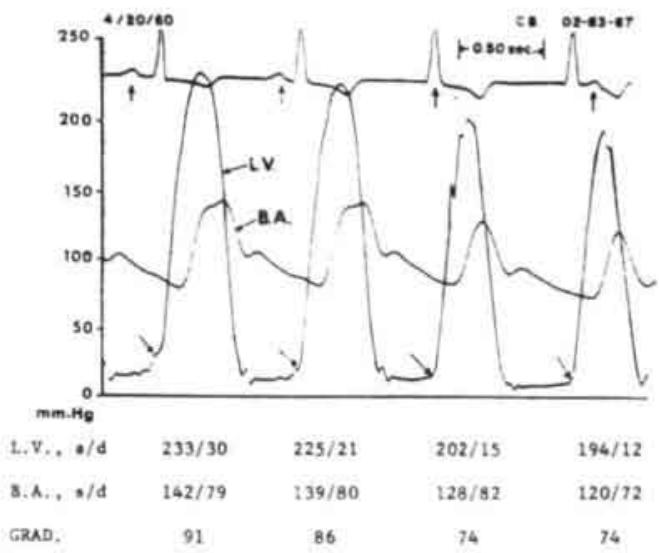

\begin{abstract}
Figure 2
Left ventricular (L.V.) and brachial artery (B.A.) pressure in a patient with aortic stenosis and arterioventricular dissociation. Vertical arrows near the top point to the P-waves of the electrocardiogram. Oblique arrows near the bottom of the tracing indicate the left ventricular end-diastolic pressure, Below: Beat to beat hemodynamic measurements. $s / d=$ systolic/diastolic pressures in $\mathrm{mmHg}$. GRAD = pressure gradient between peak left ventricular and peak brachial artery pressures. Modified from Braumwald et al."
\end{abstract}

Wood and collegues showed that in normal hearts the contribution of the atrial contraction to cardiac output was only 10 to $15 \% .{ }^{18: 19}$ It should be noted, however, that in many patients with increased left ventricular end-diastolic pressures and considerable ventricular hypertrophy (i.e. aortic valve stenosis or hypertension) the left atrial pressure pulse is particularly prominent. ${ }^{17}$ In such patients the development of AF and loss of the atrial "booster pump" often results in abrupt clinical deterioration suggesting that under certain circumstances atrial function can be critically important to maintain cardiac output. $^{17}$ Braunwald was also the first to notice loss of atrial contractility after cardioversion of AF. In the introduction to a symposium on cardiac arrhythmias of the American Medical Society held in November 1964 he stated: "Although an atrial depolarization wave (Pwave) returns, the atrial contraction waves in both the right and 
the left atrial pressure tracings are dimimutive, and it is not likely that these weak atrial contractions influenced ventricular filling significantly. ${ }^{20}$ The first systematic, although very small, study on left atrial contractility following cardioversion was published in 1965 by Logan et al.. In five of the seven patients studied they demonstrated complete loss of atrial contractility immediately after resumption of sinus rhythm (Figure 3) with slow and incomplete recovery during 20 minutes. ${ }^{21}$ The authors' disappointment was obvious: "As a result, one of the benefits expected from successful cardioversion may not be immediately achieved." Very soon Logan's results were confirmed by others. ${ }^{22 ; 23}$ Logan also pointed out that there might be another - much more important - clinical implication of the loss of atrial contraction: "...though it is possible that effective left atrial contraction may gradually return. In such cases the greatest risk of embolic episodes may not arise until some time after cardioversion. ${ }^{-21}$

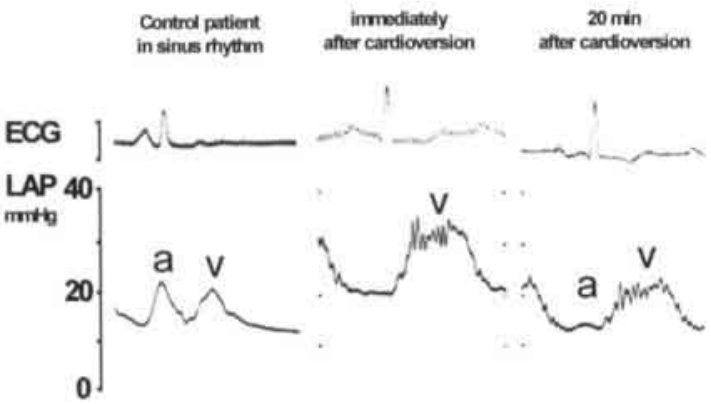

Figure 3

Left atrial pressure tracings of patients with mitral valve disease. Left: control patient in sinus rhythm without history of supraventricular tachycardia (modified from Ikram et al. ${ }^{23}$ ). Mid and right: Patient with chronic $A F$ immediately and $20 \mathrm{~min}$ after cardioversion (modified from Logan et al. ${ }^{2 l}$ ).

Two years later Resnekov presented the first larger study on complications of arrhythmias treated with DC-shocks. ${ }^{24}$ Successful cardioversion was associated with a small although significant risk of immediate embolism, and late thromboembolic complications were observed several days to weeks after cardioversion.

During the $80 \mathrm{~s}$, again introduction of new technical achievements stimulated research on atrial contractile dysfunction. Improved echocardiographic techniques allowed noninvasive monitoring of atrial function and the diagnosis of preformed thrombi attached to the atrial wall. According to these studies recovery of contractile function after cardioversion can take months $\mathrm{s}^{25-27}$ and the degree of contractile dysfunction correlates with the duration of $\mathrm{AF}^{26,28}$ Furthermore, during the first days to weeks after cardioversion to sinus rhythm new thrombus formation has been demonstrated to contribute to the thromboembolic risk associated with $\mathrm{AF}^{29: 30}$ The latter finding emphasizes the clinical significance of the atrial contractile dysfunction and reinforced the attempts to unravel the underlying mechanisms. 


\section{Potential Mechanisms of the Loss of Atrial Contractile Function During AF}

Through the decades a number of hypothesis have been suggested to explain the mechanisms causing the AF-induced atrial contractile dysfunction. Today, some of these hypothesis can clearly be regarded as falsified, whereas others survived until our days.

\section{Rheumatic heart disease}

Already in his first report Logan suggested that chronic rheumatic heart disease might cause "damage to the atrial muscle" and thereby "impair effective contraction in spite of apparently normal electrical excitation. Such damage might be the result of direct involvement in the chronic rheumatic process... ${ }^{.21}$ First, this hypothesis was supported by the observation that that delay of detectable left atrial contraction to return after cardioversion most frequently occurred in patients with rheumatic heart disease ${ }^{23}$ In a histological study Bailey et al. reported inflammatory changes and pronounced loss of atrial contractile material in $\mathrm{AF}$ patients with rheumatic mitral valve disease. ${ }^{31}$ However, the authors could not rule out the possibility that AF per se had caused these morphological changes in the atria. Later, AF-induced atrial contractile dysfunction was also described in $\mathrm{AF}$ patients with heart failure, hypertension, coronary artery disease, hypertrophic cardiomyopathy, hyperthyroidism, and even in patients without any structural heart disease. ${ }^{22: 25: 29: 32}$ Indeed, histological studies showed that loss of myofibrils and disruption of the sarcoplasmic reticulum were common in AF patients regardless of whether the underlying heart disease was rheumatic or non-rheumatic. ${ }^{33}$

\section{Application of DC-shock}

Concern that DC shock might impair the contractile function of the heart arose from the early clinical experience that in patients undergoing repetitive electrical cardioversion for recurrent ventricular fibrillation left ventricular pump function deteriorates. However, this might be due to either DC shock or to ischemia of the ventricular myocardium occurring during fibrillation. In dogs, series of 10 transthoracic DC shocks produced small and sharply localized lesions, mostly limited to a few millimeters of the endocardial surface nearest to the defribrillation pads. ${ }^{34}$ Demonstration of transient STchanges, creatine kinase (CK) elevations, ${ }^{35}$ and the presence of free radicals ${ }^{36}$ added to the evidence of myocardial injury induced by electrical cardioversion. On the other hand, the serum concentration of troponin 1, a more specific marker for myocardial damage, is not affected by electrical cardioversion, suggesting that CK elevation might also be caused by skeletal muscle damage. ${ }^{37: 38}$

There is no doubt that DC injury can not be the sole cause of AF-induced atrial contractile dysfunction. Transient depression of left atrial contractility was clearly demonstrated in patients after pharmacological ${ }^{39}$ or even spontaneous cardioversion ${ }^{40}$ or after cardioversion following surgery for long-lasting $\mathrm{AF}^{41}$ However, $\mathrm{DC}$ cardioversion might aggravate the phenomenon. Some studies have shown that atrial contractile dysfunction induced by $\mathrm{AF}$ was more pronounced in patients undergoing electrical cardioversion compared to patients in which sinus rhythm was achieved pharmacologically. ${ }^{42 ; 3}$ In other studies no effect of the mode of cardioversion on loss of left atrial function was found. ${ }^{44}$ In patients in which electrical cardioversion was not successful the blood flow velocity in the left atrial appendage was not affected, even in cases where multiple attempts up to $360 \mathrm{~J}$ were used. ${ }^{44}$ Also, in patients treated with DC 


\section{2 | Chapter 1}

shocks for termination of ventricular fibrillation during electrophysiological investigations no atrial contractile dysfunction was found. ${ }^{45}$ The most convincing study was published by Sparks et al. who showed that in patients undergoing implantation of a ventricular implantable cardioverter defibrillator neither endocardial nor transthoracic DC shocks significantly altered left atrial contractility. ${ }^{46}$ These observations provide evidence that application of DC-shocks is not responsible for "atrial stunning" observed after cardioversion of AF.

\section{Structural Remodeling}

Early studies on atrial pathology in AF patients showed diffuse fibrosis, loss of contractile material, and disruption of the normal cellular ultrastructure. ${ }^{31: 47}$ These changes were suggested to serve as a substrate of AF and to underlie the loss of atrial contractility. Mary-Rabine et al. reported degenerative changes, loss of myofibrils, accumulation of glycogen and aggregates of dilated sarcoplasmic reticulum-like material. ${ }^{33}$ The changes were most pronounced in patients with chronic AF but it was not clear whether they were due to AF or the underlying structural heart disease. An extensive histological study on structural remodeling in human right atria was published by Aimé-Sempé in $1999 .^{48}$ In tissue sections from fibrillating atria they found that $-64 \%$ of all atrial myocytes showed severe myolysis, whereas only $-12 \%$ of the myocytes from atria in sinus rhythm showed these changes. However, a high percentage of myocytes with myolysis $(-42 \%)$ was also found in samples from hearts of patients in sinus rhythm with a low left ventricular ejection fraction. Most of these patients had dilated atria and/or increased pulmonary artery pressure, suggesting that hemodynamic overload might have caused the structural changes of the right atria.

During the past years numerous studies have reported dilatation, accumulation of glycogen, myolsis, and fibrosis in fibrillating atria. ${ }^{33: 48,49}$ However, most of these studies were done in patients with cardiac disease which to some extent may account for the structural changes observed. Only very few studies were undertaken in patients with 'lone $\mathrm{AF}$, 50.51 The morphological changes observed by Frustaci et al. were very variable. $^{50}$ In 8 of the 12 patients with lone AF lymphomononuclear infiltrates with necrosis of the adjacent myocytes compatible with the diagnosis of myocarditis were described. Seven patients showed patchy fibrosis and in only two patients evidence of fibrillolysis was found. On the other hand, more recently pronounced myolytic changes of the atria were reported in patients with persistent lone AF. ${ }^{51}$

The question whether the observed changes are cause or consequence of AF could not be solved before animal models of AF or rapid atrial pacing were developed. In dogs undergoing rapid atrial pacing for six weeks electromicroscopic investigation of the dilated atria showed an increase of size and number of the mitochondria and disruption of the sarcoplasmic reticulum. ${ }^{52}$ In goats Ausma et al. maintained AF for 9-23 weeks. ${ }^{53}$ After this time, atrial myocytes showed marked changes in their cellular substructures, such as loss of myofibrils, accumulation of glycogen, changes in mitochondrial shape and size, fragmentation of sarcoplasmic reticulum, and dispersion of nuclear chromatin. These changes were accompanied by an increase in size of atrial myocytes. The loss of contractile material would well explain the poor atrial contractile function after cardioversion of AF and its slow recovery. The atrial transport function will only normalize when the atrial contractile machinery has been rebuilt and the process of dedifferentiation is reversed. Despite the obvious attractiveness of this hypothesis it should be noted that in this study loss of contractile material was moderate $(\sim 15 \%$ loss of myofibrils). 


\section{Electrical Remodeling}

In experimental and clinical studies verapamil was able to prevent part of the atrial dysfunction indicating that contractile remodeling was mediated by $\mathrm{Ca}^{2+}$-overload during $\mathrm{AF}^{54: 55}$ Several studies demonstrated that indeed altered $\mathrm{Ca}^{2+}$-metabolism contributes to atrial contractile dysfunction. In dogs with sustained atrial tachycardia atrial contractility has been shown to be reduced on the cellular level ${ }^{56}$ and a pronounced reduction of the L-type $\mathrm{Ca}^{2+}$ current $\left(\mathrm{I}_{\mathrm{CaL}}\right)$ was reported. ${ }^{57}$ Recently, reduced $\mathrm{I}_{\mathrm{CaL}}$ was confirmed in human atrial cardiomyocytes of patients with chronic $\mathrm{AF}^{58-60}$ Since $\mathrm{I}_{\mathrm{Cal}}$ triggers $\mathrm{Ca}^{2+}$ release from the sarcoplasmic reticulum and provides $\mathrm{Ca}^{2+}$ to maintain the $\mathrm{Ca}^{2+}$ load of the sarcoplasmic reticulum, it is a major determinant of myocardial force of contraction. Besides the importance of a reduced $\mathrm{I}_{\mathrm{Cat}}$ for the AFinduced atrial contractile dysfunction, a downregulation of $\mathrm{I}_{\mathrm{CaL}}$ also causes electrical remodeling. In chronically instrumented goats $\mathrm{AF}$ was shown to produce a rapid shortening of the atrial effective refractory period (2-5 days). ${ }^{61}$ This was associated with a shortening of the AF cycle length and a progressive increase in the duration of $\mathrm{AF}$ (AF begets AF). A shortening of the atrial refractory period was also found in dogs undergoing prolonged rapid atrial pacing (42 days). In atrial cardiomyocytes of these animals $\mathrm{I}_{\mathrm{CaL}}$ was found to be reduced by $70 \%$, whereas repolarizing currents were less affected. ${ }^{57}$ Inhibiting $\mathrm{I}_{\mathrm{CaL}}$ of a control cell with nifedipine mimicked the action potential changes produced by atrial tachycardia, whereas increasing $\mathrm{I}_{\text {Cat. }}$ with BayK8644 partly reversed action potential alterations in tachycardia-remodeled cardiomyocytes. These results strongly suggest that a reduction of $\mathrm{I}_{\mathrm{CaL}}$ indeed underlies the tachycardia-induced shortening of the refractory period. Since $\mathrm{I}_{\mathrm{Cat}}$ is also one of the most important regulators of atrial contractile function it is reasonable to believe that electrical and contractile remodeling are very closely related phenomena.

\section{Increased Afterload}

During the transition from AF to sinus rhythm, the outflow velocity of the left atrial appendage clearly declines. ${ }^{29}$ During AF contraction of the atrial appendages is not synchronized which means that the pressure gradient between appendage and atrial main cavity is enhanced. After cardioversion the left atrial appendage has to contract against the atrial pressure build up during atrial systole which might contribute to the reduction of the flow velocity in the left atrial appendage. ${ }^{62} \mathrm{~A}$ similar hypothesis was put forward by Zarse and coworkers. ${ }^{63}$ In a pig model of pacing induced AF they demonstrated a reduced left atrial appendage outflow velocity due to an increased afterload against which the left atrial appendage has to contract after restoration of sinus rhythm.

\section{Tachycardiomyopathy of the Atria}

In humans prolonged, rapid activation of the ventricles at rates above $100 / \mathrm{min}$ leads to a decline in contractile function of ventricular myocardium and dilatation of heart chambers. ${ }^{64}$ During the past decade numerous animal models of tachycardia-induced ventricular cardiomyopathy have been developed. The decline in ventricular contractile function occurs within weeks and recovery upon restoration of normal rate is a slow process. It turned out that the key alterations underlying tachycardia-induced cardiomyopathy resemble those identified in failing human myocardium: (1) dysregulation of intracellular signaling, e.g. desensitization of the $\beta$-adrenergic signal transduction pathway, and (2) altered cellular $\mathrm{Ca}^{2+}$-homeostasis presumably due to 


\section{4 | Chapter I}

dysfunction of the sarcoplasmic reticulum. ${ }^{65-71}$ Tachycardia-induced cardiomyopathy is therefore commonly used as animal model of heart failure.

It has been suggested that the high depolarization frequency during AF causes a disorder of the atria analogous to the cardiomyopathy of rapidly activated ventricles. ${ }^{62}$ If genetic reprogramming upon the same stimulus is similar in atria and ventricles one should expect $\beta$-adrenergic desensitization and dysfunction of the sarcoplasmic reticulum to be present in chronically fibrillating atria.

\section{Clinical Implications}

The main mechanism underlying increased cardiovascular morbidity ${ }^{72}$ and mortality ${ }^{73}$ associated with AF is the reduction of the local blood flow velocity near the atrial wall which increases the risk of thrombus formation and thromboembolic events. Possibly, delayed recovery of atrial contractile function is responsible for the slow restoration of exercise capacity following cardioversion. Moreover, atrial contractile dysfunction might promote dilatation of fibrillating atria.

\section{Thromboembolic Events}

Loss of synchronized atrial contraction results in reduction of atrial blood flow velocity favoring the development of atrial thrombi. ${ }^{74: 75}$ Accordingly, atrial fibrillation is the most common cause of cerebral embolism, accounting for approximately $15 \%$ of all strokes. ${ }^{76}$ The rate of stroke in AF patients largely depends on coexistent structural heart disease. The annual stroke rate ranges from $1.3 \%$ in patients with lone AF younger than 60 years $^{77}$ to up to $7.1 \%$ in patients with hypertrophic cardiomyopathy. ${ }^{78-80}$ Previous strokes, hypertension, heart failure, increasing age, and diabetes mellitus were independently associated with risk of stroke in patients with nonvalvular $\mathrm{AF}^{81: 82}$

Thromboembolism after cardioversion has been attributed to the dislodgement of a preformed atrial mural thrombus after the resumption of atrial contraction. Although thromboembolic events often occur immediately after cardioversion, such events have been described several days to weeks later in patients who have apparently maintained sinus rhythm. ${ }^{24}$ In theory, delayed thromboembolic events might be caused by (1) dislodgement of a thrombus after delayed return of vigorous atrial contractions or (2) by formation of new thrombi in the presence of low blood flow velocities due to delayed recovery of atrial contractility. Indeed, transesophageal echocardiography has proven that new thrombus formation can also occur after cardioversion. ${ }^{30: 83}$ In many of these patients low left atrial appendage blood flow velocities and/or spontaneous echo contrast was found during transesophageal echocardiography. ${ }^{8}$

Not much is known about the time course with which AF-induced atrial paralysis develops. In patients with an implantable intra-atrial defibrillator a significant left atrial dysfunction was reported already after AF of less than 48 hours. ${ }^{86}$ Manning et al. showed that the transmitral a-wave velocity was clearly lower after 6 weeks of AF than after 2 weeks. ${ }^{26}$ In contrast, in dogs the left atrial fractional shortening was diminished by $\sim 18 \%$ after two weeks of rapid atrial pacing and did not decrease any further after 4 or 6 weeks of rapid pacing. ${ }^{87}$ 
The duration of AF not only determines the degree of atrial contractile dysfunction but also the rate of recovery. The study of Tse et al. showed that AF of less than 48 hours is followed by prompt recovery of atrial contractility, while cardioversion of AF episodes of more than 48 hours was associated with a more delayed resolution of the atrial mechanical dysfunction. ${ }^{86}$ These findings suggest that fast recovery of the atrial dysfunction within one or two days of AF may account for the low incidence of thromboembolic events after cardioversion of AF at less than 48 hours. According to recent guidelines in such patients no anticoagulation is necessary before or after elective cardioversion. ${ }^{88: 89}$ Manning at al. showed that after 2 weeks of AF, recovery of atrial contractile function was complete within $24 \mathrm{~h}$ of sinus rhythm, whereas it took more than one month to recover from AF lasting more than 6 weeks. ${ }^{26}$ In such patients a high thromboembolic risk in the pericardioversion period has been documented ${ }^{27: 42: 43}$ and it is recommended that all patients with $\mathrm{AF}$ of more than 2 days should receive warfarin 3 weeks before and 4 weeks after cardioversion. ${ }^{8 ; 89}$ Unfortunately, there are some disadvantages of this approach, including bleeding complications, a second hospital admission for cardioversion, and the delay of restoration of sinus rhythm. Alternatively, patients can be screened for left atrial and left atrial appendage thrombi using transesophageal echocardiography. However, the absence of detectable thrombus does not preclude thromboembolism after cardioversion if patients do not receive anticoagulation therapy. ${ }^{30: 83}$ Thus, also these patients should be anticoagulated for 4 weeks after cardioversion. ${ }^{88: 89}$ The TEE-guided elective cardioversion approach has been reported to result in comparable outcomes for thromboembolism and death compared with conventional cardioversion with anticoagulation for 3 weeks before and 4 weeks after cardioversion. ${ }^{90}$ Thus, the advantage of this approach is limited to prompt restoration of sinus rhythm, which might be necessary in instable patients, desirable in patients with recent-onset AF, but of questionable benefit if AF lasted already months to years. $^{91}$

The atrial contractile dysfunction induced by short episodes of AF could be diminished or prevented with verapamil ${ }^{54,55}$ and the $\mathrm{Na}^{+} / \mathrm{H}^{+}$-exchange inhibitor $\mathrm{HOE} 642 .{ }^{92}$ For prevention of the atrial contractile dysfunction after prolonged AF no therapeutical strategy exists so far which stresses the importance of studies unraveling the mechanisms of atrial contractile dysfunction induced by prolonged AF. A few studies, including a recent echocardiographic study in patients with chronic atrial flutter undergoing radiofrequency ablation ${ }^{93}$ and the present thesis, have suggested that atrial contractile dysfunction is functional in nature and not due to loss of contractile apparatus itself. This suggests a new alternative therapeutical strategy for treatment of AF patients during the post cardioversion period. Reversal of atrial function after cardioversion by positive inotropes or appropriate atrial pacing might be of clinical interest in patients with contraindications against anticoagulation therapy.

\section{Delayed recovery of exercise capacity}

The impairment of left ventricular function during AF is partly caused by the inadequate ventricular rate response, but was also suggested to be due to the loss of atrial systole. $^{20: 32: 94-96}$ Nevertheless, it is still a matter of debate whether the delayed improvement of exercise capacity after cardioversion of AF is directly related to the slow recovery of atrial contractile function. Lipkin reported that the exercise capacity in 14 patients was unchanged at day 1 and increased at day 28 after successful cardioversion. ${ }^{32}$ Transmitral flow velocity also significantly increased from day 1 to day 28. The authors concluded that the delayed improvement of exercise capacity might at 
least in part be due to the slow improvement in atrial contractility. In contrast, van Gelder et al. showed in 8 patients without valvular heart disease that ejection fraction and exercise capacity significantly improved between 1 week and 1 month post cardioversion, whereas the atrial systole was already improved at week 1 and remained unchanged thereafter. ${ }^{64}$ This discrepancy in time course of recovery suggests that the improvement of exercise tolerance might not exclusively be related to the atrial systole. It rather appears that an intrinsic left ventricular cardiomyopathy was present in these patients which gradually subsided after cardioversion.

\section{Promotion of Atrial Dilatation}

Clinical $^{97}$ as well as experimental studies ${ }^{52: 87}$ have shown that prolonged AF per se results in progressive atrial dilatation. In contrast, restoration and maintenance of sinus rhythm in patients with $\mathrm{AF}$ has been shown to reduce atrial size. ${ }^{98-100}$ The mechanisms underlying atrial dilatation during AF have not been elucidated yet. In theory, loss of contractility of the fibrillating atrium might increase atrial compliance and size. In the absence of vigorous atrial contractions stretch will be transferred to the passive filaments of the atrial wall enhancing elongation of collagen fibres. Stretching of atrial cardiomyocytes will activate numerous intratracellular signalling cascades resulting in cellular hypertrophy and proliferation of fibroblasts. ${ }^{101}$ All these changes will contribute to increase in atrial tissue mass which in turn promotes AF. In larger atria more re-entry circuits can coexist which will stabilize the arrhythmia. Stretch itself ${ }^{02: 103}$ and the resulting structural changes ${ }^{104: 105}$ will predispose to conduction disturbances which further increases the propensity for AF. Indeed, a relation between atrial size and vulnerability for AF was demonstrated in several clinical studies ${ }^{106: 107}$ and in trials assessing the success rate of antiarrhythmic drugs. ${ }^{108: 109}$ Thus, AF-induced atrial contractile dysfunction might contribute to the self-perpetuating nature of the arrhythmia by facilitating atrial dilatation. This interesting hypothesis could provide an alternative vicious circle by which $\mathrm{AF}$ begets $\mathrm{AF}$.

\section{Excitation-Contraction Coupling in the Heart}

Excitability of muscle by electricity was already recognized by Luigi Galvani (17371798) who showed that frog muscle would contract when connected to a rotating static electricity generator. The first quantitative analysis of isolated cardiac muscle contractions was performed by Bowditch when he established the positive shape of the force-frequency relationship in frog heart. ${ }^{110}$ In 1883 Sydney Ringer demonstrated for the first time that $\mathrm{Ca}^{2+}$ in the bathing solution is a prerequisite for frog heart to contract."' In figure 4 a modern version of the Ringer's experiment is shown where $\mathrm{Ca}^{2+}$ is removed quickly from the medium around a rat ventricular myocyte causing an immediate abolition of contraction. ${ }^{12}$ 


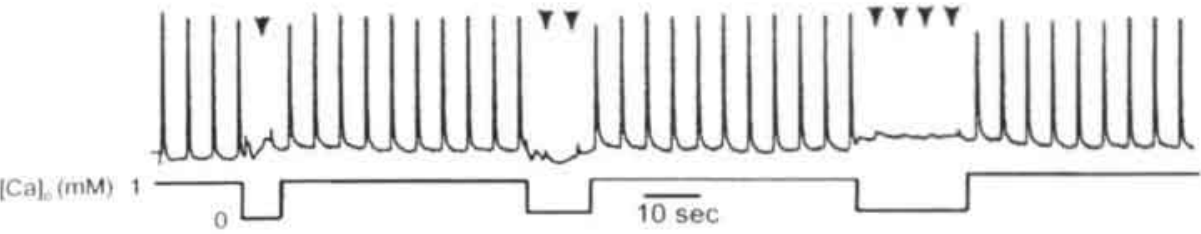

Figure 4

Crucial role of $\mathrm{Ca}^{2}$ in cardiac excitation-contraction coupling. Immediate abolition of contraction in

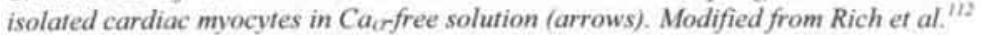

Research during the past 50 years has revealed that $\mathrm{Ca}^{2+}$ ubiquitously mediates excitation-contraction, excitation-secretion, and excitation-transciption coupling. Furthermore, numerous cellular responses are directly or indirectly regulated by this important second messenger. In the heart, $\mathrm{Ca}^{2+}$ is the fundamental regulator of actinmyosin cross-bridge interaction and contraction. Alterations in $\mathrm{Ca}^{2+}$ handling and excitation-contraction coupling, such as decrease in $\mathrm{Ca}^{2+}$ transient amplitude or increase of enddiastolic $\mathrm{Ca}^{2+}$ concentration, have been shown to underlie functional defects of hypertrophied and failing hearts.

\section{Intracellular $\mathrm{Ca}^{2+}$ handling}

Figure 5 gives an overview on the main $\mathrm{Ca}^{2+}$ transport pathways in cardiac myocytes. ${ }^{113}$ ${ }^{120}$ During an action potential voltage dependent L-type $\mathrm{Ca}^{2+}$ channels open and $\mathrm{Ca}^{2+}$ enters the cell ( $\mathrm{L}$-type $\mathrm{Ca}^{2+}$ current, $\mathrm{I}_{\text {Cat }}$ ). A much smaller amount of $\mathrm{Ca}^{2+}$ enters the cell via the $\mathrm{Na}^{+} / \mathrm{Ca}^{2+}$ exchanger (NCX). $\mathrm{Ca}^{2+}$ influx triggers the release of $\mathrm{Ca}^{2+}$ from the sarcoplasmic reticulum (SR) and, to some extent, can also activate the myofilaments directly. $\mathrm{I}_{\mathrm{Cal}}$ together with the $\mathrm{Ca}^{2+}$ released from the sarcoplasmic reticulum via $\mathrm{Ca}^{2+}$ induced $\mathrm{Ca}^{2+}$ release $(\mathrm{CICR})$ raises the cytosolic free $\mathrm{Ca}^{2+}$ concentration causing $\mathrm{Ca}^{2+}$ to bind to thin filament protein troponin $\mathrm{C}(\mathrm{TnC})$. When $\mathrm{Ca}^{2+}$ binds to $\mathrm{TnC}$, the actinmyosin filaments are activated in a cooperative manner and the myocyte starts to contract. Relaxation is initiated by a decline in cytosolic $\mathrm{Ca}^{2+}$ concentration, which causes $\mathrm{Ca}^{2+}$ to dissociate from $\mathrm{TnC}$ thereby turning off actin myosin crossbridge cycling. $\mathrm{Ca}^{2+}$ can be eliminated from the cytosol by four alternatives pathways: (1) resequestration into the $\mathrm{SR}$ by the $\mathrm{SR} \mathrm{Ca}^{2+}$-ATPase (SERCA), which is controlled by the inhibitory protein phospholamban ( $\mathrm{Plb}),(2)$ extrusion to the extracellular space by the sarcolemmal NCX, (3) extrusion by the sarcolemmal $\mathrm{Ca}^{2+}$-ATPase, (4) sequestration into mitochondria by $\mathrm{Ca}^{2+}$-uniporters. In mammalian cardiomyocytes SERCA and NCX are by far the most relevant $\mathrm{Ca}^{2+}$ transporters. In rabbit ventricular myocytes SERCA removes $70 \%$ of activator $\mathrm{Ca}^{2+}$, whereas $28 \%$ are eliminated via NCX. Only $2 \%$ are removed by the sarcolemmal $\mathrm{Ca}^{2+}$-ATPase or by the mitochondrial uniporter. ${ }^{121}$ In rat ventricle SERCA activity is higher and $\mathrm{Ca}^{2+}$ removal via $\mathrm{NCX}$ is lower. $92 \%$ of $\mathrm{Ca}^{2+}$ are removed by SERCA and $7 \%$ by $\mathrm{NCX}^{121} \mathrm{Ca}^{2+}$ handling in mouse ventricle is qualitatively like rat, ${ }^{122}$ while the balance of $\mathrm{Ca}^{2+}$ fluxes in ferret, dog, cat, guinea-pig, and human myocardium is similar to rabbit. ${ }^{113}$ The balance between SERCA- and NCXmediated $\mathrm{Ca}^{2+}$ removal is also sensitive to changes in neurohumoral regulation and hemodynamic load. During heart failure in humans and rabbits, SERCA activity is reduced while $\mathrm{NCX}$ is increased ${ }^{123}$ and both systems contribute more equally to the diastolic decline of $\mathrm{Ca}^{2+}$ concentration. ${ }^{114}$ 
The amount of $\mathrm{Ca}^{2+}$ which leaves the cytosol by entering mitochondria is not relevant for excitation-contraction coupling, but slow cumulative changes of intramitochondrial $\mathrm{Ca}^{2+}$ can increase the production of NADH and ATP to match increased energetic demands. $^{124}$

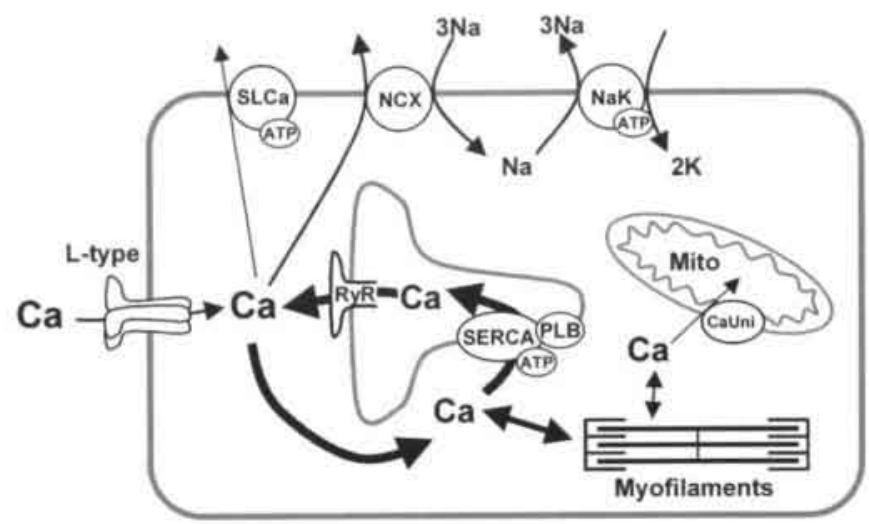

Figure 5

Intracellular $\mathrm{Ca}^{2}$ handling in atrial cardiomyocytes.

L-type: L-type $\mathrm{Ca}^{2+}$ channel. $\mathrm{NaK}: \mathrm{Na} / \mathrm{K}^{-}$-pump, NCX: $\mathrm{Na} / \mathrm{Ca}^{2}$-exchanger, SERCA: SR $\mathrm{Ca}^{2+}$-ATPase, Plb: phospholamban, SLCa: sarcolemmal $\mathrm{Ca}^{2}$-ATPase, RyR: ryanodine receptor (SR Ca' release channel), CaUni: mitochondrial $\mathrm{Ca}^{2}$ uniporter.

\section{Physiological Adaptation Mechanisms}

The main physiological mechanisms by which the heart adapts to variations in peripheral demand and venous return are (1) the Frank-Starling mechanism, (2) sympathetic stimulation, and (3) frequency potentiation of contractile force.

Basically, the Frank-Starling mechanism means that the stronger the heart is filled and cardiac chambers are stretched just before the contraction, the higher is contractile force and the more blood is pumped into aorta or pulmonary artery. By this mechanism the enddiastolic pressures are maintained within a narrow range despite large variations in venous return. When an isolated muscle bundle contracting under isometric conditions is stretched, the increase in length will produce an immediate increase in force of contraction. This rapid change in developed tension does not go along with an increase in the amount $\mathrm{Ca}^{2+}$ released from the sarcoplasmic reticulum. Rather, the myofilament $\mathrm{Ca}^{2+}$ sensitivity increases due to a change in the affinity of troponin for $\mathrm{Ca}^{2+} \cdot{ }^{125}$ After a delay of several minutes a further slow increase in force occurs associated with an increase in $\mathrm{Ca}^{2+}$ transient amplitude. The slow phase accounts for $20-30 \%$ of the total force increase in response to stretch. ${ }^{126}$

Sympathetic stimulation allows the heart to function effectively during different environmental conditions, e.g. during "fight or flight reactions". Myocardial $\beta$ adrenoceptors mediate increases in heart rate (3-fold), contractile force of the heart (5fold), and the rate of cardiac relaxation. $\beta$-adrenoceptors in the heart activate adenylylcyclase $(\mathrm{AC})$ via the stimulatory $\mathrm{G}$ protein $(\mathrm{Gs})$ to trigger the formation of cyclic adenosine monophosphate (cAMP), ${ }^{127}$ leading to activation of the protein kinase A (PKA) phosphorylation cascade (Figure 6). The opposing parasympathetic branch is 
regulated via acetylcholine, which reduces the cAMP level in the heart by activation of murcarinic cholinergic receptors and the inhibitory $\mathrm{G}$ protein (Gi) transduction pathway. $^{128}$

Activation of PKA increases contractile force (inotropy) and accelerates relaxation (lusitropy) by phosphorylation of several proteins involved in excitation-contraction coupling (phopsholamban, L-type $\mathrm{Ca}^{2+}$ channel, ryanodine receptors, and troponin $\mathrm{I}$ ). The lusitropic effect of PKA is mediated by phosphorylation of phospholamban and troponin I, which speed up relaxation by enhancing $\mathrm{Ca}^{2+}$ reuptake into the sarcoplasmic reticulum and dissociation of $\mathrm{Ca}^{2+}$ from the myofilaments, respectively. Accelerated $\mathrm{Ca}^{2+}$ reuptake, which by far is the most prominent lusitropic mechanism, ${ }^{129}$ also contributes to increasing $\mathrm{SR} \mathrm{Ca}^{2+}$ content. The inotropic effect of $\beta$-adrenergic stimulation is mediated by a combination of the increased SR $\mathrm{Ca}^{2+}$ load and phosphorylation of the L-type $\mathrm{Ca}^{2+}$ channel enhancing $\mathrm{I}_{\mathrm{CaL}}$. This synergistic combination greatly enhances $\mathrm{Ca}^{2+}$ transient amplitude and clearly overrules the reduction of myofilament $\mathrm{Ca}^{2+}$ sensitivity by phosphorylation of troponin $\mathrm{I}^{115}$ The functional consequences of PKA activation on the ryanodine receptor are less clear. The responsiveness of $\mathrm{SR}$ release to an $\mathrm{I}_{\mathrm{Cal}}$ trigger signal after phosphorylation of the ryanodine receptor has been reported to be increased, decreased or unchanged. ${ }^{130-132}$

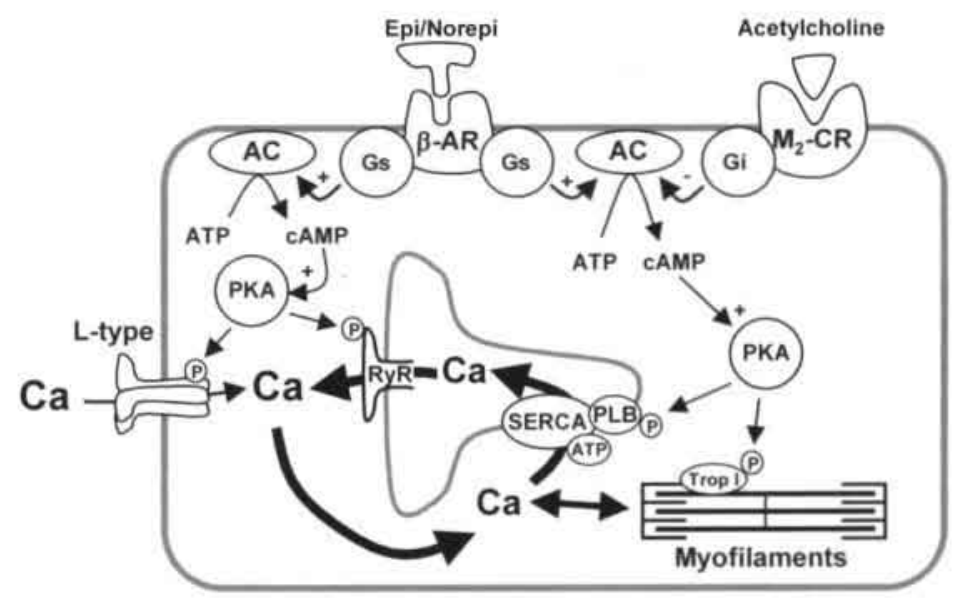

Figure 6

B-adrenergic signaling with phosphorylation targets relevant to excitation-contraction coupling in cardiac myocytes. $\beta$-AR: $\beta$-adrenoceptor, $M_{-}-C R: M_{2}$-cholinoceptor, AC: adenylyl cylase, cAMP: cyclic adenosine monophosphate, Gs: stimulatory G protein. Gi: inhibitory G protein. PKA: protein kinase A, L-type: L-type $\mathrm{Ca}^{2}$ channel, SERCA: SR Ca'-ATPase, Plb: phospholamban. RyR: nyanodine receptor $\left(S R \mathrm{Ca}^{2}\right.$ release channel).

Although the linkage between frequency of activation and contractile force has been noticed by Bowditch (1871) and Woodworth (1902) already more than a century ago, most of the cellular mechanisms underlying this phenomenon have been described only during the last two decades. Figure 7 shows a classical response to a transient increase in stimulation frequency from 0.5 to $1.5 \mathrm{~Hz}$ in rabbit ventricular muscle. The first contraction at $1.5 \mathrm{~Hz}$ is smaller probably due to insufficient time for the SR $\mathrm{Ca}^{2+}$ release channel to recover from inactivation. ${ }^{113}$ Then, contractile force gradually increases until 
a new steady state is reached. The following mechanisms probably contribute to this increase: (1) Due to greater $\mathrm{Ca}^{2+}$ influx (via $\mathrm{I}_{\mathrm{CaL}}$ ) per sec the $\mathrm{SR} \mathrm{Ca}^{2+}$ load increases. ${ }^{113}$ (2) The increased average $\mathrm{Ca}^{2+}$ concentration in the cell stimulates $\mathrm{Ca}^{2+}$-Calmodulin dependent protein kinase (CaMKII) which increases the fractional release of $\mathrm{Ca}^{2+}$ from the SR. ${ }^{133}$ (3) Due to a rise in cytosolic $\mathrm{Na}^{+}$concentration the NCX balance is shifted towards less $\mathrm{Ca}^{2+}$ extrusion and more $\mathrm{Ca}^{2+}$ influx. ${ }^{134-136}$ Switching back to $0.5 \mathrm{~Hz}$ results in a large first contraction reflecting the high $\mathrm{SR} \mathrm{Ca}^{2+}$ content and a high fraction of the $\mathrm{SR} \mathrm{Ca}{ }^{2+}$ to be released. ${ }^{113}$ The large $\mathrm{Ca}^{2+}$ release inhibits $\mathrm{I}_{\mathrm{Cal}}$ and stimulates $\mathrm{Ca}^{2+}$ extrusion via NCX. Thus, contractile force progressively declines until the initial steady state is re-attained.

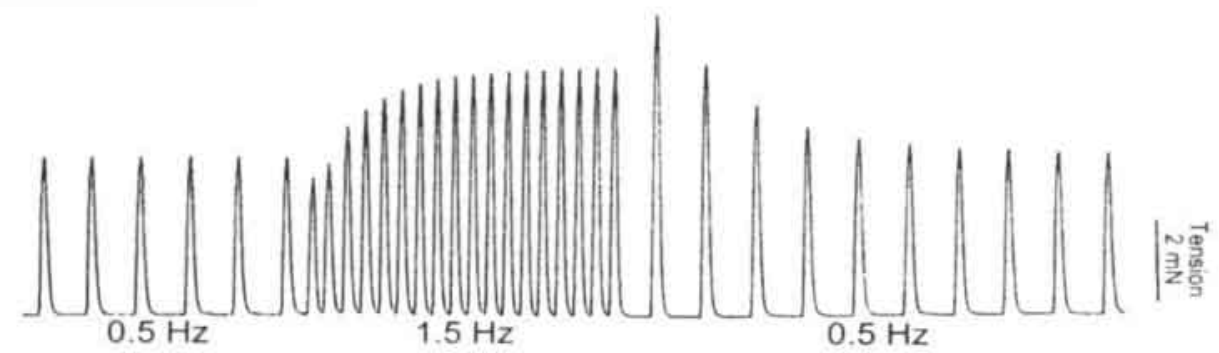

Figure 7

Effect of a transient increase in stimulation frequency on twitch force of rabbit ventricular muscle. Modified from Bers D."'s

It should be noted, however, that this concept of excitation-contraction coupling only represents the framework of intracellular $\mathrm{Ca}^{2+}$ handling which in fact is in dymanic and critical balance created by numerous microdomains of local control which surely overlap spatially and functionally. ${ }^{115: 119}$ These microdomains might be responsible for important differences in excitation-contraction coupling between atria and ventricles. In ventricular myocytes T-tubules conduct depolarization axially to the center of the cell and local CICR throughout the cell is synchronized by $\mathrm{I}_{\text {Cat. activation. }}{ }^{113}$ Atrial cardiomyocytes lack appreciable T-tubules and the cytosolic $\mathrm{Ca}^{2+}$ concentration first rises at the cell periphery and then spreads to the center of the cell. ${ }^{137-139}$ Release of $\mathrm{Ca}^{2+}$ from the sarcoplasmic reticulum appears to propagate transversly via CICR, because the peak $\mathrm{Ca}^{2+}$ concentration at the center can be as high as the subsarcolemmal $\mathrm{Ca}^{2+}$ concentration. When the SR $\mathrm{Ca}^{2+}$ load is low, propagation fails. ${ }^{139}$ These observations stress the crucial role of $\mathrm{SR} \mathrm{Ca}^{2+}$ load for regulation of contractile force in atrial muscle. 


\section{Aim of the Study}

The aim of the present study was twofold: (1) to investigate the mechanisms of the AFinduced atrial contractile dysfunction with special attention paid to the different time domains of the remodeling process (chapters 2,3,4,5), and (2) to elucidate the effect of atrial contractile remodeling on atrial size and stability of AF (chapters 6 and 7).

The mechanisms of atrial paralysis induced by prolonged AF was studied in thin atrial muscle preparations isolated from patients undergoing open chest surgery. To study the contribution of myolysis to atrial contractile dysfunction the contractile reserve of the muscle bundles was compared to their sarcomere content assessed by light microscopy. We also addressed the question whether atrial contractile dysfunction is due to similar mechanisms as classical ventricular tachycardiomyopathy. For this purpose, we assessed changes of the $\beta$-adrenergic signal transduction pathway and of the $\mathrm{Ca}^{2+}$. reuptake and storage function of the sarcoplamic reticulum in atrial myocardium of AF patients. To investigate whether AF-induced atrial paralysis is due to changes in number or function of the L-type $\mathrm{Ca}^{2+}$-channel the stimulatory effect of the L-type $\mathrm{Ca}^{2+}$ channel agonist BayK 8644 was studied. Also, the protein expression of L-type $\mathrm{Ca}^{2+}$-channel subunits was quantified.

The time course of atrial contractile dysfunction during the first days of $A F$ and its recovery was studied chronically instrumented goats. Using this model we also tested the hypothesis that electrical and contractile remodeling were closely related processes in fibrillating atria. The time course of the shortening of the refractory period was compared to the time course of the decline of atrial contractility. Also, the effect of "undoing electrical remodeling" by application of the L-type $\mathrm{Ca}^{2+}$-channel agonist BayY5959 was investigated.

Finally, the hypothesis was tested whether atrial contractile remodeling during AF might contribute to the self-perpetuating nature of the arrhythmia. This question consists of two aspects: (1) Does loss of atrial contractile function during AF result in an increase in atrial compliance and size? To address this questions atrial contractility, compliance and size were monitored in goats during 5 days of AF. (2) Does atrial dilatation indeed promote AF, as suggested by numerous clinical observations? For this purpose, chronic, complete AV-block was made in goats and changes of atrial size, and propensity to AF were followed during four weeks. 


\section{Reference List}

1. Harvey W. Exercitatio anatomica de motu cordis \& sanguinis in animalibus 1628.

2. McWilliam J. Fibrillar contraction of the heart. J Physiol 1887: 8:296-310.

3. Sommerbrodt J. Ueber allorhythmie und arrhythmie des herzen und deren ursachen. Deutsch Archiv Klin Med 1877: 19:392-423.

4. MacKenzie J. The cause of heart irregularity in influenza. British Medical Journal 1902; 1:1411-1413.

5. Cushny AR, Edmunds CW. Paroxysmal irregularity of the heart in auricular fibrillation. AM J Med Sci 1907: 133:66-77.

6. Sanderson. On the time-relations of the excitatory process in the ventricle of the heart of the frog. J Physiol 1879; 2:384-435.

7. Einthoven W. Ein neues Galvanometer. Ann Physik 1903; 4:1059-1061.

8. Einthoven W. Le télécardiogramme. Arch Internat Physiol 1906; 4:132-164.

9. Rothberger C, Winterberg H. Vorhofflimmern und arrhythmia perpetua. Wien Klin Wochenschr 1909; 22:839-844.

10. Lewis T. Auricular fibrillation and its relationship to clinical irregularity of the heart. Heart 1909; 1:306-372.

11. Hering HE. Analyse des pulsus irregularis pertetuus. Prag Med Wochenschr 1903; 28:377-381.

12. MacKenzie J. The inception of the rhythm of the heart by the ventricle, as the cause of the continuous irregularity of the heart. British Medical Journal 1904; 2:529-536.

13. Straub H. The diastolic filling of the mammalian heart. J Physiol Lond 1910;40:378-388.

14. Gsell R. Auricular systole and its relation to ventricular output. Am J Physiol 1911; 29:32-63.

15. Nathan DA, Samet P. Center S, ZouWu C, Long term correction of complete heart block. Clinical and physiologic studies of a new type of implantable synchronous paces. Prog Cardiovasc Dis 1964; 6:538.

16. Lown B, Amarasingham R. Neuman J. New method for terminating cardiac arrhythmias. Use of synchronized capacitor discharge. JAMA 1962; 182:548.

17. Braunwald E, Frahm CJ. Studies on Starling's law of the heart. IV. Observations of the hemodynamic functions of the left atrium in man. Circulation 1961; 24:633.

18. Snyder J, Wood EH. Effect of heart rate on atrial contribution to cardiac performance in dogs with complete heart block. Fed Proc 1962; $21: 137$.

19. Sellers WJ, Donald DE, Wood EH. Atrial contribution to stroke volume in dogs with chronic cardiac denervation. Physiologist 1962;5:211.

20. Braunwald E. Symposium on cardiac arrhythmias. Introduction. With comments on the hemodynamic significance of atrial systole. Am J Med 1964:37:665-669.

21. Logan W, Rowlands D, Howitt G. Holmes A. Left atrial activity following cardioversion. Lancet 1965; 2:471-473.

22. Rowlands D. Logan W, Howitt G. Atrial function after cardioversion. Am Heart J 1967: 74:149-160.

23. Ikram H, Nixon GF. Arcan T. Left atrial function after electrical coversion to sinus rhythm. Br Heart J 1968: 30:80-83.

24. Resnekov L, McDonald L. Complications in 220 patients with cardiac dysrhythmias treated by phased direct current shock, and indications for electroconversion. Br Heart J 1967: 29:926-936.

25. Manning WJ, Leeman DE, Gotch PJ, Come PC. Pulsed Doppler evaluation of atrial mechanical function after electrical cardioversion of atrial fibrillation. J Am Coll Cardiol 1989; 13:617-623.

26. Manning WJ. Silverman DI. Katz SE, Riley MF, Come PC, Doherty RM, Munson JT, Douglas PS Impaired left atrial mechanical function after cardioversion: relation to the duration of atrial fibrillation. J Am Coll Cardiol 1994; 23:1535-1540.

27. Mattioli AV, Tarabini CE, Vivoli D. Molinari R, Mattioli G. Restoration of atrial function after atrial fibrillation of different etiological origins. Cardiology 1996; 87:205-211.

28. Shapiro EP. Effron MB, Lima S, Ouyang P, Siu CO, Bush D. Transient atrial dysfunction after conversion of chronic atrial fibrillation to sinus rhythm. Am J Cardiol 1988: 62:1202-1207.

29. Grimm RA, Stewart WJ, Maloney JD. Cohen GI, Pearce GL, Salcedo EE, Klein AL. Impact of electrical cardioversion for atrial fibrillation on left atrial appendage function and spontaneous echo contrast: characterization by simultaneous transesophageal echocardiography. J Am Coll Cardiol 1993; 22:1359-1366.

30. Black IW. Fatkin D. Sagar KB. Khandheria BK, Leung DY. Galloway JM. Feneley MP, Walsh WF, Grimm RA. Stollberger C. Exclusion of atrial thrombus by transesophageal echocardiography does not preclude embolism after cardioversion of atrial fibrillation. A multicenter study. Circulation 1994; 89:2509-2513.

31. Bailey GW, Braniff BA. Hancock EW, Cohn KE. Relation of left atrial pathology to atrial fibrillation in mitral valvular disease. Ann Intern Med 1968: 69:13-20. 
32. Lipkin DP, Frenneaux M, Stewart R, Joshi J, Lowe T, MeKenna WJ. Delayed improvement in exercise capacity after cardioversion of atrial fibrillation to sinus rhythm. Br Heart J 1988; 59:572-577.

33. Mary Rabine L. Albert A. Pham TD, Hordof A, Fenoglio-JJ J. Malm JR, Rosen MR. The relationship of human atrial cellular electrophysiology to clinical function and ultrastructure. Circ Res 1983; 52:188-199.

34. Warner ED, Dahl C. Ewy GA. Myocardial injury from transthoracic defibrillator countershock. Arch Pathol 1975; 99:55-59.

35. Dahl CF, Ewy GA, Warner ED, Thomas ED, Myocardial necrosis from direct current countershock. Effect of paddle electrode size and time interval between discharges. Circulation 1974; 50:956-961.

36. Caterine MR, Spencer KT, Pagan-Carlo LA. Smith RS, Buettner GR, Kerber RE. Direct current shocks to the heart generate free radicals: an electron paramagnetic resonance study. J Am Coll Cardiol 1996; 28:1598-1609.

37. Georges J, Spentchian M, Caubel C, Collignon I, Schwob J, Livarek B, Normand JP. Time course of troponin I, myoglobulin, and cardiac enzyme release after electrical cardioversion. Am J Cardiol 1996; $78: 825-826$.

38. Bonnefoy E, Chevalier P, Kirkorian G, Guidolet J, Marchand A, Touboul P, Cardiac troponin 1 does not increase after cardioversion. Chest 1997; 111:15-18.

39. Jovic A, Troskot R. Recovery of atrial systolic function after pharmacological conversion of chronic atrial fibrillation to sinus rhythm: a Doppler echocardiographic study. Heart 1997; 77:46-49.

40. Grimm RA, Leung DY, Black IW, Stewart WJ, Thomas JD, Klein AL. Left atrial appendage "stunning" after spotaneous conversion of atrial fibrillation demonstrated by transesophageal Doppler echocardiography. Am Heart J 1995: 130:174-176.

41. Shyu KG, Cheng JJ, Chen JJ, Lin JL, Lin FY, Tseng YZ, Kuan P, Lien WP. Recovery of atrial function after atrial compartment operation for chronic atrial fibrillation in mitral valve disease. J Am Coll Cardiol 1994; 24:392-398.

42. Manning WJ, Silverman DI, Katz SE, Riley MF, Doherty RM, Munson JT, Douglas PS. Temporal dependence of the return of atrial mechanical function on the mode of cardioversion of atrial fibrillation to sinus rhythm. Am J Cardiol 1995; 75:624-626.

43. Harjai KJ, Mobarek SK, Cheirif J, Boulos LM, Murgo JP, Abi-Samra F. Clinical variables affecting recovery of left atrial mechanical function after cardioversion from atrial fibrillation. J Am Coll Cardiol $1997 ; 30: 481-486$.

44. Falcone RA, Morady F, Armstrong WF. Transesophageal echocardiographic evaluation of left atrial appendage function and spontaneous contrast formation after chemical or electrical cardioversion of atrial fibrillation. Am J Cardiol 1996: 78:435-439.

45. Dodds GA. III. Wilkinson WE, Greenfield RA, Natale A, Kisslo J, Pritchett EL. Evaluation of the effect of transthoracic cardioversion from ventricular tachycardia to sinus rhythm on left atrial mechanical function. Am J Cardiol 1996; 78:1436-1439.

46. Sparks PB, Kulkarni R, Vohra JK, Mond HG, Jayaprakash S, Yapanis AG, Grigg LE, Kalman JM. Effect of direct current shocks on left atrial mechanical function in patients with structural heart disease. J Am Coll Cardiol 1998; 31:1395-1399.

47. Davies MJ, Pomerance A. Pathology of atrial fibrillation in man. Br Heart J 1972; 34:520-525.

48. Aimé-Sempé C. Folliguet T. Rucker-Martin C, Krajewska M, Krajewska S, Heimburger M. Aubier M. Mercadier JJ. Reed JC. Hatem SN. Myocardial cell death in fibrillating and dilated human right atria. J Am Coll Cardiol 1999: 34:1577-1586.

49. Schotten U, Ausma J, Stellbrink C, Sabatschus I, Vogel M. Frechen D, Schoendube F, Hanrath P. Allessie MA. Cellular mechanisms of depressed atrial contractility in patients with chronic atrial fibrillation. Circulation 2001; 103:691-698.

50. Frustaci A, Chimenti C, Bellocci F, Morgante E, Russo MA, Maseri A. Histological substrate of atrial biopsies in patients with lone atrial fibrillation. Circulation 1997; 96:1180-1184.

51. Brundel BJ, Ausma J, Van Gelder IC, Van der Want JJ, Van Gilst WH, Crijns HJ, Henning RH. Activation of proteolysis by calpains and structural changes in human paroxysmal and persistent atrial fibrillation. Cardiovasc Res 2002; 54:380-389.

52. Morillo CA, Klein GJ. Jones DL. Guiraudon CM. Chronic rapid atrial pacing. Structural, functional, and electrophysiological characteristics of a new model of sustained atrial fibrillation. Circulation 1995: $91: 1588-1595$.

53. Ausma J, Wijffels M. Thoné F, Wouters L, Allessie M. Borgers M. Structural changes of atrial myocardium due to sustained atrial fibrillation in the goat. Circulation 1997; 96:3157-3163.

54. Leistad E, Aksnes G. Verburg E. Christensen G. Atrial contractile dysfunction after short-term atrial fibrillation is reduced by verapamil but increased by BAY K8644. Circulation 1996; 93:1747-1754. 
55. Daoud EG, Marcovitz P, Knight BP, Goyal R, Man KC, Strickberger SA. Armstrong WF, Morady F. Short-term effect of atrial fibrillation on atrial contractile function in humans. Circulation 1999; 99:3024-3027.

56. Sun H, Gaspo R, Leblanc N, Nattel S. Cellular mechanisms of atrial contractile dysfunction caused by sustained atrial tachycardia. Circulation 1998; 98:719-727.

57. Yue L, Feng J. Gaspo R, Li GR. Wang Z. Nattel S. Ionic remodeling underlying action potential changes in a canine model of atrial fibrillation. Circ Res 1997; 81:512-525.

58. Van Wagoner DR, Pond AL, Lamorgese M, Rossie SS, McCarthy PM. Nerbonne JM. Atrial L-type $\mathrm{Ca}^{2+}$ currents and human atrial fibrillation. Circ Res $1999 ; 85: 428-436$.

59. Bosch RF, Zeng XR, Grammer JB, Popovic K, Mewis C. Kuehlkamp V. Ionic mechanisms of electrical remodeling in human atrial fibrillation. Cardiovase Res 1999; 44:121-131.

60. Skasa M, Jungling E, Picht E, Schondube F, Luckhoff A. L-type calcium currents in atrial myocytes from patients with persistent and non-persistent atrial fibrillation. Basic Res Cardiol 2001; 96:151-159.

61. Wijffels MC, Kirchhof CJ. Dorland R, Allessie MA. Atrial fibrillation begets atrial fibrillation. A study in awake chronically instrumented goats. Circulation 1995: 92:1954-1968.

62. Gallagher MM, Obel OA, Camm JA. Tachycardia-induced atrial myopathy: an important mechanism in the pathophysiology of atrial fibrillation? J Cardiovasc Electrophysiol 1997; 8:1065-1074.

63. Zarse M, Waldmann M. Muehlenbruch G. Sinha AM. Seipelt R. Schoendube F, Messmer BJ. Franke A. Stellbrink C, Hanrath P. Left atrial appendage outflow is augmented during atrial fibrillation compared to sinus rhythm: insights from a pig model of pacing-induced atrial fibrillation. Eur Heart J 1999;20:226 (abstract)

64. Van Gelder IC. Crijns HJ, Blanksma PK. Landsman ML, Posma JL, Van Den Berg MP, Meijler FL, Lie K1. Time course of hemodynamic changes and improvement of exercise tolerance after cardioversion of chronic atrial fibrillation unassociated with cardiac valve disease. Am J Cardiol 1993; 72:560-566.

65. Bristow MR, Ginsburg R, Minobe W, Cubicciotti RS, Sageman WS, Lurie K, Billingham ME, Harrison DC, Stinson EB. Decreased catecholamine sensitivity and beta-adrenergic- receptor density in failing human hearts. N Engl J Med 1982; 307:205-211.

66. Beuckelmann DJ. Nabauer M. Erdmann E. Intracellular calcium handling in isolated ventricular myocytes from patients with terminal heart failure. Circulation 1992; 85:1046-1055.

67. Marzo KP, Frey MJ. Wilson JR, Liang BT, Manning DR. Lanoce V. Molinoff PB. Beta-adrenergic receptor-G protein-adenylate cyclase complex in experimental canine congestive heart failure produced by rapid ventricular pacing. Circ Res 1991; 69:1546-1556.

68. Kiuchi K, Shannon RP, Komamura K. Cohen DJ. Bianchi C, Homcy CJ, Vatner SF, Vatner DE, Myocardial beta-adrenergic receptor function during the development of pacing-induced heart failure. J Clin Invest 1993; 91:907-914.

69. Yao A, Su Z. Nonaka A, Zubair I, Spitzer KW. Bridge JH, Muelheims G, Ross JJ, Barry WH. Abnormal myocyte $\mathrm{Ca}^{2-}$ homeostasis in rabbits with pacing-induced heart failure. Am J Physiol 1998: 275:H1441-H1448.

70. O'Rourke B, Kass DA, Tomaselli GF, Kääb S, Tunin R, Marbán E, Mechanisms of altered excitationcontraction coupling in canine tachycardia-induced heart failure, I: experimental studies. Circ Res 1999: 84:562-570.

71. Igarashi SK. Tsutsui H. Yamamoto S, Takahashi M. Kinugawa S, Tagawa H, Usui M, Yamamoto M, Egashira K. Takeshita A. Role of SR $\mathrm{Ca}^{2-}$-ATPase in contractile dysfunction of myocytes in tachycardia-induced heart failure. Am J Physiol 1998: 275: H31-H40.

72. Wolf PA, Dawber TR, Thomas HEJ, Kannel WB. Epidemiologic assessment of chronic atrial fibrillation and risk of stroke: the Framingham study. Neurology 1978; 28:973-977.

73. Kannel WB. Abbott RD. Savage DD. McNamara PM. Epidemiologic features of chronic atrial fibrillation; the Framingham study. N Engl J Med 1982; 306:1018-1022.

74. Pollick C. Taylor D. Assessment of left atrial appendage function by transesophageal echocardiography. Implications for the development of thrombus. Circulation 1991; 84:223-231.

75. Fatkin D, Kelly RP. Feneley MP. Relations between left atrial appendage blood flow velocity. spontaneous echocardiographic contrast and thromboembolic risk in vivo. J Am Coll Cardiol 1994; 23:961-969.

76. Wolf PA, Abbott RD. Kannel WB. Atrial fibrillation as an independent risk factor for stroke: the Framingham Study. Stroke 1991: 22:983-988.

77. Kopecky SL, Gersh BJ, McGoon MD. Whisnant JP. Holmes DR, Jr., Ilstrup DM. Frye RL. The natural history of lone atrial fibrillation. A population-based study over three decades. N Engl J Med 1987; 317:669-674. 
78. Russell JW, Biller J. Hajduczok ZD, Jones MP, Kerber RE, Adams HP. Ischemic cerebrovascular complications and risk factors in idiopathic hypertrophic subaortic stenosis. Stroke 1991; 22:11431147.

79. Shigematsu Y, Hamada M, Mukai M, Matsuoka H, Sumimoto T, Hiwada K. Mechanism of atrial fibrillation and increased incidence of thromboembolism in patients with hypertrophic cardiomyopathy. Jpn Circ J 1995; 59:329-336.

80. Robinson K. Frenneaux MP, Stockins B, Karatasakis G, Poloniecki JD, McKenna WJ. Atrial fibrillation in hypertrophic cardiomyopathy: a longitudinal study. J Am Coll Cardiol 1990; 15:1279. 1285.

81. Hart RG, Pearce LA, McBride R, Rothbart RM, Asinger RW. Factors associated with ischemic stroke during aspirin therapy in atrial fibrillation: analysis of 2012 participants in the SPAF I-III clinical trials. The Stroke Prevention in Atrial Fibrillation (SPAF) Investigators. Stroke 1999; 30:1223-1229.

82. Feinberg WM, Blackshear JL, Laupacis A, Kronmal R, Hart RG. Prevalence, age distribution, and gender of patients with atrial fibrillation. Analysis and implications. Arch Intern Med 1995; 155:469. 473.

83. Fatkin D, Kuchar DL, Thorburn CW, Feneley MP. Transesophageal echocardiography before and during direct current cardioversion of atrial fibrillation: evidence for "atrial stunning" as a mechanism of thromboembolic complications. J Am Coll Cardiol 1994; 23:307-316.

84. Transesophageal echocardiographic correlates of thromboembolism in high-risk patients with nonvalvular atrial fibrillation. The Stroke Prevention in Atrial Fibrillation Investigators Committee on Echocardiography. Ann Intern Med 1998; 128:639-647.

85. Zabalgoitia M, Halperin JL. Pearce LA, Blackshear JL, Asinger RW. Hart RG. Transesophageal echocardiographic correlates of clinical risk of thromboembolism in nonvalvular atrial fibrillation. Stroke Prevention in Atrial Fibrillation III Investigators. J Am Coll Cardiol 1998; 31:1622-1626.

86. Tse HF, Wang Q, Yu CM, Ayers GM, Lau CP. Time course of recovery of left atrial mechanical dysfunction after cardioversion of spontaneous atrial fibrillation with the implantable atrial defibrillator. Am J Cardiol 2000; 86:1023-5, A10.

87. Shi Y. Ducharme A, Li D. Gaspo R. Nattel S. Tardif JC. Remodeling of atrial dimensions and emptying function in canine models of atrial fibrillation. Cardiovase Res 2001: 52:217-225.

88. Lip GY, Hart RG. Conway DS. Antithrombotic therapy for atrial fibrillation. British Medical Journal 2002; 325:1022-1025.

89. Fuster V, Ryden LE, Asinger RW, Cannom DS, Crijns HJ, et al. ACC/AHA/ESC Guidelines for the Management of Patients With Atrial Fibrillation: Executive Summary A Report of the American College of Cardiology/American Heart Association Task Force on Practice Guidelines and the European Society of Cardiology Committee for Practice Guidelines and Policy Conferences (Committee to Develop Guidelines for the Management of Patients With Atrial Fibrillation) Developed in Collaboration With the North American Society of Pacing and Electrophysiology. Circulation 2001: 104:2118-2150.

90. Asher CR, Klein AL. The ACUTE trial. Transesophageal echocardiography to guide electrical cardioversion in atrial fibrillation. Assessment of Cardioversion Using Transesophageal Echocardiography. Cleve Clin J Med 2002; 69:713-718.

91. Klein AL, Murray RD, Grimm RA. Role of transesophageal echocardiography-guided cardioversion of patients with atrial fibrillation. J Am Coll Cardiol 2001; 37:691-704.

92. Altemose GT, Zipes DP, Weksler J, Miller JM, Olgin JE. Inhibition of the $\mathrm{Na}^{*} / \mathrm{H}^{\prime}$ exchanger delays the development of rapid pacing-induced atrial contractile dysfunction. Circulation 2001; 103:762-768.

93. Sanders P, Morton JB, Morgan JG, Davidson NC, Spence SJ, Vohra JK, Kalman JM, Sparks PB. Reversal of atrial mechanical stunning after cardioversion of atrial arrhythmias: implications for the mechanisms of tachycardia-mediated atrial cardiomyopathy. Circulation 2002; 106:1806-1813.

94. Atwood JE, Myers J. Sullivan M, Forbes S, Sandhu S, Callaham P, Froelicher V. The effect of cardioversion on maximal exercise capacity in patients with chronic atrial fibrillation. Am Heart J 1989; 118:913-918.

95. Resnekov L. Haemodynamic studies before and after electrical conversion of atrial fibrillation and flutter to sinus rhythm. Br Heart J 1967; 29:700-708.

96. Khaja F, Parker JO. Hemodynamic effects of cardioversion in chronic atrial fibrillation. Special reference to coronary artery disease. Arch Intern Med 1972; 129:433-440.

97. Sanfilippo AJ, Abascal VM. Sheehan M, Oertel LB, Harrigan P. Hughes RA, Weyman AE. Atrial enlargement as a consequence of atrial fibrillation. A prospective echocardiographic study. Circulation 1990; 82:792-797.

98. Tse HF, Lau CP. Yu CM. Lee KL., Michaud GF, Knight BP. Morady F, Strickberger SA. Effect of the implantable atrial defibrillator on the natural history of atrial fibrillation. J Cardiovasc Electrophysiol 1999; I0:1200-1209. 
99. Gosselink AT, Crijns HJ, Hamer HP, Hillege H. Lie KI. Changes in left and right atrial size after cardioversion of atrial fibrillation: role of mitral valve disease. J Am Coll Cardiol 1993: 22:1666-1672.

100. Van Gelder IC, Crijns HJ, Van Gilst WH, Hamer HP, Lie KI. Decrease of right and left atrial sizes after direct-current electrical cardioversion in chronic atrial fibrillation. Am J Cardiol 1991; 67:93-95.

101. Goette A, Lendeckel U, Klein HU. Signal transduction systems and atrial fibrillation. Cardiovasc Res 2002; $54: 247-258$.

102. Eijsbouts S, Majidi M. von Zandvoort M. Allessie M. The effects of acute atrial dilatation on heterogeneity in conduction in the isolated rabbit heart. J Cardiovasc Electrophysiol 2003; 14:269-278.

103. Ravelli F. Allessie M. Effects of atrial dilatation on refractory period and vulnerability to atrial fibrillation in the isolated Langendorff-perfused rabbit heart. Circulation 1997; 96:1686-1695.

104. Boyden PA, Hoffman BF. The effects on atrial electrophysiology and structure of surgically induced right atrial enlargement in dogs. Circ Res 1981: 49:1319-1331.

105. Boyden PA, Tilley LP, Pham TD, Liu SK, Fenoglic JJJ, Wit AL. Effects of left atrial enlargement on atrial transmembrane potentials and structure in dogs with mitral valve fibrosis. Am J Cardiol 1982; 49:1896-1908,

106. Vaziri SM. Larson MG, Benjamin EJ, Levy D. Echocardiographic predictors of nonrheumatic atrial fibrillation. The Framingham Heart Study. Circulation 1994; 89:724-730.

107. Psaty BM, Manolio TA, Kuller LH, Kronmal RA, Cushman M. Fried LP, White R, Furberg CD, Rautaharju PM. Incidence of and risk factors for atrial fibrillation in older adults. Circulation 1997; 96:2455-2461.

108. Brodsky MA, Allen BJ, Capparelli EV, Luckett CR, Morton R, Henry WL. Factors determining maintenance of sinus rhythm after chronic atrial fibrillation with left atrial dilatation. Am J Cardiol 1989; 63:1065-1068.

109. Tieleman RG, Gosselink AT, Crijns HJ, Van Gelder IC, Van Den Berg MP, De Kam PJ, Van Gilst WH, Lie KI. Efficacy, safety, and determinants of conversion of atrial fibrillation and flutter with oral amiodarone. Am J Cardiol 1997; 79:53-57.

110. Bowditch HP. Ober Eigenthümlichkeiten der Reizbarkeit, welche die Muskelfasern des Herzens zeigen. Ber Sachs Ges Wiss 1871: 23:652-689.

111. Ringer S. A further contribution regarding the influence of different constituents of the blood on the contracting heart. J Physiol 1882:4:29.

112. Rich TL. Langer GA. Klassen MG. Two components of coupling calcium in single ventricular cell of rabbits and rats. Am J Physiol 1988: 254:H937-H946.

113. Bers DM. Control of cardiac contraction by SR and sarcolemmal Ca fluxes. In: Bers DM, editor. Excitation-contraction coupling and cardiac contractile force. Dordrecht: Kluwer Academic Publishers. 2002: 245-272.

114. Pogwizd SM. Bers DM. Calcium cycling in heart failure: the arrhythmia connection. J Cardiovasc Electrophysiol 2002; 13:88-91.

115. Bers DM. Cardiac excitation-contraction coupling. Nature 2002; 415:198-205.

116. Bers DM. Calcium and cardiac rhythms: physiological and pathophysiological. Circ Res 2002; 90:1417.

117. Bers DM. Calcium fluxes involved in control of cardiac myocyte contraction. Circ Res 2000; 87:275281.

118. Eisner DA, Choi HS, Diaz ME. O'Neill SC. Trafford AW. Integrative analysis of calcium cycling in cardiac muscle. Cire Res 2000; 87:1087-1094.

119. Wier WG, Balke CW. $\mathrm{Ca}^{2+}$ release mechanisms, $\mathrm{Ca}^{2+}$ sparks, and local control of excitation-contraction coupling in normal heart muscle. Circ Res 1999; 85:770-776.

120. Wankerl M. Schwartz K. Calcium transport proteins in the nonfailing and failing heart: gene expression and function. J Mol Med 1995: 73:487-496.

121. Bassani JW, Bassani RA, Bers DM. Relaxation in rabbit and rat cardiac cells: species-dependent differences in cellular mechanisms. J Physiol 1994; 476:279-293.

122. Li L, Chu G, Kranias EG, Bers DM. Cardiac myocyte calcium transport in phospholamban knockout mouse: relaxation and endogenous CaMKIl effects, Am J Physiol 1998; 274:HI335-H1347.

123. Hasenfuss G. Alterations of calcium-regulatory proteins in heart failure. Cardiovasc Res 1998: $37: 279$ 289.

124. Brandes R. Bers DM. Simultaneous measurements of mitochondrial NADH and $\mathrm{Ca}^{2+}$ during increased work in intact rat heart trabeculae. Biophys J 2002; 83:587-604.

125. Allen DG. Kentish JC. The cellular basis of the length-tension relation in cardiac muscle. J Mol Cell Cardiol 1985; 17:821-840.

126. Fuchs F. Smith SH. Calcium, cross-bridges, and the Frank-Starling relationship. News Physiol Sci 2001: 16:5-10. 
127. Sutherland E, Rall T. Fractionation and characterisation of a cyclic adenine nucleotide formed by tissue particles. J Biol Chem 1958; 232:1077-1091.

128. Bokoch GM, Katada T, Northup JK, Ui M, Gilman AG. Purification and properties of the inhibitory guanine nucleotide-binding regulatory component of adenylate cyclase. J Biol Chem 1984; 259:35603567.

129. Li L, Desantiago J, Chu G, Kranias EG. Bers DM. Phosphorylation of phospholamban and troponin I in beta-adrenergic-induced acceleration of cardiac relaxation. Am J Physiol Heart Circ Physiol 2000; 278:H769-H779.

130. Ginsburg KS, Bers DM. Isoproterenol does not increase the intrinsic gain of excitation-contraction coupling. Biophys J 2001;80:590.

131. Viatchenko-Karpinski S, Gyorke $\mathrm{S}$. Modulation of the $\mathrm{Ca}^{2+}$-induced $\mathrm{Ca}^{2+}$ release cascade by betaadrenergic stimulation in rat ventricular myocytes. J Physiol 2001; 533:837-848.

132. Song LS, Wang SQ, Xiao RP, Spurgeon H, Lakatta EG, Cheng H. beta-Adrenergic stimulation synchronizes intracellular $\mathrm{Ca}^{2+}$ release during excitation-contraction coupling in cardiac myocytes. Circ Res 2001; 88:794-801.

133. Li L, Satoh H, Ginsburg KS, Bers DM. The effect of $\mathrm{Ca}^{2 *}$-calmodulin-dependent protein kinase II on cardiac excitation-contraction coupling in ferret ventricular myocytes. J Physiol 1997; 501:17-31.

134. January CT, Fozzard HA. The effects of membrane potential, extracellular potassium, and tetrodotoxin on the intracellular sodium ion activity of sheep cardiac muscle. Circ Res 1984; 54:652-665.

135. Ellis D. Effects of stimulation and diphenylhydantoin on the intracellular sodium activity in Purkinje fibres of sheep heart. J Physiol 1985; 362:331-348.

136. Boyett MR, Hart G. Levi AJ, Roberts A. Effects of repetitive activity on developed force and intracellular sodium in isolated sheep and dog Purkinje fibres. J Physiol 1987; 388:295-322.

137. Berlin JR. Spatiotemporal changes of $\mathrm{Ca}^{22}$ during electrically evoked contractions in atrial and ventricular cells. Am J Physiol 1995: 269:H1165-H1170.

138. Blatter LA, Kockskamper J, Sheehan KA, Zima AV, Huser J, Lipsius SL. Local calcium gradients during excitation-contraction coupling and alternans in atrial myocytes. J Physiol 2003; 546:19-31.

139. Hüser J, Lipsius SL, Blatter LA. Calcium gradients during excitation-contraction coupling in cat atrial myocytes. J Physiol 1996; 494:641-651. 



\section{Chapter 2}

\section{Cellular Mechanisms of Depressed Atrial Contractility in Patients with Chronic Atrial Fibrillation}

Ulrich Schotten, Jannie Ausma, Christoph Stellbrink, Ingo Sabatschus, Miriam Vogel, Dirk Frechen, Friedrich Schoendube, Peter Hanrath, Maurits Allessie 


\section{$\underline{\text { Abstract }}$}

\section{Background}

After cardioversion of atrial fibrillation (AF) the contractile function of the atria is temporarily impaired. Although this has significant clinical implications the underlying cellular mechanisms are poorly understood.

\section{Methods}

Forty-nine consecutive patients submitted for mitral valve surgery were investigated. Twenty-three were in persistent $\mathrm{AF}$ ( $\geq 3$ months), the others were in sinus rhythm (SR). Before extracorporal circulation the right atrial appendage was excised. $\beta$-adrenoceptors were quantified by radioligand binding and G-proteins by Western blot analysis. The isometric contractile response to $\mathrm{Ca}^{2+}$, isoproterenol, BayK8644, and the post-rest potentiation of contractile force were investigated in thin atrial trabeculae which were also examined histologically.

\section{Results}

The contractile force of the atrial preparations obtained from AF patients was $75 \%$ less compared to SR patients. Also the positive inotropic effect of isoproterenol was impaired and BayK8644 failed to increase atrial contractile force. In contrast, the response to extracellular $\mathrm{Ca}^{2+}$ was maintained and the post-rest potentiation was preserved. $\beta$-adrenoceptor density and G-protein expression were unchanged. Histological examination revealed $14 \%$ more myolysis in the atria of AF patients.

\section{Conclusion}

After prolonged AF atrial contractility was reduced by $75 \%$. The impairment of $\beta$ adrenergic modulation of contractile force can not be explained by downregulation of $\beta$ adrenoceptors or changes in G-proteins. Dysfunction of the sarcoplasmic reticulum does not occur after prolonged AF. Failure of BayK 8644 to restore contractility suggests that the $\mathrm{L}$-type $\mathrm{Ca}^{2+}$-channel is responsible for the contractile dysfunction. The restoration of contractile force by high extracellular $\mathrm{Ca}^{2+}$ shows that the contractile apparatus itself is nearly completely preserved after prolonged AF.

\section{$\underline{\text { Introduction }}$}

Contractile dysfunction of the atria following cardioversion of atrial fibrillation (AF) has been recognized for more than 30 years. ' Echocardiographic studies showed that the transmitral blood flow during atrial contraction was markedly reduced after restoration of sinus rhythm (SR). ${ }^{2}$ The degree of atrial contractile dysfunction and the time required for restoration of normal atrial transport function depends on the duration of $\mathrm{AF}{ }^{2.3}$ This temporary loss of atrial contraction may lead to thromboembolic events even when atrial thrombi are not present at the time of cardioversion. ${ }^{4}$

The cellular mechanisms responsible for AF-induced contractile dysfunction are still poorly understood. First it has been thought that the electric energy applied during DC 
cardioversion caused, ,atrial stunning“.5 However, later studies have shown that contraction of the atria was also impaired after pharmacological ${ }^{6}$ and spontaneous ${ }^{7}$ cardioversion. Sustained AF has been shown to cause alterations in atrial cellular ultrastructure. Myolysis and fragmentation of the sarcoplasmic reticulum might explain the contractile dysfunction in remodeled atria. ${ }^{8}$ Prolonged rapid atrial rhythms have also been shown to cause a pronounced reduction in the L-type $\mathrm{Ca}^{2+}$ current. ${ }^{9-11}$ This offers an alternative explanation for the loss of contractile force in the course of prolonged AF. Tachycardia-induced changes of intracellular $\mathrm{Ca}^{2+}$ handling have been studied by Sun et al. $^{12}$ in canine atrial cardiomyocytes. They found that both contractility and intracellular $\mathrm{Ca}^{2+}$ transients were markedly reduced.

In this study we investigated the cellular mechanisms of postfibrillatory atrial contractile dysfunction in man. In atrial trabeculae isolated from patients with and without $\mathrm{AF}$, the $\beta$-adrenergic response, the positive inotropic effect of $\mathrm{Ca}^{2+}$ and BayK8644, and the post-rest potentiation were evaluated. In addition, the most important proteins involved in the $\beta$-adrenergic signal transduction pathway were biochemically determined.

\section{$\underline{\text { Methods }}$}

\section{Patients}

Right atrial appendages were obtained from 49 patients undergoing mitral valve surgery (Table 1). Twenty-three patients were in chronic AF ( $\geq 3$ month), the others were in SR. Despite a tendency for a lower cardiac index and a higher wedge pressure in AF patients, hemodynamics did not differ significantly between the two groups. AF patients more often received $\mathrm{Ca}^{2+}$-antagonists and digitalis for control of their ventricular rate. The patients did not receive drugs at least $12 \mathrm{~h}$ before surgery.

All patients gave written informed consent and the study was approved by an institutional review committee.

\begin{tabular}{|c|c|c|c|}
\hline 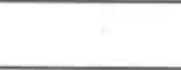 & & $\begin{array}{c}\text { Sinus rhythm } \\
(n=26)\end{array}$ & $\begin{array}{c}\text { Atrial fibrillation } \\
\qquad(n=23)\end{array}$ \\
\hline \multicolumn{2}{|l|}{ Age (v) } & $57 \pm 4$ & $59 \pm 5$ \\
\hline \multicolumn{2}{|l|}{ Gender $(m / f)$} & $(10 / 16)$ & $(9 / 14)$ \\
\hline \multicolumn{2}{|c|}{ Cardiac index $\left(1 / \mathrm{min} / \mathrm{m}^{2}\right)$} & $3.1 \pm 0.3$ & $2.9 \pm 0.2$ \\
\hline \multicolumn{2}{|c|}{ Mean pulmonary capillary wedge pressure $(\mathrm{mmHg})$} & $13.3 \pm 1.8$ & $14.9 \pm 3.0$ \\
\hline \multicolumn{2}{|c|}{ Mean right atrial pressure $(\mathrm{mmHg})$} & $5.4 \pm 0.8$ & $7.3 \pm 0.9$ \\
\hline \multirow[t]{5}{*}{ Medication (n) } & Diuretics & 10 & II \\
\hline & Beta-blockers & 5 & 5 \\
\hline & Digitalis & 6 & $14^{*}$ \\
\hline & $A C E$-Inhibitors & 10 & 11 \\
\hline & $\mathrm{Ca}{ }^{2+}-$ Antagonists & 6 & $12 *$ \\
\hline
\end{tabular}

Table 1. Patients - hemodynamic and clinical data * $p<0.05$. 


\section{Contractility studies}

Immediately after surgical excision, right atrial appendages were placed into Tyrode solution ( $\mathrm{pH} 7.4$; gassed with $5 \% \mathrm{CO}_{2} / 95 \% \mathrm{O}_{2}$ ). Thin myocardial muscle bundles were prepared in parallel to the muscle fiber direction under stereomicroscopic control. The length of the bundles ranged between 3 and $6 \mathrm{~mm}$ and the diameters were $0.45 \pm 0.03 \mathrm{~mm}$ $(\mathrm{n}=55)$ in SR patients and $0.43 \pm 0.03 \mathrm{~mm}(\mathrm{n}=5 \mathrm{l})$ in AF patients $(\mathrm{p}=\mathrm{n} . \mathrm{s}$.). They were connected to isometric force transducers with silk threads and placed in an organ bath filled with prewarmed $\left(37^{\circ} \mathrm{C}\right)$ bathing solution. After an equilibration period of 30 minutes the muscles were stretched to a resting tension of $1.0 \mathrm{mN}$. External field stimulation was performed with rectangular pulses $(5 \mathrm{~ms}, 5-10 \%$ above threshold) at a frequency of $1 \mathrm{~Hz}$. Resting tension was increased in steps by $0.2 \mathrm{mN}$ until the muscle length providing maximal active force generation was reached $\left(\mathrm{L}_{\max }, 5.1 \pm 0.2 \mathrm{~mm}\right.$ in $\mathrm{SR}$, $5.2 \pm 0.2 \mathrm{~mm}$ in $\mathrm{AF}, \mathrm{p}=\mathrm{n} . \mathrm{s}$.). The resting tension at $\mathrm{L}_{\max }$ was not different in the two groups $(1.80 \pm 0.04 \mathrm{mN}(\mathrm{n}=55)$ in $\mathrm{SR}, 1.74 \pm 0.06 \mathrm{mN}(\mathrm{n}=51)$ in $\mathrm{AF}, \mathrm{p}=\mathrm{n} . \mathrm{s}$.). The muscles were allowed to equilibrate for $30 \mathrm{~min}$. All muscles showing a decline of force of contraction (FC) of more than $5 \%$ during this period were excluded from the study. In 20 preparations obtained from 16 patients in SR and in 19 preparations from $13 \mathrm{AF}$ patients first a cumulative dose-response curve of isoproterenol was determined. After isoproterenol was washed-out and baseline FC was restored, the positive inotropic effect of $\mathrm{Ca}^{2+}$ was studied for comparison. Another subgroup of preparations (19 bundles prepared from $16 \mathrm{SR}$ patients and 16 bundles prepared from $12 \mathrm{AF}$ patients) was first exposed to $10.8 \mathrm{mM}$ extracellular $\mathrm{Ca}^{2+}$ followed by wash-out. Thereafter BayK 8644 was cumulatively added to the organ bath.

To study the post-rest potentiation of contractile force, $1 \mathrm{~Hz}$ external field stimulation was interrupted for $10 \mathrm{~s}$ and $\mathrm{FC}$ of the first twitch after the pause was compared with the steady state force amplitude (16 muscle preparations from 16 patients in both patient groups).

\section{Histological examination}

At the end of the experiments the bundles were examined histologically. To compare the atrial morphology with less diseased hearts right atrial specimens were obtained from 19 patients undergoing coronary artery bypass graft surgery (10 in SR, 9 in AF). All preparations were fixed in $3 \%$ glutaraldehyde in $90 \mathrm{mmol} / / \mathrm{KH}_{2} \mathrm{PO}_{4}$ for $48 \mathrm{~h}$. After post-fixation with $\mathrm{OsO}_{4}$ the specimens were dehydrated by a graded ethanol series, and embedded in epoxy resin. The sections $(2 \mu \mathrm{m})$ were stained with PAS and toluidine blue. Morphometric quantification was carried out in transverse sections of each bundle using a grid of 500 intersections as described previously. ${ }^{8}$ At each intersection the cellular and extracellular structures were classified as: 1) Sarcomeres, 2) nuclei, 3) other intracellular structures of cardiomyocytes (mostly glycogen), 4) extracellular matrix including fibroblasts and other non-myocytes, 5) vessels including perivascular cells. The content of each structure was expressed as percentage of all 500 measuring points. The transnuclear cell diameter of 50 cardiomyocytes (shortest axis) was measured with a digital imaging system (Sony CCD camera equipped with NIH image software).

\section{$\beta$-Adrenoceptors}

$\beta$-Adrenoceptor density was determined by radioligand binding as described previously..$^{13}$ Briefly, a crude membrane preparation of the atrial tissue was incubated with ${ }^{125}$ I-lodocyanopindolol $(4-350 \mathrm{pM})$. After filtration through Whatman GF/C filters 
the retained radioactivity was counted in a $\gamma$-counter. CGP $12177(1 \mu \mathrm{M})$ was used to determine nonspecific binding. Protein content of the membrane preparations was measured according to Bradford. ${ }^{14}$

\section{Western blot analysis}

To quantify G-proteins electrophoresis of homogenate aliquots containing $80 \mu \mathrm{g}$ protein/lane was carried out using $10 \%$ polyacrylamid gels. ${ }^{13}$ After tank blotting the nitrocellulose membranes were exposed to primary antibody (antiserum AS/7 [inhibitory G-protein] or RM/I [stimulatory G-protein], NEN Life Science). After labeling with ${ }^{125} \mathrm{I}$-protein $\mathrm{A}$ nitrocellulose membranes were cut and single band signals were quantified in a $\gamma$-counter.

\section{Statistical analysis}

Data are expressed as means $\pm \mathrm{SEM}$. For $\mathrm{EC}_{50}$-values $95 \%$ confidence intervals are given. Statistical significance was determined with the unpaired Student's t-test or by one-way analysis of variance (ANOVA) for comparison of multiple groups. Significance of differences in medication or gender were calculated by Chi-square test. A p-value of less than 0.05 was considered as statistically significant.

\section{$\underline{\text { Results }}$}

\section{Light microscopy}

Representative examples of longitudinal and transverse sections of atrial muscle preparations are shown in Figure 1. Both in SR and AF patients marked myolytic alterations and pronounced interstitial fibrosis were present. However, the degree of myolysis was more pronounced in chronically fibrillating atria. Also the cell size was larger in AF, the average transverse cell diameter being $11.2 \pm 0.4 \mu \mathrm{m}$ in SR patients and $17.3 \pm 0.6 \mu \mathrm{m}$ in AF patients $(+55 \%, \mathrm{p}<0.01)$.

SR

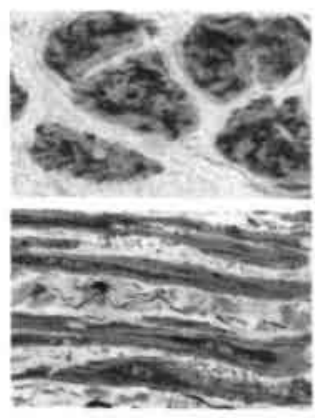

AF

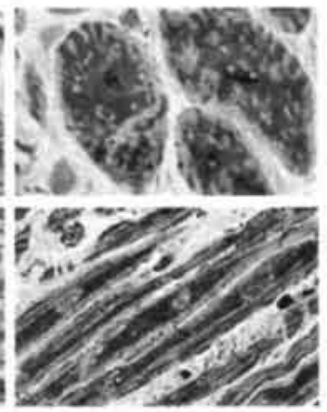

SR

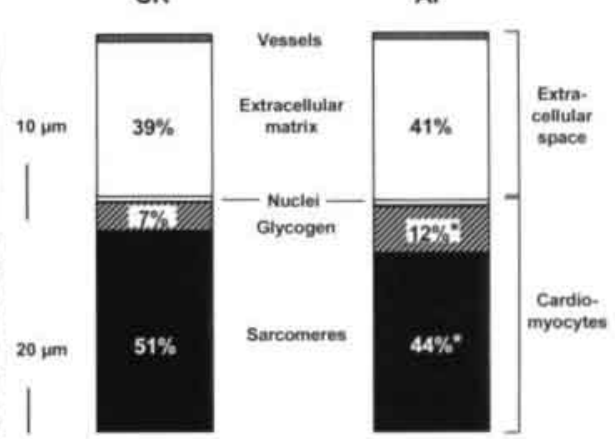

Figure 1

Light microscopy of transversal and longifudinal sections (2 $\mu \mathrm{m}$ thick) of atrial muscle preparations. PAS staining (red) representing glycogen accumulation was more pronounced in AF patients. Sarcomeres stained with toluidine blue are partly displaced by glycogen in these patients.

Right panel: Relative tissue composition of atrial muscle bundles. ":p<0.05. 
In all bundles the sarcomere content was $14 \%$ lower in AF patients compared to SR patients (Figure 1, Table 2). The amount of non-contractile material (mostly glycogen) was nearly two times higher in AF patients. The extracellular matrix composed about $40 \%$ of the muscle bundles in both groups. This relatively high amount of extracellular matrix is consistent with changes described as the result of mitral valve or rheumatic heart disease. ${ }^{15,16}$ In the additional group of patients with coronary heart disease the amount extracellular matrix was less (Table 2). The differences between coronary artery disease patients in $\mathrm{SR}$ compared to those in $\mathrm{AF}$, however, were similar to the observations in mitral valve disease patients.

\begin{tabular}{|c|c|c|c|c|c|}
\hline & & \multicolumn{2}{|c|}{$\begin{array}{c}\text { Mitral valve } \\
\text { disease }\end{array}$} & \multicolumn{2}{|c|}{$\begin{array}{c}\text { Coronary artery } \\
\text { disease }\end{array}$} \\
\hline & & $S R$ & $\overrightarrow{A F}$ & $S R$ & $A F$ \\
\hline $\begin{array}{l}\text { Muscle preparations } \\
\text { I patients }\end{array}$ & (n) & $3 / / 19$ & $30 / 15$ & $12 / 10$ & $11 / 9$ \\
\hline \multirow[t]{3}{*}{ Cardiomyocytes } & Sarcomeres & $50.4 \pm 2.0$ & $43.5 \pm 2.0^{*}$ & $60.7 \pm 2.9+$ & $52.7 \pm 1.4^{*}+$ \\
\hline & $\begin{array}{l}\text { Intracellular non- } \\
\text { contractile material }\end{array}$ & $6.8 \pm 0.3$ & $11.7 \pm 0.3^{*}$ & $8.1 \pm 0.8$ & $13.0 \pm 0.8^{*}$ \\
\hline & Nuclei & $1.2 \pm 0.1$ & $1.1 \pm 0.1$ & $1.4 \pm 0.2$ & $1.5 \pm 0.2$ \\
\hline \multirow[t]{2}{*}{ Extracellular space } & $\begin{array}{l}\text { Extracellular matrix } \\
\text { incl. fibroblasts }\end{array}$ & $38.7 \pm 2.0$ & $41.1 \pm 1.9$ & $26.7 \pm 2.6+$ & $29.7 \pm 1.4+$ \\
\hline & $\begin{array}{l}\text { Vessels incl. } \\
\text { perivascular cells }\end{array}$ & $2.9 \pm 0.2$ & $2.6 \pm 0.2$ & $3.1 \pm 0.4$ & $3 . I \pm 0.2$ \\
\hline
\end{tabular}

Table 2. Relative tissue composition of right atrial muscle bundles.

All data in $\%$ of total tissue volume. * $p<0.05$ AF versus SR. + $p<0.05$ coronary artery disease veraus mitnal salse disease.

\section{Contractility}

Single contractions at baseline conditions $\left(37^{\circ} \mathrm{C}, 1 \mathrm{~Hz}, 2.5 \mathrm{mM} \mathrm{Ca}^{2}\right)$ of all muscle preparations are superimposed in Figure 2. In trabeculae isolated from patients in SR the strength was $11.5 \mathrm{mN} / \mathrm{mm}^{2}$ ( $\mathrm{n}-55$, range $4.1-21.9 \mathrm{mN} / \mathrm{mm}^{2}$ ). In contrast, in muscle bundles of AF patients $\mathrm{FC}$ was only $3.1 \mathrm{mN} / \mathrm{mm}^{2}$ (n=51, range $0.9-7.4 \mathrm{mN} / \mathrm{mm}^{2}$, $p<0.01$ ). Thus, in atrial myocardium of AF patients baseline contractility was reduced by approximately $75 \%$.

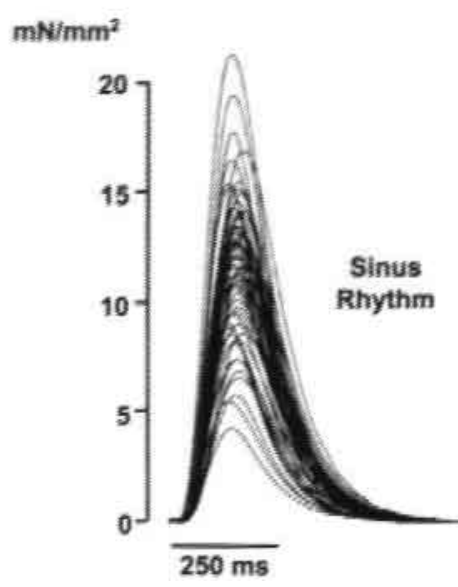

Atrial Fibrillation
Figure 2

Superimposed force recardings of atrial muscle preparations fram 25 patients in SR (35 preparations) and from $22 \mathrm{AF}$ patients (51 preparations) recorded under isometric conditions $\left(37^{\circ} \mathrm{C}\right.$. $\mathrm{HHz}$. 
Increasing the extracellular $\mathrm{Ca}^{2+}$ concentration increased $\mathrm{FC}$ both in $\mathrm{SR}$ and $\mathrm{AF}$ patients (Figure 3). However, the relative increase was more pronounced in the AF group. As a result, at $\mathrm{Ca}^{2+}$ concentrations $\geq 7.4 \mathrm{mM} \mathrm{FC}$ was no longer significantly lower than in the SR group (but still slightly below the force in the SR group). Thus, high extracellular $\mathrm{Ca}^{2+}$ concentrations nearly overcame the contractile dysfunction in muscle preparations of AF patients. In 31 bundles of $19 \mathrm{SR}$ patients and 30 bundles of $15 \mathrm{AF}$ patients maximal FC $\left(\mathrm{F}_{\max }\right)$ was directly compared with the differences in sarcomere content. In $\mathrm{AF}$ patients the reduction in sarcomere content $(-14 \%)$ was similar to the slight decrease in $\mathrm{F}_{\max }(-15 \%)$, although the latter only nearly reached the level of statistical significance $(\mathrm{p}=0.069)$. The correlation coefficient between sarcomere content and $\mathrm{F}_{\max }$ was $0.89(\mathrm{p}<0.001)$.

$\mathrm{mN} / \mathrm{mm}^{2}$

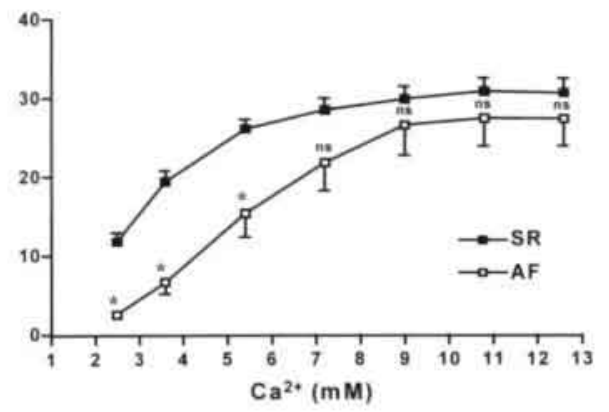

Sarcomere content

$F_{\max }$
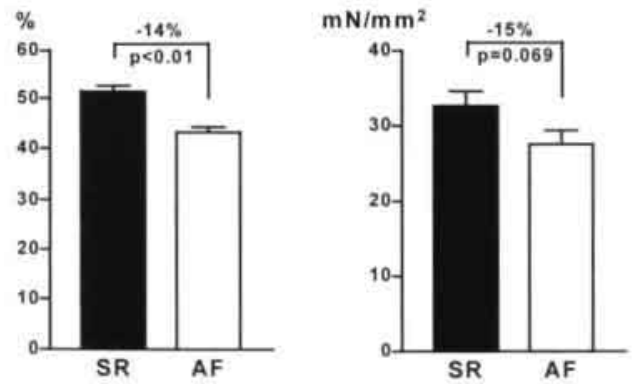

Figure 3

Upper panel: Effect of the extracellular $\mathrm{Ca}^{2}$ concentration on $\mathrm{FC}\left(\mathrm{mN} / \mathrm{mm}^{2}\right)$ of muscle preparations from patients in $S R$ (20 bundles prepared from 16 patients) or in $A F$ ( 19 bundles prepared from 13 patients). High extracellular $\mathrm{Ca}^{2}$ concentrations nearly overcame the depression of contractile force due to $A F$. $p<0.05 A F$ versus $S R$.

Mid panel: In 31 muscle preparations from 19 SR patients and in 30 muscle preparations from $15 \mathrm{AF}$ patients both maximal FC during exposure to $10.8 \mathrm{mM}$ extracellular $\mathrm{Ca}^{2}$ concentration $\left(F_{\operatorname{mad}}\right)$ and structural changes were studied. On average, the sarcomere content was reduced in the $A F$ patients by $14 \%$. The slight reduction in $F_{\min }$ was of similar extent $(-15 \%)$ nearly reaching statistical significance $(p=0.069)$

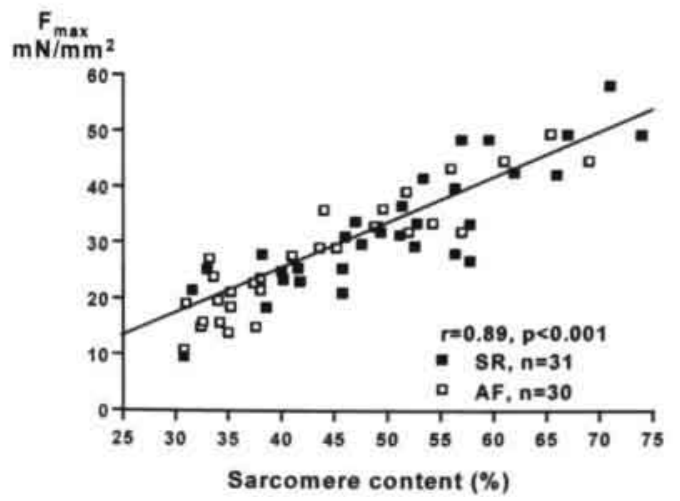

Lower panel: The relative sarcomere content was positively correlated to $F_{\max }$ 
The $\beta$-adrenoceptor agonist isoproterenol exerted a pronounced positive inotropic effect in both the SR and the AF group (Figure 4). However, in AF patients the concentrationresponse curve was shifted downwards and to the right. $\mathrm{FC}$ at the maximal isoproterenol concentration $\left(10^{-6} \mathrm{M}\right)$ was lower in the $\mathrm{AF}$ group $\left(18.3 \pm 1.8 \mathrm{mN} / \mathrm{mm}^{2}\right.$ versus $\left.30.0 \pm 1.3 \mathrm{mN} / \mathrm{mm}^{2}, \mathrm{p}<0.01\right)$. In the $\mathrm{SR}$ group the half-maximal positive inotropic effect of isoproterenol was reached at $2.6(1.8-4.4) \mathrm{nM}\left(\mathrm{EC}_{50}\right)$. A nearly 10-fold higher isoproterenol concentration was needed in the $\mathrm{AF}$ group to elicit the half-maximal response $\left(\mathrm{EC}_{50}=22(14-41) \mathrm{nM}, \mathrm{p}<0.01\right)$. Thus, the positive inotropic potency of isoproterenol was markedly reduced in atrial muscle preparations from AF patients. Neither in the SR patients nor in the AF patients $\beta$-blocker therapy altered the maximal response to isoproterenol (SR: $32.2 \pm 4.3 \mathrm{mN} / \mathrm{mm}^{2} \quad(\mathrm{n}=4$, with $\beta$-blocker) vs. $29.2 \pm 1.9 \mathrm{mN} / \mathrm{mm}^{2}\left(\mathrm{n}=12\right.$, no $\beta$-blocker, $\mathrm{p}=\mathrm{n} . \mathrm{s}$.); AF: $20.1 \pm 2.1 \mathrm{mN} / \mathrm{mm}^{2}(\mathrm{n}=4$, with $\beta$ blocker) vs. $17.4 \pm 1.8 \mathrm{mN} / \mathrm{mm}^{2}(\mathrm{n}=9$, no $\beta$-blocker, $\mathrm{p}=n . \mathrm{s}$.)). Similarly, the potency of isoproterenol $\left(\mathrm{EC}_{50}\right)$ was not changed.

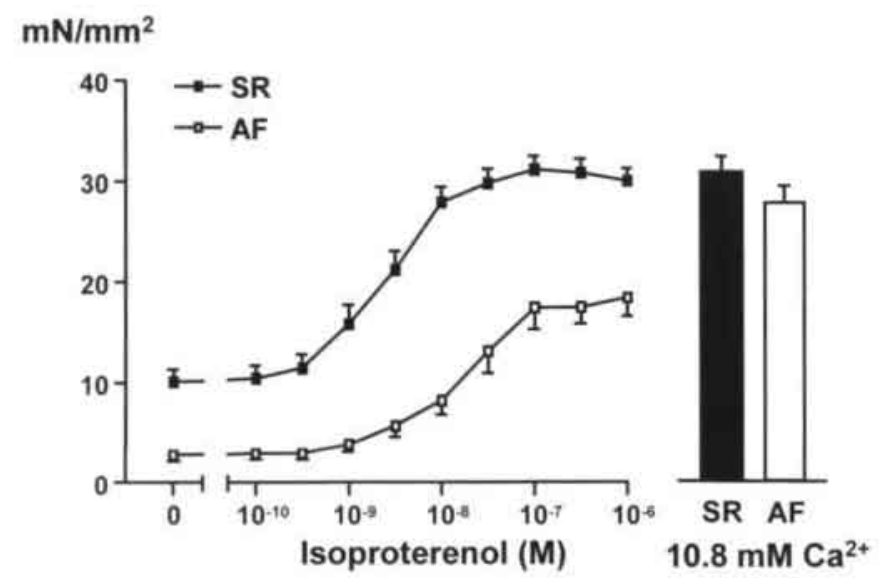

Figure 4

A: Effect of the $\beta$-adrenoceptor agonist isoproterenol on $F C\left(\mathrm{mN} / \mathrm{mm}^{2}\right)$ of isolated muscle preparations (same preparations as in Figure 3, upper panel). Compared to the response to $10.8 \mathrm{mM} \mathrm{Ca}{ }^{2}$ the positive inotropic effect of isoproterenol was reduced in AF patients.

\section{$\beta$-adrenergic signaling}

${ }_{25}^{25}$ I-Iodocyanopindolol binding experiments on atrial membrane preparations showed saturation characteristics in SR and in AF patients (Figure 5, left panel). The $\beta$ adrenoceptor density was $58 \pm 5 \mathrm{fmol} / \mathrm{mg}$ in the SR group $(\mathrm{n}=11)$ and $54 \pm 5 \mathrm{fmol} / \mathrm{mg}$ in the AF group $(n=10, p=n . s$.). Thus, in comparison to the right atrial myocardium of 6 healthy donor hearts $(81 \pm 7 \mathrm{fmol} / \mathrm{mg})$ right atrial $\beta$-adrenoceptor density was reduced to a similar extent in mitral valve disease patients in SR or AF. The right panel of figure 5 shows representative immunoblots of the stimulatory and the inhibitory G-protein. The antiserum $\mathrm{AS} / 7$ bound specifically to a single band at $40 \mathrm{kDa}$, which represents the Gi $\alpha$ 2 subunit. $\mathrm{RM} / 1$ bound to a $45 \mathrm{kDa}$ and a $52 \mathrm{kDa}$ protein representing 2 splicing variants of the stimulatory G-protein $\alpha$-subunit. ${ }^{13}$ Neither the level of the stimulatory G-protein $(12719 \pm 883 \mathrm{cpm} / \mathrm{mg}$ in $14 \mathrm{SR}$ patients versus $14676 \pm 1243 \mathrm{cpm} / \mathrm{mg}$ in $12 \mathrm{AF}$ patients, $\mathrm{p}=\mathrm{n} . \mathrm{s}$.) nor the level of the inhibitory G-protein $(3951 \pm 300 \mathrm{cpm} / \mathrm{mg}$ in $14 \mathrm{SR}$ patients versus $3476 \pm 309 \mathrm{cpm} / \mathrm{mg}$ in $12 \mathrm{AF}$ patients, $\mathrm{p}=\mathrm{n} . \mathrm{s}$.) was affected by $\mathrm{AF}$. 


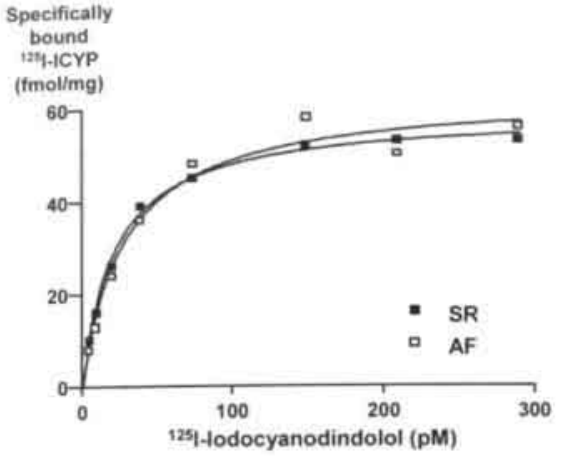

\author{
Stimulatory G protein
}
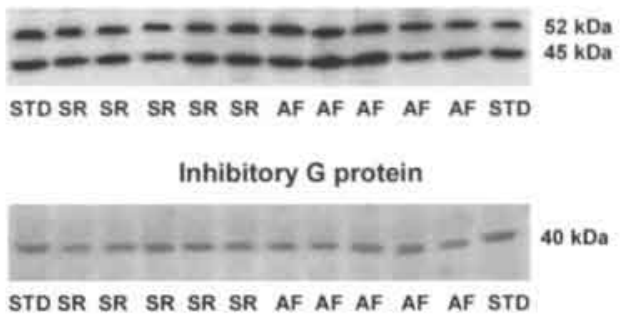

Figure 5

Left: Representative binding experiments on right atrial membrane preparations using ${ }^{125}$ I-lodocyanopindolol ${ }^{125}$ I-ICYP) as radioligand. Neither the affinity of the radioligand to $\beta$-adrenoceptors nor the density of the receptors were different in these patients.

Right: Representative immunoblot of stimulatory and inhibitory G-protein quantification. Each lane of the autoradiography represents one patient with either SR or AF. STD = Standard sample, which was subjected to each gel to promote comparability of determination from different blots.

\title{
Loss of effect of BayK8644
}

The positive inotropic effect of BayK8644 is shown in Figure 6. In the SR group the $\mathrm{Ca}^{2+}$-channel agonist exerted a pronounced positive inotropic effect. At $10^{-5} \mathrm{M}$ BayK8644 FC was comparable to FC at $10.8 \mathrm{mM}$ extracellular $\mathrm{Ca}^{2+}$. In contrast, the response to BayK8644 was abolished in the AF group, although these muscle preparations did respond to an increase in extracellular $\mathrm{Ca}^{2+}$ concentration. At the highest concentration of BayK $8644\left(10^{-5} \mathrm{M}\right) \mathrm{FC}$ was $4.5 \pm 1.1 \mathrm{mN} / \mathrm{mm}^{2}$ compared to $28.0 \pm 2.6 \mathrm{mN} / \mathrm{mm}^{2}$ at $10.8 \mathrm{mM} \mathrm{Ca}^{2+}(\mathrm{p}<0.01)$. Treatment with $\mathrm{Ca}^{2+}$-antagonists did not change the response to BayK8644 in the AF patients. In the treated patients $\mathrm{FC}$ at $10^{-5} \mathrm{M}$ BayK8644 was $4.7 \pm 1.3 \mathrm{mN} / \mathrm{mm}^{2}(\mathrm{n}=7)$ versus $4.2 \pm 1.3 \mathrm{mN} / \mathrm{mm}^{2}(\mathrm{n}=5)$ in the patients who were not treated with $\mathrm{Ca}^{2+}$-antagonists $(\mathrm{p}=\mathrm{n} . \mathrm{s}$.). Digitalis did also not affect the response to BayK8644.

$\mathrm{mN} / \mathrm{mm}^{2}$

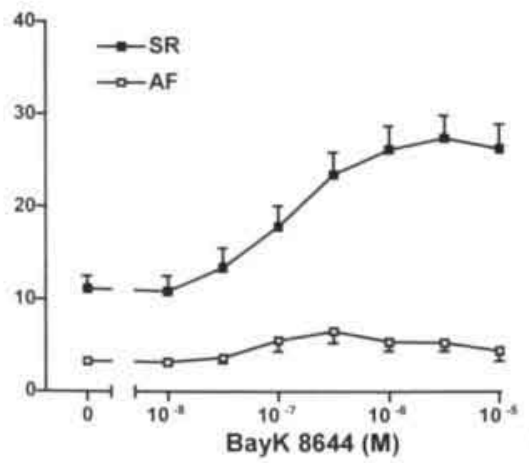

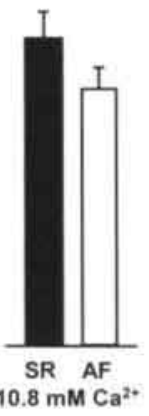

Figure 6

Effect of BayK8644 on FC $\left(\mathrm{mN} / \mathrm{mm}^{2}\right)$ of isolated muscle preparations from patients in $S R$ (19 muscle preparations prepared from 16 patients) or in $A F(16$ muscle preparations prepared from 12 patients). In the SR patients BayK8644 elicited a pronounced positive inotropic effect which was comparable to the effect of $10.8 \mathrm{mM}$ $\mathrm{Ca}^{2}$. In the $\mathrm{AF}$ patients BayK8644 failed to increase FC although the same muscle bundles did respond to $10.8 \mathrm{mMCa} \mathrm{Ca}^{2}$, 


\section{Preserved post-rest potentiation of contractile force}

Figure 7 shows representative experiments on post-rest potentiation of contractile force (rest interval $10 \mathrm{~s}$ ). FC of the first post-rest twitch was markedly increased in both the $\mathrm{SR}$ and the $\mathrm{AF}$ patient. Compared to the force amplitude at steady state conditions the post-rest $\mathrm{FC}$ was equally enhanced in both patient groups ( $\mathrm{SR}:+4.1 \pm 1.0 \mathrm{mN} / \mathrm{mm}^{2}, \mathrm{n}=16$, versus $+3.9 \pm 1.1 \mathrm{mN} / \mathrm{mm}^{2}$ in $A F, n=16$, $p=$ n.s.).

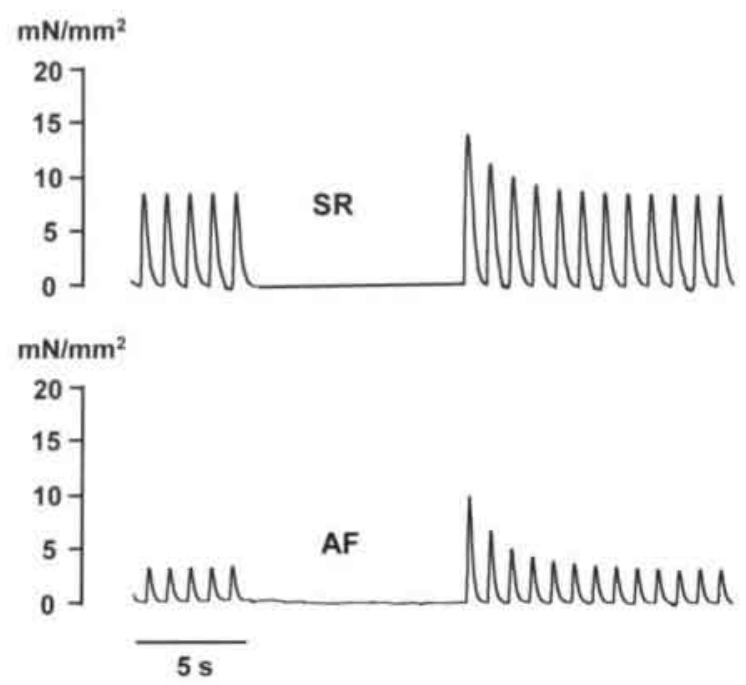

\section{$\underline{\text { Discussion }}$}

The present study provides first insights into the cellular mechanisms of the postfibrillatory atrial contractile dysfunction in man. It demonstrates that the contractility of atrial muscle bundles isolated from $\mathrm{AF}$ patients is reduced by $\sim 75 \%$. The study confirms previous observations in a dog model of tachycardia-induced atrial contractile dysfunction in which the systolic shortening of atrial cardiomyocytes was found to be reduced to a similar extent. ${ }^{12}$ The present study demonstrates that AFinduced myolysis is only of limited importance as a cause of the atrial contractile dysfunction. Instead, downregulation and/or altered function of the L-type $\mathrm{Ca}^{2+}$ channels seem to underlie the AF-induced atrial dysfunction.

\section{Myolysis and AF-induced loss of atrial contractility}

In patients with chronic AF recovery of atrial contractile function after cardioversion may require several weeks or month. ${ }^{3}$ Restoration of cellular (ultra)structure might explain such a long recovery of contractile function. ${ }^{8}$ Indeed, the present study shows that myolysis and replacement of sarcomeres by glycogen was more pronounced in trabeculae of AF patients. The same alterations have previously been reported in the goat model of $\mathrm{AF}^{8}$ and it was concluded that the loss of sarcomeres might contribute to the delayed recovery of atrial function after conversion to SR. However, in the latter study a direct relation between structural changes and the contractile function of the 
atrial myocardium was not investigated. In the present study the loss of sarcomeres was compared to the maximal achievable FC in the same muscle preparations to evaluate the contribution of structural remodeling to the AF-induced atrial contractile dysfunction. At high extracellular $\mathrm{Ca}^{2+}$ concentrations atrial $\mathrm{FC}$ was only slightly reduced in the AF group $(-15 \%)$. This moderate reduction in maximal $\mathrm{FC}$ corresponded to a similar reduction in sarcomere content $(-14 \%)$. There was a strong correlation between the maximal FC and the sarcomere content of the individual muscle preparations. Therefore, AF-induced myolysis can only partly explain the pronounced reduction of contractility in remodeled atria. The main mechanism of post-cardioversion atrial contractile dysfunction is a disturbed activation rather than a loss of atrial myofilaments.

\section{$\beta$-Adrenergic signaling}

An important mechanism controlling myocardial force in atrial and ventricular myocardium is the $\beta$-adrenergic signal transduction pathway. Our data demonstrate that in atrial myocardium of AF patients the positive inotropic effect of isoproterenol was markedly reduced. Although the impaired $\beta$-adrenergic response can not explain the reduced atrial contractility in-vitro, it might contribute to the atrial contractile dysfunction in-vivo by blunting the positive inotropic response to the physiological variations in sympathetic tone.

In human failing ventricular myocardium and in a canine model of pacing-induced heart failure desensitization towards catecholamines has been shown to be due to a reduced density of the $\beta$-adrenoceptors and an upregulation of the inhibitory G-protein. ${ }^{17-19}$ In contrast, in our study atrial $\beta$-adrenoceptor density and G-protein levels were not altered in AF patients. This indicates that the atrial contractile dysfunction after the cessation of $\mathrm{AF}$ is due to different mechanisms than the ventricular cardiomyopathy in heart failure or the experimental tachycardia-induced cardiomyopathy on the ventricular level.

\section{The role of the L-type $\mathrm{Ca}^{2+}$-channel}

Since the positive inotropic effect of catecholamines is mainly due to activation of the $\mathrm{L}$-type $\mathrm{Ca}^{2+}$-channel, we tested the hypothesis that alterations of the $\mathrm{Ca}^{2+}$-channels were responsible for the diminished isoproterenol effect. A reduction in $\mathrm{Ca}^{2+}$-current has been shown to be the most important ionic mechanism of AF-induced electrical remodeling." Several studies have demonstrated a downregulation of L-type $\mathrm{Ca}^{2+}$-channel subunits in $\mathrm{AF}^{20-22}$ In our present study the L-type $\mathrm{Ca}^{2+}$-channel agonist BayK8644 failed to increase atrial FC in AF patients. Potential explanations include changes in the number and/or function of the L-type $\mathrm{Ca}^{2+}$-channels. Downregulation of channel subunits is expected to reduce the positive inotropic effect of the $\mathrm{Ca}^{2+}$-channel agonist and might have caused the lack of response to BayK8644. Altered function of the channel due to changes of the phoshorylation state is a second possibility to explain the loss of effect of BayK8644. In failing ventricular myocardium the spatial relationship between the Ltype $\mathrm{Ca}^{2+}$-channel and the $\mathrm{Ca}^{2+}$-release-channel of the sarcoplasmic reticulum is disturbed. ${ }^{23}$ This would provide a third explanation for the absence of the BayK8644 effect. The latter possibility would also explain, why the positive inotropic effect of BayK8644 is abolished in atrial myocardium of AF patients, whereas BayK 8644 could partly overcome the decrease of the $\mathrm{Ca}^{2+}$ inward current in atrial cells of dogs undergoing rapid atrial pacing.

The blunted response to BayK 8644 not only emphasizes that changes in the function and/or number of the L-type $\mathrm{Ca}^{2+}$-channels is the key to understand post-AF atrial 
contractile dysfunction. It also explains, why the positive inotropic effect of isoproterenol was reduced in AF patients, although $\beta$-adrenoceptor density and Gproteins levels were unaltered. Isoproterenol increases $\mathrm{FC}$ by increasing the $\mathrm{Ca}^{2+}$ inward current and by enhancing the $\mathrm{Ca}^{2+}$ reuptake by the $\mathrm{Ca}^{2+}$-ATPase of the sarcoplasmic reticulum (SERCA). As a result of both effects the $\mathrm{Ca}^{2+}$ load of the sarcoplasmic reticulum is increased. In atrial myocardium of AF patients the inotropic effect of isoproterenol was reduced which can be explained by the above mentioned changes of the L-type $\mathrm{Ca}^{2+}$-channel. Interestingly, isoproterenol still elicits some positive inotropic effect in atrial myocardium of AF patients. This remaining stimulatory effect is most likely due to stimulation of the $\mathrm{Ca}^{2+}$ reuptake into the sarcoplasmic reticulum by SERCA which would be consistent with our hypothesis that the function of the sarcoplasmic reticulum is preserved in atrial myocardium of AF patients (see below). In contrast, BayK8644, purely acting on the L-type $\mathrm{Ca}^{2+}$-channel, lacks this alternative positive inotropic mechanism and becomes ineffective in atrial myocardium of $\mathrm{AF}$ patients.

\section{No dysfunction of the sarcoplasmic reticulum}

As reported in human failing ventricular myocardium and in experimental tachycardiainduced heart failure ${ }^{24}$ dysfunction of the sarcoplasmic reticulum might also contribute to the reduced atrial contractility after the cessation of AF. Post-rest potentiation of contractile force critically depends on the ability of the sarcoplasmic reticulum to store and release $\mathrm{Ca}^{2+}$ and reflects the functional capacity of the sarcoplasmic reticulum. ${ }^{25}$ In atrial myocardium of AF patients the post-rest potentiation was fully preserved, indicating that in fibrillating atria FC is not limited by the capacity of the sarcoplasmic reticulum to release and reuptake $\mathrm{Ca}^{2+}$. This observation is in accordance with the finding of Sun et al. ${ }^{12}$ that the post-rest potentiation was still present in atrial cardiomyocytes from dogs with tachycardia-induced atrial contractile dysfunction.

\section{Limitations}

Although the present study has demonstrated that in atrial muscle bundles from $\mathrm{AF}$ patients contractility is reduced by $75 \%$, a causative relationship between AF and the atrial contractile dysfunction has not been studied. We can not exclude the possibility that a common underlying factor causes both the atrial contractile dysfunction and AF. However, the L-type $\mathrm{Ca}^{2+}$ current is the main determinant of contractile force and becomes downregulated by AF. Therefore, it is reasonable to assume that electrical remodeling goes hand in hand with the atrial contractile dysfunction. This hypothesis is supported by the study of Sun et al. showing that in dogs undergoing rapid atrial pacing the decrease in atrial contractility follows a similar time course as the shortening of the action potential duration and the decrease of the $\mathrm{Ca}^{2+}$ inward current. ${ }^{12}$

In all patients the atria showed histological changes probably due to the underlying structural heart disease. Although the structural differences in atria from patients in AF and SR were similar to the changes found in the goat model of AF (resembling the situation in lone AF) extrapolation to AF in less diseased hearts should be done with great caution. Further studies on atrial preparations from patients with lone AF would certainly be worthwhile.

A further limitation concerns the heterogeneity of our study population. Digitalis and $\mathrm{Ca}^{2+}$-antagonists were more frequently taken by the AF patients and a part of our study population was on $\beta$-blockers. The subgroup analysis revealed that drug treatment did not change contractile force and the response to positive inotropes in the atrial muscle 
preparations. Thus, although we can not exclude that differences in medication might have influenced the contractile behavior of the muscle preparations, the marked differences in atrial contractility between SR and AF patients could not be explained by differences in drug therapy.

\section{$\underline{\text { References }}$}

1. Logan W, Rowlands D, Howitt G. Holmes A: Left atrial activity following cardioversion. Lancet $1965: 2: 471-473$

2. Shapiro EP. Effron MB, Lima S, Ouyang P. Siu CO, Bush D: Transient atrial dysfunction after conversion of chronic atrial fibrillation to sinus rhythm. Am.J.Cardiol. 1988;62:1202-1207

3. Manning WJ, Silverman DI, Katz SE, Riley MF, Come PC, Doherty RM, Munson JT. Douglas PS: Impaired left atrial mechanical function after cardioversion: relation to the duration of atrial fibrillation. J.Am.Coll.Cardiol. 1994:23:1535-1540

4. Black IW. Fatkin D. Sagar KB, Khandheria BK, Leung DY, Galloway JM, Feneley MP, Walsh WF, Grimm RA, Stollberger C, Verhorst PMJ, Klein AL: Exclusion of atrial thrombus by transesophageal echocardiography does not preclude embolism after cardioversion of atrial fibrillation. A multicenter study. Circulation. 1994;89:2509-2513

5. Fatkin D, Kuchar DL. Thorburn CW, Feneley MP: Transesophageal echocardiography before and during direct current cardioversion of atrial fibrillation: evidence for "atrial stunning" as a mechanism of thromboembolic complications. J.Am.Coll.Cardiol. 1994;23:307-316

6. Dethy M, Chassat C, Roy D, Mercier LA: Doppler echocardiographic predictors of recurrence of atrial fibrillation after cardioversion. Am.J.Cardiol. 1988;62:723-726

7. Grimm RA, Leung DY, Black IW, Stewart WJ. Thomas JD, Klein AL: Left atrial appendage "stunning" after spotaneous conversion of atrial fibrillation demonstrated by transesophageal Doppler echocardiography. Am.Heart.J 1995;130:174-176

8. Ausma J. Wijffels M. Thoné F. Wouters L. Allessie M. Borgers M: Structural changes of atrial myocardium due to sustained atrial fibrillation in the goat. Circulation 1997;96:3157-3163

9. Yue L. Feng J. Gaspo R, Li GR, Wang Z, Nattel S: lonic remodeling underlying action potential changes in a canine model of atrial fibrillation. Circ. Res. 1997:81:512-525

10. Bosch RF. Zeng XR. Grammer JB. Popovic K. Mewis C, Kuehlkamp V; Ionic mechanisms of electrical remodeling in human atrial fibrillation. Cardiovasc Res. 1999:44:121-131

11. Van Wagoner DR, Pond AL, Lamorgese M, Rossie SS, McCarthy PM, Nerbonne JM: Atrial L-type $\mathrm{Ca}^{2 *}$-currents and human atrial fibrillation. Circ.Res. 1999:85:428-436

12. Sun H, Gaspo R. Leblane N. Nattel S: Cellular mechanisms of atrial contractile dysfunction caused by sustained atrial tachycardia. Circulation 1998:98:719-727

13. Schotten U. Filzmaier K, Borghardt B, Kulka S. Schoendube F, Schumacher C. Hanrath P: Changes of the $\beta$-adrenergic signal transduction in compensated human cardiac hypertrophy depend on the underlying disease. Am.J.Physiol. 2000;278:H2076-H2083

14. Bradford $\mathrm{MM}$ : A rapid and sensitive method for the quantitation of microgram quantities of protein utilizing the principle of protein-dye binding. Anal.Biochem. 1976:72:248-254

15. Boyden PA. Tilley LP. Pham TD. Liu SK. Fenoglic JJJ, Wit AL: Effects of left atrial enlargement on atrial transmembrane potentials and structure in dogs with mitral valve fibrosis. Am.J.Cardiol. 1982:49:1896-1908

16. Pham TD, Fenoglio-JJ J: Right atrial ultrastructure in chronic rheumatic heart disease. Int.J.Cardiol. $1982 ; 1: 289-304$

17. Bristow MR, Ginsburg R. Minobe W, Cubicciotti RS, Sageman WS, Lurie K, Billingham ME, Harrison DC, Stinson EB: Decreased catecholamine sensitivity and beta-adrenergic-receptor density in failing human hearts. N.Engl.J.Med. 1982;307:205-211

18. Feldman AM, Cates AE, Veazey WB, Hershberger RE, Bristow MR, Baughman KL, Baumgartner WA, Van DC: Increase of the 40,000 -mol wt pertussis toxin substrate (G-protein) in the failing human heart. J.Clin.Imvest. 1988:82:189-197

19. Marzo KP, Frey MJ, Wilson JR. Liang BT, Manning DR, Lanoce V, Molinoff PB: Beta-adrenergic receptor-G-protein-adenylate cyclase complex in experimental canine congestive heart failure produced by rapid ventricular pacing. Circ. Res. 1991;69:1546-1556 
20. Brundel BJJM, Van Gelder IC, Henning RH, Tuinenburg AE, Deelman L, Tieleman RG, Grandjean JG, Van Gilst WH, Crijns HJ: Gene expression of proteins influencing the calcium homeostasis in patients with persistent and paroxysmal atrial fibrillation. Cardiovasc. Res. 1999:42:443-454

21. Van Gelder IC, Brundel BJ, Henning RH, Tuinenburg AE, Tieleman RG, Deelman L, Grandjean JG, De Kam PJ, Van Gilst WH, Crijns HJ: Alterations in gene expression of proteins involved in the calcium handling in patients with atrial fibrillation. J.Cardiovasc. Electrophysiol. 1999;10:552-560

22. Gaspo R, Sun H, Fareh S, Levi M, Yue L, Allen BG, Hebert TE, Nattel S: Dihdropyridine and betaadrenergic receptor binding in dogs with tachycardia-induced atrial fibrillation. Cardiovase.Res 1999:42:434-442

23. Gomez AM, Valdivia HH, Cheng H, Lederer MR, Santana LF, Cannell MB, McCune SA, Altschuld RA, Lederer WJ: Defective excitation-contraction coupling in experimental cardiac hypertrophy and heart failure. Science 1997;276:800-806

24. Mittmann C, Eschenhagen T, Scholz H: Cellular and molecular aspects of contractile dysfunction in heart failure. Cardiovasc. Res. 1998;39:267-275

25. Bers DM: Ca-influx and sarcoplasmic reticulum $\mathrm{Ca}$-release in cardiac muscle activation during postrest recovery. Am.J.Physiol. 1985;248:H366-H381 


\section{Chapter 3}

\section{Atrial Fibrillation-Induced Atrial Contractile Dysfunction: A Tachycardiomyopathy of a Different Sort}

Ulrich Schotten, Maura Greiser, Dirk Benke, Kai Buerkel, Britta Ehrenteidt, Christoph Stellbrink, Jaime F Vazquez-Jimenez, Friedrich Schoendube, Peter Hanrath, Maurits Allessie 


\section{$\underline{\text { Abstract }}$}

\section{Objective}

Although AF-induced atrial contractile dysfunction has significant clinical implications the underlying intracellular mechanisms are poorly understood.

\section{Methods}

From the right atrial appendages of 59 consecutive patients undergoing mitral valve surgery ( 31 in SR, 28 in chronic AF) thin muscle preparations (diameter $<0.7 \mathrm{~mm}$ ) were isolated. Isometric force of contraction was measured in the presence of different concentrations of $\mathrm{Ca}^{2+}$ and isoprenaline. To assess the function of the sarcoplasmic reticulum the force-frequency relationship and the post-rest potentiation were studied. The myocardial density of the ryanodine-sensitive calcium release channel (CRC) of the sarcoplasmic reticulum was determined by ${ }^{3} \mathrm{H}$-ryanodine binding. Myocardial content of SR-Ca ${ }^{2+}$-ATPase (SERCA), phospholamban (Plb), calsequestrin (Cals) and the $\mathrm{Na}^{+} / \mathrm{Ca}^{2+}$-exchanger (NCX) were analyzed by Western blot analysis. Adenylyl cyclase activity was measured with a radiolabeled bioassay using ${ }^{32} \mathrm{P}-\mathrm{ATP}$ as a tracer.

\section{Results}

In 72 muscle preparations of SR patients contractile force was $10.9 \pm 1.8 \mathrm{mN} / \mathrm{mm}^{2}$ compared to $3.3 \pm 0.9 \mathrm{mN} / \mathrm{mm}^{2}(\mathrm{n}=49, \mathrm{p}<0.01)$ in $\mathrm{AF}$ patients. The positive inotropic effect of isoprenaline was diminished but the stimulatory effect on relaxation and the adenylyl cyclase were not altered in AF patients. The force-frequency relation and the post-rest potentiation were enhanced in atrial myocardium of AF patients. The protein levels of CRC, SERCA, PIb, and Cals were not different between the two groups. In contrast, the $\mathrm{Na}^{+} / \mathrm{Ca}^{2+}$-exchanger was upregulated by $67 \%$ in atria of $\mathrm{AF}$ patients.

\section{Conclusions}

AF-induced atrial contractile dysfunction is not due to $\beta$-adrenergic desensitization or dysfunction of the sarcoplasmic reticulum and thus is based on different cellular mechanisms than a ventricular tachycardia-induced cardiomyopathy. Instead, downregulation or altered function of the L-type $\mathrm{Ca}^{2+}$-channel and an increased $\mathrm{Ca}^{2+}$ extrusion via the $\mathrm{Na}^{4} / \mathrm{Ca}^{2+}$-exchanger seem to be responsible for the depressed contractility in remodeled atria.

\section{$\underline{\text { Introduction }}$}

The rapid and irregular atrial contractions during atrial fibrillation (AF) result in a depression of atrial transport function and contribute to the reduction of ventricular filling and cardiac output. The main clinical relevance of the loss of synchronized atrial contraction is the development of atrial thrombi presumably due to increased stasis of blood near the atrial wall. Accordingly, AF is a common cause of cerebral embolism, accounting for approximately $15 \%$ of all strokes.' Therefore, maintenance of sinus rhythm (SR) is of primary importance in the treatment of AF. Echocardiographic studies in patients have shown that after cardioversion contractile function of the atria is impaired. The degree of contractile dysfunction correlates with the previous duration of 
AF and complete recovery of atrial function can take months. ${ }^{2}$ The post-fibrillatory atrial contractile dysfunction favors the development of atrial thrombi after cardioversion to SR and therefore contributes to the thromboembolic risk associated with $\mathrm{AF}^{3}$

Studies in goats with sustained AF have shown that AF is associated with alterations of the cellular ultrastructure. ${ }^{4}$ These data suggest that the contractile abnormalities in remodeled atria are caused by a loss of myofibrils and fragmentation of the sarcoplasmic reticulum. In a previous study we demonstrated that the contribution of myolysis to the AF-induced atrial contractile dysfunction is limited. ${ }^{5}$ In experimental and clinical studies the $\mathrm{Na}^{+} / \mathrm{H}^{+}$-exchange inhibitor $\mathrm{HOE}_{642}{ }^{6}$ and verapamil ${ }^{7,8}$ were shown to delay the effects of $\mathrm{AF}$ on the atrial contractility indicating that they were mediated by $\mathrm{Ca}^{2+}$-overload during AF. Several studies demonstrated that altered $\mathrm{Ca}^{2+}$ metabolism indeed contributed to atrial dysfunction. In dogs with sustained atrial tachycardia atrial contractility has been shown to be reduced on the cellular level ${ }^{9}$ and a pronounced reduction of the L-type $\mathrm{Ca}^{2+}$ current $\left(\mathrm{I}_{\text {CaL }}\right)$ was reported. ${ }^{10}$ Recently, a reduced $\mathrm{I}_{\mathrm{Cal}}$. was also reported in human atrial cardiomyocytes of patients with chronic $\mathrm{AF}{ }^{11.12}$ Also, altered expression of sarcoplasmic reticulum $\mathrm{Ca}^{2+}$ handling proteins ${ }^{13}$ or alterations in the $\beta$-adrenergic signal transduction might contribute to the changes in $\mathrm{Ca}^{2+}$. metabolism in fibrillating atria. In addition, $\beta$-adrenergic desensitization and dysfunction of the sarcoplasmic reticulum have been described as the main pathophysiological alterations in experimental tachycardia-induced cardiomyopathy on the ventricular level..$^{14-16}$

The present study was designed to investigate the cellular mechanisms of postfibrillatory atrial contractile dysfunction. Additionally, we aimed to study whether the pathophysiological mechanisms underlying ventricular tachycardiomyopathy also account for the AF-induced atrial contractile dysfunction.

\section{$\underline{\text { Methods }}$}

\section{Patients}

Right atrial appendages were obtained from 59 consecutive patients undergoing mitral valve surgery. At the time of operation 28 patients were in chronic AF ( $>3$ months), the others were in SR and had no history of AF $(n=31)$. The clinical characteristics of the patients are given in Table 1. Hemodynamic parameters did not differ between the two patient groups, but $\mathrm{Ca}^{2+}$-antagonists and digitalis were more frequently taken by $\mathrm{AF}$ patients for control of their ventricular rate. The study conforms with the principles outlined in the Declaration of Helsinki. All patients gave written informed consent and the study was approved by an institutional ethical committee. 


\begin{tabular}{|c|c|c|c|}
\hline & & $\begin{array}{c}\text { Sinus rhythm } \\
(n=3 I)\end{array}$ & $\begin{array}{l}\text { Atrial fibrillation } \\
(n=28)\end{array}$ \\
\hline \multirow{5}{*}{\multicolumn{2}{|c|}{$\begin{array}{l}\text { Age }(y) \\
\text { Gender }(m / f) \\
\text { Cardiac index }\left(\mathrm{m} / \mathrm{min} / \mathrm{m}^{2}\right) \\
\text { Mean pulmonary capillary wedge pressure }(\mathrm{mmHg}) \\
\text { Mean right atrial pressure }(\mathrm{mmHg})\end{array}$}} & $55 \pm 8$ & $57 \pm 7$ \\
\hline & & $(13 / 18)$ & $(13 / 15)$ \\
\hline & & $3.0 \pm 0.6$ & $2.8 \pm 0.8$ \\
\hline & & $12 \pm 6$ & $15 \pm 6$ \\
\hline & & $5.6 \pm 2.1$ & $7.9 \pm 2.3$ \\
\hline \multirow[t]{5}{*}{ Medication ( $n$ ) } & Diuretics & 15 & 16 \\
\hline & Beta-blockers & 7 & 6 \\
\hline & Digitalis & 8 & $17 *$ \\
\hline & $A C E$-Inhibitors & 14 & 15 \\
\hline & $\mathrm{Ca}^{2}-$ Antagonists & 9 & $16^{*}$ \\
\hline
\end{tabular}

Table l

Patients - hemodynamic and clinical data. * $p<0.05$

\section{Contraction Experiments}

Immediately after surgical resection, the atrial tissue was placed in a $4^{\circ} \mathrm{C}$ cold Tyrode's solution ( $\mathrm{pH} 7.4$, gassed with $5 \% \mathrm{CO}_{2} / 95 \% \mathrm{O}_{2}$ ) and transferred to the laboratory. Thin myocardial muscle bundles of a length between 3 and $6 \mathrm{~mm}$ were prepared under stereomicroscopic control (diameters: SR $(n=72)$ : $0.47 \pm 0.09 m m, \quad A F \quad(n=48)$ : $0.45 \pm 0.10 \mathrm{~mm}$; n.s.), connected to force transducers and placed in an organ bath with prewarmed bathing solution $\left(37^{\circ} \mathrm{C}\right)$. The muscle strips were electrically stimulated with rectangular impulses at $1 \mathrm{~Hz}(5 \mathrm{~ms}$ duration, $5-10 \%$ above threshold). After an equilibration period of $30 \mathrm{~min}$ the muscles were stretched by increasing the resting tension from $1 \mathrm{mN}$ stepwise by $0.2 \mathrm{mN}$ until the muscle length providing maximal active force generation was reached $\left(\mathrm{L}_{\max }\right)$. Resting tension at $\mathrm{L}_{\max }$ was $3.2 \pm 0.6 \mathrm{mN}$ $(\mathrm{n}=72)$ in $\mathrm{SR}$ and $3.4 \pm 0.8 \mathrm{mN}(\mathrm{n}=48)$ in $\mathrm{AF}$ (n.s.). To assess the relaxation properties of the muscle preparations the time to $90 \%$ relaxation was measured.

In a subgroup of muscle preparations the effects of isoprenaline on force of contraction and time to $90 \%$ relaxation was studied. For this purpose isoprenaline was cumulatively added to the organ bath. After wash-out of isoprenaline a concentration-response curve of $\mathrm{Ca}^{2+}$ was studied.

In another set of experiments the force-frequency relationship (FFR) was studied by increasing the stimulation frequency from $0.5 \mathrm{~Hz}$ to $3 \mathrm{~Hz}$.

In a third subgroup we studied the post-rest potentiation of contractile force as an index for the capacity of the sarcoplasmic reticulum to store $\mathrm{Ca}^{2+}$. Electrical stimulation at 1 $\mathrm{Hz}$ was interrupted for $2 \mathrm{~s}$ to $5 \mathrm{~min}$ and the contractile force of the first post-rest contraction was measured. In SR patients post-rest potentiation was also measured after adding $100 \mathrm{nM}$ of nifedipine or $10 \mathrm{nM}$ of ryanodine in the bathing solution.

\section{Adenylyl Cyclase Activity}

Adenylyl cyclase (AC) activity was determined as described previously. ${ }^{17}$ Briefly, enzyme activity was determined in assays $(100 \mu \mathrm{l})$ containing $1 \mathrm{mM} \mathrm{Na}$-ATP $\left({ }^{32} \mathrm{P}\right.$ ATP, $1 \mu \mathrm{Ci}$ ) as tracer substrate. The reaction was started by the addition of the homogenates ( $75 \mu \mathrm{g}$ protein) to the reaction mixture and stopped after $20 \mathrm{~min}$ by the addition of $100 \mu \mathrm{l} 1 \mathrm{M} \mathrm{HCl}$ and subsequent heating to $95^{\circ} \mathrm{C}$ for $5 \mathrm{~min}$. After chromatographic purification the ${ }^{32} \mathrm{P}$-cAMP fraction was counted in a $\beta$-counter (Canberra-Packard). 
Under these experimental conditions AC activity was linear with respect to incubation time (up to $30 \mathrm{~min}$ ) and protein concentration (up to $150 \mu \mathrm{g} /$ assay) indicating that determination of AC activity using $75 \mu \mathrm{g}$ protein and $20 \mathrm{~min}$ incubation time was performed within the linear range.

\section{${ }^{3}$ H-Ryanodine Radioligand Binding}

A homogenate of atrial tissue was incubated with different concentrations of ${ }^{3} \mathrm{H}$ ryanodine ranging from 0.3 to $40 \mathrm{nM}$. $^{18}$ Free calcium concentration was adjusted to $10^{-4}$ $\mathrm{M}$ according to the calculations of Fabiato. ${ }^{19}$ The reaction was stopped by rapid filtration of the homogenates through Whatman GF/C filters and the retained radioactivity was counted in a $\beta$-counter. Nonspecific radioactivity was determined by the addition of $10 \mu \mathrm{M}$ of unlabeled ryanodine to the binding assay.

\section{Western Blot Analysis}

To quantify the $\mathrm{Na}^{+} / \mathrm{Ca}^{2+}$-exchanger, SR- $\mathrm{Ca}^{2+}$-ATPase, phospholamban, and calsequestrin, electrophoresis of homogenate aliquots was carried out using polyacrylamide gels. ${ }^{18}$ After tank blotting the nitrocellulose $(0.45 \mu \mathrm{m})$ was exposed to primary antibody solution followed by radioactive labeling with the secondary antibody. The nitrocellulose membranes were cut and single band signals were quantified in a $\gamma$ counter. Table 2 shows the details of the Western blot conditions.

For all proteins investigated there was a linear correlation between the amount of protein subjected to gel electrophoresis and the radioactive signals. The protein content of the homogenates was measured by the method of Bradford. ${ }^{20}$

\begin{tabular}{|c|c|c|c|c|}
\hline & SR-Ca $a^{2}-A T P a s e$ & Phospholamban & $\begin{array}{l}\mathrm{Na} / \mathrm{Ca}^{2}- \\
\text { exchanger }\end{array}$ & Calsequestrin \\
\hline $\begin{array}{l}\text { Stacking gel } \\
\text { percentage }(\%)\end{array}$ & 4 & 4 & 4 & 4 \\
\hline $\begin{array}{l}\text { Separating gel } \\
\text { percentage }(\%)\end{array}$ & 7.5 & 10 & 7.5 & 10 \\
\hline $\begin{array}{l}\text { Protein loading } \\
\text { ( } \mu \mathrm{g} / \text { /ane })\end{array}$ & 80 & 20 & 80 & 80 \\
\hline $\begin{array}{l}\text { Primary } \\
\text { antibody }\end{array}$ & $\begin{array}{c}\text { Monoclonal } \\
\text { mouse anti canine } \\
\text { cardiac SR-Ca }{ }^{2} \text { - } \\
\text { ATPase IgG }\end{array}$ & $\begin{array}{c}\text { Manoclonal } \\
\text { mouse anti canine } \\
\text { phospholamban } \\
\operatorname{Ig} G\end{array}$ & $\begin{array}{c}\text { Monoclonal } \\
\text { mouse anti canine } \\
\text { cardiac } \mathrm{Na} / \mathrm{Ca}^{2} \text { - } \\
\text { exchanger } \mathrm{IgM}\end{array}$ & $\begin{array}{c}\text { Polyclonal rabbit } \\
\text { anti canine cardiac } \\
\text { calsequestrin } \\
\text { antiserum }\end{array}$ \\
\hline $\begin{array}{l}\text { Dilution } \\
\text { Secondary } \\
\text { antibody }\end{array}$ & $\begin{array}{c}1: 2500 \\
\text { Anti-mouse } \operatorname{Ig} G\end{array}$ & $\begin{array}{c}\text { l:2500 } \\
\text { Anti-mouse } \operatorname{Ig} G\end{array}$ & $\begin{array}{c}1: 1000 \\
\text { Anti-mouse } \lg G\end{array}$ & $\begin{array}{c}\text { 1:2000 } \\
\text { Protein A }\end{array}$ \\
\hline Dilution & $1: 1000$ & $1: 500$ & $1: 1000$ & $1: 10000$ \\
\hline
\end{tabular}

Table 2

Western Blot Analysis - Conditions

\section{Statistical Analysis}

All data are expressed as means $\pm \mathrm{SD} . \mathrm{K}_{\mathrm{D}}$-values and $\mathrm{EC}_{50}$-values are given with the $95 \%$ confidence intervals. Statistical significance of mean differences was determined by unpaired students t-test (for comparison of two groups) or by one way analysis of variance (ANOVA) and Newmann-Keuls post test for comparison of multiple groups. A p-value of less than 0.05 was considered as statistically significant. 


\section{$\underline{\text { Results }}$}

\section{Inotropic Effects of $\mathrm{Ca}^{2+}$ and Isoprenaline}

The baseline force of contraction was reduced in the AF group by $\sim 73 \%$ (SR: $\left.10.9 \pm 1.8 \mathrm{mN} / \mathrm{mm}^{2}(\mathrm{n}=72), \mathrm{AF}: 3.3 \pm 0.9 \mathrm{mN} / \mathrm{mm}^{2} \quad(\mathrm{n}=48), \mathrm{p}<0.01\right)$. Representative force recordings are shown in Figure 1. In the SR patients isoprenaline $(1 \mu \mathrm{M})$ elicited the same response as $10.8 \mathrm{mM} \mathrm{Ca}^{2+}$. In contrast, the response to isoprenaline was impaired in $\mathrm{AF}$ patients, whereas the positive inotropic effect of $\mathrm{Ca}^{2+}$ was almost completely preserved. The time course of single contractions was not altered in AF patients.

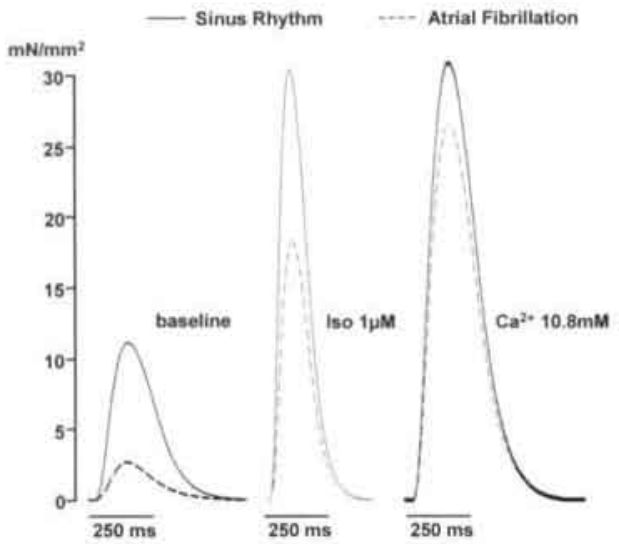

Figure 1

Representative isometric force recordings $\left(37^{\circ} \mathrm{C}, \mathrm{l} \mathrm{Hz}\right)$ of isolated muscle preparations from a patient in $S R$ and an $A F$ patient. Baseline contractile force and the force at $1 \mu \mathrm{M}$ isoprenaline were reduced in the $A F$ patient, whereas the force at $10.8 \mathrm{mM}$ was nearly as high as in the $S R$ patient.

Statistical analysis of all experiments is shown in Figure 2. Increasing the extracellular $\mathrm{Ca}^{2+}$ concentrations caused an increase in force of contraction in both $\mathrm{SR}$ and $\mathrm{AF}$ patients. However, at high $\mathrm{Ca}^{2+}$ concentrations $(\geq 7.4 \mathrm{mM})$ force of contraction was no longer significantly lower than in the SR group. $\mathrm{Ca}^{2+}$ did not change the time to $90 \%$ relaxation $\left(\mathrm{TR}_{90}\right)$ and there were no differences in $\mathrm{TR}_{90}$ between $\mathrm{SR}$ and $\mathrm{AF}$ patients. The $\beta$-adrenoceptor agonist isoprenaline exerted a pronounced positive inotropic effect in the SR and AF group. However, in AF patients the concentration-response curve was shifted to the right and downwards. Force of contraction at the maximal isoprenaline concentration $\left(10^{-6} \mathrm{M}\right)$ was lower in the AF group $\left(17.3 \pm 3.6 \mathrm{mN} / \mathrm{mm}^{2}\right)$ than in the SR group $\left(32.9 \pm 5.0 \mathrm{mN} / \mathrm{mm}^{2}, \mathrm{p}<0.01\right)$. Additionally, in the $\mathrm{SR}$ group the half-maximal positive inotropic effect of isoprenaline was reached at $3.2(1.9-4.7) \mathrm{nM}\left(\mathrm{EC}_{50}\right)$, whereas in the $\mathrm{AF}$ group a nearly 10 -fold higher isoprenaline concentration was needed to elicit the half-maximal response $\left(\mathrm{EC}_{50}=20(12-39) \mathrm{nM}, \mathrm{p}<0.01\right)$. The effect of isoprenaline on relaxation, however, was not different. In the $\mathrm{SR}$ group, $\mathrm{TR}_{90}$ shortened from $261 \pm 23 \mathrm{~ms}$ under baseline conditions to $198 \pm 18 \mathrm{~ms}$ in the presence of $1 \mu \mathrm{M}$ of isoprenaline $(\mathrm{p}<0.01)$. In the AF patients neither at baseline conditions $(252 \pm 22 \mathrm{~ms})$ nor in the presence of $1 \mu \mathrm{M}$ of isoprenaline $(194 \pm 18 \mathrm{~ms}) \mathrm{TR}_{\varphi_{0}}$ was significantly different compared to the SR patients. The concentration of isoprenaline eliciting a half-maximal shortening of $\mathrm{TR}_{00}$ (positive lusitropic potency) was similar in both groups (SR: $\mathrm{EC}_{50}=$ $6.1(3.2-12.1) \mathrm{nM}, \mathrm{AF}: \mathrm{EC}_{50}=7.1(3.2-13.4) \mathrm{nM}, \mathrm{n} . \mathrm{s}$.). Subgroup analysis revealed that differences in medication did not influence contractile force of the muscle preparations or their response to positive inotropes. 

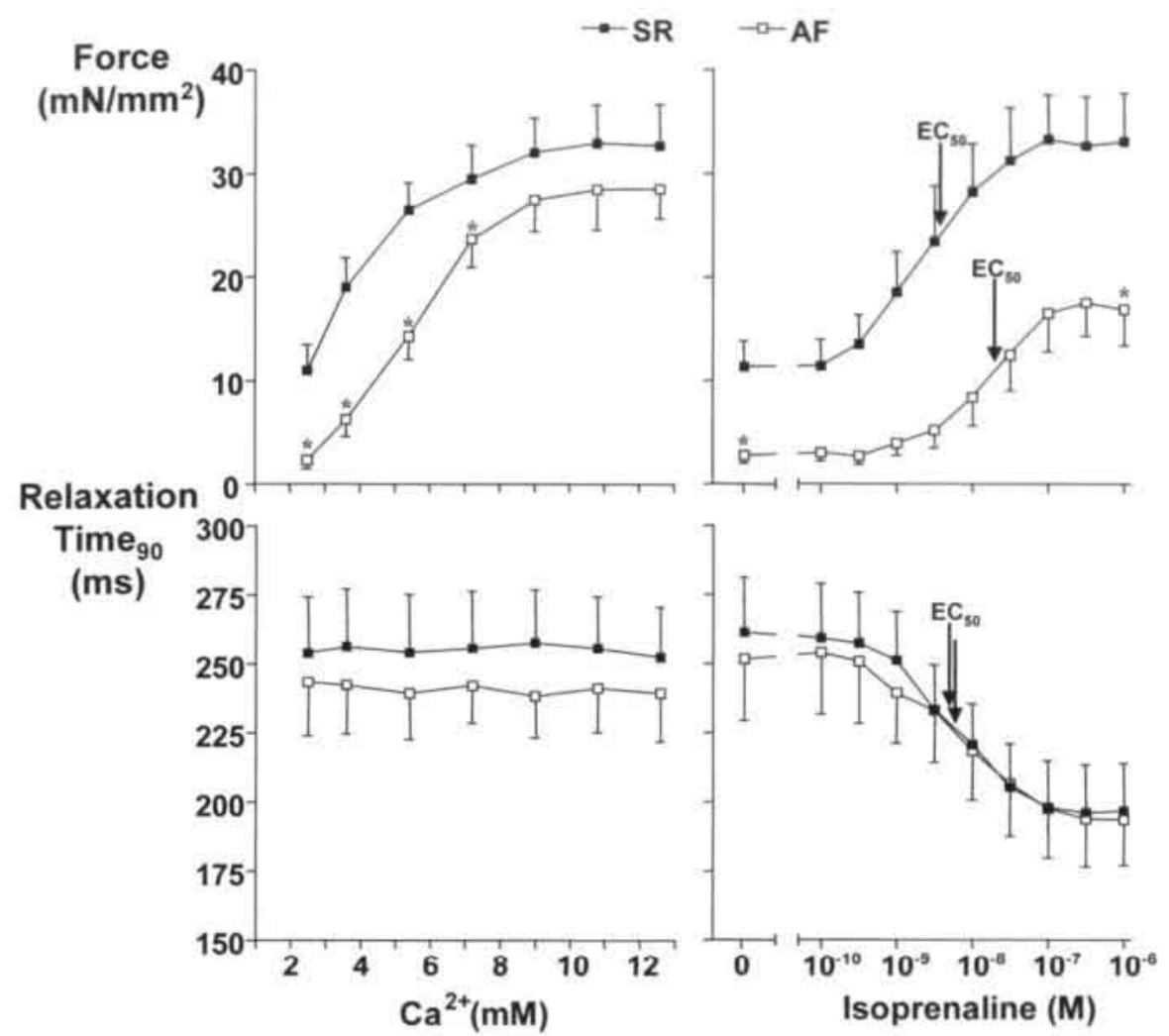

Figure 2

Effect of the extracellular $\mathrm{Ca}^{2 *}$ concentration and the $\mathrm{B}$-adrenoceptor agonist isoprenaline on force of contraction ( $\mathrm{mN} / \mathrm{mm}^{2}$ ) (upper panel) and time to $90 \%$ relaxation lower panel) of isolated muscle preparations of 12 patients in SR ( 18 muscle preparations) and 12 AF patients ( 17 muscle preparations). $* 0.05$.

\section{Adenylyl Cyclase}

Figure 3 shows the results of the AC activity assays. Baseline AC activity was the same in $\mathrm{SR}$ and $\mathrm{AF}$ patients. Isoprenaline $(1 \mu \mathrm{M})$ stimulated $\mathrm{AC}$ activity by a factor of 3 in both patient groups. AC activity in the presence of $5 \mathrm{mM} \mathrm{MnCl}$, resulting in maximal activation of the enzyme, exceeded the activity exerted by isoprenaline and also did not differ between the patient groups.

\section{Force-Frequency Relationship}

In SR patients FFR was positive up to a stimulation frequency of $2.0 \mathrm{~Hz}$ (Figure 4). At higher frequencies contractile force declined slightly. In AF patients the FFR was also positive but shifted to higher frequencies. The half-maximal response was reached at 0.9 $(0.6-1.6) \mathrm{Hz}$ in SR patients, whereas in AF patients $1.7(1.2-2.4) \mathrm{Hz}(\mathrm{p}<0.05)$ was required to elicit the same effect. Also, the relative increase in contractile force was more pronounced in AF patients. Compared to the force at $0.5 \mathrm{~Hz}$ the maximal force was increased to $242 \pm 39 \%$ (at $2.5 \mathrm{~Hz}$ ), whereas in SR patients only $167 \pm 26 \%$ (at 2.0 $\mathrm{Hz}, \mathrm{p}<0.05$ ) were reached. $\mathrm{TR}_{90}$, as a measure of the relaxation behavior, did not differ between the two groups. 


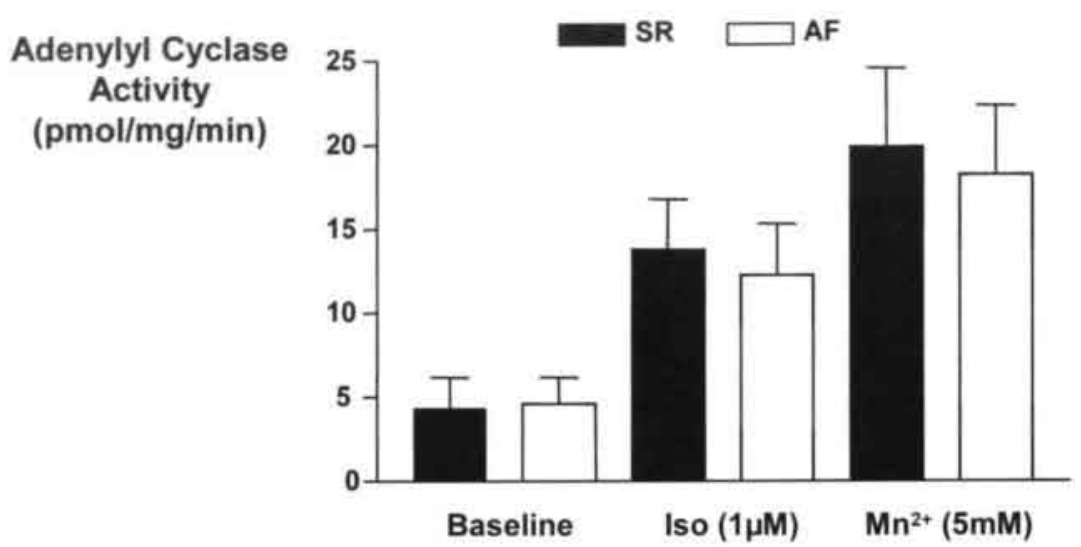

Figure 3

Lower panel: AC activity in homogenates of right atrial myocardium. Neither at baseline conditions, nor in the presence of isoprenaline $(I \mu \mathrm{M})$ or $\mathrm{Mn}^{2}(5 \mathrm{mM})$, activity of the enzyme differed between the two groups ( $n=12$ in each group).

\section{Post-Rest Potentiation}

Figure 5 shows representative experiments on post-rest contractile force (rest interval 10 s). In the SR patient force of contraction of the first post-rest twitch was increased by $40 \%$ compared to steady state force of contraction (post-rest potentiation). Ryanodine abolished post-rest potentiation in the same patient. In AF patients the steady state force of contraction was lower than in the SR patients, but post-rest potentiation of contractile force was fully preserved. Similarly, when muscle preparations of SR patients were exposed to nifedipine, steady state force of contraction was low, but the post-rest potentiation was less affected.

The extent of the post-rest potentiation depended on the rest interval in both SR and AF patients (Figure 6). In the SR group maximal post-rest potentiation was reached at a rest- interval of $10 \mathrm{~s}$, whereas in $\mathrm{AF} 30 \mathrm{~s}$ rest-interval provoked the maximal post-rest response. The increase in post-rest force of contraction compared to the steady state contraction was more pronounced in the AF patients $(275 \pm 42 \%$ versus steady state) compared to the SR group $(151 \pm 18 \%$ versus steady state, $\mathrm{p}<0.01)$. Ryanodine abolished the post-rest response (rest decay). Similar to the behavior of atrial myocardium of AF patients, also in SR patients the post-rest potentiation was enhanced, when the L-type $\mathrm{Ca}^{2+}$ channel was blocked with nifedipine. The maximal response occurred after $30 \mathrm{~s}$ of rest and reached $297 \pm 58 \%$ compared to the steady state contractile force (n.s. versus AF). 

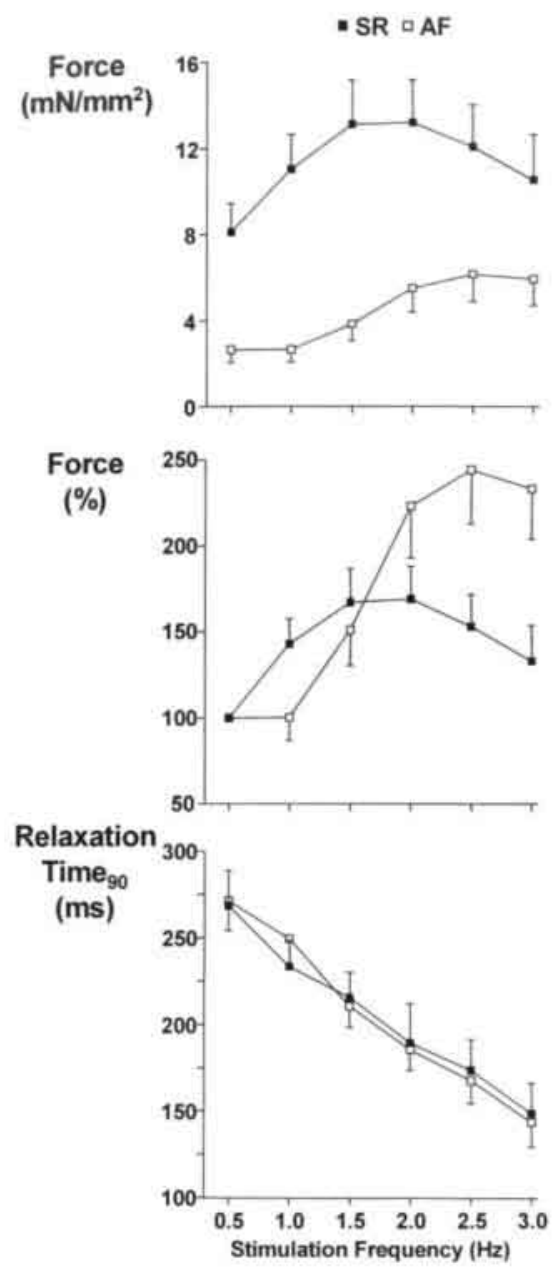

Figure 4

FFR in atrial myocardium of 14 SR patients 116 muscle preparations) and 13 patients in $A F$ (I6 muscle preparations). Upper panel: Absolute force of contraction $\left(\mathrm{mN} / \mathrm{mm}^{2}\right)$, mid panel: force normalized to the force at $0.5 \mathrm{~Hz}$, lower panel: Time to $90 \%$ relaxation.

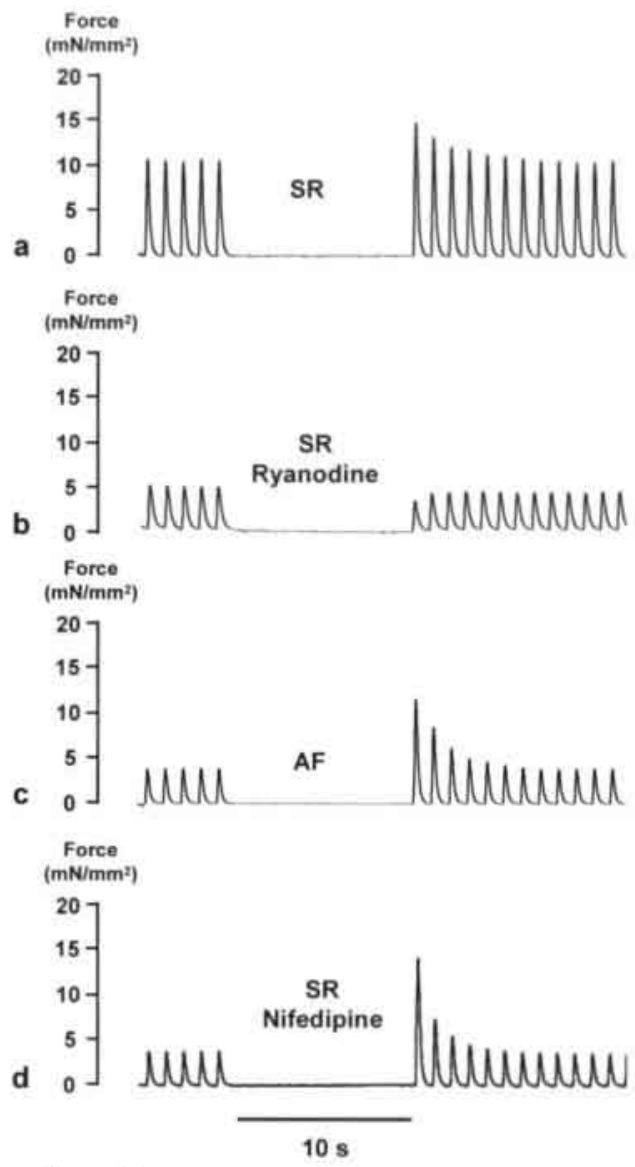

Figure 5

Post-rest behavior of contractile force of atrial muscle strips prepared from a $S R$ patient (a), a patient in AF (b) and a patient in $S R$ after the exposure of the muscle strip to $10 \mathrm{nM}$ of ryanodine (c) or $100 \mathrm{nM}$ of nifedipine (d). Muscle bundles $a, c$, and $d$ were prepared from the same patient. In this patient force of contraction of the first post-rest witch after a $10 \mathrm{~s}$ rest interval was higher compared to steady state (post-rest potentiation). Post-rest potentiation was abolished by ryanodine, whereas it was preserved in the AF patient and in the SR patient, when the muscle bundles was exposed to nifedipine.

\section{Expression of $\mathrm{Ca}^{2+}$-Handling Proteins}

Representative autoradiographies of right atrial myocardium are depicted in Figure 7. There was no significant difference in protein levels of SR-Ca ${ }^{2+}$-ATPase, calsequestrin, and phospholamban in atrial myocardium of AF and SR patients (Table 3). Figure 7 also shows a representative ${ }^{3} \mathrm{H}$-ryanodine binding experiment in one $\mathrm{SR}$ and one $\mathrm{AF}$ 
patient. In both groups specific ${ }^{3} \mathrm{H}$-ryanodine binding was saturable and of high-affinity. In atrial myocardium of SR patients, the ${ }^{3} \mathrm{H}$-ryanodine binding site density was $133 \pm 23 \mathrm{fmol} / \mathrm{mg}$ protein $(\mathrm{n}=13)$ compared to $123 \pm 24 \mathrm{fmol} / \mathrm{mg}$ in AF patients $(\mathrm{n}=13$; n.s.). The affinity of the radioligand to the binding sites also did not differ between the different patient groups ( $\mathrm{K}_{\mathrm{D}}$-values: $\mathrm{SR}: 1.3(0.4-3.3) \mathrm{nM}, \mathrm{AF}: 1.6(0.5-3.7) \mathrm{nM}$, n.s.). In contrast, as shown in Figure 8 , the $\mathrm{Na}^{+} / \mathrm{Ca}^{2+}$-exchanger was significantly upregulated by $67 \%$ in atrial myocardium of $\mathrm{AF}$ patients.

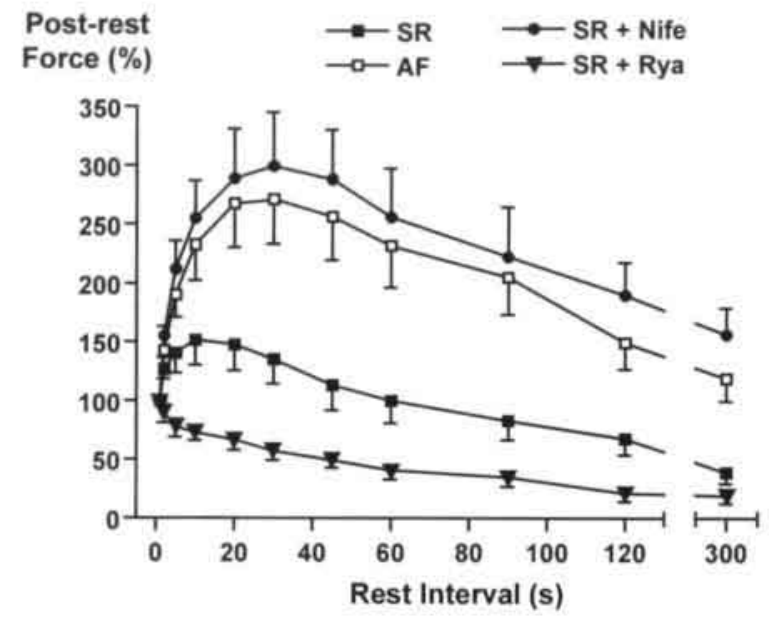

Figure 6

Force of contraction of the first post-rest twitch normalized to the steady state force of contraction as a function of the rest interval in 15 preparations of 15 patients (SR and $A F$ group). In $10 S R$ patients the experiment was performed after the addition of $10 \mathrm{nM}$ of ryanodine $\quad 10$ muscle preparations). In 13 patients 100 $n M$ of nifedipine was given in the organ bath (13 muscle preparations).

STD SR AF AF AF SR SR SR AF AF SR

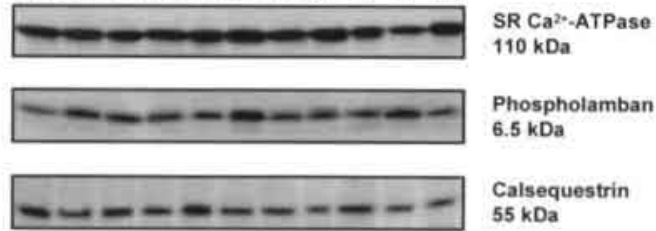

Figure 7

Upper panel: Representative Western blot analysis of calcium transport proteins in atrial myocardium of patients in SR or in $A F . S T D=$ Standard sample which was used as a standard on all blots to provide comparability of determination from different blots.

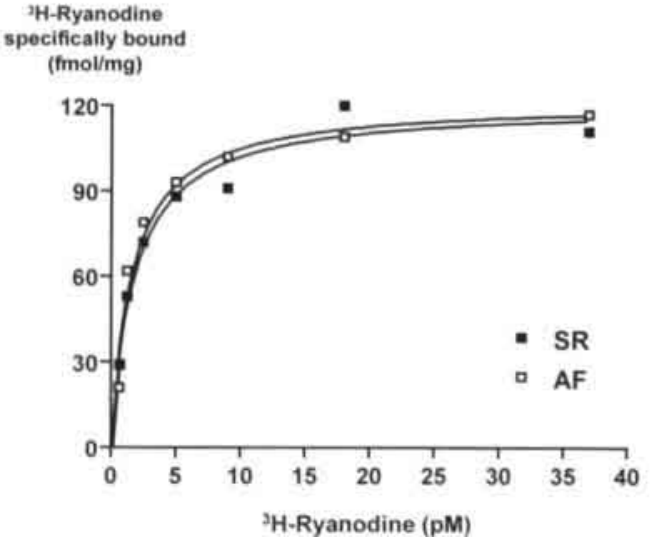

Lower panel: Representative saturation binding of ${ }^{3} \mathrm{H}$ ryanodine to a homogenate of atrial myocardium of one $S R$ patient and one patient in $A F$. 


\begin{tabular}{|c|c|c|}
\hline & $S R(n=13)$ & $A F(n=13)$ \\
\hline SR Ca ${ }^{2}-A T P a s e /$ protein & $22604 \pm 2994$ & $22407 \pm 2870$ \\
\hline Calsequestrin/protein & $3581 \pm 495$ & $3459 \pm 454$ \\
\hline Phospholamban/protein & $16543 \pm 2190$ & $14558+2712$ \\
\hline
\end{tabular}

Table 3

Protein expression of SR-Ca' $-A T P$ ase, phospholamban, and calsequestrin.

Protein expression given in cpm of bound secondary antibody per mg protein. No significant differences were observed between $S R$ and AF patients.

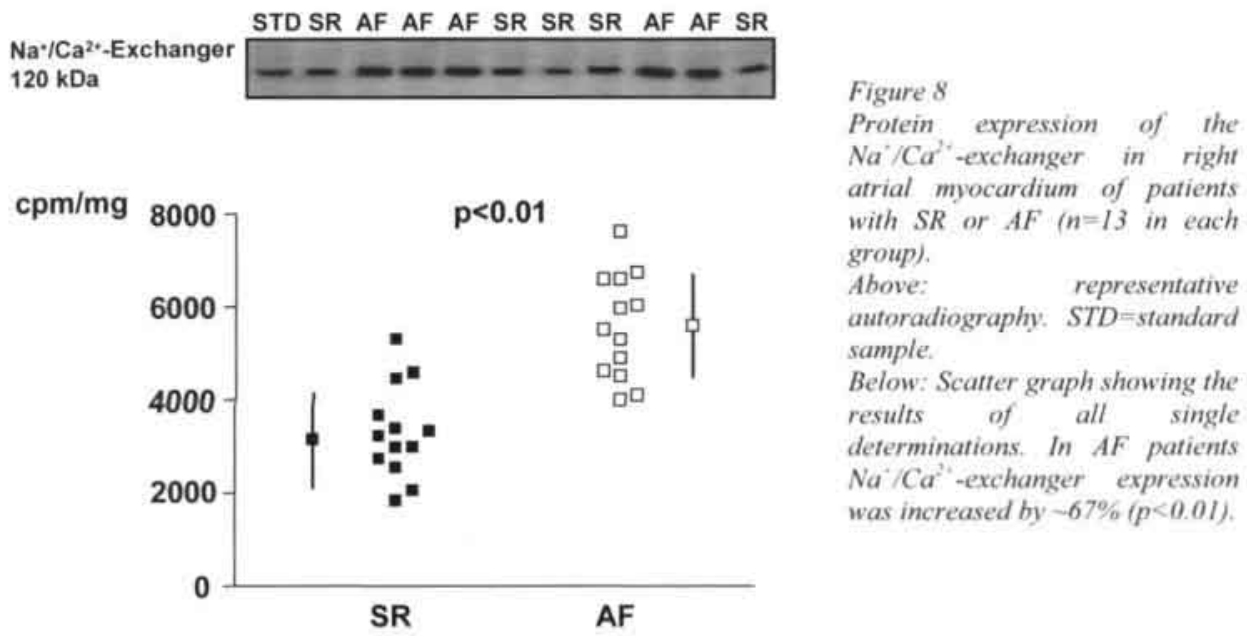

\section{$\underline{\text { Discussion }}$}

Although the postfibrillatory atrial contractile dysfunction is of significant clinical relevance the underlying cellular mechanisms are not completely understood. In a previous study we demonstrated that the isometric force of contraction of isolated atrial myocardium of patients with prolonged $\mathrm{AF}$ is reduced by $75 \%$ compared to a control group in SR. ${ }^{5}$ Of interest, the contractile reserve in these muscle preparations was only slightly reduced indicating that a loss of myofilaments is not the main mechanism of post-fibrillatory atrial contractile dysfunction. The impaired activation of the myofilaments might be due to impaired myofibrillar energetics ${ }^{21}$ but could also be explained by an altered $\mathrm{Ca}^{2+}$ metabolism of the atrial cardiomyocytes. Sun et al. showed that $3 \mathrm{~min}$ of rapid pacing were sufficient to reduce the $\mathrm{Ca}^{2+}$ transient in atrial canine cardiomyocytes. ${ }^{22}$ Prolonged atrial tachycardia in dogs (rapid atrial pacing for 6 weeks) results in a reduction of the $\mathrm{Ca}^{2+}$ transient by $50 \%{ }^{9}$. In diseased ventricular myocardium 
a similar reduction in the $\mathrm{Ca}^{2+}$ transient is due to a dysfunction of the sarcoplasmic reticulum probably caused by changes in the expression of $\mathrm{Ca}^{2+}$ handling proteins. ${ }^{18,23,24}$ Also, an upregulation of the $\mathrm{Na}^{+} / \mathrm{Ca}^{2+}$-exchanger was suggested to contribute to the depressed $\mathrm{Ca}^{2+}$ transient. ${ }^{25}$

Another important mechanism controlling the generated force is the $\beta$-adrenergic signal transduction pathway. ${ }^{26}$ Like in a ventricular tachycardiomyopathy dysfunction of the $\beta$ adrenergic signal transduction pathway might impair the inotropic response of the atria to physiological variations in sympathetic tone.

The present study was undertaken to investigate whether the atrial dysfunction resulting from $\mathrm{AF}$ is due to the same intracellular mechanisms as the ventricular tachycardiomyopathy. We showed that neither $\beta$-adrenergic desensitization nor dysfunction of the sarcoplasmic reticulum can adequately explain the post-AF atrial contractile dysfunction. Instead, downregulation or altered function of the L-type $\mathrm{Ca}^{2+}$ channel and possibly an upregulation of the $\mathrm{Na}^{+} / \mathrm{Ca}^{2+}$-exchanger are responsible for the depressed atrial contractility in AF patients. Since subgroup analysis revealed no effect of medication on force of contraction or responsiveness of the muscle bundles to positive inotropes the observed differences are most probably caused by the arrhythmia itself and not due to the drug therapy.

\section{No Desensitization of the $\beta$-Adrenergic Signal Transduction Pathway}

Downregulation of $\beta$-adrenoceptors ${ }^{26}$ and an upregulation of the inhibitory $\mathrm{G}$ protein ${ }^{27}$ have been shown to cause $\beta$-adrenergic desensitization in human failing myocardium and in a canine model of tachycardia-induced heart failure. ${ }^{14}$ Since atrial contractile dysfunction can also be provoked by rapid atrial pacing ${ }^{9}$ it has been classified as a tachycardia-induced atrial cardiomyopathy. ${ }^{28}$ Our previous and the present study show that the positive inotropic effect of isoprenaline is clearly reduced in atrial myocardium of AF patients. However, a reduced inotropic response to $\beta$-adrenergic stimulation does not necessarily mean that the $\beta$-adrenergic signal transduction is impaired. Since the positive inotropic effect of catecholamines is mainly due to protein kinase A mediated phosphorylation of the L-type $\mathrm{Ca}^{2+}$ channel, changes in protein expression or function of this ion channel could also explain the diminished inotropic effect of isoprenaline. In this case, a $\beta$-adrenergic response not mediated by the $\mathrm{L}$-type $\mathrm{Ca}^{2+}$ channel would be unchanged. In our present study the positive lusitropic effect of isoprenaline was found to be preserved in atrial myocardium of AF patients. The increase in speed of relaxation is governed by phoshorylation of phospholamban and a consecutive activation of the SR-Ca ${ }^{2+}$-ATPase, i.e. not dependent on L-type $\mathrm{Ca}^{2+}$ channel function. Therefore, the preserved effect of isoprenaline on relaxation indicates that the $\beta$-adrenergic signaling is not impaired. Also, isoprenaline-activated, and maximal catalytic capacity of the AC was unaltered in AF patients. These data provide direct evidence that the $\beta$-adrenergic signal transduction pathway itself is not desensitized in atrial myocardium of AF patients. Rather, the diminished positive inotropic effect of isoprenaline is due to the well established reduction of $\mathrm{I}_{\mathrm{CaL}}{ }^{11}$ in atrial cardiomyocytes of $\mathrm{AF}$ patients.

\section{The Function of the Sarcoplasmic Reticulum is Preserved.}

In human failing myocardium as well as in animal models of tachycardia-induced heart failure changes in intracellular $\mathrm{Ca}^{2+}$ handling result in prolonged relaxation and impaired systolic force development especially at higher rates. As a result the FFR becomes flat or even inversed. ${ }^{29}$ 
In the present study the FFR was positive in atria of SR and AF patients. In AF patients the response of the depressed contractions to an increase in rate was even more pronounced than in SR patients. Since a dysfunction of the sarcoplasmic reticulum inhibits an increase in contractile force at higher stimulation rates it is not very likely that AF-induced atrial contractile dysfunction is due to impaired $\mathrm{Ca}^{2+}$ handling of the sarcoplasmic reticulum. Alternatively, the enhancement and the rightward shift of the FFR in AF patients can be explained by a $\mathrm{Ca}^{2+}$ depletion of the atrial cardiomyocytes during slow rates. At higher stimulation rates the increased $\mathrm{Ca}^{2+}$ influx restores the intracellular $\mathrm{Ca}^{2+}$ load and contractility is improved.

Dysfunction of the sarcoplasmic reticulum has been reported to impair the diastolic function of isolated myocardium. ${ }^{30}$ In atrial myocardium of AF patients relaxation was not prolonged in the absence or presence of isoprenaline, at high stimulation frequencies, or during maximal stimulation of contractile force with high extracellular $\mathrm{Ca}^{2+}$ concentrations. This absence of slowed relaxation also favors the hypothesis that the $\mathrm{Ca}^{2+}$ reuptake function of the sarcoplasmic reticulum is preserved atrial myocardium of AF patients.

Post-rest potentiation of contractile force is a marker for the capacity of the sarcoplasmic reticulum to store $\mathrm{Ca}^{2+}{ }^{21}$ Ryanodine inhibits the repetitive storage and release of $\mathrm{Ca}^{2+}$ by the sarcoplasmic reticulum and completely abolished the post-rest potentiation. In atrial myocardium of AF patients the post-rest potentiation was more pronounced than in SR patients indicating that force of contraction was not limited by a disturbed reuptake of $\mathrm{Ca}^{2+}$ by the sarcoplasmic reticulum. This observation is in accordance with our finding that the protein expression of the $\mathrm{Ca}^{2+}$ release channel of the sarcoplasmic reticulum, the SR-Ca ${ }^{2+}-\mathrm{ATPase}$, phospholamban and calsequestrin was unaltered in atrial myocardium of AF patients.

The $\mathrm{L}$-type $\mathrm{Ca}^{2+}$ channel agonist BayK8644 was shown to inhibit post-rest potentiation in ferret ventricular muscle by activating the physical linkage between the $\mathrm{L}$-type $\mathrm{Ca}^{2+}$ channel and the $\mathrm{Ca}^{2+}$ release channel of the sarcoplasmic reticulum. The resulting opening of the $\mathrm{Ca}^{2+}$ release channel accelerates the $\mathrm{Ca}^{2+}$ release of the sarcoplasmic reticulum during the rest interval. ${ }^{32}$ In atrial myocardium of $\mathrm{AF}$ patients a downregulation or depressed function of the L-type $\mathrm{Ca}^{2+}$ channel might inhibit this interaction between the L-type $\mathrm{Ca}^{2+}$ channel and the ryanodine receptor. This would decrease the leakage of $\mathrm{Ca}^{2+}$ out of the sarcoplasmic reticulum during rest and might explain why the post-rest potentiation is enhanced in atrial myocardium of AF patients. This hypothesis is supported by our observation that, when atrial muscle preparations of SR patients were exposed to nifedipine, the post-rest potentiation was enhanced to a similar extent as in AF patients.

\section{Upregulation of the $\mathrm{Na}^{+} / \mathrm{Ca}^{2+}$-Exchanger}

In failing ventricular myocardium increased expression of the $\mathrm{Na}^{+} / \mathrm{Ca}^{2+}$-exchanger has been shown to contribute to the altered $\mathrm{Ca}^{2+}$ cycling and impaired systolic force development. ${ }^{33}$ In our study the sarcolemmal $\mathrm{Na}^{+} / \mathrm{Ca}^{2+}$-exchanger was found to be upregulated in atrial myocardium of patients with chronic AF.

Under physiological conditions the $\mathrm{Na}^{+} / \mathrm{Ca}^{2+}$-exchanger primarily works in its forward mode to extrude $\mathrm{Ca}^{2+}$ out of the cell. ${ }^{34}$ Therefore, an increased protein expression of the $\mathrm{Na}^{+} / \mathrm{Ca}^{2+}$-exchanger will result in an increased $\mathrm{Ca}^{2+}$ elimination via the exchanger and might lead to $\mathrm{Ca}^{2+}$ depletion of the cardiomyocyte. Thus, the upregulation of the $\mathrm{Na}^{+} / \mathrm{Ca}^{2+}$-exchanger could contribute to the observed postfibrillatory contractile dysfunction. In dogs undergoing rapid atrial pacing for 6 weeks, Sun et al. demonstrated 
a reduced amplitude of the $\mathrm{Ca}^{2+}$ transient when the atrial cardiomyocytes were stimulated with $1 \mathrm{~Hz}^{9}$. This shows that, after cessation of $\mathrm{AF}$, the $\mathrm{Ca}^{2+}$ content of the atrial cells is low rather than that they are overloaded with $\mathrm{Ca}^{2+}$. Therefore, although it is difficult to estimate direction and strength of the $\mathrm{Na}^{+} / \mathrm{Ca}^{2+}$-exchange during $\mathrm{AF}$ (the $\mathrm{Na}^{4} / \mathrm{Ca}^{2+}$-exchange rate depends on depolarization frequency, $\mathrm{Ca}^{2+}$ transient and resting potential ${ }^{34}$ ) the upregulation of the $\mathrm{Na}^{+} / \mathrm{Ca}^{2+}$-exchanger might well cause a depletion of $\mathrm{Ca}^{2+}$ after the cessation of AF. However, the relative contribution of the upregulation of the $\mathrm{Na}^{+} / \mathrm{Ca}^{2+}$-exchanger to the postfibrillatory atrial contractile dysfunction remains to be determined.

\section{What Causes the AF-Induced Atrial Contractile Dysfunction?}

Our previous study on the AF-induced changes in atrial contractility had demonstrated that downregulation or dysfunction of the L-type $\mathrm{Ca}^{2+}$ channel is a main mechanism of the atrial dysfunction. ${ }^{5}$ In contrast, myolysis can only explain a small part of it. The present study adds some new aspects to this concept: (1) $\beta$-adrenergic desensitization does not contribute to the AF-induced atrial contractile dysfunction. (2) Neither biochemical nor physiological experiments provided any indication that the $\mathrm{Ca}^{2+}$ storage function of the sarcoplasmic reticulum is impaired in atrial myocardium of AF patients. (3) Potentially, the upregulation of the $\mathrm{Na}^{+} / \mathrm{Ca}^{2+}$-exchanger worsens the $\mathrm{Ca}^{2+}$ depletion in atrial cardiomyocytes of $\mathrm{AF}$ patients and thereby contributes to the atrial contractile dysfunction after cardioversion of AF.

Furthermore, our data demonstrate that clear differences exist in pathophysiological mechanisms underlying a tachycardia-induced cardiomyopathy of the ventricles and the AF-induced tachycardiomyopathy of the atria. The main pathophysiological alterations attributed to classical ventricular tachycardiomyopathy - $\beta$-adrenergic desensitization and dysfunction of the sarcoplasmic reticulum - do not occur in atrial myocardium of $\mathrm{AF}$ patients indicating that adaptation processes upon the same stimulus may be very different in atria and ventricles.

\section{$\underline{\text { References }}$}

1. Wolf PA, Abbott RD, Kannel WB. Atrial fibrillation as an independent risk factor for stroke: the Framingham Study. Stroke 1991:22:983-988

2. Manning WJ. Silverman DI, Katz SE. Riley MF, Doherty RM. Munson JT, Douglas PS. Temporal dependence of the return of atrial mechanical function on the mode of cardioversion of atrial fibrillation to sinus rhythm. Am J Cardiol 1995;75:624-626

3. Black IW, Fatkin D, Sagar KB, Khandheria BK, Leung DY, Galloway JM, Feneley MP, Walsh WF. Grimm RA, Stollberger C. Exclusion of atrial thrombus by transesophageal echocardiography does not preclude embolism after cardioversion of atrial fibrillation. A multicenter study. Circulation 1994:89:2509-2513

4. Ausma J. Wijffels M. Thone F, Wouters L. Allessie M. Borgers M. Structural changes of atrial myocardium due to sustained atrial fibrillation in the goat. Circulation 1997:96:3157-3163

5. Schotten U, Ausma J, Stellbrink C. Sabatschus I, Vogel M, Frechen D, Schoendube F, Hanrath P. Allessie MA. Cellular mechanisms of depressed atrial contractility in patients with chronic atrial fibrillation. Circulation 2001:103:691-698

6. Altemose GT. Zipes DP. Weksler J. Miller JM. Olgin JE. Inhibition of the $\mathrm{Na}^{*} / \mathrm{H}^{+}$-exchanger delays the development of rapid pacing-induced atrial contractile dysfunction. Circulation 2001:103:762-768 
7. Daoud EG, Marcovitz P, Knight BP, Goyal R, Man KC, Strickberger SA, Armstrong WF, Morady F. Short-term effect of atrial fibrillation on atrial contractile function in humans. Circulation I999;99:3024-3027

8. Leistad E. Aksnes G, Verburg E, Christensen G. Atrial contractile dysfunction after short-term atrial fibrillation is reduced by verapamil but increased by BAYK8644. Circulation 1996;93:1747-1754

9. Sun H, Gaspo R, Leblanc N, Nattel S. Cellular mechanisms of atrial contractile dysfunction caused by sustained atrial tachycardia. Circulation 1998;98:719-727

10. Yue L, Feng J, Gaspo R, Li GR, Wang Z, Nattel S, Ionic remodeling underlying action potential changes in a canine model of atrial fibrillation. Circ Res 1997;81:512-525

11. Bosch RF, Zeng XR, Grammer JB, Popovic K, Mewis C, Kuehlkamp V. Ionic mechanisms of electrical remodeling in human atrial fibrillation. Cardiovasc Res 1999;44:121-131

12. Van Wagoner DR, Pond AL, Lamorgese M, Rossie SS, McCarthy PM, Nerbonne JM. Atrial L-type $\mathrm{Ca}^{2 *}$ currents and human atrial fibrillation. Circ Res 1999:85:428-436

13. Van Gelder IC, Brundel BJ, Henning RH, Tuinenburg AE, Tieleman RG, Deelman L, Grandjean JG, De Kam PJ, Van Gilst WH, Crijns HJ. Alterations in gene expression of proteins involved in the calcium handling in patients with atrial fibrillation. J Cardiovasc Electrophysiol 1999:10:552-560

14. Marzo KP. Frey MJ, Wilson JR, Liang BT, Manning DR, Lanoce V, Molinoff PB. Beta-adrenergic receptor-G protein-adenylate cyclase complex in experimental canine congestive heart failure produced by rapid ventricular pacing. Circ Res 1991:69:1546-1556

15. O'Rourke B, Kass DA, Tomaselli GF, Kaăb S, Tunin R, Marbán E. Mechanisms of altered excitationcontraction coupling in canine tachycardia-induced heart failure, 1: experimental studies. Circ Res 1999;84:562-570

16. Igarashi SK, Tsutsui H. Yamamoto S, Takahashi M. Kinugawa S. Tagawa H, Usui M, Yamamoto M. Egashira K. Takeshita A. Role of SR $\mathrm{Ca}^{2+}$-ATPase in contractile dysfunction of myocytes in tachycardia-induced heart failure. Am J Physiol 1998;275: H31-H40

17. Schotten U. Filzmaier K. Borghardt B, Kulka S, Schoendube F, Schumacher C, Hanrath P. Changes of the $\beta$-adrenergic signal transduction in compensated human cardiac hypertrophy depend on the underlying disease. Am J Physiol 2000;278:H2076-H2083

18. Schotten U, Koenigs B, Rueppel M, Schoendube F, Boknik P, Schmitz W, Hanrath P. Reduced myocardial sarcoplasmic reticulum $\mathrm{Ca}^{2-}$-ATPase expression in compensated primary and secondary human cardiac hypertrophy. J Mol Cell Cardiol 1999;31:1483-1494

19. Fabiato A. Computer programs for calculating total from specified free or free from specified total ionic concentrations in aqueous solutions containing multiple metals and ligands. Methods Enzymol $1988: 157: 378-417$

20. Bradford MM. A rapid and sensitive method for the quantitation of microgram quantities of protein utilizing the principle of protein- dye binding. Anal Biochem 1976;72:248-254

21. Mihm MJ. Yu F, Carnes CA. Reiser PJ. McCarthy PM, Van Wagoner DR, Bauer JA. Impaired myofibrillar energetics and oxidative injury during human atrial fibrillation. Circulation 2001:104:174-180

22. Sun H, Chartier D, Leblanc N, Nattel S. Intracellular calcium changes and tachycardia-induced contractile dysfunction in canine atrial myocytes. Cardiovasc Res 2001;49:751-761

23. Beuckelmann DJ, Näbauer M, Erdmann E. Intracellular calcium handling in isolated ventricular myocytes from patients with terminal heart failure. Circulation 1992;85:1046-1055

24. Hasenfuss G. Reinecke H, Studer R, Meyer M, Pieske B, Holtz J. Holubarsch C, Posival H, Just H, Drexler H. Relation between myocardial function and expression of sarcoplasmic reticulum $\mathrm{Ca}^{2+}$. ATPase in failing and nonfailing human myocardium. Circ Res 1994;75:434-442

25. Studer R, Reinecke H. Bilger J. Eschenhagen T, Böhm M. Hasenfuss G. Just H, Holtz J, Drexler H. Gene expression of the cardiac $\mathrm{Na}^{2}-\mathrm{Ca}^{2}$ exchanger in end-stage human heart failure. Circ Res I994:75:443-453

26. Brodde OE, Hillemann S, Kunde K. Vogelsang M. Zerkowski HR. Receptor systems affecting force of contraction in the human heart and their alterations in chronic heart failure. J Heart Lung Transplant 1992;11:S164-S174

27. Feldman AM, Cates AE, Veazey WB, Hershberger RE, Bristow MR, Baughman KL, Baumgartner WA, Van DC. Increase of the 40,000-mol wt pertussis toxin substrate ( $\mathrm{G}$ protein) in the failing human heart. J Clin Invest 1988;82:189-197

28. Gallagher MM, Obel OA, Camm JA. Tachycardia-induced atrial myopathy: an important mechanism in the pathophysiology of atrial fibrillation? J Cardiovasc Electrophysiol 1997;8:1065-1074

29. Mulieri LA, Hasenfuss G, Leavitt B, Allen PD, Alpert NR. Altered myocardial force-frequency relation in human heart failure. Circulation 1992;85:1743-1750

30. Mittmann C. Eschenhagen T. Scholz H. Cellular and molecular aspects of contractile dysfunction in heart failure. Cardiovasc Res 1998:39:267-275 
58 | Chapter 3

31. Bers DM. Ca influx and sarcoplasmic reticulum $\mathrm{Ca}$ release in cardiac muscle activation during postrest recovery. Am J Physiol 1985;248:H366-H381

32. McCall E, Hryshko LV, Stiffel VM, Christensen DM, Bers DM. Possible functional linkage between the cardiac dihydropyridine and ryanodine receptor: acceleration of rest decay by BayK8644. J Mol Cell Cardiol 1996;28:79-93

33. Hasenfuss G, Schillinger W, Lehnart SE, Preuss M, Pieske B, Maier LS, Prestle J, Minami K, Just H. Relationship between $\mathrm{Na}^{*}-\mathrm{Ca}^{2+}$-exchanger protein levels and diastolic function of failing human myocardium. Circulation 1999;99:641-648

34. Janvier $\mathrm{NC}$, Boyett MR. The role of $\mathrm{Na}^{-}-\mathrm{Ca}^{2+}$-exchange current in the cardiac action potential. Cardiovasc Res 1996:32:69-84 


\section{Chapter 4}

\section{The L-Type $\mathrm{Ca}^{2+}$ Channel Subunits $\alpha_{1 \mathrm{C}}$ and $\beta_{2}$ are not Downregulated in Atrial Myocardium of Patients with Chronic Atrial Fibrillation}

Ulrich Schotten, Hannelore Haase, Dirk Frechen, Maura Greiser, Christoph Stellbrink, Jaime F. Vazquez-Jimenez, Ingo Morano, Maurits Allessie, Peter Hanrath. 


\section{Abstract}

\section{Objective}

Electrical remodeling as well as the atrial contractile dysfunction after the conversion of atrial fibrillation (AF) to sinus rhythm (SR) are mainly caused by a reduction of the inward L-type $\mathrm{Ca}^{2+}$ current $\left(\mathrm{I}_{\mathrm{CaL}}\right)$. We investigated whether the expression of L-type $\mathrm{Ca}^{2+}$ channel subunits was reduced in atrial myocardium of $\mathrm{AF}$ patients.

\section{Methods}

Right atrial appendages were obtained from patients undergoing coronary artery bypass graft surgery (CAD, $n=35$ ) or mitral valve surgery (MVD, $n=37$ ). 17 of the CAD patients and 18 of the MVD patients were in chronic ( $>3$ months) AF, whereas the others were in SR. The protein expression of the L-type $\mathrm{Ca}^{2+}$ channel subunits $\alpha_{1 \mathrm{C}}$ and $\beta_{2}$ was quantified by Western blot analysis. Furthermore, we measured the density of dihydropyridine binding sites (DHP) of the L-type $\mathrm{Ca}^{2+}$ channel using ${ }^{3} \mathrm{H}-\mathrm{PN} 220-100$ as radioligand.

\section{Results}

Surprisingly, the $\alpha_{1 C}$ and the $\beta_{2}$-subunit expression was not altered in atrial myocardium of AF patients. Also, the DHP binding site density was unchanged.

\section{Conclusion}

The protein expression of the L-type $\mathrm{Ca}^{2+}$ channel subunits $\alpha_{1 \mathrm{C}}$ or $\beta_{2}$ is not reduced in atrial myocardium of AF patients. Therefore, the reduced $\mathrm{I}_{\mathrm{Ca}}$ might be due to downregulation of other accessory subunits $\left(\alpha_{2} \delta\right)$, expression of aberrant subunits, changes in channel trafficking or alterations in channel function.

\section{$\underline{\text { Introduction }}$}

In 1995 a rapid shortening of the atrial effective refractory period due to atrial fibrillation (AF) was demonstrated in goats and dogs. ${ }^{1: 2}$ The shortening of the atrial refractoriness was associated with a shortening of the AF cycle length and a progressive increase in the duration of AF (AF begets AF). In atrial cardiomyocytes of dogs undergoing prolonged rapid atrial pacing (42 days) the shortening of the atrial refractory period was due to a $70 \%$ reduction of the L-type $\mathrm{Ca}^{2+}$ inward current $\left(\mathrm{I}_{\mathrm{Cal}}\right) \mathrm{.}^{3} \mathrm{Later}$ studies confirmed a downregulation of $\mathrm{I}_{\mathrm{Cal}}$ in atrial cardiomyocytes of patients with chronic $\mathrm{AF}^{4.6}$

In cardiac muscle, functional L-type $\mathrm{Ca}^{2+}$ channels consist of the three subunits $\alpha_{1 \mathrm{C}}$, $\alpha_{2} \delta$, and $\beta$. The $\alpha_{1 C}$-subunit resides in the sarcolemmal membrane, forms the ionconducting pore and carries the receptor sites for dihydropyridines (DHP). In cardiac tissue the $\beta_{2}$ subunit isoform, a putative hydrophilic protein, binds to $\alpha_{I C}$ and influences markedly L-type $\mathrm{Ca}^{2+}$ channel properties such as channel gating and DHP binding parameters. ${ }^{7}$ In contrast, the physiological role of the $\alpha_{2} \delta$-subunit is much less understood.

Whether the reduction of $\mathrm{I}_{\text {Cat }}$ in atrial cardiomyocytes of $\mathrm{AF}$ patients is due to a downregulation of $\mathrm{L}$-type $\mathrm{Ca}^{2+}$ channel subunits is still a matter of debate. Several authors 
reported a reduction of the mRNA content of the $\alpha_{1 \mathrm{c}}$-subunit in atrial myocardium of patients with chronic $\mathrm{AF},{ }^{8-10}$ whereas others reported only minor changes. ${ }^{11}$ Instead, the latter authors found that the mRNA of the $\beta$ and the $\alpha_{2} \delta$-subunits was reduced. Data on protein expression of the L-type $\mathrm{Ca}^{2+}$ channel in atrial myocardium are very limited. So far, only the $\alpha_{1 \mathrm{c}}$-subunit has been quantified in atrial myocardium of a small population of patients with chronic AF. Brundel et al. found a downregulation of this subunit by $\sim 55 \%{ }^{8}$ The present study was designed to investigate whether in patients with different underlying heart diseases the L-type $\mathrm{Ca}^{2+}$ channel subunits $\alpha_{1 \mathrm{C}}$ or $\beta_{2}$ are downregulated in chronically fibrillating atria. The obtained results were compared to the density of DHP binding sites in the same tissue.

\section{$\underline{\text { Materials and Methods }}$}

\section{Patients}

During open chest surgery right atrial appendages were obtained from 35 patients with coronary artery disease (CAD, 18 in SR, 17 in chronic AF for $>3$ months) and from 37 patients suffering from mitral valve disease (MVD, 19 in SR, 18 in chronic AF). Hemodynamic parameters did not differ significantly between SR and AF patients but the left atria were slightly enlarged in AF patients (Table 1). $\mathrm{Ca}^{2+}$-antagonists and digitalis were more frequently taken by the AF patients for control of ventricular rate. All patients gave written informed consent and the study was approved by an institutional ethical committee.

\begin{tabular}{|c|c|c|c|c|}
\hline & \multicolumn{2}{|c|}{ Coronary Artery Disease } & \multicolumn{2}{|c|}{ Mitral Valve Disease } \\
\hline & Sinus Rhythm & Atrial Fibrillation & Simus Rhythm & Atrial Fibrillation \\
\hline$N$ & 18 & 17 & 19 & 18 \\
\hline Age (y) & $65 \pm 3$ & $67 \pm 2$ & $59 \pm 4$ & $67 \pm 3$ \\
\hline Gender $(m / f)$ & $13 / 5$ & $12 / 5$ & $8 / 11$ & $8 / 10$ \\
\hline $\mathrm{Cl}\left(\mathrm{A} / \mathrm{min} / \mathrm{m}^{2}\right)$ & $3.5 \pm 0.4$ & $3.4 \pm 0.3$ & $3.1 \pm 0.4$ & $2.9 \pm 0.4$ \\
\hline$L D(m m)$ & $35.1 \pm 3.3(n=6)$ & $42.0 \pm 3.9(n=6)^{*}$ & $44.0 \pm 3.4$ & $50.2 \pm 3.6^{\circ}$ \\
\hline \multicolumn{5}{|l|}{ Medication } \\
\hline $\mathrm{Ca}$-antagonists & 7 & $12^{*}$ & 7 & $12^{*}$ \\
\hline Digitalis & 0 & $11^{\circ}$ & 5 & $13^{*}$ \\
\hline Beta-blockers & 7 & 6 & 2 & $I$ \\
\hline ACE-inhibitors & 7 & 5 & 3 & 2 \\
\hline Diuretics & 6 & 5 & 4 & 6 \\
\hline Nitrates & 15 & 12 & 0 & 0 \\
\hline
\end{tabular}

\section{Table I}

Patients - clinical and hemodynamic data.

$L D=$ left atrial diameter (echocardiography), $C I=$ cardiac index. * $p<0.05$ versus $S R$

\section{Dihydropyridine Binding Studies}

Because of the limited size of the tissue samples radioligand binding studies were performed in 20 of the CAD patients ( $n=10$ in SR and $n=10$ in AF) and in 21 of the MVD patients ( $n=10$ in SR and $n=11$ in AF). $100 \mathrm{mg}$ myocardium of each appendage were homogenized with an Ultraturrax in $3 \mathrm{ml}$ buffer $\mathrm{A}(50 \mathrm{mM}$ Tris-base, $1 \mathrm{mM} \mathrm{CaCl}$, $0.1 \mathrm{mM}$ PMSF, $\mathrm{pH} 7.4,4^{\circ} \mathrm{C}$ ). After filtration through 4 layers of gauze a protein 
concentration of $0.5 \mathrm{mg} / \mathrm{ml}$ (Bradford) was adjusted by dilution with buffer $\mathrm{A}$. Incubation with the dihydropyridine ${ }^{3} \mathrm{H}-\mathrm{PN} 200-110$ (NEN DuPont; 7 concentrations 12 $2000 \mathrm{pM}, 37^{\circ} \mathrm{C}$ ) was stopped after $60 \mathrm{~min}$ by vacuum filtration through Whatman $\mathrm{GF} / \mathrm{C}$ filters. The retained radioactivity was counted in a $\beta$-counter. Nonspecific binding was determined by adding $1 \mu \mathrm{M}$ nitrendipine to the binding assay.

\section{Production and Purification of Antibodies}

New Zealand white rabbits were immunized with synthetic peptides coupled to carriers as previously described. ${ }^{12}$ Antigenic epitopes comprised the amino acid residues (EEEEKERKKLARTASPEKK) 740-758 of the human cardiac $\alpha_{i c}$ (cytoplasmic linker between domain $\mathrm{II}$ and $\mathrm{III})^{13}$ and the C-terminal amino acid residues (EWNRDVYIRQ) of the rabbit cardiac $\beta_{2 a b b}{ }^{14}$ The antibodies were affinity-purified on antigen columns according to Calovini et al.. ${ }^{15}$ The specificity of the antibodies has previously been demonstrated elsewhere. ${ }^{16: 17}$

\section{Western blot analysis}

Western blot analysis was performed in 27 CAD patients ( $n=14$ in SR, $n=13$ in AF) and in 27 MVD patients $(n=15$ in $S R, n=12$ in AF). Atrial myocardium (100mg) was homogenized in $1.5 \mathrm{ml}$ of $20 \mathrm{mM}$ HEPES, $0.1 \mathrm{mM}$ Leupeptin, $250 \mathrm{mM}$ sucrose, and $0.1 \mathrm{mM}$ PMSF ( $\mathrm{pH}$ 7.4). Electrophoresis of homogenate aliquots containing $20 \mu \mathrm{g}$ protein/lane was carried out using $6.5 \%$ polyacrylamid gels. After the subsequent electrophoretic transfer the nitrocellulose $(0.45 \mu \mathrm{m})$ was incubated with the previously characterized antibodies ${ }^{17}$ raised against the $\alpha_{1 \mathrm{C}}$ or the $\beta_{2}$-subunit of the L-type $\mathrm{Ca}^{2+}$ channel $(0.5-1 \mu \mathrm{g} \mathrm{IgG} / \mathrm{ml})$ for $90 \mathrm{~min}$ and afterwards for $2 \mathrm{~h}$ with the secondary peroxidase-conjugated antibody (anti-rabbit IgG [BioGenes, Berlin, Germany]). ${ }^{16}$ Immunoreactive protein bands were visualised by an enhanced chemiluminescence reaction kit and quantified densitometrically using an Epson GT 8000 scanner. The protein dependency of the densitometric signals was linear up to $30 \mu \mathrm{g}$ indicating that quantification using $20 \mu \mathrm{g}$ per lane was performed within the linear range (Figure 1).
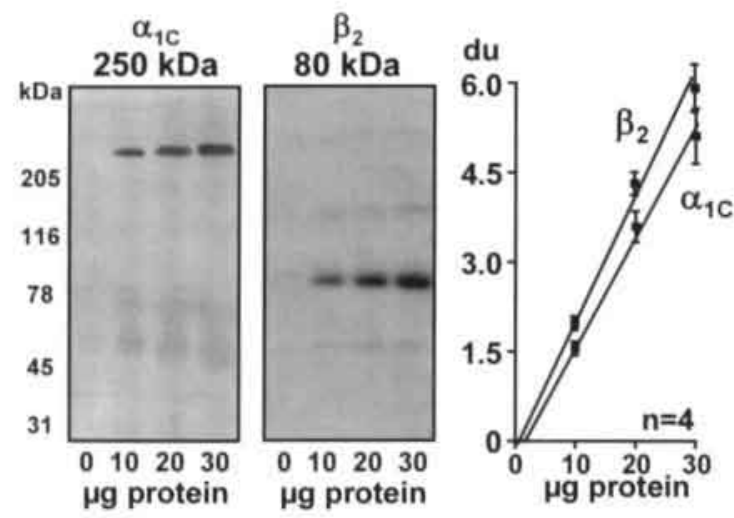

Figure 1

L-type $\mathrm{Ca}^{\prime}$-channel Western blots

Relationship between L-type $\mathrm{Ca}^{2}$ channel subunit signals and the protein loaded to each lane. Left: Representative autoradiographs. Right: The Ltype $\mathrm{Ca}^{2}$ channel subunit signals increased linearily between 0 and $30 \mu \mathrm{g}$ protein loaded to each lane indicating that routine quantification of the subunits using $20 \mu \mathrm{g}$ per lane was performed within the linear range. $d u=$ density units.

Quantification of the subunits $\alpha_{1 C}$ and $\alpha_{2} \delta$ was also tried using the commercially available polyclonal antibodies anti-rat- $\alpha_{1 C}$ and anti-rabbit- $\alpha_{2} \delta$ (ACC-003 and ACC015, Alomone Labs, Jerusalem, Israel). However, in these experiments multiple bands 
were detected on the autoradiographs. These bands were not reproducible and labelling of proteins near the predicted molecular weight of the respective subunits was not sensitive to preincubation of the antibody with control antigen.

\section{Myosin content}

Electrophoretic separation of the proteins was performed as described above but with $1.5 \mu \mathrm{g}$ protein per lane. The gel was stained in Coomassie brilliant blue G. Myosin bands were identified by the same mobility as a commercially available myosin marker at $205 \mathrm{kDa}$ and quantified with a laser densitometer.

\section{Statistical analysis}

Data are means \pm SD. Statistical significance of differences were determined with unpaired Student's t-test. Significance of differences in medication or gender were calculated by Chi-square test. A p-value of less than 0.05 was considered as statistically significant.

\section{$\underline{\text { Results }}$}

\section{DHP-Binding Sites}

Specific ${ }^{3} \mathrm{H}-\mathrm{PN} 200-110$ binding to atrial membrane preparations showed saturation characteristics (Figure 2). The Scatchard plots of all radioligand binding experiments were linear indicating that ${ }^{3} \mathrm{H}-\mathrm{PN} 200-110$ bound to one single binding site. The specific binding curves of all patients are superimposed in figure 3 . In CAD patients in SR $(\mathrm{n}=10)$ the DHP binding site density was $88.4 \pm 17.1 \mathrm{fmol}{ }^{3} \mathrm{H}-\mathrm{PN} 200-110$ specifically bound $/ \mathrm{mg}$ protein. In CAD patients with $\mathrm{AF}(\mathrm{n}=10) 79.3 \pm 15.6 \mathrm{fmol} / \mathrm{mg}$ protein was found ( $p=n . s$.). Also in patients suffering from MVD the DHP binding site density was not different in the two patient groups (SR: $n=10,79.5 \pm 17.4 \mathrm{fmol} / \mathrm{mg}, A F: n=11$, $74.8 \pm 12.6 \mathrm{fmol} / \mathrm{mg}, \mathrm{p}=\mathrm{n} . \mathrm{s}$.). The affinity of the radioligand to the DHP-binding sites $\left(\mathrm{K}_{\mathrm{D}}\right.$-value) ranged from 48 to $352 \mathrm{pM}$ and did not differ between the patient groups.

Representative DHP-Binding Experiment

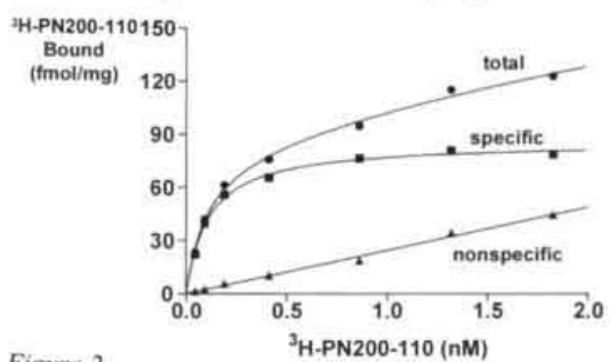

Figure 2

Representative 'H-PN200-110-binding curves

Representative saturation binding of ${ }^{3} \mathrm{H}-\mathrm{PN200-110}$ to an atrial membrane preparation of a CAD patient in $S R$. Binding was performed at 7 concentrations of ${ }^{3} \mathrm{H}-P N 200-110$ ranging from 12 to $2000 \mathrm{pM}$ in the absence (total binding) and in the presence (nonspecific binding) of $1 \mu \mathrm{M}$ nitrendipine. Specific binding calculated as the difference between total and non-specific binding (left panel). Scatchard Plot of the same experiment (right panel). 


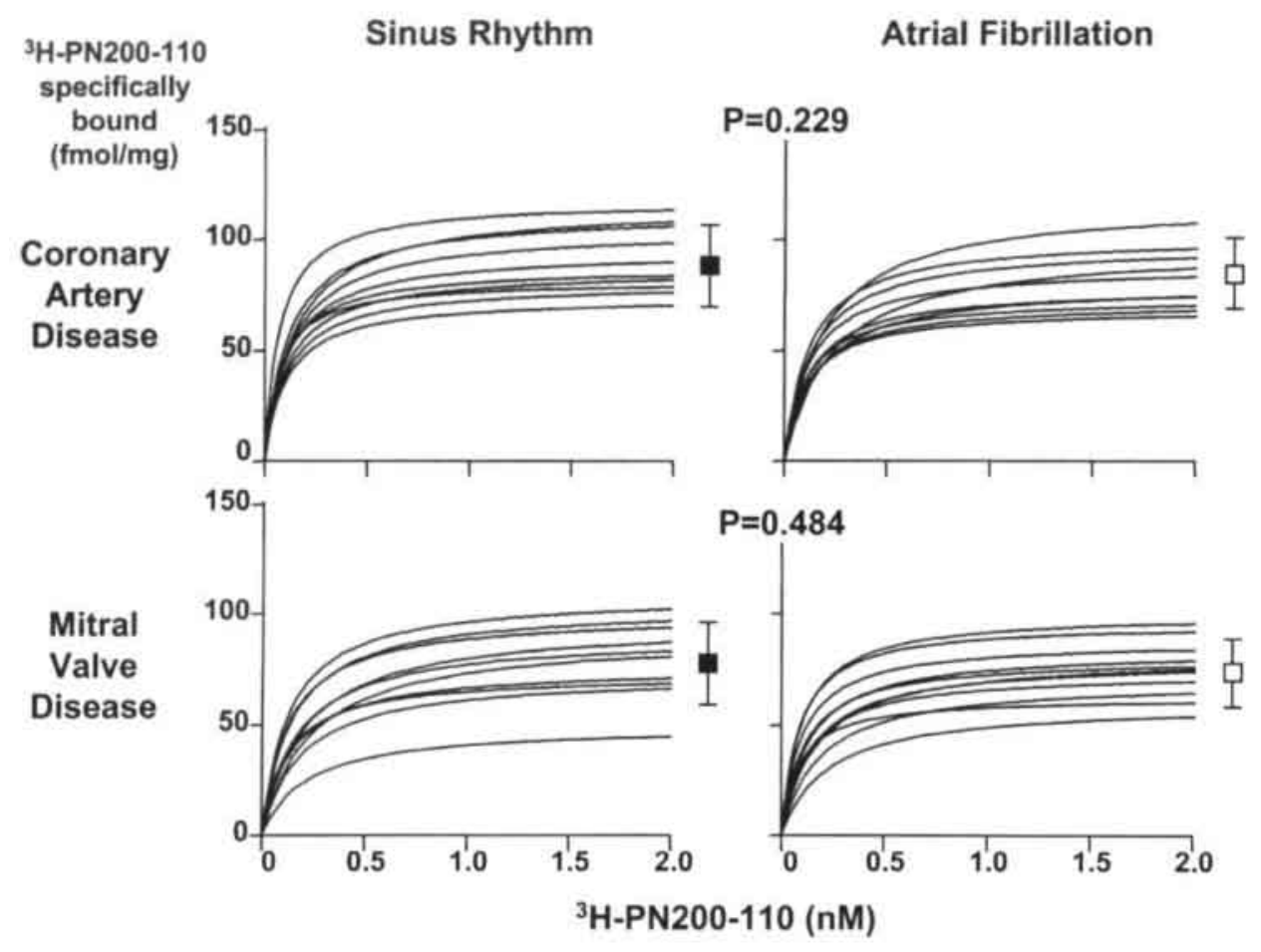

Figure 3

L-type $\mathrm{Ca}^{2}$-channel expression: ${ }^{\prime} \mathrm{H}$-PN200-110-binding

Specific radioligand binding curves of all patients studied. The density of the DHP-binding sites did not differ between SR and AF patients.

\section{Protein Expression of $\alpha_{1 \mathrm{C}}$ and $\beta_{2}$-Subunits}

The anti- $\alpha_{1 \mathrm{C}}$ antibody detected specifically a single $250-\mathrm{kDa}$ protein indicating the presence of the full-length $\alpha_{1 C}$ protein (Figure 4). In concordance with previous studies the anti- $\beta_{2}$ antibody bound to a $80 \mathrm{kDa}$ protein identified as the $\beta_{2}$ subunit of the L-type $\mathrm{Ca}^{2+}$ channel. ${ }^{17: 18}$ Neither $\alpha_{1 \mathrm{C}}$ nor $\beta_{2}$ subunit expression varied between SR and AF patients, regardless of their underlying cardiac disease (Figure 4). The same held true when the protein expression of the L-type $\mathrm{Ca}^{2+}$ channel subunits was related to the myosin content of the homogenates or when the ratio of the subunits was calculated (Table 2). Treatment with $\mathrm{Ca}^{2+}$ antagonists did not change the expression of $\alpha_{1 C}$ or $\beta_{2-}$ subunits or DHP binding site density. For example, in treated AF patients suffering from MVD the $\alpha_{1 C}$ expression was $152 \pm 33 \mathrm{du} / \mathrm{mg}(\mathrm{n}=7)$, whereas it was $143 \pm 42(\mathrm{n}=5$, $\mathrm{p}=\mathrm{n} . \mathrm{s}$.) in untreated patients. Digitalis also did not effect L-type $\mathrm{Ca}^{2+}$ channel expression. 


\section{$\alpha_{1 \mathrm{c}}$-Subunit}
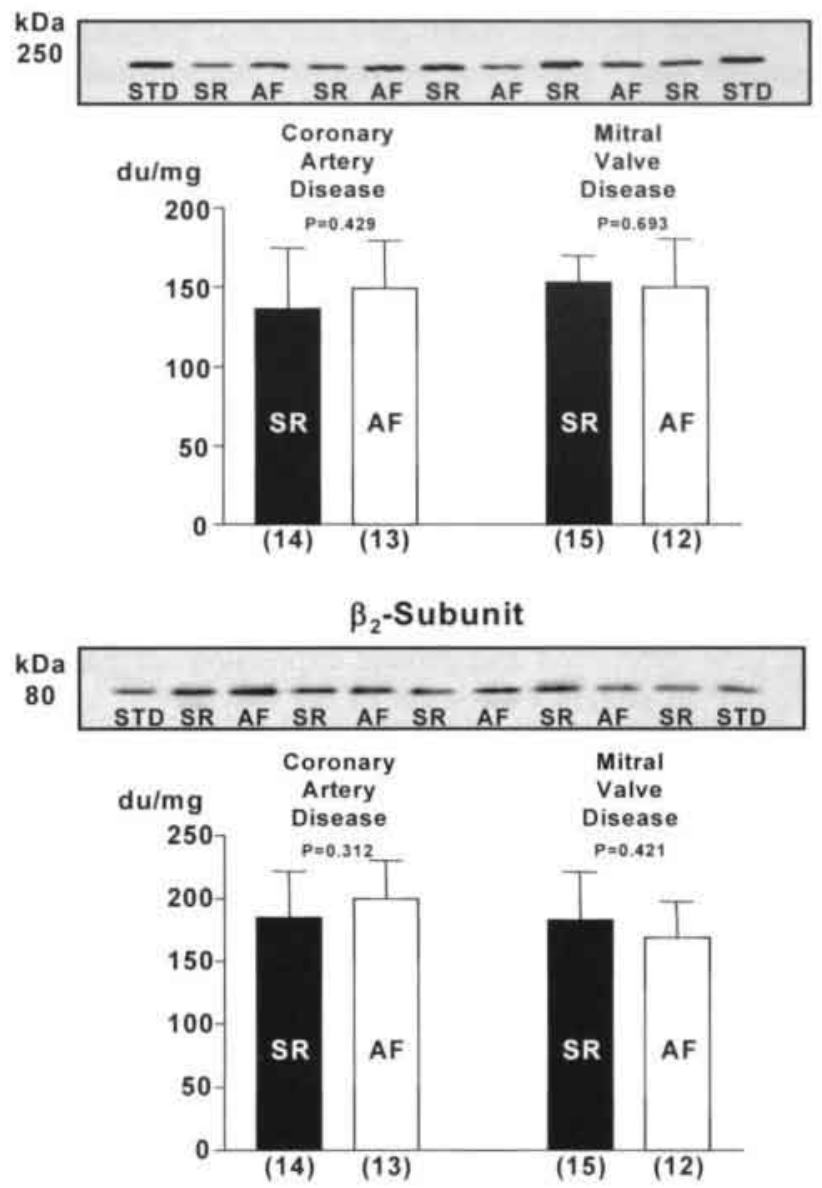

Figure 4

L-type $\mathrm{Ca}$ '-channel expression: Immunoblots of the subunits $\alpha_{1 C}$ and $\beta_{2}$

Each lane of the representative autoradiographs represents a patient with CAD in either $S R$ or AF. STD = Standard sample of a patient with $S R$. which was subjected to each gel to promote comparability of determination from the different blots.

\begin{tabular}{|c|c|c|c|c|c|c|}
\hline & \multicolumn{2}{|c|}{ Coronary Artery Disease } & \multicolumn{3}{|c|}{ Mitral Valve Disease } & \multirow[b]{2}{*}{ P-value } \\
\hline & $\begin{array}{c}S R \\
(n=14)\end{array}$ & $\begin{array}{c}A F \\
(n=13)\end{array}$ & $\begin{array}{c}P- \\
\text { value }\end{array}$ & $\begin{array}{c}S R \\
(n=15)\end{array}$ & $\underset{(n=12)}{A F}$ & \\
\hline $\begin{array}{l}\alpha_{i d} / m y o s i n \\
(d w d u)\end{array}$ & $6818 \pm 1142$ & $742 I \pm 986$ & 0.156 & $7652 \pm 1323$ & $7368 \pm 984$ & 0.542 \\
\hline $\begin{array}{l}\text { By/myosin } \\
(d w / d u)\end{array}$ & $9245 \pm 1438$ & $\begin{array}{c}10021 \pm 165 \\
9\end{array}$ & 0.205 & $9159 \pm 1423$ & $8239 \pm 1.592$ & 0.126 \\
\hline $\begin{array}{l}\text { Ratio } \alpha_{l d} / \beta z \\
(d u / d u)\end{array}$ & $0.75 \pm 0.11 \mathrm{I}$ & $0.74 \pm 0.09$ & 0.799 & $0.83 \pm 0.13$ & $0.89 \pm 0.15$ & 0.276 \\
\hline
\end{tabular}

Table 2

L-type $\mathrm{Ca}^{+}$channel subunit protein expression. $d u=$ density units. 


\section{$\underline{\text { Discussion }}$}

\section{Major Findings}

Using previously characterized specific antibodies we quantified the protein expression of the subunits $\alpha_{1 \mathrm{C}}$ and $\beta_{2}$ in atrial myocardium of AF patients in Western blot analysis. Related to total protein in the homogenates there was no change of the protein expression of either subunit. Since AF causes substantial structural alterations in atrial myocardium ${ }^{19}$ we also compared the expression of the subunits to the myosin content of the homogenates to exclude that differences in the protein concentration of the homogenates mask altered subunit protein expression. Related to the myosin content there was also no change in the protein expression of either subunit. Furthermore, the ratio between both subunits was not affected by AF. The result is confirmed by the fact that the DHP-binding site density is not reduced in AF patients.

Studies on gene expression of the L-type $\mathrm{Ca}^{2+}$ channel, however, have reported different results. Several authors have reported a downregulation of the $\alpha_{i c}$ mRNA in patients with chronic $\mathrm{AF}^{8-10}$ While these data are not challenging our observations, because differences between gene expression and protein expression are not uncommon, ${ }^{8}$ the contrast between studies on protein expression of the L-type $\mathrm{Ca}^{2+}$ channel in patients with $\mathrm{AF}$ and ours is more striking. Brundel et al. studied the protein expression of the $\alpha_{1 \mathrm{c}}$-subunit in atrial myocardium of AF patients using Western blot analysis. ${ }^{8}$ Comparing patients with lone AF with control patients suffering from coronary artery disease they found that the $\alpha_{1 \mathrm{C}}$-subunit was downregulated by $55 \%$. In a limited number of patients with mitral valve disease (4 control patients) a similar degree of downregulation was observed. The obviously different results between the study of Brundel et al. and ours might be due to the described differences in study population or to the antibodies chosen.

\section{What Could Explain the Reduced $\mathrm{I}_{\mathrm{CaL}}$ in Atrial Myocytes of Patients with AF?}

The underlying defects in $\mathrm{Ca}^{2+}$ channels in AF can include 1) a diminished number of channel subunits in the membrane (diminished synthesis of channel constituents or aberrant targeting to the plasma membrane) or 2) an altered function of the channel due to expression of aberrant channel subunits, posttranslational modification or an altered regulation of the channel function by intracellular pathways.

Because of the lack of appropriate antibodies we were unable to quantify the expression of the $\alpha_{2} \delta$-subunit in the specimens. Coexpression of this subunit with $\alpha_{1 \mathrm{C}}$ in oocytes has been demonstrated to augment the $\mathrm{Ca}^{2+}$-channel activity. ${ }^{20}$ Thus, a downregulation of the $\alpha_{2} \delta$-subunit might well explain the reduction of $\mathrm{I}_{\text {Cal }}$ in atrial myocardium of AF patients. Also, the expression of aberrant $\alpha_{1 \mathrm{C}}$ or $\beta$-subunits might potentially explain diminished function of the L-type $\mathrm{Ca}^{2+}$ channel. Although the $\alpha_{1 \mathrm{C}}$ and the $\beta_{2}$-subunits identified in atrial myocardium of AF patients were virtually of the same molecular weight (no shift of the bands and no additional bands were observed on the autoradiographies) we cannot exclude the possibility that different splicing variants of the subunits are expressed in atrial myocardium of $\mathrm{AF}$ patients.

Also the posttranslational modification and its consequences for the regulation of the channel during AF are potential explanations for the diminished $\mathrm{I}_{\mathrm{Cal}}$. The full-length $\alpha_{1 \mathrm{C}}$-subunit is proteolytically truncated at its $\mathrm{C}$-terminus. The $\mathrm{C}$-terminal fragment, which remains attached to the channel, contains the only detectable phosphorylation site 
for protein kinase A (PKA) indicating that the truncation is probably of relevance for the regulation of the channel. ${ }^{21}$ However, important changes of the PKA dependent regulation of the channel seem not very likely, since in atria of AF patients the $\beta$ adrenergic signal transduction pathway is not altered ${ }^{22}$ and the stimulatory effect of isoprenaline on $\mathrm{I}_{\mathrm{CaL}}$ is preserved. ${ }^{4}$ No data are currently available on the effect of $\mathrm{AF}$ on the control of the L-type $\mathrm{Ca}^{2+}$ channel by protein kinase $\mathrm{C}$ or tyrosine protein kinases which cooperatively regulate $\mathrm{I}_{\mathrm{Cal}} .{ }^{23}$. These kinases are activated by $\alpha_{1}$-adrenergic-, angiotensin II-, or growth factor receptors, respectively. The fact that in fibrillating atria angiotensin II signalling is altered ${ }^{24}$ and pronounced cellular hypertrophy has consistently been demonstrated ${ }^{2: 19: 25}$ support the hypothesis that changes in these pathways might result in a dysregulation of the L-type $\mathrm{Ca}^{2+}$ channel in atria of AF patients.

The functional properties of the $\mathrm{Ca}^{2+}$ channels determine the whole cell $\mathrm{I}_{\mathrm{Cal}}$ by the equation $\mathrm{I}_{\text {CaL. }}=\mathrm{N} * \mathrm{i} * \mathrm{p}_{0} * \mathrm{f}_{\text {active }}$, with $\mathrm{N}$ being the total number of L-type $\mathrm{Ca}^{2+}$ channels, $\mathrm{i}$ is the single channel current, $\mathrm{p}_{0}$ is the probability of an active channel to be open, and $f_{\text {active }}$ is the fraction of the channel that are available to open during a depolarisation. Assumed that $\mathrm{N}$ is indeed not changed in atrial myocardium of $\mathrm{AF}$ patients, the downregulation of $\mathrm{I}_{\mathrm{Cal}}$ can theoretically be explained by a reduction of one or several of the other three parameters. The current-voltage-relationship has been shown to be unaltered in atrial cardiomyocytes of AF patients and voltage dependent activation and inactivation were also unchanged. ${ }^{4 ; 5}$ Recovery from inactivation has been shown to be moderately prolonged. ${ }^{5}$ All these findings, however, can not rule out the possibility that the reduction of $\mathrm{I}_{\mathrm{CaL}}$ is the result of a decrease in the single channel current amplitude, the open probability or the availability of the channel. To our knowledge, none of these parameters has been assessed in atrial cardiomyocytes of patients with AF. These parameters might be sensitive to changes of the phosphorylation state of the channel and also to the cellular redox potential. Recently, oxygen sensitive modifications of thiol groups on specific cysteine residues in the $\mathrm{C}$ terminus of the $\alpha_{1 C}$ subunit have been reported to cause rapid reduction of the channel activity. ${ }^{26}$ These changes might not only contribute to the reduction of $\mathrm{l}_{\mathrm{CaL}}$ in atrial cardiomyocytes of $\mathrm{AF}$ patients but could also point to a new target of therapeutical intervention. For example, the application of antioxidant vitamin $\mathrm{C}$ has been shown to attenuate pacing-induced atrial electrical remodeling in dogs and to reduce the incidence of post-operative $\mathrm{AF}^{27}$

\section{Limitations}

In the present study no functional experiments to quantify electrophysiological remodeling were performed. However, in similar study populations a downregulation of the L-type $\mathrm{Ca}^{2+}$-current has been reported consistently by several groups. ${ }^{4-6} \mathrm{Also}$, in a parallel study in the same population contractile force development of isolated atrial trabeculae was found to be reduced by $\sim 70 \%$ which could be attributed to a reduction of $\mathrm{I}_{\mathrm{Cal} .}{ }^{25}$

Other limitations of the study are primarily related to the general shortcomings of protein expression analysis as such which are usually performed on tissue homogenates or crude membrane preparations. Neither radioligand binding studies nor quantification of proteins by Western blot analysis can address the localisation of the quantified protein within the cell. Possibly, in AF assembly and integration of new channels into the sarcolemma is disturbed. In this case, the number of functional channels in the membrane would be reduced without an apparent decrease in channel subunit 
expression determined by radioligand binding or Western blot analysis. To address this important question the $\mathrm{L}$-type $\mathrm{Ca}^{2+}$ channel expression would have to be quantified in purified sarcolemmal membranes of the atrial specimens which usually requires larger amounts of tissue. More importantly, evaluation of functional changes of the L-type $\mathrm{Ca}^{2+}$ channel on the single channel level is necessary to investigate the molecular mechanisms of electrical remodeling during $\mathrm{AF}$.

\section{$\underline{\text { Reference List }}$}

1. Wijffels MC, Kirchhof CJ. Dorland R, Allessie MA. Atrial fibrillation begets atrial fibrillation. A study in awake chronically instrumented goats. Circulation 1995: 92:1954-1968.

2. Morillo CA, Klein GJ, Jones DL, Guiraudon CM. Chronic rapid atrial pacing. Structural, functional, and electrophysiological characteristics of a new model of sustained atrial fibrillation. Circulation 1995: 91:1588-1595.

3. Yue L, Feng J. Gaspo R, Li GR, Wang Z, Nattel S. lonic remodeling underlying action potential changes in a canine model of atrial fibrillation. Circ Res 1997; 81:512-525.

4. Van Wagoner DR, Pond AL, Lamorgese M, Rossie SS, McCarthy PM, Nerbonne JM. Atrial L-type $\mathrm{Ca}^{2 *}$ currents and human atrial fibrillation. Circ Res 1999; 85:428-436.

5. Bosch RF, Zeng XR. Grammer JB. Popovic K. Mewis C. Kuehlkamp V. Ionic mechanisms of electrical remodeling in human atrial fibrillation. Cardiovase Res 1999; 44:121-131.

6. Skasa M, Jungling E, Picht E, Schondube F, Luckhoff A. L-type calcium currents in atrial myocytes from patients with persistent and non-persistent atrial fibrillation. Basic Res Cardiol 2001: 96:151159.

7. Hosey M, Chien A, Puri T. Structure and regulation of L-type calcium channels. A current assessment of the properties and roles of channel subunits. Trends Cardiovasc Med 1996; 6:265-273.

8. Brundel BJ, Van Gelder IC. Henning RH, Tieleman RG, Tuinenburg AE, Wietses M, Grandjean JG, Van Gilst WH. Crijns HJ. Ion channel remodeling is related to intraoperative atrial effective refractory periods in patients with paroxysmal and persistent atrial fibrillation. Circulation 2001; 103:684-690.

9. Van Gelder IC, Brundel BJ. Henning RH. Tuinenburg AE, Tieleman RG, Deelman L, Grandjean JG, De Kam PJ, Van Gilst WH. Crijns HJ. Alterations in gene expression of proteins involved in the calcium handling in patients with atrial fibrillation. J Cardiovasc Electrophysiol 1999; 10:552-560.

10. Lai LP, Su MJ, Lin JL, Lin FY. Tsai CH, Chen YS, Huang SK, Tseng YZ, Lien WP. Downregulation of L-type calcium channel and sarcoplasmic reticular $\mathrm{Ca}^{2}$-ATPase mRNA in human atrial fibrillation without significant change in the mRNA of ryanodine receptor. calsequestrin and phospholamban: an insight into the mechanism of atrial electrical remodeling. J Am Coll Cardiol 1999: 33:1231-1237.

II. Grammer JB, Zeng X, Bosch RF. Kuhlkamp V. Atrial L-type $\mathrm{Ca}^{2-2}$-channel, beta-adrenorecptor, and 5-hydroxytryptamine type 4 receptor mRNAs in human atrial fibrillation. Basic Res Cardiol 2001: 96:82-90,

12. Haase H, Karczewski P. Becken R. Krause EG. Phosphorylation of the L-type calcium channel beta subunit is involved in beta-adrenergic signal transduction in canine myocardium. FEBS Lett 1993; 335:217-222.

13. Schultz D, Mikala G, Yatani A. Engle DB, lles DE, Segers B. Sinke RJ, Weghuis DO, Klockner U, Wakamori $\mathrm{M}$. Cloning, chromosomal localization, and functional expression of the alpha I subunit of the L-type voltage-dependent calcium channel from normal human heart. Proc Natl Acad Sci USA 1993: 90:6228-6232.

14. Hullin R, Singer LD, Freichel M. Biel M, Dascal N, Hotmann F, Flockerzi V. Calcium channel beta subunit heterogeneity: functional expression of cloned cDNA from heart, aorta and brain. EMBO J 1992; 11:885-890.

15. Calovini T. Haase H, Morano 1. Steroid-hormone regulation of myosin subunit expression in smooth and cardiac muscle. J Cell Biochem 1995: 59:69-78.

16. Gollasch M. Haase H, Ried C. Lindschau C, Morano I, Luft FC, Haller H. L-type calcium channel expression dependes on the differentiated state of vascular smooth muscle cells. FASEB J 1998:12:593-601. 
17. Haase H, Pfitzmaier B, McEnery MW, Morano I. Expression of $\mathrm{Ca}(2+)$ channel subunits during cardiac ontogeny in mice and rats: identification of fetal alpha(1C) and beta subunit isoforms. J Cell Biochem 2000; 76:695-703.

18. Haase H, Bartel S, Karczewski P. Morano I, Krause EG. In-vivo phosphorylation of the cardiac Ltype calcium channel beta-subunit in response to catecholamines. Mol Cell Biochem 1996; 163:99. 106.

19. Ausma J, Wijffels M. Thoné F, Wouters L, Allessie M, Borgers M. Structural changes of atrial myocardium due to sustained atrial fibrillation in the goat. Circulation 1997; 96:3157-3163.

20. Mikami A, Imoto K, Tanabe T, Niidome T, Mori Y, Takeshima H, Narumiya S. Numa S. Primary structure and functional expression of the cardiac dihydropyridine-sensitive calcium channel. Nature 1989; 340:230-233.

21. Kamp TJ, Hell JW. Regulation of cardiac L-type calcium channels by protein kinase A and protein kinase C. Circ Res 2000; 87:1095-1102.

22. Schotten U, Greiser M, Benke D, Buerkel K. Ehrenteidt B, Stellbrink C, Vazquez-Jimenez JF, Schoendube F, Hanrath P. Allessie M. Atrial fibrillation-induced atrial contractile dysfunction: a tachycardiomyopathy of a different sort. Cardiovasc Res 2002; 53:192-201.

23. Boixel C, Tessier S, Pansard Y, Lang-Lazdunski L, Mercadier JJ, Hatem SN. Tyrosine kinase and protein kinase $\mathrm{C}$ regulate $\mathrm{L}$-type $\mathrm{Ca}^{2+}$ current cooperatively in human atrial myocytes. Am $\mathrm{J}$ Physiol Heart Circ Physiol 2000; 278:H670-H676.

24. Goette A, Arndt M, Rocken C, Spiess A, Staack T, Geller JC, Huth C, Ansorge S, Klein HU, Lendeckel U. Regulation of angiotensin II receptor subtypes during atrial fibrillation in humans. Circulation 2000; 101:2678-2681.

25. Schotten U, Ausma J, Stellbrink C, Sabatschus I, Vogel M. Frechen D, Schoendube F, Hanrath P, Allessie MA. Cellular mechanisms of depressed atrial contractility in patients with chronic atrial fibrillation. Circulation 2001: 103:691-698.

26. Fearon IM, Varadi G, Koch S, Isaacsohn I, Ball SG, Peers C. Splice variants reveal the region involved in oxygen sensing by recombinant human L-type $\mathrm{Ca}^{2 *}$ channels. Circ Res 2000; 87:537-539.

27. Cames CA, Chung MK. Nakayama T, Nakayama H, Baliga RS, Piao S, Kanderian A, Pavia S, Hamlin RL, McCarthy PM, Bauer JA, Van Wagoner DR. Ascorbate attenuates atrial pacing-induced peroxynitrite formation and electrical remodeling and decreases the incidence of postoperative atrial fibrillation. Circ Res 2001; 89:32-38. 



\section{L-type $\mathrm{Ca}^{2+}$ Channels in Atrial Fibrillation: Wallflowers or a Vanishing Act}

\section{Editorial}

Timothy J Kamp, Jason D Foell

Journal of Molecular and Cellular Cardiology 2003;35:427-431 


\section{Introduction}

Atrial fibrillation (AF) is the most common arrhythmia encountered in clinical practice, and treatment strategies have proven largely inadequate. Despite the best efforts, including cardioversions and antiarrhythmic drugs, most patients ultimately end up with chronic AF. Clinical experience has demonstrated that the longer a patient remains in $\mathrm{AF}$, the more difficult it is to convert to and maintain sinus rhythm. What is happening at the tissue, cellular, and molecular level that is responsible for this stubborn arrhythmia? Fortunately, the last decade has witnessed remarkable advances in our understanding of $\mathrm{AF}$, and the $\mathrm{L}$-type $\mathrm{Ca}^{2+}$ channel has emerged as a major actor in this drama. In this issue of the Journal of Molecular and Cellular Cardiology, Schotten et al. provide potentially surprising results examining the abundance of the L-type $\mathrm{Ca}^{2+}$ channel complex in atrial samples from patients with and without AF. ${ }^{1}$ To put these results in context, the role of the L-type $\mathrm{Ca}^{2+}$ channel in the electrophysiology of $\mathrm{AF}$ will be briefly reviewed.

\section{Electrophysiology of Atrial Fibrillation and $\mathrm{Ca}^{2+}$ Channels}

The irregular and rapid atrial electrical activity of atrial fibrillation (AF) is generally considered to be due to the presence of multiple wavelets of re-entry throughout the atria as described by Moe et al. ${ }^{2}$ The ability of a tissue to support re-entrant circuits is critically dependent on a number of factors including the volume of tissue, effective refractory period, conduction velocity, and electrical heterogeneity. Furthermore, the electrical properties of the heart can evolve as a result of an arrhythmia, and in the case of $\mathrm{AF}$, a significant decrease in atrial effective refractory period has been identified. ${ }^{3.4}$ The shortening of the atrial effective refractory period strongly favors re-entry and persistence of $\mathrm{AF}$. At the cellular level, a reduction in atrial action potential duration underlies this electrical remodeling. Shorter action potentials can be due to any number of changes in ionic currents, but studies in animal models of AF as well as in human atrial myocytes from AF patients have all pointed to a clear reduction in the density of currents through L-type $\mathrm{Ca}^{2+}$ channels $\left(\mathrm{I}_{\mathrm{Ca}, \mathrm{L}}\right)$ as the major factor. ${ }^{5.9}$ In addition, the reduction in associated $\mathrm{Ca}^{2+}$ influx also contributes to the impaired mechanical response of the fibrillating atria. Therefore, there is substantial interest in understanding this reduction of $\mathrm{I}_{\mathrm{Ca} . \mathrm{L}}$ and for considering this as a potential target for therapy.

The reduction in $\mathrm{I}_{\mathrm{C} \text { a. }}$ could be due to changes in the number of channels or the properties of the existing channels because whole-cell $\mathrm{I}_{\mathrm{Ca} . \mathrm{L}}$ is determined by the number of functional channels $(\mathrm{N})$, the probability of a channel being open $\left(\mathrm{P}_{\mathrm{o}}\right)$, and the current through a single-open channel (i) as described by the simple relationship: $\mathrm{I}_{\mathrm{Ca}, \mathrm{L}}=\mathrm{N} \times \mathrm{P}_{o}$ $\mathrm{x} \mathrm{i}$. The challenge for investigators in the field is to determine which of these parameters are changed. Have the $\mathrm{Ca}^{2+}$ channels in the fibrillating atria become more reticent wallflowers less likely to open or have some of their numbers simply vanished? Schotten et al.' take aim at determining whether the number of L-type $\mathrm{Ca}^{2+}$ channels is reduced in patients with AF using a combination of western blot analysis of $\mathrm{Ca}^{2+}$ channel subunits and radioligand binding. Their results suggest that there is no change in L-type $\mathrm{Ca}^{2+}$ channel density in persistent $\mathrm{AF}$ patients. However, these results are in apparent conflict with other published results showing decreased $\mathrm{L}$-type $\mathrm{Ca}^{2+}$ channel 
subunits and decreased $\mathrm{I}_{\mathrm{Ca}, \mathrm{L}}$. The seemingly simple question of whether there are fewer $\mathrm{L}$-type $\mathrm{Ca}^{2+}$ channels in $\mathrm{AF}$ is proving less simple to answer.

\section{Changes in Density of $\mathrm{Ca}^{2+}$ Channels in AF?}

Measuring the density of ion channels (number of channels per surface membrane area) can be done by a number of different electrophysiological and biochemical techniques, each with its own limitations. The study by Schotten et al. ${ }^{\prime}$ used both radioligand binding with ${ }^{3} \mathrm{H}-\mathrm{PN} 2 \mathrm{OO}-110$, a ligand specific for L-type $\mathrm{Ca}^{2+}$ channels, and quantitative western blotting with antibodies specific for $\mathrm{Ca}^{2+}$ channel subunits. These investigators obtained multiple samples of human right atrial appendage at the time of coronary artery bypass surgery or mitral valve surgery comparing patients in chronic AF with those in normal sinus rhythm. The ${ }^{3} \mathrm{H}$-PN2OO-110-binding capacity per milligram protein and the density of $\mathrm{a}_{1 \mathrm{C}}\left(\mathrm{Ca}_{v} 1.2\right)$ and $\mathrm{Ca}_{v} \beta_{2}$ subunits were not significantly different in sinus rhythm and chronic AF patients. These results argue strongly that in this study the pore-forming and dihydropyridine-binding subunit of the L-type $\mathrm{Ca}^{2+}$ channel, $\mathrm{Ca}_{v} 1.2$, is not reduced in these patient populations with $\mathrm{AF}$. However, the results initially seem to fly in the face of published literature suggesting a decrease in Ltype $\mathrm{Ca}^{2+}$ channel density that in part contributes to the reduction of $\mathrm{I}_{\mathrm{Ca}, \mathrm{L}}$.

How can the results of Schotten et al. be reconciled with previous studies suggesting a decrease in L-type $\mathrm{Ca}^{2+}$ channels and their $\mathrm{Ca}_{v} 1.2$ subunit? Several of the previous studies have demonstrated reduced mRNA levels for the $\mathrm{Ca}_{v} 1.2$ subunit, ${ }^{10-12}$ but mRNA levels may not necessarily correlate with protein expression. The clearest conflict is with the data of Brundel et al. ${ }^{13}$ which also studied patient samples obtained the time of heart surgery and demonstrated a $48-65 \%$ decrease in $\mathrm{Ca}_{v} 1.2$ protein levels in the setting of AF. It is difficult to reconcile these two studies as relatively similar patient populations were investigated. Technical differences may have contributed to the disparate results as one study used slot blots and the other used western blots to quantify protein expression of $\mathrm{Ca}_{\mathrm{v}} 1.2$ using different antibodies. In addition, regional heterogeneity in atrial properties may contribute to the confusion because the study of Schotten et al. utilized only right atrial appendages, while Brundel et al. utilized both right and left atrial appendages for measurements. ${ }^{14}$ The Schotten et al. data are also different from similar studies done using a canine rapid atrial pacing model of AF which showed clear decreases in both $\mathrm{Ca}_{4} 1.2$ subunit protein expression and ${ }^{3} \mathrm{H}-\mathrm{PN} 200-110$ binding density. ${ }^{12.15}$ Perhaps, these differences can be attributed to differences in the duration of $\mathrm{AF}$ as well as differences in tissues studied as Brundel et al. have pointed out that the changes in L-type $\mathrm{Ca}^{2+}$ currents and channel abundance seem to occur much more slowly over time in $\mathrm{AF}$ for humans compared to animal models studied to date. ${ }^{16}$

The issue at hand is even more complicated than these studies suggest at first glance. For example, are the ${ }^{3}$ H-PN200-110-binding sites truly functional channels on the surface sarcolemma? Are these binding sites present only on the surface sarcolemma or are they present in intracellular compartments? Likewise, is the measured immunoreactivity for $\mathrm{Ca}^{2+}$ channel subunits present predominantly on surface membranes or do intracellular compartments contribute? In other words, could alterations in membrane trafficking of channels be a major mechanism in this disease process with trapped pools of intracellular channels in AF patients as has been found with some inherited ion channel diseases? ${ }^{17,18}$ 
A second challenge in counting $\mathrm{Ca}^{2+}$ channel subunits in the myocyte is to know which channel subunits to count. The $\mathrm{Ca}_{v} \mathrm{l} .2$ subunit has been presumed to be the major $\alpha_{1}$ subunit for L-type $\mathrm{Ca}^{2+}$ channels in the heart, but it is clear that at least in the mouse sinoatrial node the $\alpha_{1 \mathrm{D}}\left(\mathrm{Ca}_{\mathrm{v}} 1.3\right)$ subunit is expressed and plays a fundamental role in pacemaking activity. ${ }^{19.20}$ Could $\mathrm{Ca}_{\mathrm{v}} 1.3$ be more widely expressed in the human atria and particularly in the setting of AF? The situation gets even more complicated in the case of the auxiliary $\mathrm{Ca}_{\sqrt{ }} \beta$ subunits. The $\mathrm{Ca}^{2+}$ channel $\mathrm{Ca}_{4} \beta$ subunits have been demonstrated to be important in membrane trafficking of the channel and in regulating the gating of channels, ${ }^{21-25}$ so changes in this subunit could be a key mechanism in the electrical remodeling of AF. In the work by Schotten et al., the abundance of $\mathrm{Ca}_{1} \beta_{2}$ protein was not changed comparing sinus rhythm and $\mathrm{AF}$ patients, but remarkably in another study with human atrial samples, mRNA levels were measured for a different $\mathrm{Ca}_{v} \beta$ gene family $\left(\mathrm{Ca}_{v} \beta_{\mathrm{la}}, \mathrm{Ca}_{v} \beta_{\mathrm{Ib}}, \mathrm{Ca}_{\sqrt{v}} \beta_{\mathrm{lc}}\right)$ in which a significant decrease in $\mathrm{Ca}_{v} \beta_{\mathrm{Ib}} \mathrm{mRNA}$ was detected. ${ }^{26}$ Are there even more $\mathrm{Ca}, \beta$ subunit isoforms $\left(\mathrm{Ca}_{4} \beta_{3}\right.$ or $\mathrm{Ca}_{\sqrt{v}} \beta_{4}$ genes $)$ expressed in the human atria? A variety of different $\mathrm{Ca}_{2} \beta$ subunits isoforms have been detected in the ventricle with likely species variability, ${ }^{27}$ but we are unaware of any published reports systematically determining the $\mathrm{Ca}^{2+}$ channel $\mathrm{Ca}_{v} \beta$ subunits expressed in atria. The $C a_{v} \alpha_{2} \delta_{1}$ subunit can also play a role in trafficking the $\mathrm{Ca}_{v} 1.2$ to the surface membrane, ${ }^{28}$ and at least one study has found the mRNA level for $\mathrm{Ca}_{2} \alpha_{2} \delta_{1}$ decreased in $\mathrm{AF}^{26}$ Finally, the most recently appreciated cardiac $\mathrm{Ca}^{2+}$ channel subunits are the auxiliary $\gamma$ subunits. ${ }^{29}$ Are they expressed in the atria or altered in AF? Each of these $\mathrm{Ca}^{2+}$ channel subunit genes can also be expressed as a variety of different splice variants, so much work is needed to truly understand changes in calcium channel expression in AF.

\section{Changes in Function of L-type $\mathrm{Ca}^{2+}$ Channels in AF?}

While investigations using the patch-clamp technique agree that $\mathrm{I}_{\mathrm{Ca}, \mathrm{L}}$ is substantially reduced in amplitude in AF myocytes, no major differences in the properties of the currents have commonly been detected. For example, the voltage dependence of activation and inactivation $\mathrm{I}_{\mathrm{Ca}, \mathrm{L}}$ are unchanged. Likewise, current decay rates using $\mathrm{Ca}^{2+}$ as the charge carrier were unchanged and recovery times from inactivation were not different except in one study where a delay in recovery from inactivation was detected. ${ }^{7}$ The similar electrophysiological properties of the whole-cell currents could lead one to suspect that there are just fewer channels whose function remains comparable. However, when investigators have probed further examining the regulation of the channels, new clues have emerged.

Regulation of $\mathrm{I}_{\mathrm{Ca}, \mathrm{L}}$ in normal atrial myocytes shows important differences compared to the more extensively characterized regulation in ventricular myocytes. For example, the $\beta$-adrenergic-mediated increases in the second messenger cAMP via PKA stimulates $\mathrm{I}_{\mathrm{Ca}, \mathrm{L}}$ in most cardiac preparations studied; ${ }^{30}$ however, the regulation of basal cAMP levels can be markedly different in atrial compared to ventricular myocytes. ${ }^{31,32}$ In human atrial myocytes, cGMP acting predominately by cGMP-inhibited phosphodiesterase (PDE3) strongly impacts basal cAMP levels and hence regulation of the L-type $\mathrm{Ca}^{2+}$ channels, but such regulation has not been seen in ventricular myocytes. ${ }^{31.32}$ Furthermore, in disease states, such as heart failure, the relative effect of $\beta$-adrenergic stimulation on atrial $\mathrm{I}_{\mathrm{Ca}, \mathrm{L}}$ is increased in failing compared to nonfailing 
atrial myocytes in stark contrast to the blunted $\beta$-adrenergic stimulation of $\mathrm{I}_{\mathrm{Ca}, \mathrm{L}}$ in failing ventricular myocytes. ${ }^{30,33}$ In the case of $\mathrm{AF}$, the response of $\mathrm{I}_{\mathrm{Ca}, \mathrm{L}}$ to saturating concentrations of a $\beta$-adrenergic agonist, isoproterenol, is enhanced with AF myocytes showing a 5.2-fold increase in $\mathrm{I}_{\mathrm{Ca}, \mathrm{L}}$ compared to a 3.5 -fold increase in sinus rhythm myocytes. ${ }^{6.8}$ While the isoproterenol stimulated AF currents did not reach the level of the isoproterenol-stimulated sinus rhythm currents, the results clearly suggest that more than just a decrease in the number of channels is responsible for the decreased $\mathrm{I}_{\mathrm{Ca}, \mathrm{L}}$ in AF. Altered basal regulation of the channels activity seems likely based on these results and those using the $\mathrm{Ca}^{2+}$ channel activator, Bay K8644, which also caused a greater potentiation of $\mathrm{I}_{\mathrm{Ca}, \mathrm{L}}$ in AF myocytes.

Another potentially important second messenger system impacting the L-type $\mathrm{Ca}^{2+}$ channel in $\mathrm{AF}$ is intracellular $\left[\mathrm{Ca}^{2+}\right]$. A popular hypothesis for the changes in atrial electrical and mechanical properties after the initiation of AF is that more frequent action potentials result in " $\mathrm{Ca}^{2+}$ overload" which triggers a variety of regulatory effects. Most of the data supporting this hypothesis have come from indirect studies utilizing $\mathrm{Ca}^{2+}$-channel-blocking drugs to blunt the electrical and mechanical remodeling, ${ }^{34-36}$ but at least one study has directly examined $\mathrm{Ca}^{2+}$ transients and found evidence for changes in $\mathrm{Ca}^{2+}$ cycling after rapid pacing. ${ }^{37}$ Some have viewed the downregulation of $\mathrm{I}_{\mathrm{Ca} . \mathrm{L}}$ as a protective mechanism that the cell invokes to limit further $\mathrm{Ca}^{2+}$ overload during $\mathrm{AF}$. Recently, a whole-cell patch-clamp study has unmasked a role of intracellular $\left[\mathrm{Ca}^{2+}\right]$ in the altered regulation of $\mathrm{I}_{\mathrm{Ca}, \mathrm{L}}$ in the setting of $\mathrm{AF}$. ${ }^{9}$ Yagi et al. demonstrated in a canine rapid atrial pacing model that dogs, which have nonsustained or brief episodes of AF following pacing, the reduction in $\mathrm{I}_{\mathrm{Ca}, \mathrm{L}}$ observed under patch-clamp condition with moderate $\mathrm{Ca}^{2+}$ buffering using EGTA is eliminated by stronger buffering of intracellular $\left[\mathrm{Ca}^{2+}\right]$ with BAPTA. In contrast, in the dogs that developed chronic AF, the reduction in $\mathrm{I}_{\mathrm{Ca}, \mathrm{L}}$ was not sensitive to BAPTA. ${ }^{9}$ Thus, there appears to be a role for intracellular $\left[\mathrm{Ca}^{2+}\right]$ directly regulating $\mathrm{I}_{\mathrm{Ca}, \mathrm{L}}$ in early or paroxysmal $\mathrm{AF}$, but in the more chronic setting, other mechanisms may predominate. The mechanism of this reversible downregulation of $\mathrm{I}_{\mathrm{Ca}, \mathrm{L}}$ has not yet been uncovered, but it may be related to regulation by calmodulin $(\mathrm{CaM})$ or related $\mathrm{Ca}^{2+} / \mathrm{CaM}$ kinases. Another potential mediator of the $\mathrm{Ca}^{2+}$-regulated changes in AF could be the activation of calpains, a family of $\mathrm{Ca}^{2+}$. activated proteases, which show greater abundance and activity in fibrillating atria. ${ }^{16}$ Interestingly, the L-type $\mathrm{Ca}^{2+}$ channel has been suggested to be a substrate for this protease. $^{38,39}$

$\mathrm{Ca}^{2+}$ overload in AF has also been recently implicated to regulate atrial function by increasing oxidative stress. ${ }^{40}$ Changes in redox state with free radical formation can impact many cellular processes, and the carboxy-terminus of the $\mathrm{Ca}_{\mathrm{v}} \mathrm{I} .2$ subunit of the Ltype $\mathrm{Ca}^{2+}$ channel is a known site for redox modulation. ${ }^{41,42}$ Thus, multiple regulatory pathways may ultimately impact on the $\mathrm{L}$-type $\mathrm{Ca}^{2+}$ channel to control its function and expression. Other regulatory pathways, such as the renin-angiotensin and endothelin systems, are also likely to impact $\mathrm{Ca}^{2+}$ channels during $\mathrm{AF}$, but little is known about the regulation of $\mathrm{I}_{\mathrm{Ca}, \mathrm{L}}$ by these pathways specifically in atrial myocytes.

\section{Where to go from here?}

There is little doubt that the L-type $\mathrm{Ca}^{2+}$ channel can play a key role in the initiation and persistence of $\mathrm{AF}$. Decreased $\mathrm{I}_{\mathrm{C} a \mathrm{~L}}$ has been reproducibly observed in atrial myocytes in 
the setting of AF in both animal models and human atrial samples. However, the molecular changes occurring at the level of the L-type $\mathrm{Ca}^{2+}$ channel are far less clear as the current publication of Schotten et al. indicates. Overall, there is evidence for both changes in function of channels as well as a reduction in the number of channels; however, which of these factors predominate depends on a number of things including the duration of AF, the associated cardiac conditions, and the species or model studied. One can speculate that early in the course of AF altered function of the L-type $\mathrm{Ca}^{2+}$ channels primarily accounts for decreased $\mathrm{I}_{\mathrm{Ca}, \mathrm{L}}$ while at longer time points reductions in channel density become a major factor possibly due to changes in gene expression.

Do we need to know more about how and when $\mathrm{Ca}^{2+}$ channels become wallflowers or vanish in AF? Given our current lack of therapeutic success, it may be well to understand the atrial-specific regulatory pathways impacting L-type $\mathrm{Ca}^{2+}$ channels. The use of $\mathrm{Ca}^{2+}$ channel blockers to inhibit electrical remodeling and prevent recurrences of $\mathrm{AF}$ has met with limited success thus far. ${ }^{43}$ Thus, new insights may provide novel targets for intervention in hopes of preventing this arrhythmia from becoming a constant companion for patients. Further biochemical, molecular biological, and immunocytochemical studies are needed to clarify the subunits composing the L-type $\mathrm{Ca}^{2+}$ channel in the atria and any significant changes in that subunit expression pattern or altered posttranslational modification in AF. Additional cellular electrophysiology studies focusing on regulation of the channel including single-channel techniques to more precisely probe for changes in gating or conductance may be revealing. Determining the density of channels in the membrane could be done measuring charge movement associated with gating of the channels. ${ }^{44}$ But alas, $\mathrm{AF}$ is not so simple as to only involve alterations in L-type $\mathrm{Ca}^{2+}$ channels, and a myriad of other changes occur as the atria undergoes electrical and structural remodeling. ${ }^{45}$ So despite the most remarkable decade of advances in understanding AF, there remains much to learn.

\section{$\underline{\text { References }}$}

I. Schotten U, Haase H, Frechen D, Greiser M, Stellbrink C, Vazquez-Jimenez FF, et al. The L-type Ca ${ }^{2 *}$ channel subunits $\alpha_{1 c}$ and $\beta_{2}$ are not downregulated in atrial myocardium of patients with chronic atrial fibrillation. J Mol Cell Cardiol 2003;35:437-443.

2. Moe OK, Rheinboldt WC, Abildskov JA. A computer model of atrial fibrillation. Am Heart J 1964:67:200-220.

3. Wijffels MC, Kirchhof CJ, Dorland R, Allessie MA. Atrial fibrillation begets atrial fibrillation. A study in awake chronically instrumented goats. Circulation 1995;92:1954-1968.

4. Morillo CA. Klein GJ, Jones DL, Guiraudon CM. Chronic rapid atrial pacing. Structural, functional, and electrophysiological characteristics of a new model of sustained atrial fibrillation. Circulation 1995;91:1588-1595.

5. Yue L. Feng J. Gaspo R, Li GR, Wang Z, Nattel S. Ionic remodeling underlying action potential changes in a canine model of atrial fibrillation. Circ Res 1997:81:512-25.

6. Van Wagoner DR, Pond AL, Lamorgese M, Rossie SS, McCarthy PM, Nerbonne JM. Atrial L-type $\mathrm{Ca}^{2+}$ currents and human atrial fibrillation. Circ Res 1999;85:428-36.

7. Bosch RF. Zeng X. Grammer JB, Popovic K. Mewis C, Kuhlkamp V. Ionic mechanisms of electrical remodeling in human atrial fibrillation. Cardiovasc Res 1999;44:121-131.

8. Skasa M. Jungling E. Picht E, Schondube F. Luckhoff A. L-type calcium currents in atrial myocytes from patients with persistent and non-persistent atrial fibrillation. Basic Res Cardiol 2001; 96:151-159.

9. Yagi T, Pu J, Chandra P. Hara M, Danilo JrP, Rosen MR, et al. Density and function of inward currents in right atrial cells from chronically fibrillating canine atria. Cardiovase Res 2002;54:405-415.

10. Van Gelder IC, Brundel BJ, Henning RH, Tuinenburg AE, Tieleman RG, Deelman L, et al. Alterations in gene expression of proteins involved in the calcium handling in patients with atrial fibrillation. $J$ 
Cardiovasc Electrophysiol 1999:10:552-560.

11. Lai LP, Su MJ, Lin JL, Lin FY, Tsai CH, Chen YS, et al. Down-regulation of L-type calcium channel and sarcoplasmic reticular $\mathrm{Ca}^{2}$-ATPase mRNA in human atrial fibrillation without significant change in the mRNA of ryanodine receptor; calsequestrin and phospholamban: an insight into the mechanism of atrial electrical remodeling. J Am Coll Cardiol 1999;33:1231-1237.

12. Yue L, Melnyk P, Gaspo R, Wang Z, Nattel S. Molecular mechanisms underlying ionic remodeling in a dog model of atrial fibrillation. Circulation 1999:84:776-784.

13. Brundel BJ, Van Gelder IC, Henning RH, Tieleman RG, Tuinenburg AE, Wietses M, et al. Ion channel remodeling is related to intraoperative atrial effective refractory periods in patients with paroxysmal and persistent atrial fibrillation. Circulation 2001:103:684-690.

14. Spach MS, Dolber PC, AndersonAW. Multiple regional differences in cellular properties that regulate repolarization and contraction in the right atrium of adult and newborn dogs. Circ Res 1989;65:15941561 .

15. Gaspo R, Sun H, Fareh S, Levi M, Yue L, Allen BG, et al. Dihydropyridine and beta adrenergic receptor binding in dogs with tachycardia-induced atrial fibrillation. Cardiovase Res 1999; 42:434-442.

16. Brundel BJ, Henning RH, Kampinga HH, Van Gelder IC, Crijns HJ. Molecular mechanisms of remodeling in human atrial fibrillation. Cardiovasc Res 2002;54:315-324.

17. Cheng SH, Gregory U, Marshall J, Paul S, Souza DW, White GA, et al. Defective intracellular transport and processing of CFTR is the molecular basis of most cystic fibrosis. Cell 1990;63:827-834.

18. Zhou Z, Gong Q, Epstein ML, January CT. HERG channel dysfunction in human long QT syndrome. Intracellular transport and functional defects. J Biol Chem 1998;273:21061-21066.

19. Zhang $\mathrm{Z}, \mathrm{Xu} \mathrm{Y}$ Song $\mathrm{H}$, Rodriguez J, Tuteja D, Nanumng $\mathrm{Y}$ et al. Functional roles of $\mathrm{Ca}(\mathrm{v}) 1.3$ (alpha(ID)) calcium channel in sinoatrial nodes: insight gained using gene-targeted null mutant mice. Circ Res 2002;90:981-987.

20. Bohn G, Moosmang S, Conrad H, Ludwig A, Hofinann F, Klugbauer N. Expression of T- and L-type calcium channel mRNA in murine sinoatrial node. FEBS Lett 2000;481:73-77.

21. Chien Al, Zhao X, Shirokov RE, Purl TS, Chang CF, Sun D, et al. Roles of a membrane-localized Bsubunit in the formation and targeting of functional L-type $\mathrm{Ca}^{2+}$ channels. J Biol Chem 1995;270:30036-30044.

22. Kamp TJ, Perez-Garcia MT, Marban E. Enhancement of ionic current and charge movement by coexpression of calcium channel $\beta_{1 \mathrm{I}}$ with $\alpha_{\mathrm{IC}}$ in ahuman embryonic kidney cell line. J Physiol 1996;492:89-96.

23. Neely A, Wei X, Olcese R, Bimbaumer L, Stefani E. Potentiation by the beta subunit of the ratio of the ionic current to the charge movement in the cardiac calcium channel. Science 1993; 262:575-578.

24. Praguell M. DeWaard M, Mori Y. Tanabe T, Snutch TP. Campbell KP. Calcium channel beta-subunit binds to a conserved motif in the I-Il cytoplasmic linker of the alpha 1-subunit. Nature 1994:368:67-70.

25. Singer D, Biel M, Lotan I. Flockerzi V, Hofinann F, Dascal N. The roles of the subunits in the function of the calcium channel. Science 1991;253:1553-1557.

26. Grammer JB, Zeng X. Bosch RF, Kuhlkamp V. Atrial L-type Ca ${ }^{2+}$-channel, beta-adrenorecptor, and 5hydroxytryptamine type 4 receptor mRNAs in human atrial fibrillation. Basic Res Cardiol 2001;96:8290.

27. Bimbaumer L. Qin N, Olcese R, Tareilus E. Platano D, Costantin J, et al. Structures and functions of calcium channel $\beta$-subunits. J Bioenergetic 1998;30:357-375.

28. Bangalore R, Mehrke G, Gingrich K. Hofinann F; Kass RS. Influence of L-type Ca channel $\alpha_{2} \delta$ subunit on ionic and gating current in transiently transfected HE293 cells. Am J Physiol 1996;39:H1521-1528.

29. Klugbauer N, Dai S. Specht V Lacinova L, Marais E, Bohn G, et al. A family of $\gamma$-like calcium channel subunits. FEBS Lets 2000:470:189-198.

30. Kainp TJ, Hell JW. Regulation of cardiac L-type calcium channels by protein kinase A and protein kinase C. Circ Res 2000:87:1095-1102.

31. Rivet-Bastide M, Vandecasteele G. Hatem S, Verde I, Benardeau A, Mercadier JJ, et al. cGMPstimulated cyclic nucleotide phosphodiesterase regulates the basal calcium current in human atrial myocytes. J Clin Invest 1997:99:2710-2718.

32. Vandecasteele G, Verde I. Rucker-Martin C, Donzeau-Gouge P. Fischmeister R. Cyclic GMP regulation of the L-type Ca"* channel current in human atrial myocytes. J Physiol 2001;533:329-340.

33. Boixel C, Gonzalez W, Louedec L. Hatem SN. Mechanisms of L-type $\mathrm{Ca}^{2+}$ current downregulation in rat atrial myocytes during heart failure. Circ Res 2001:89:607-613.

34. Daoud EG, Knight BP Weiss R. Bahu M, Paladino W, Goyal R, et al. Effect of verapamil and procainamide on atrial fibrillation-induced electrical remodeling in humans. Circulation 1997:96:15421550.

35. Tieleman RG, De Langen C, Van Gelder IC, De Kam PJ, Grandjean J, Bel KI, et al. Verapamil reduces tachycardia-induced electrical remodeling of the atria. Circulation 1997:95:1945-1953.

36. Leistad E, Aksnes G, Verburg E, Christensen G. Atrial contractile dysfimction after short-term atrial 


\section{Chapter 4}

fibrillation is reduced by verapamil but increased by BAY K8644. Circulation 1996;93:1747-1754

37. Sun H, Chartier D, Leblanc N, Nattel S. Intracellular calcium changes and tachycardia-induced contractile dysfunction in canine atrial myocytes. Cardiovase Res 2001;49:751-761.

38. Belles B, Hescheler J, Trautwein W, Blomgren K, Karlsson JO. A possible physiological role of the Ca-dependent protease calpain and its inhibitor calpastatin on the Ca current in guinea pig myocytes. Pflugers Arch 1988;412:554-556.

39. De Jongh KS, Colvin AA, Wang KK, Catterall WA. Differential proteolysis of the full-length form of the L-type calcium channel alpha 1 subunit by calpain. J Neurochem 1994;63:1558-1564 .

40. Carnes CA, Chung MK, Nakayama T, Nakayama H, Baliga RS, Piao S, et al. Ascorbate attenuates atrial pacing-induced peroxynitrite formation and electrical remodeling and decreases the incidence of postoperative atrial fibrillation. Circ Res 2001;89:E32-38.

41. Fearon IM, Palmer ACV Balmforth Al, Ball SG, Varadi G, Peers C. Modulation of recombinant human cardiac L-type $\alpha_{1 C}$ subunits by redox agents and hypoxia. J Physiol 1999;514:629-637.

42. Fearon IM, Issacsohn I, Koch S, Varadi G, Ball SG, Peers C. Splice variants reveal the region involved in oxygen sensing by recombinant human cardiac L-type Ca ${ }^{2+}$ channels. Circ Res 2000:87:537-539.

43. Van Noord T, Van Gelder IC, Tieleman RG, Bosker HA, Tuinenburg AE, Volkers C, et al. VERDICT: the verapamil versus digoxin cardioversion trial: a randomized study on the role of calcium lowering for maintenance of sinus rhythm after cardioversion of persistent atrial fibrillation. J Cardiovasc Electrophysiol 2001;12:766-769.

44. He J, Conklin MW, Foell JD, Wolff MR, Haworth RA, Coronado R, et al. Reduction in density of transverse tubules and $\mathrm{L}$-type $\mathrm{Ca}^{2+}$ channels in canine tachycardia-induced heart failure. Cardiovasc Res 2001;49:298-307.

45. Allessie M, Ausma J, Schotten U. Electrical, contractile and structural remodeling during atrial fibrillation. Cardiovasc Res 2002;54:230-246. 


\section{Chapter 5}

\section{Electrical and Contractile Remodeling during the First Days of Atrial Fibrillation go Hand-in-Hand}

Ulrich Schotten, Mattias Duytschaever, Jannie Ausma, Sabine Eijsbouts, Hans-Ruprecht Neuberger, Maurits Allessie 


\section{Abstract}

\section{Background}

The mechanisms of the atrial contractile dysfunction induced by atrial fibrillation (AF) are not completely understood. Particularly, the relation between the atrial dysfunction and electrical remodeling has not been studied yet.

\section{Methods}

Seven goats were chronically instrumented with electrodes sutured to the atria and with ultrasonic piezoelectric crystals to record the atrial diameters. A pressure transducer was implanted in the right atrium. After $5 \mathrm{~min}, 3 \mathrm{~h}$, and throughout the first 5 days of artificially maintained AF atrial contractile function was measured and the atrial effective refractory period (AERP) was monitored for comparison. Also, the positive inotropic effects of the L-type $\mathrm{Ca}^{2+}$-channel agonist BayY5959 and short trains of rapid atrial pacing were studied. After resumption of sinus rhythm the recovery of atrial contractile function was followed.

\section{Results}

After $5 \mathrm{~min}$ of AF atrial contractility was decreased by $\sim 55 \%$ but recovered completely within $10 \mathrm{~min}$. Five days of AF nearly completely abolished the atrial contractile function and recovery took 2 days. During the first days of AF the development of the contractile dysfunction followed the same time course as the shortening of AERP (electrical remodeling). In remodeled atria BayY5959 increased atrial contractility to the same extent as it prolonged AERP. The inotropic effect of short trains of rapid atrial pacing was similar in normal and remodeled atria.

\section{Conclusion}

Depending on the duration of AF different mechanisms contribute to the AF-induced atrial hypocontractility. Atrial contractile remodeling during several days of AF goes hand-in-hand with electrical remodeling and might be caused by a reduction of the Ltype $\mathrm{Ca}^{2+}$-current.

\section{$\underline{\text { Introduction }}$}

An important clinical implication of the loss of synchronized atrial contractions during atrial fibrillation (AF) is the high risk of thrombus formation and stroke. The atrial emptying function is not only impaired during AF but also after the cardioversion to sinus rhythm (SR). The degree of atrial contractile dysfunction and the time required for recovery depend on the duration of $\mathrm{AF}$. ${ }^{1}$ During the first days to weeks after cardioversion to SR new thrombus formation has been demonstrated to contribute to the thromboembolic risk associated with $\mathrm{AF}^{2}$

Experimental and clinical studies have shown that brief episodes of AF may already cause a significant impairment of atrial contractility. ${ }^{3-5}$ The loss of atrial function is thought to be triggered by $\mathrm{Ca}^{2+}$-overload during $\mathrm{AF}$ and might be mediated by a decrease in the release of $\mathrm{Ca}^{2+}$ from the sarcoplasmic reticulum. ${ }^{6}$ However, these studies focused on relatively short episodes (several minutes to hours) of AF or rapid atrial 
pacing. Less is known about the effect of prolonged AF on atrial contractile function. Neither the exact time course of the atrial contractile dysfunction nor the relation with electrical remodeling - caused by a downregulation of the L-type Ca ${ }^{2+}$-current $\left(\mathrm{I}_{\mathrm{CaL}}\right)^{7}-$ has been elucidated yet.

In the present study we used the goat model of persistent $\mathrm{AF}^{8}$ to test the hypothesis that electrical and contractile remodeling are closely related. The AF-induced changes in atrial contractility were compared with changes in electrophysiological properties of the atrium.

\section{$\underline{\text { Methods }}$}

\section{Animal Model}

In 7 goats (45 to $61 \mathrm{~kg}$ ) a left intercostal thoracotomy was made during general anesthesia. Five silicon patches each containing 4 silver electrodes $(\varnothing=2 \mathrm{~mm})$ were sutured to the upper and lower free wall of the right and left atrium and to the left ventricular apex. A pair of ultrasonic piezoelectric crystals was sutured both to the right and left atria. One crystal was placed between the aorta and the auricle and the other was fixed in the middle of the free wall of the atrium (figure 1). A tip pressure transducer was implanted transvenously in the right atrium. After recovery from surgery (2-3 weeks) AF was induced by burst pacing with an automatic fibrillation pacemaker. ${ }^{8}$ The study was performed according to the institutional guidelines and was approved by the local ethical committee.
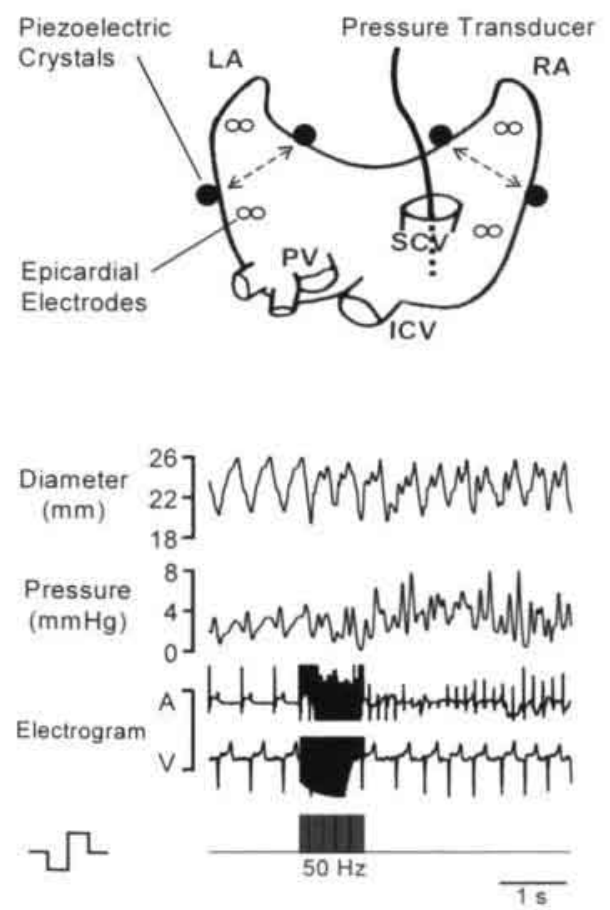

Figure 1

Above: Chronic instrumentation: Piezoelectric crystals were sutured to the atrial epicardium. Right atrial pressure was measured with $a$ an implantable pressure transducer. $L A=l$ eft atrium, $R A=$ right atrium, $S C V=$ superior caval vein, $I C V=$ inferior caval vein.

Below: Simultaneous recording of the right atrial diameter and pressure. $A F$ was induced by burst stimulation of the atria as previously described. 


\section{Study Protocol}

Before the induction of AF baseline electrophysiological and contractile properties of both atria were measured. In three consecutive protocols the effects of $5 \mathrm{~min}, 3 \mathrm{~h}$, and 5 days of AF were studied. After spontaneous cardioversion of $5 \mathrm{~min}$ of AF the atria were paced at $400 \mathrm{~ms}$ cycle length and the atrial effective refractory period (AERP) and atrial contractility were monitored during $30 \mathrm{~min}$. After $3 \mathrm{~h}$ of AF the atrial contractility and AERP were monitored during the subsequent $48 \mathrm{~h}$. During the 5 days protocol, the maintenance of AF was interrupted after 6, 12 and 24 hours as well as after 2, 3, 4 and 5 days of AF. During the first $30 \mathrm{~min}$ after termination of AF the atrial contractile function and AERP were studied at different pacing rates. After 5 days of AF the recovery of the atrial contractility was studied for 5 days. To study the mechanism of the AF-induced atrial contractile dysfunction the positive inotropic effect of the L-type $\mathrm{Ca}^{2+}$-channel agonist BayY5959 was tested $(1 \mathrm{mg} / \mathrm{kg}$ during $10 \mathrm{~min}$ intravenously). This dosage produced a maximal prolongation of AERP (data not shown). The transient hypercontractility induced by a short train of rapid pacing has been demonstrated to reflect $\mathrm{Ca}^{2+}$-reuptake and storage function of the sarcoplasmic reticulum. ${ }^{9}$ Thus, we also studied the positive inotropic effect of 20 s of rapid atrial pacing.

\section{Electrophysiological and Contractile Measurements}

The AERP was measured during unipolar pacing at 4 sites (upper and lower right and left atrial free wall) by interpolating single premature stimuli at 4 times threshold. The longest coupling interval that did not result in propagated atrial response was taken as AERP.

The atrial contractility was assessed during SR and during atrial pacing at the upper right atrial wall at a cycle length of $250,300,350,400$, and $450 \mathrm{~ms}$. The distance between the pair of piezoelectric crystals on the right and left atria was measured with a commercially available sonomicrometer system (Sonometrics, London, Canada) and was taken as the atrial medio-lateral diameter. In the right atrium we also measured the atrial systolic pressure amplitude $(\Delta p)$ and the maximal pressure rise velocity $\left(\Delta p / \mathrm{dt}_{\max }\right)$ of the a-wave. The atrial systolic shortening amplitude $(\Delta D)$ was defined as the difference between the atrial diameter at the onset of the a-wave $\left(\mathrm{D}_{0}\right)$ and the minimal atrial diameter (Figure 2). ${ }^{4}$ The ratio $\Delta \mathrm{D} / \mathrm{D}_{0}$ was taken as fractional shortening. Right atrial pressure diameter loops were obtained by plotting right atrial pressure against its medio-lateral diameter. These surrogate 'pressure-volume loops' are the result of both the right atrial and ventricular contraction. The atrial part of the PV-loop (a-loop) starts at the onset of the a-wave and ends when the same atrial diameter is reached again (figure 2). The area enclosed by this part of the atrial PV-loop was taken as the atrial work index (AWI).

\section{Statistical Analysis}

Data are expressed as means \pm SD. Time constants are given with $95 \%$ confidence intervals. Statistical significance was determined with the unpaired Student's t-test or by one-way analysis of variance (ANOVA) for comparison of multiple groups. Recovery of contractile function was analyzed by nonlinear least squares regression of the data to a one or two-phase exponential association curve. $\mathrm{P}<0.05$ was considered statistically significant. 


\section{$\underline{\text { Results }}$}

\section{The Atrial Contraction Cycle}

The upper left panel of figure 2 shows the changes in right atrial diameter and pressure during an atrial contraction cycle in SR. Shortly after the atrial activation the atrial pressure increases (a-wave) and the diameter declines (atrial ejection). The onset of the ventricular contraction is marked by the closure of the tricuspid valve (c-wave). During the ventricular systole blood accumulates in the atria and atrial pressure and diameter increase ( $\mathrm{v}$-wave). During the early ventricular diastole the atria empty passively into the ventricles causing a decline in atrial pressure and diameter. Thus, the atrial 'PVloop' (upper right panel) consists of two parts. The a-loop represents the atrial contraction. The v-loop reflects passive filling and emptying of the atria during contraction and early relaxation of the ventricle.

During atrial pacing (cycle length $400 \mathrm{~ms}$ ) the atria are still filled at the onset of the atrial contraction and the $\mathrm{v}$-loop is small. Because of the high preload the resulting atrial a-wave and the atrial ejection are more pronounced than during SR. As a result, AWI (gray area) is higher than during SR.
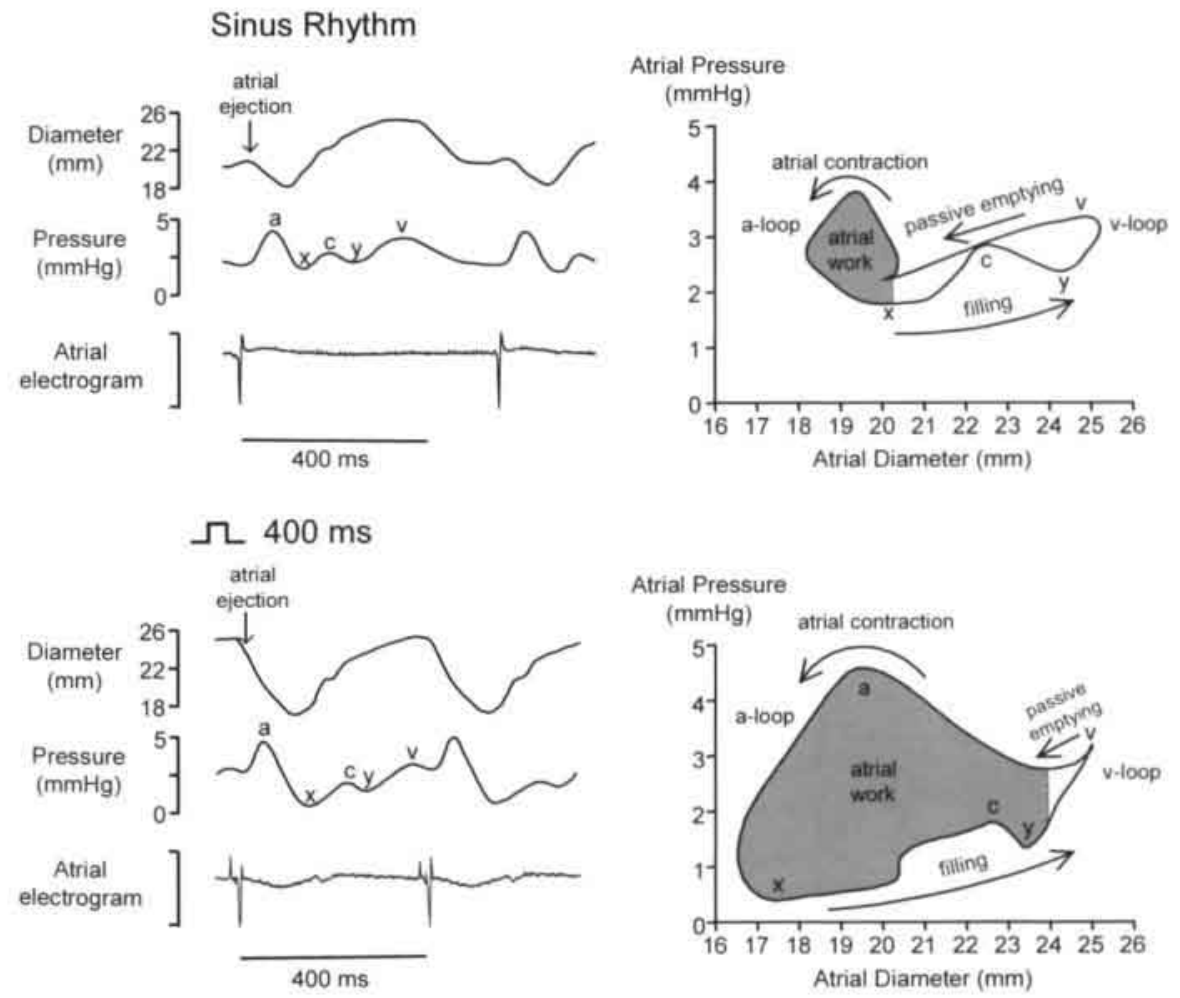

Figure 2

Right atrial diameter and pressure recordings and $P V$-loops 'during $S R$ (upper panels) and during slow atrial pacing at the upper right atrium at a cycle length of $400 \mathrm{~ms}$ (lower panels). The area enclosed by the active part of the loop (a-loop) is marked in gray and was taken as atrial work index (AWI). 


\section{Atrial Hypocontractility Induced by Short-lasting AF}

The upper panel of figure 3 shows the effect of AF on atrial contractility $15 \mathrm{~s}$ and $10 \mathrm{~min}$ after spontaneous termination of AF lasting $5 \mathrm{~min}, 3 \mathrm{~h}, 24 \mathrm{~h}$, or 5 days. In the lower panel the statistical data of the recovery of atrial contractile function during the first $30 \mathrm{~min}$ after spontaneous cardioversion are depicted. Already $5 \mathrm{~min}$ of AF significantly impaired atrial contractility. $15 \mathrm{~s}$ after spontaneous cardioversion AWI was reduced by $\sim 55 \%$. However, atrial function completely recovered within $10 \mathrm{~min}$ of SR. $15 \mathrm{~s}$ after termination of $\mathrm{AF}$ lasting for $3 \mathrm{~h}$ atrial contractility was reduced by $\sim 95 \%$. Again, during the first minutes after cardioversion AWI rapidly increased but atrial contractility only partly recovered during the first $10 \mathrm{~min}$ after cardioversion. Rather, AWI remained significantly depressed throughout the first $30 \mathrm{~min}$ post cardioversion. AF episodes of longer duration were associated with a more pronounced degree of this longer lasting atrial contractile dysfunction. Whereas after $3 \mathrm{~h}$ of AF $\sim 70 \%$ of the atrial contractility were restored during the first minutes post cardioversion, after 5 days of AF no early recovery of atrial contractile function occurred and even $30 \mathrm{~min}$ after cardioversion atrial contractility was depressed by more than $90 \%$.
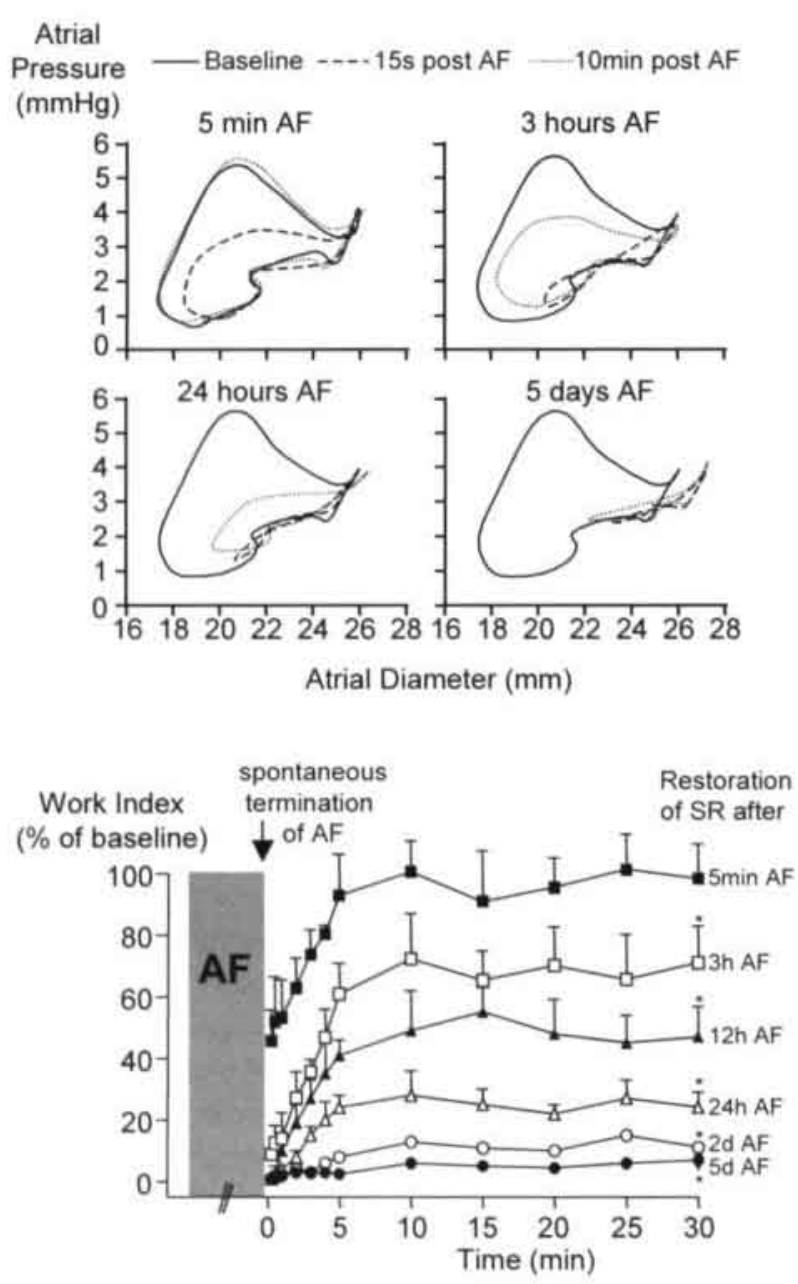

Figure 3
Early recovery of atrial contractility after spontaneous termination of $A F$.

Upper panel: Right atrial PVloops at baseline, 15s, and $10 \mathrm{~min}$ after termination of $A F$. All loops were recorded at $400 \mathrm{~ms}$ cycle length.
Lower panel: Statistical data from $n=7$ goats. $* p<0.05$ versus baseline. 


\section{Time Course of Electrical and Contractile Remodeling}

The post AF atrial contractile dysfunction was assessed during right atrial pacing (400ms) $30 \mathrm{~min}$ after spontaneous cardioversion of AF (figure 4). With increasing duration of $\mathrm{AF}$ the amplitude of the a-wave and the atrial systolic shortening progressively declined (upper left panel). At the same time the area enclosed by the right atrial PV-loop decreased (upper right panel). After 12h of AF AWI was reduced by $50 \%$ and after 2 days the loop was almost closed indicating that the atrial contractile function was nearly completely abolished.

In the lower left panel of figure 4 the time courses of the atrial contractile dysfunction and electrical remodeling (shortening of the AERP) are compared. Both during the first 5 days of AF and after resumption of SR the changes in AWI and AERP followed exactly the same time course. The AWI correlated positively with AERP ( $r=0.878$, $\mathrm{p}<0.01$ ) (lower right panel).
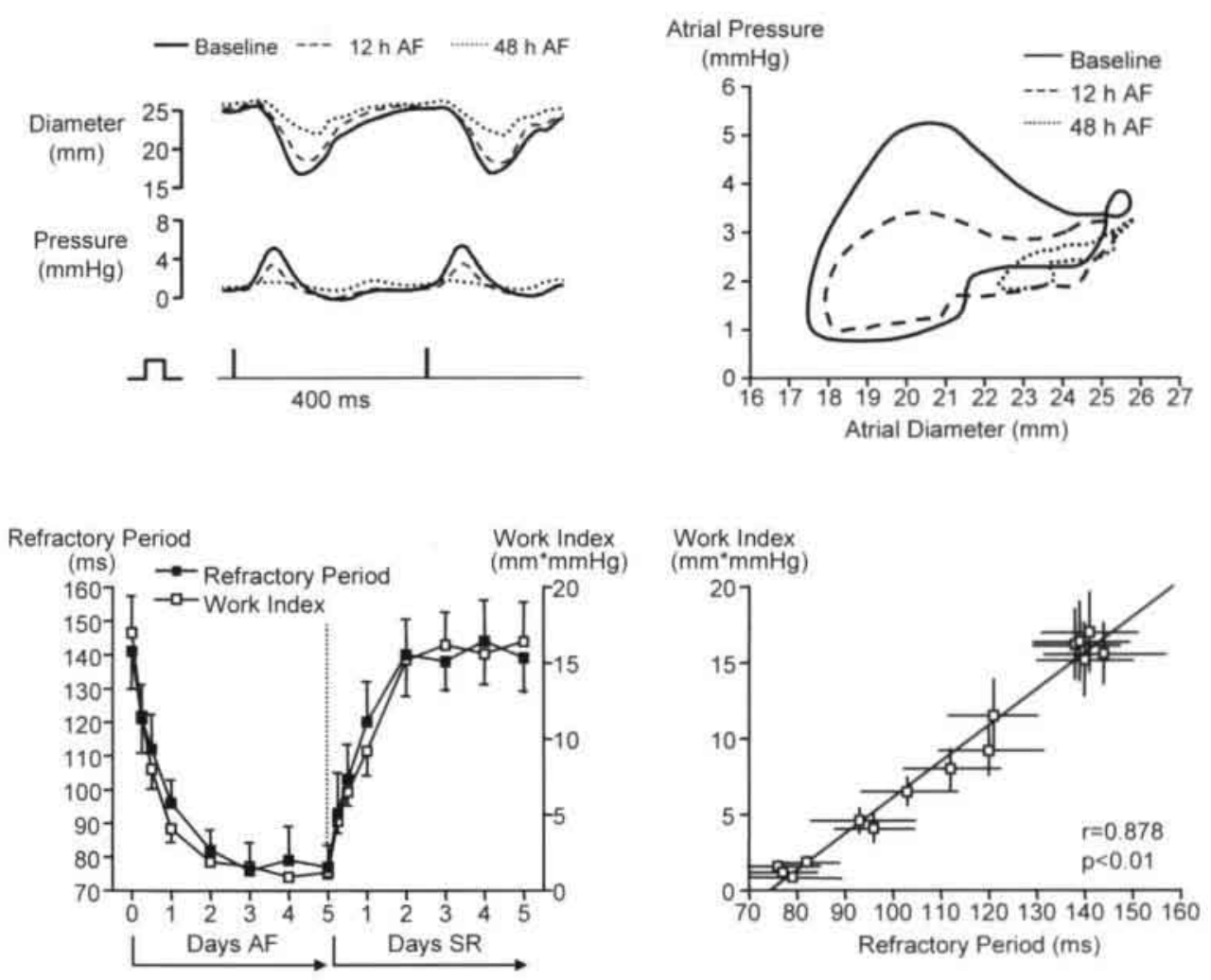

Figure 4

Time course of electrical and contractile remodeling during the first days of $A F$. Atrial contractile function and AERP were recorded $30 \mathrm{~min}$ after spontaneous cardioversion during atrial pacing at a cycle length of 400ms. Upper panels: Right atrial pressure and diameter recordings at baseline, after $12 \mathrm{~h}$ and after $48 \mathrm{~h}$ of $A F$ (left) and respective 'PV-loops' (right). Lower left panel: Time course of electrical and contractile remodeling and reversibility. Lower right panel: Correlation between right atrial work index and refractory period. $n=7$ goats. 
The tables 1 and 2 show the numerical data of electrical and contractile remodeling during 5 days of $\mathrm{AF}$ and its recovery. During the 5 days of AF right atrial $\Delta \mathrm{p}$ and $\Delta \mathrm{p} / \mathrm{dt}_{\max }$ declined to less than $5 \%$ of control. In right and in left atria the atrial fractional shortening declined to $-45 \%$ of the baseline value. Right and left atrial diameters $\left(\mathrm{D}_{0}\right)$ increased to $108.3 \pm 1.1 \%$ and $108.5 \pm 1.2 \%$ of baseline $(\mathrm{p}<0.05)$ which was reversible within 2 to 3 days of SR. Neither the time course nor the extent of contractile remodeling differed between right and left atria (figure 5, upper panels). In both atria, the fractional shortening correlated positively with the shortening of the AERP during the first days of $\mathrm{AF}$ (figure 5, lower panels).

\begin{tabular}{|c|c|c|c|c|c|c|c|}
\hline & & Baseline & Atrial Fibr & lation & & & \\
\hline & & & $6 h$ & $12 h$ & $24 h$ & 2 days & 5 days \\
\hline \multirow{2}{*}{$\begin{array}{l}A E R P \\
\text { (ms) }\end{array}$} & right & $141 \pm 12$ & $121 \pm 10^{*}$ & $112 \pm 10^{*}$ & $96 \pm 7^{*}$ & $82 \pm 6^{\circ}$ & $77 \pm 7^{*}$ \\
\hline & left & $132 \pm 19$ & $118 \pm 19$ & $105 \pm 12^{*}$ & $85 \pm 12^{*}$ & $72 \pm 13^{*}$ & $72 \pm 13^{*}$ \\
\hline $\begin{array}{l}A W I \\
\left(m m^{*} m m H g\right)\end{array}$ & right & $17.0 \pm 2.6$ & $11.5 \pm 2.4^{*}$ & $8.0 \pm 1.3^{*}$ & $4.1 \pm 0.9^{\circ}$ & $1.9 \pm 0.3^{*}$ & $1.2 \pm 0.4^{*}$ \\
\hline $\begin{array}{l}\Delta p \\
(m m H g)\end{array}$ & right & $2.5 \pm 0.4$ & $1.5 \pm 0.3^{*}$ & $1.2 \pm 0.3^{*}$ & $0.7 \pm 0.1^{\circ}$ & $0.3 \pm 0.1^{*}$ & $0.1 \pm 0.1^{*}$ \\
\hline $\begin{array}{l}4 p / d t_{\max } \\
(m m / g / s)\end{array}$ & right & $90 \pm 15$ & $60 \pm 12^{*}$ & $43 \pm 12^{*}$ & $19 \pm 8^{*}$ & $13 \pm 5^{*}$ & $0 \pm 3^{*}$ \\
\hline \multirow{2}{*}{$\begin{array}{l}A D / D_{i} \\
(\%)\end{array}$} & right & $21.4 \pm 3.5$ & $16.4 \pm 2.6^{*}$ & $16.1 \pm 2.7^{*}$ & $15.0 \pm 2.6^{*}$ & $12.4 \pm 1.9^{*}$ & $9.3 \pm 1.0^{*}$ \\
\hline & left & $24.7 \pm 2.4$ & $18.2 \pm 3.3^{*}$ & $16.2 \pm 2.8^{*}$ & $14.8 \pm 2.2^{*}$ & $13.9 \pm 2.5^{\circ}$ & $10.9 \pm 2.0^{\circ}$ \\
\hline
\end{tabular}

Table 1

Electrical and contractile remodeling in right and left atria during the first 5 days of $A F$

$* 0.05$ versus baseline.

\begin{tabular}{|c|c|c|c|c|c|c|c|}
\hline & & $5 d A F$ & Simus Rhyth & & & & \\
\hline & & & $6 h$ & $12 h$ & $24 h$ & 2 days & 5 days \\
\hline \multirow{2}{*}{$\begin{array}{l}\text { AERP } \\
\text { (ms) }\end{array}$} & right & $77 \pm 7$ & $93 \pm 12$ & $103 \pm 10^{*}$ & $120 \pm 12^{\circ}$ & $140 \pm 11^{*}$ & $139 \pm 10^{*}$ \\
\hline & left & $72 \pm 13$ & $88 \pm 18$ & $100+13^{\circ}$ & $121 \pm 15^{\circ}$ & $138 \pm 17^{*}$ & $136 \pm 15^{\circ}$ \\
\hline $\begin{array}{l}A W I \\
\left(\mathrm{~mm}^{*} \mathrm{mmHg}\right)\end{array}$ & right & $1.2 \pm 0.4$ & $4.6 \pm 0.8^{*}$ & $6.5 \pm 0.9 *$ & $9.2 \pm 1.6^{*}$ & $15.2 \pm 2.4^{*}$ & $16.4 \pm 2.6^{*}$ \\
\hline $\begin{array}{l}\Delta p \\
(m m H g)\end{array}$ & right & $0.1 \pm 0.1$ & $0.3 \pm 0.2$ & $1.1 \pm 0.3^{*}$ & $1.7 \pm 0.2^{*}$ & $2.4 \pm 0.3^{*}$ & $2.4 \pm 0.4^{\circ}$ \\
\hline $\begin{array}{l}\Delta p / d t_{\max } \\
(m m \mathrm{Hg} / \mathrm{s})\end{array}$ & right & $0 \pm 3$ & $13 \pm 9$ & $38 \pm 10^{*}$ & $67 \pm 9^{\circ}$ & $92 \pm 13^{\circ}$ & $88 \pm 14^{*}$ \\
\hline \multirow{2}{*}{$\begin{array}{l}\Delta D / D_{0} \\
(\%)\end{array}$} & right & $9.3 \pm 1.0$ & $12.8 \pm 1.2^{*}$ & $12.7 \pm 1.6^{*}$ & $17.4 \pm 2.7^{*}$ & $19.9 \pm 3.0^{*}$ & $19.7 \pm 3.0^{\circ}$ \\
\hline & left & $10.9 \pm 2.0$ & $14.6 \pm 3.6$ & $15.4 \pm 3.6$ & $20.1 \pm 2.9^{*}$ & $23.4 \pm 3.1^{*}$ & $23.2 \pm 3.2^{*}$ \\
\hline
\end{tabular}

Table 2

Reverse electrical and contractile remodeling in right and left atria afler 5 days of $A F$

* $p<0.05$ versus 5 days $A F$. 

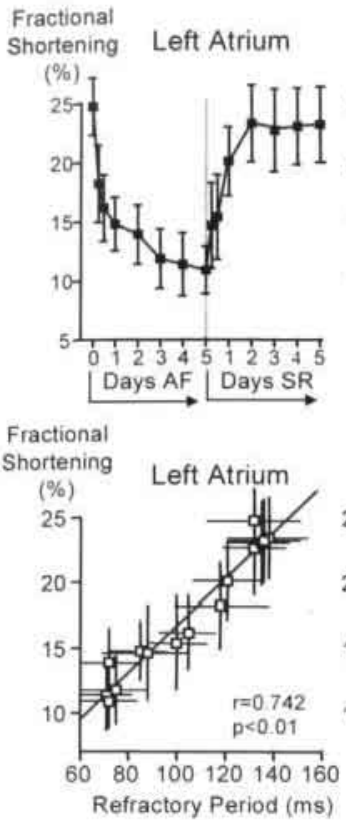

Right Atrium

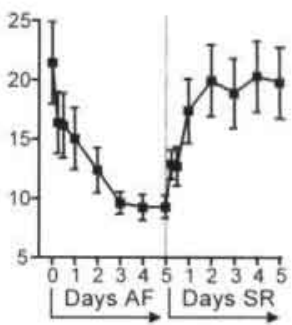

Right Atrium

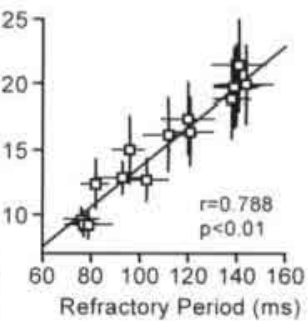

Figure 5

Above: Changes in fractional shortening of the left and the right atrium during 5 days of $A F$ and recovery. Below: Correlation between fractional shortening and refractory period. $n=7$ goats.

\section{Rate Adaptation of Atrial Contractility}

Incremental atrial pacing with a cycle length between 450 and $250 \mathrm{~ms}$ increased the size of the atrial PV loop (figure 6). At baseline AWI was $4.8 \pm 0.8 \mathrm{~mm} * \mathrm{mmHg}$ during SR and reached a maximum at a pacing interval of $300 \mathrm{~ms}(45.1 \pm 5.6 \mathrm{~mm} * \mathrm{mmHg})$. During the first days of AF the atrial contractility progressively declined at all pacing rates. However, the positive rate adaptation was preserved until, after 5 days of AF, the atrial contractility was nearly completely lost at all rates.
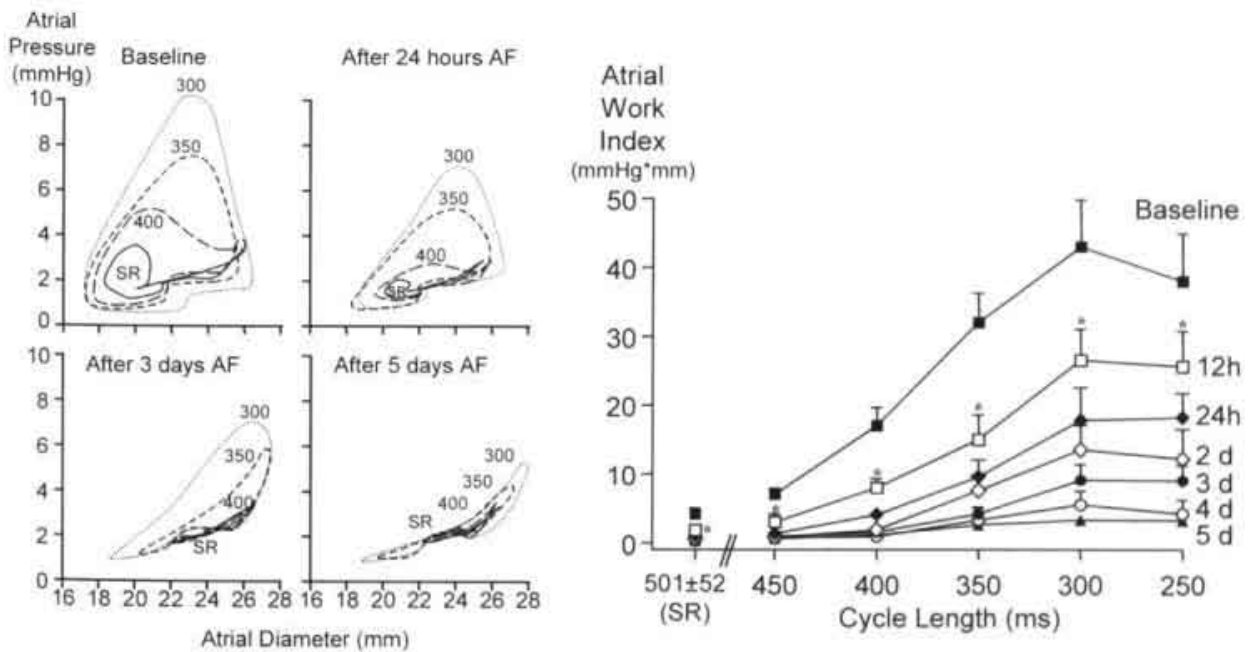

Figure 6

Effect of different pacing rates on the atrial contractile function at different stages of the remodeling process. Above: Representative 'PV-loops' recorded during SR and during pacing at 400, 350 and $300 \mathrm{~ms}$ cycle length. Below: Statistical data from 7 goats. ": $p<0.05$ versus baseline. 


\section{Effect of Transient Rapid Atrial Pacing on Atrial Contractility}

20 s of rapid atrial pacing (cycle length of $180 \mathrm{~ms}$ ) induced a short-lasting increase in atrial contractility in normal and remodeled atria (figure 7, upper panels). In the control goat, the first beat after the cessation of the tachycardia was twice as strong as during steady state. The work index was increased by $11.8 \pm 4.9 \mathrm{~mm} * \mathrm{mmHg}$. After 3 days of AF the steady state atrial contraction was nearly completely lost but immediately after the cessation of $20 \mathrm{~s}$ of rapid pacing the work index was increased to a similar extent as under control conditions $(+12.1 \pm 2.9 \mathrm{~mm} * \mathrm{mmHg}, \mathrm{n} . \mathrm{s}$. $)$.

\section{Effect of BayY5959}

After 3 days of AF the L-type $\mathrm{Ca}^{2+}$-channel agonist BayY5959 partly restored atrial contractility (figure 7 , lower panels). The atrial work index increased from $0.8 \pm 0.4$ to $7.9 \pm 1.6 \mathrm{~mm}^{*} \mathrm{mmHg}$ ( $\mathrm{n}=5$ goats), which was $46.3 \pm 5.2 \%$ of the atrial contractility lost during 3 days of AF. At the same time, AERP was prolonged from $80.8 \pm 10.3 \mathrm{~ms}$ to $117.6 \pm 20.6 \mathrm{~ms}$, which made $50.2 \pm 3.7 \%$ of the AERP shortening induced by 3 days AF. Thus, BayY5959 increased AWI to a similar extent as it prolonged AERP. There was a strong correlation between AWI and AERP measured at control, and before and after the administration of BayY5959 after 3 days of $\mathrm{AF}(\mathrm{r}=0.931, \mathrm{p}<0.01)$.
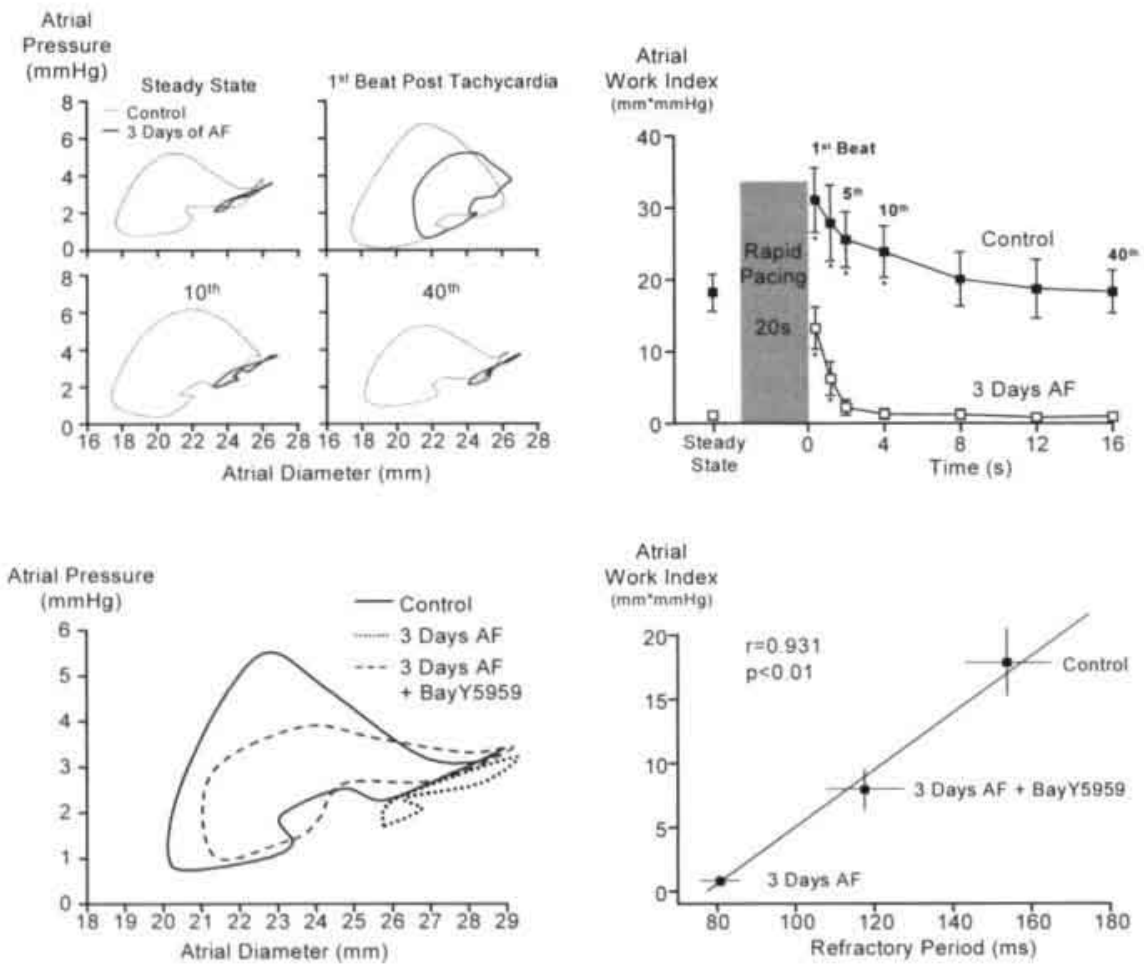

Figure 7

Upper panels: Effect of 20 s of rapid atrial pacing (180ms cycle length) on atrial contractility at baseline and after 3 days of $A F$. The $P V$-loops were recorded at $400 \mathrm{~ms}$ cycle length. $n=7, * p<0.05$ versus steady state. Lower panels: In remodeled atria BayY5959 partly restored atrial contractility and prolonged AERP (atrial pacing $400 \mathrm{~ms}$ ). AWI and AERP measured during control, and before and after application of BayY5959 after 3 days of $A F$ were significantly correlated $n=5$ goats. 


\section{Different Time Domains during Recovery of Atrial Contractile Function}

Figure 8 shows a direct comparison between the time courses of recovery of the atrial function after $5 \mathrm{~min}, 3 \mathrm{~h}$, and 5 days of $\mathrm{AF}$. The recovery of contractile function after $5 \mathrm{~min}$ of AF took several minutes, whereas after 5 days of AF it required 2 days. After $3 \mathrm{~h}$ of $\mathrm{AF}$ the recovery was biphasic, $\mathrm{t}_{1 / 2}$ of the early recovery being not significantly different from $\mathrm{t}_{1 / 2}$ after $5 \mathrm{~min} \mathrm{AF}$ (table 3 ). The delayed recovery followed the same time course as the recovery of the contractile function after 5 days of AF. In both time domains recovery of AERP shortening occurred with the same time constant as recovery of contractile function (table 3 ).

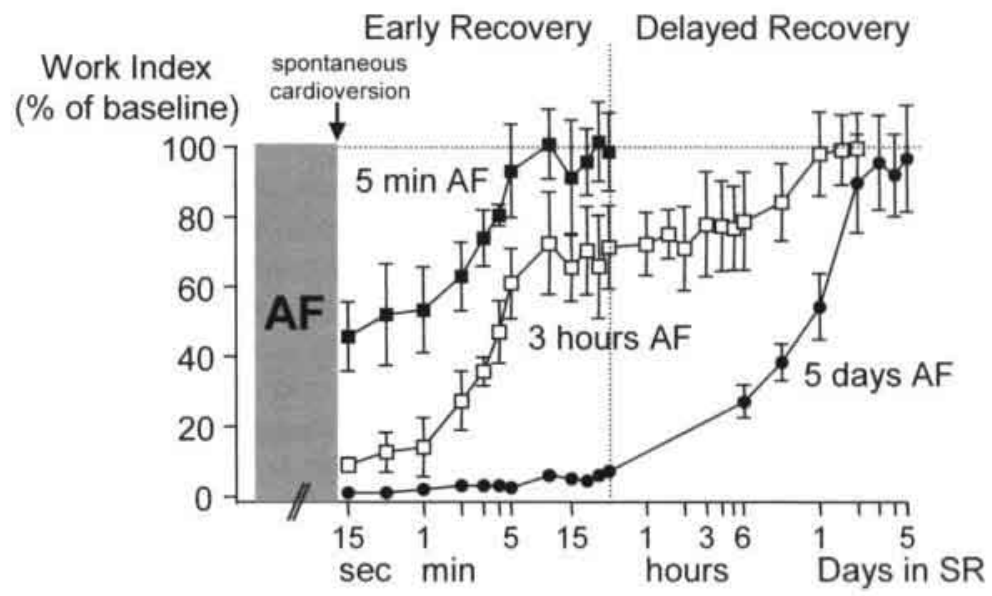

Figure 8

Different time domains of the recovery of contractile function after termination of AF of $5 \mathrm{~min}, 3 \mathrm{~h}$, and 5 days in duration. Atrial contractility was measured at $400 \mathrm{~ms}$ cycle length. $n=7$ goats.

\begin{tabular}{|c|c|c|c|c|}
\hline & $5 \min A F$ & & & 5 days $A F$ \\
\hline & & Early recovery & Delayed recovery & \\
\hline$A W I$ & $2.1(1.6-3.2)$ & $2.0(1.5-2.9)$ & $802(655-1207)$ & $987(777-1398)$ \\
\hline AERP & $2.3(1.5-3.9)$ & n.d. & $893(722-1194)$ & $801(678-1161)$ \\
\hline
\end{tabular}

Table 3

Time constants of recovery of contractile and electrical function in different time domains.

Within the respective time domains the time required for $50 \%$ recovery $\left(t_{1}\right.$; in $\min$ ) of $A W I$ and $A E R P$ were not different. $n=7$ goats.

\section{$\underline{\text { Discussion }}$}

The present study provides the first evaluation of the time course of contractile remodeling during the first days of $\mathrm{AF}$. The loss of atrial contractility followed exactly the same time course as the shortening of the atrial refractory period. This strongly suggests that AF-induced electrical and contractile remodeling are due to the same cellular mechanisms. Our study also demonstrated that atrial hypocontractility due to short episodes of AF ( 5 minutes) has much faster on- and offset kinetics than the atrial contractile dysfunction after several days of $\mathrm{AF}$. 


\section{The Atrial PV-Loop}

The atrial PV-loop during sinus rhythm consists of the 'a-loop' representing the active atrial contraction and the ' $v$-loop' which is due to the passive filling and emptying of the atria during ventricular contraction and relaxation. The latter reflects the 'reservoir function' of the atria. ${ }^{10}$ During slow overdrive pacing the phase of passive atrial emptying becomes shorter and fuses with the active atrial shortening. Although less clearly distinguishable, also under these conditions both the atrial pump function and the reservoir function are still present. This becomes obvious when the atrial contraction is completely abolished after 3 days of AF. At that time amplitude and pressure rise velocity of the a-wave, and AWI were all reduced to less than $10 \%$ of control. In contrast, the atrial fractional shortening was only reduced to $-45 \%$ of baseline. This is due to the fact that the atria are still passively filling and emptying during ventricular contraction and relaxation. Although the reduced atrial fractional shortening certainly reflects atrial contractile dysfunction, the 'reservoir function' of the atria still causes significant excursions of the atrial wall. This might explain the seemingly conflicting results between a pronounced reduction in atrial cellular contractility after 6 weeks of rapid atrial pacing in dogs $(-70 \%)^{11}$ and the rather moderate reduction of the atrial fractional shortening $(-19.3 \%)$ in the same model. ${ }^{12}$

\section{Transient Atrial Hypocontractility versus Contractile Remodeling}

Our study confirms previous observations that after brief episodes of AF a transient phase of atrial hypocontractility exists. ${ }^{3-6}$ This transient atrial hypocontractility had much shorter on- and offset kinetics than the atrial contractile dysfunction after a couple of days of AF. Since in a previous study even three repetitive cycles of AF for 5 days did not have a cumulative effect on AF duration or changes in refractoriness ${ }^{13}$ it is unlikely that repetitive induction of $\mathrm{AF}$ in the three consecutive protocols underlies these differences in kinetics. Rather, the slower kinetics of the AF-induced atrial contractile dysfunction induced by several days of AF reflect a different cellular mechanism causing the contractile dysfunction. Thus, minutes after termination of AF atrial contractile function is depressed both by the rapidly reversible hypocontractility and contractile remodeling. Measurements of atrial contractility immediately after termination of AF might therefore overestimate the degree of contractile remodeling. To avoid this confounding factor, we waited $30 \mathrm{~min}$ after cardioversion of AF before atrial contractile remodeling was assessed.

\section{Time Course and Mechanisms of Contractile Remodeling}

Echocardiographic studies in patients showed that the transmitral a-wave velocity was clearly lower after 6 weeks of AF than after 2 weeks.' In contrast, in the dog the left atrial fractional shortening was diminished by $\sim 18 \%$ after two weeks of rapid atrial pacing and did not decrease any further after 4 or 6 weeks of rapid pacing. ${ }^{12}$ In the present study we have followed the exact time course of contractile remodeling in the chronically instrumented goat model of AF. It turned out that within 2 days of AF the atrial contractile function was almost completely abolished. Comparison of the fractional shortening of right and left atria revealed no differences in extent or time course of contractile remodeling.

The development of AF-induced atrial contractile dysfunction and its reversal followed exactly the same time course as the shortening of the refractory period (electrical remodeling). Obviously, the two phenomena are very closely linked indicating that 
electrical and contractile remodeling may share common mechanisms. Electrical remodeling was shown to be mainly due to a reduction of $\mathrm{I}_{\mathrm{CaL}}{ }^{7}$ which might explain the pronounced decrease in atrial contractility. This hypothesis is supported by our observation that in remodeled atria the L-type $\mathrm{Ca}^{2+}$-channel agonist BayY5959 increased atrial contractility to the same extent as it prolonged the refractory period. In contrast, the $\mathrm{Ca}^{2+}$-reuptake and storage function of the sarcoplasmic reticulum is not affected. The increase in atrial contractility induced by 20 s of rapid atrial pacing was similar in normal and in remodeled atria suggesting that atrial contractile function in remodeled atria is not limited by dysfunction of the sarcoplasmic reticulum.

\section{Limitations and Clinical Relevance}

Recent work has shown that also in humans AF-induced electrical remodeling is completely reversible within a few days. ${ }^{14}$ This is true even after prolonged duration of AF (months to years). In contrast, recovery of the contractile function after cardioversion in these patients takes weeks.' This discrepancy strongly suggests that apart from a reduction of $\mathrm{I}_{\text {Cal }}$ additional mechanisms contribute to the contractile dysfunction of atrial myocardium in patients with chronic AF. One possibility is that atrial myolysis explains the loss of contractility after chronic AF. However, in right atrial muscle preparations of patients with chronic AF the sarcomere content and the contractile reserve were reduced by only $\sim 15 \%$ indicating that the contribution of myolysis to the atrial dysfunction in AF patients is limited. ${ }^{15}$ Mihm et al. suggested that also altered energetics of the myofibrils due to oxidative modification of the myofibrillar proteins contributes to the loss of atrial contractility. ${ }^{16}$ Also, slowing of the transfer of $\mathrm{Ca}^{2+}$ from non-junctional to junctional parts of the sarcoplasmic reticulum and a depressed release function of the ryanodine receptor could reduce atrial contractile function. ${ }^{17}$

Our results emphasize that prevention of the atrial contractile dysfunction might reduce the thromboembolic risk after cardioversion. Some benefit in this respect was demonstrated by verapamil ${ }^{4: 5}$ and the $\mathrm{Na}^{+} / \mathrm{H}^{+}$-exchange inhibitor HOE642 during shortlasting $\mathrm{AF}^{3}$. For prevention of the atrial contractile dysfunction after prolonged $\mathrm{AF}$ no therapeutical strategy exists and anticoagulant therapy has to be continued after cardioversion for some time.

\section{$\underline{\text { Reference List }}$}

1. Manning WJ. Silverman DI. Katz SE et al. Impaired left atrial mechanical function after cardioversion: relation to the duration of atrial fibrillation. JACC 1994:23:1535-1540.

2. Fatkin D. Kuchar DL. Thorburn CW et al. Transesophageal echocardiography before and during direct current cardioversion of atrial fibrillation: evidence for "atrial stunning" as a mechanism of thromboembolic complications. JACC 1994;23:307-316.

3. Altemose GT, Zipes DP. Weksler J et al. Inhibition of the $\mathrm{Na}^{*} / \mathrm{H}^{+}$-exchanger delays the development of rapid pacing-induced atrial contractile dysfunction. Circulation 2001:103:762-768.

4. Leistad E, Aksnes G, Verburg E et al. Atrial contractile dysfunction after short-term atrial fibrillation is reduced by verapamil but increased by BayK8644. Circulation 1996:93:1747-1754.

5. Daoud EG, Marcovitz P, Knight BP et al. Short-term effect of atrial fibrillation on atrial contractile function in humans. Circulation 1999:99:3024-3027.

6. Sun $\mathrm{H}$, Chartier $\mathrm{D}$, Leblanc $\mathrm{N}$ et al. Intracellular calcium changes and tachycardia-induced contractile dysfunction in canine atrial myocytes. Cardiovasc Res 2001;49:751-761. 


\section{2 | Chapter 5}

7. Yue L, Feng J, Gaspo R et al. lonic remodeling underlying action potential changes in a canine model of atrial fibrillation. Circ Res 1997;81:512-525.

8. Wijffels MC, Kirchhof CJ, Dorland R et al. Atrial fibrillation begets atrial fibrillation. A study in awake chronically instrumented goats. Circulation 1995:92:1954-1968.

9. Bers DM. Excitation-contraction coupling and cardiac contractile force. Kluwer Academic Publishers, 2002:245-272.

10. Stefanadis C, Dernellis J, Toutouzas P, A clinical appraisal of left atrial function. Eur Heart J 2001;22:22-36.

11. Sun H, Gaspo R, Leblanc $\mathrm{N}$ et al. Cellular mechanisms of atrial contractile dysfunction caused by sustained atrial tachycardia. Circulation 1998:98:719-727.

12. Shi Y, Ducharme A, Li D et al. Remodeling of atrial dimensions and emptying function in canine models of atrial fibrillation. Cardiovasc Res 2001;52:217-225.

13. Garratt CJ, Duytschaever M, Killian M et al. Repetitive electrical remodeling by paroxysms of atrial fibrillation in the goat: no cumulative effect on inducibility or stability of atrial fibrillation. $J$ Cardiovasc Electrophysiol 1999;10:1101-1108.

14. Yu WC, Lee SH, Tai CT et al. Reversal of atrial electrical remodeling following eardioversion of long-standing atrial fibrillation in man. Cardiovasc Res 1999;42:470-476.

15. Schotten U, Ausma J, Stellbrink C et al. Cellular mechanisms of depressed atrial contractility in patients with chronic atrial fibrillation. Circulation 2001:103:691-698.

16. Mihm MJ, Yu F, Carnes CA et al. Impaired myofibrillar energetics and oxidative injury during human atrial fibrillation. Circulation 2001;104:174-180.

17. Kneller $\mathrm{J}$, Sun $\mathrm{H}$, Leblanc $\mathrm{N}$ et al. Remodeling of $\mathrm{Ca}^{2+}$-handling by atrial tachycardia: evidence for a role in loss of rate-adaptation. Cardiovase Res 2002:54:416-426. 


\section{Chapter 6}

\section{Effect of Atrial Contractile Remodeling on Compliance and Size of the Fibrillating Atrium}

Ulrich Schotten, Hans-Ruprecht Neuberger, Sabine Eijsbouts, Yuri Blaauw, Robert Tieleman, Maurits Allessie 


\section{$\underline{\text { Abstract }}$}

\section{Background}

Atrial fibrillation (AF) induces a progressive dilatation of the atria which in turn might promote the arrhythmia. The mechanism of atrial dilatation during AF is not known. We hypothesized that loss of atrial contractile function is the main cause of atrial dilatation during the first days of AF.

\section{Methods}

8 Goats were chronically instrumented with epicardial electrodes, a pressure transducer in the right atrium and piezoelectric crystals to measure right atrial diameter. $\mathrm{AF}$ was induced by repetitive burst pacing. Atrial contractility was assessed during sinus rhythm, right atrial pacing $(160,300$, and $400 \mathrm{~ms}$ cycle length) and electrically induced $\mathrm{AF}$. The compliance of the fibrillating atrium was measured during unloading the atria with diuretics and loading with $1 \mathrm{~L}$ saline. All measurements were repeated after 6,12 , and $24 \mathrm{~h}$ of $\mathrm{AF}$ and then once per day during the first 5 days of AF. Also, the recovery of the observed changes after spontaneous cardioversion was studied.

\section{Results}

After 5 days of AF atrial contractility during sinus rhythm or slow atrial pacing (300 or $400 \mathrm{~ms}$ ) was almost abolished. The amplitude of the pressure waves following each atrial activation during $\mathrm{AF}$ or rapid atrial pacing $(160 \mathrm{~ms})$ declined to $20 \%$ of control. As a result the compliance of the fibrillating atrium increased 4-fold and the mean atrial diameter increased by $\sim 12 \%$. In contrast, the mean right atrial pressure did not change throughout the experiment. All changes were reversible within 2 days of sinus rhythm.

\section{Conclusion}

Progressive atrial dilatation during the first days of $\mathrm{AF}$ is due to an increase in atrial compliance caused by loss of atrial contractility during AF. Atrial size and compliance are restored when atrial contractility recovers following cardioversion.

\section{$\underline{\text { Introduction }}$}

A relationship between atrial size and $\mathrm{AF}$ was established more than 50 years ago when Fraser and Turner showed that the incidence of $\mathrm{AF}$ in patients with mitral valve disease correlated with left and right atrial size.' In 1976 Henry et al. reported that in patients with mitral or aortic valve disease or with asymmetric septal hypertrophy, AF was rare ( $3 \%$ ) when the left atrial diameter was less than $40 \mathrm{~mm}$, but common $(54 \%)$ when it exceeded $40 \mathrm{~mm}^{2}$ Later, large prospective trials showed that left atrial enlargement is an independent risk factor for the development of $\mathrm{AF}^{3,4}$

Atrial dilatation can be both cause and consequence of AF. Enlargement of the atria will promote $\mathrm{AF}$ by increasing atrial tissue mass allowing more re-entry circuits to coexist in the atria or by stretch-induced conduction disturbances. ${ }^{5 \cdot 7}$ On the other hand, prolonged $\mathrm{AF}$ per se has been demonstrated to result in progressive atrial dilatation ${ }^{8}$ which in turn might contribute to the self-perpetuating nature of the arrhythmia. 
The mechanism of atrial dilatation during AF in not known. AF induces a pronounced contractile dysfunction of the atria ${ }^{9-11}$ which theoretically might increase atrial compliance and size. In isolated canine hearts, AF did not result in significant changes of atrial compliance. ${ }^{12}$ In contrast, in anesthetized dogs ${ }^{13}$ and pigs $^{14}$ atrial compliance was found to decrease during transition from sinus rhythm to AF. However, these studies focused on acute AF and the effect of a decrease of atrial contractility on compliance of fibrillating atria during prolonged AF has not been studied yet.

We hypothesized that the main cause of atrial dilatation during the first days of AF is a loss of atrial contractility resulting in an increase in atrial compliance. In the present study we measured the time course of changes in contractility, compliance and size of fibrillating atria of chronically instrumented goats during the first 5 days of AF.

\section{$\underline{\text { Methods }}$}

\section{Animal Model}

In 8 goats (43-63kg) a left intercostal thoracotomy was made during general anesthesia (halothane, $\mathrm{N}_{2} \mathrm{O}, \mathrm{O}_{2}$ ). Small silicon patches containing 3 silver electrodes $(2 \mathrm{~mm}$ diameter) were sutured on the upper free wall of the right and left atria and the left ventricular apex. A pair of ultrasonic piezoelectric crystals was used to measure right atrial diameter. One crystal was placed between the aorta and the auricle and the other was sutured on the middle of the right atrial free wall (Figure 1). A tip pressure transducer was implanted in the right atrium via the right jugular vein. After the goats were recovered from surgery (2-3 weeks) AF was induced by burst pacing with an automatic fibrillation pacemaker. ${ }^{15}$ The study was performed according to the institutional guidelines and was approved by the local ethical committee.

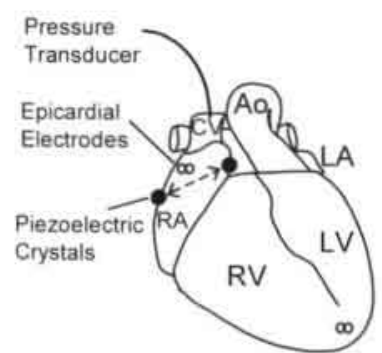

Atrial

Pressure

$(\mathrm{mmHg}) \mathrm{SR}$

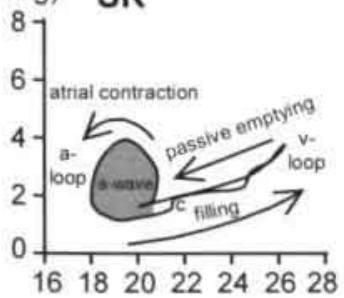

Atrial Diameter ( $\mathrm{mm}$ )
Figure I

Upper left panel: Chronic instrumentation: Piezoelectric crystals were sutured to the right atrial epicardium. Right atrial pressure was measured with an implantable pressure transducer. $L A=l e f t$ atrium, $R A=r i g h t$ atrium. $C V=$ superior caval vein, $A o=$ Aorta . Upper right panel: Simultaneous recording of the right atrial diameter and pressure. $A F$ was induced by burst stimulation of the atria as previously described."

Lower panels: Right atrial 'PV-loops during $S R$ (left) and during slow atrial pacing at the upper right atrium at a cycle length of $400 \mathrm{~ms}$ (right). The area enclosed by the active part of the loop (a-loop) is marked in gray and was taken as atrial work index. 


\section{Study Protocol}

Before AF was induced the baseline electrophysiological and contractile properties as well as right atrial pressure, size and compliance were determined. Afterwards, AF was maintained for 5 days. During these 5 days the maintenance of AF was briefly interrupted at $6,12,24,48,72,96$ and 120 hours of AF. 30 minutes after spontaneous termination of $\mathrm{AF}$ the atrial contractile function was studied at different pacing rates. 20 min after reinduction of AF right atrial pressure, size and compliance were measured. After 5 days of AF the recovery of atrial contractility, size and compliance was studied for 5 days.

\section{Electrophysiological and Contractile Measurements}

Median $\mathrm{AF}$ cycle length ( $\mathrm{AFCl}$ ) was measured from a bipolar atrial electrogram during $10 \mathrm{~s}$ of AF. Atrial contractility was assessed $30 \mathrm{~min}$ post cardioversion during sinus rhythm and atrial pacing at the upper right atrial wall at a cycle length of 160,300 and $400 \mathrm{~ms}$. The distance between the pair of piezoelectric crystals sutured to the right atrium was measured with a commercially available sonomicrometer system (Sonometrics, London, Canada) and was taken as the medio-lateral atrial diameter. ${ }^{16}$ During right atrial pacing at 300 or $400 \mathrm{~ms}$ cycle length pressure diameter loops were obtained by plotting right atrial pressure against the medio-lateral diameter. These surrogate 'pressure-volume loops' are the result of both atrial and ventricular contractions. The atrial part of the PV-loop (a-loop) starts at the onset of the a-wave and ends when the same atrial diameter is reached again (Figure 1). The area enclosed by this part of the PV-loop was taken as the atrial work index (AWI). At a pacing cycle length of $160 \mathrm{~ms}, 2: 1$ or $3: 1$ atrio-ventricular conduction occurred. To quantify atrial contractility the amplitude of pressure waves following each atrial activation was measured. Two types of atrial pressure waves were distinguished. When both the ascending and descending limb of the pressure wave occurred during the ventricular diastole the atria ejected blood into the ventricle through the open AV-valve. In these cases the pressure amplitude $\left(\Delta \mathrm{P}_{\text {open }}\right)$ and the shortening of the atrial diameter during the pressure wave $\left(\Delta D_{\text {open }}\right)$ were measured. When the wave completely occurred during the ventricular systole (during the QT-interval) no blood was ejected into the ventricles and only the pressure amplitudes $\left(\Delta \mathrm{P}_{\text {closed }}\right)$ were used for quantification.

During AF mean atrial pressure $\left(\mathrm{P}_{\text {mean }}\right)$ and diameter $\left(\mathrm{D}_{\text {mean }}\right)$ were calculated by averaging the recorded pressure and diameter data during $10 \mathrm{~s}$. The maximal $\left(\mathrm{D}_{\max }\right)$ and the minimal atrial diameters $\left(\mathrm{D}_{\min }\right)$ occurring during the ventricular contraction cycles were also averaged during $10 \mathrm{~s}$. Contractility of the fibrillating atrium $\left(\Delta \mathrm{P}_{\text {open }}, \Delta \mathrm{P}_{\text {closed }}\right.$, $\Delta \mathrm{D}_{\text {open }}$ ) was measured using the same criteria as during rapid atrial pacing with a cycle length of $160 \mathrm{~ms}$. To calculate compliance curves of the fibrillating atrium atrial pressure-diameter data were recorded during 2 to $3 \mathrm{~s}$ of $\mathrm{AF}$ ( 4 to 5 contraction cycles) without medication, after unloading the atria with a loop diuretic $(30 \mathrm{~min}$ after administration of $125 \mathrm{mg}$ furosemide), and after loading the atria with $1 \mathrm{~L}$ saline infused within $10 \mathrm{~min}$. The compliance curve was obtained by fitting the merged pressure diameter data to the exponential function $\mathrm{p}=$ offset $+\mathrm{a} \cdot \mathrm{e}^{\mathrm{b}-\mathrm{d}}$, where $\mathrm{a}$ is the elastic constant and $b$ the stiffness constant of the fibrillating atrium. ${ }^{17: 18}$ For each given atrial diameter the compliance of the fibrillating atrium can be calculated as the reciprocal steepness of the compliance curve. We calculated compliance at $\mathrm{D}_{\text {mean }}$ of the baseline study at the beginning of the protocol (Compliance base $_{\text {) }}$ and at the 'working point' on the compliance curve of that particular experiment (Compliance $\left.{ }_{\text {work }}\right)$. 


\section{Statistical Analysis}

Data are expressed as means $\pm \mathrm{SD}$. Compliances curves were calculated by least squares regression analysis of the pressure diameter data to a monoexponential function. Statistical significance was determined with the unpaired Student's t-test or by one-way analysis of variance (ANOVA) for comparison of multiple groups. A p-value of less than 0.05 was considered statistically significant.

\section{$\underline{\text { Results }}$}

\section{The Atrial Contraction Cycle}

The lower left panel of figure 1 shows a right atrial pressure-diameter loop during sinus rhythm. During atrial contraction the atrial pressure increases (a-wave) while its diameter declines. The onset of ventricular contraction is marked by the closure of the tricuspid valve (c-wave). During the ventricular systole blood accumulates in the atria and atrial pressure and diameter both increase (v-wave). During the early ventricular diastole the atria empty passively into the ventricles causing a decline in atrial pressure and diameter. Thus, the atrial 'pressure-volume loop' consists of two parts. The a-loop represents the atrial contraction. The area enclosed by the a-loop can serve as a measure of the work performed by this atrial beat (atrial work index=AWI, marked in gray). The v-loop reflects passive filling and emptying of the atria during contraction and early relaxation of the ventricle.

During atrial pacing (cycle length $400 \mathrm{~ms}$, lower right panel) the atria are still filled at the onset of the atrial contraction and the v-loop is small. Because of the high preload the resulting atrial a-wave and the atrial ejection are more pronounced than during SR. As a result, AWI is higher than during SR.

\section{Time Course of Contractile Remodeling}

The left panels of figure 2 show representative PV-loops recorded during SR and during right atrial pacing at a cycle length of 400 and $300 \mathrm{~ms}$. In the right panels the time course of AF-induced atrial contractile dysfunction (contractile remodeling) is depicted. At baseline, AWI was highest during pacing at $300 \mathrm{~ms}\left(40.0 \pm 8.7 \mathrm{~mm} \mathrm{mmmg}^{*} \mathrm{mmd}\right.$ lowest during SR $(4.4 \pm 1.2 \mathrm{~mm} * \mathrm{mmHg})$. Both during SR and atrial pacing AWI declined during the first days of AF. After $24 \mathrm{~h}$ of AF AWI was reduced by more than $50 \%$ and after 3 days the atrial loop was almost closed indicating that atrial contractile function was nearly completely abolished. After resumption of SR it took about 2 days for atrial contractile function to recover. 

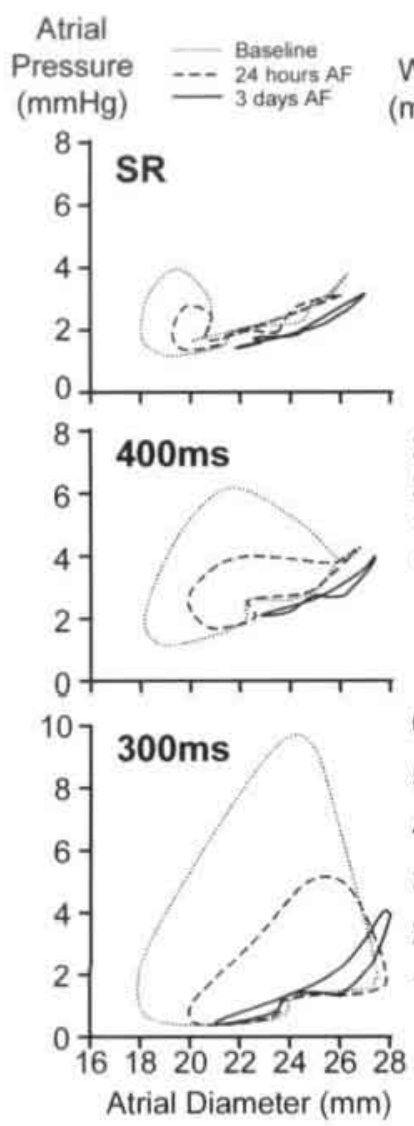

Atrial

Work Index

$(\mathrm{mm} * \mathrm{mmHg})$
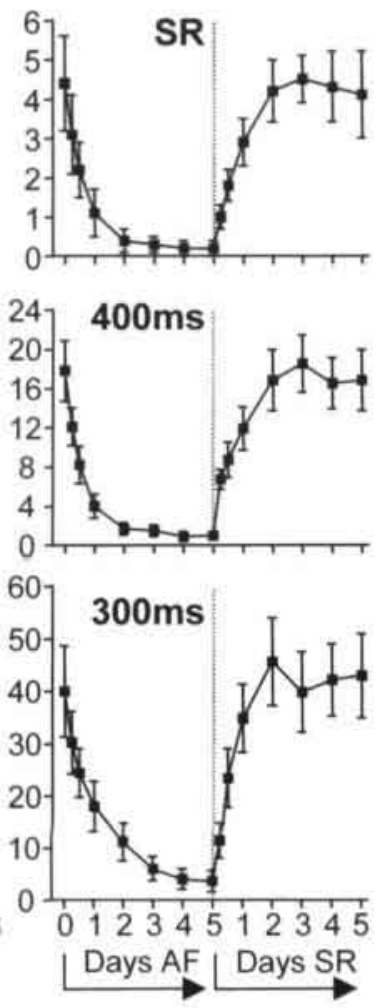

Figure 2

Time course of contractile remodeling during the first days of $A F$ assessed during $S R$ and right atrial pacing at a cycle length of 300 or $400 \mathrm{~ms}$. Left panels: Atrial $P V$-loops at baseline, after $24 \mathrm{~h}$, and after 3 days of $A F$. Right panels: Mean atrial work index during the first 5 days of $A F$ and 5 days of recovery. $n=8$ goats. * $p<0.05$ versus baseline.

Figure 3 illustrates the quantification of atrial contractility during rapid atrial pacing at a cycle length of $160 \mathrm{~ms}$. The upper panels show the cyclic changes in atrial pressure and diameter at baseline. Four atrial contractions are marked in gray (left panel). The corresponding pressure-diameter diagrams are shown in the right panel. Contractions 1 and 3 occurred during ventricular contraction when the AV-valve was closed. Therefore, no significant ejection of blood into the right ventricle occurred and at the end of the contraction atrial diameter was the same as at the onset of the atrial contraction. Only the pressure amplitude $\left(\Delta \mathrm{P}_{\text {closed }}\right)$ was used for quantification of atrial contractility. Contractions 2 and 4 occurred during ventricular diastole when the AVvalve is open. During these contractions blood was expelled from the atria into the ventricles and the right atrial diameter decreased. Both the pressure amplitude $\left(\Delta \mathrm{P}_{\text {open }}\right)$ and the shortening of the atrial diameter during the pressure wave $\left(\Delta D_{\text {open }}\right)$ were measured. After 3 days of AF the amplitude of the pressure waves and the atrial wall excursions during AF were clearly reduced. In figure 4 the time course of contractile remodeling assessed during rapid atrial pacing is shown. During the first 5 days of $\mathrm{AF}$, $\Delta \mathrm{P}_{\text {closed }}$ and $\Delta \mathrm{P}_{\text {open }}$ declined to less than $20 \%$ of the baseline values with most of the effect occurring during the first 3 days of $\mathrm{AF}$. With a similar time course $\Delta \mathrm{D}_{\text {open }}$ declined to $33 \%$ of the baseline value. After resumption of SR atrial contractility recovered completely within 3 days. 


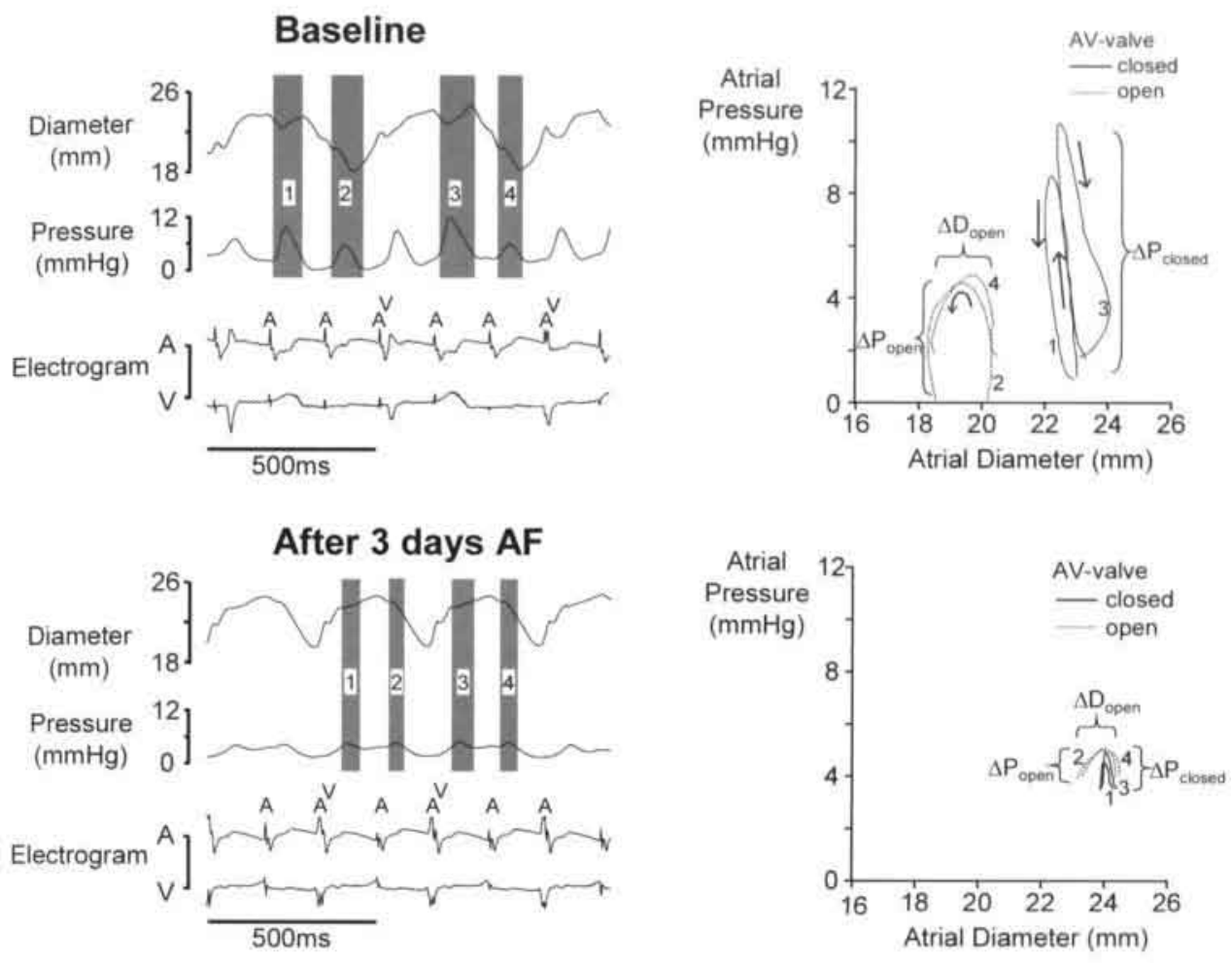

Figure 3

Contractile remodeling assessed during rapid right atrial pacing $(160 \mathrm{~ms})$.

Upper panels: Right atrial pressure and diameter recordings at baseline (left) and 'PV-loops' of the contractions marked in gray (right). Lower panels: Right atrial pressure and diameter recordings after 3 days of $A F$ (left) and 'PV-loops' of the contractions marked in gray (right).
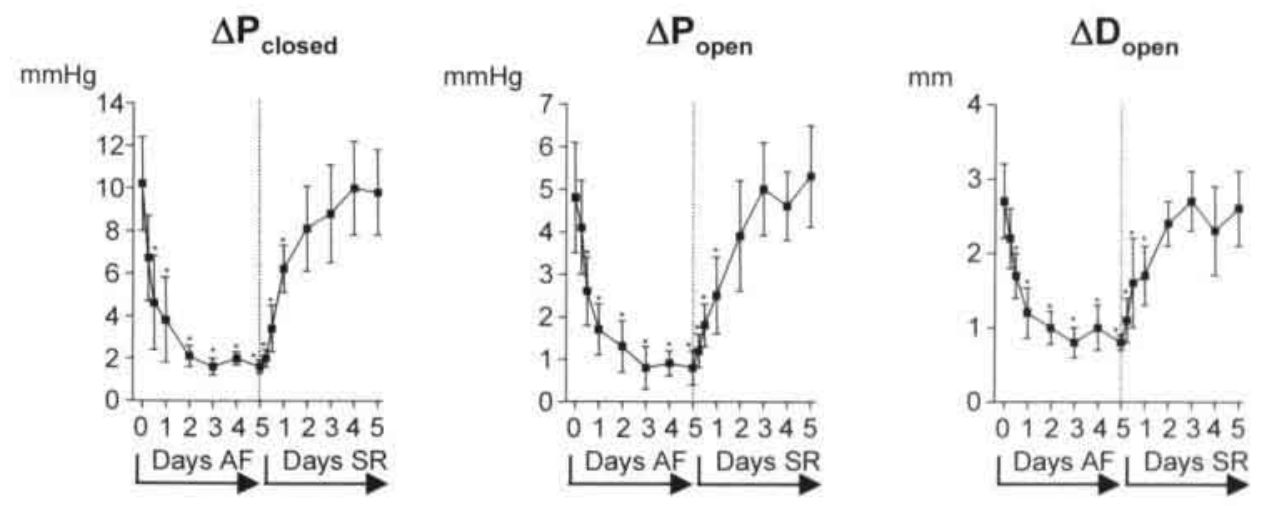

Figure 4

Time course of contractile remodeling during the first 5 days of $A F$ and during recovery. Contractility was assessed during rapid right atrial pacing (160ms). $n=8$ goats. * $p<0.05$ versus baseline. 


\section{Contractile Remodeling of the Fibrillating Atrium}

Figure 5 shows the decrease of atrial contractility during AF. Comparable to rapid atrial pacing two types of atrial contractions can be distinguished. At baseline, contractions 1 and 3 occurred during ventricular contraction and atrial diameter did not shorten. Again, only the pressure amplitude $\left(\Delta \mathrm{P}_{\text {closed }}\right)$ was used for quantification of atrial contractility. During contractions 2 and 4 , blood was pumped into the ventricles and both pressure amplitude $\left(\Delta \mathrm{P}_{\text {open }}\right)$ and shortening of atrial diameter during the pressure wave $\left(\Delta \mathrm{D}_{\text {open }}\right)$ were measured. During the first 5 days of $\mathrm{AF}, \Delta \mathrm{P}_{\text {closed }}$ and $\Delta \mathrm{P}_{\text {open }}$ declined to less than $20 \%$, and $\Delta \mathrm{D}_{\text {open }}$ to $\sim 32 \%$ of the baseline values (figure 6 ). In parallel to the changes in atrial contractility, $\mathrm{AFCl}$ decreased from $152 \pm 13 \mathrm{~ms}$ at baseline to $85 \pm 10 \mathrm{~ms}$ after 5 days of $\mathrm{AF}$. After resumption of $\mathrm{SR}$ atrial contractility and $\mathrm{AFCl}$ recovered completely within 3 days.
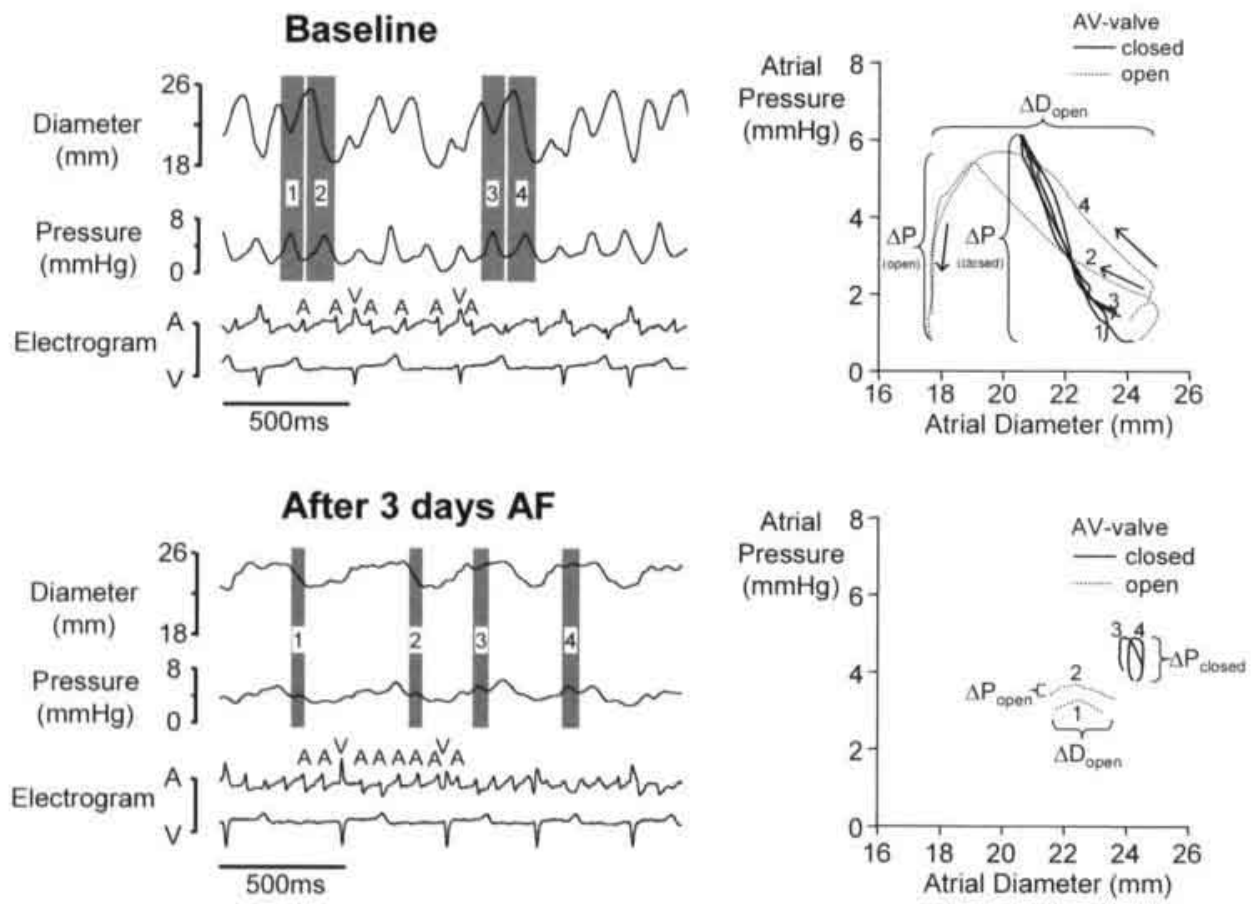

Figure 5

Contractile remodeling assessed during $A F$.

Upper panels: Right atrial pressure and diameter recordings at baseline (left) and 'PV-loops' of the contractions marked in gray (right). Lower panels: Right atrial pressure and diameter recordings after 3 days of $A F$ (left) and 'PV-loops' of the contractions marked in gray (right). 

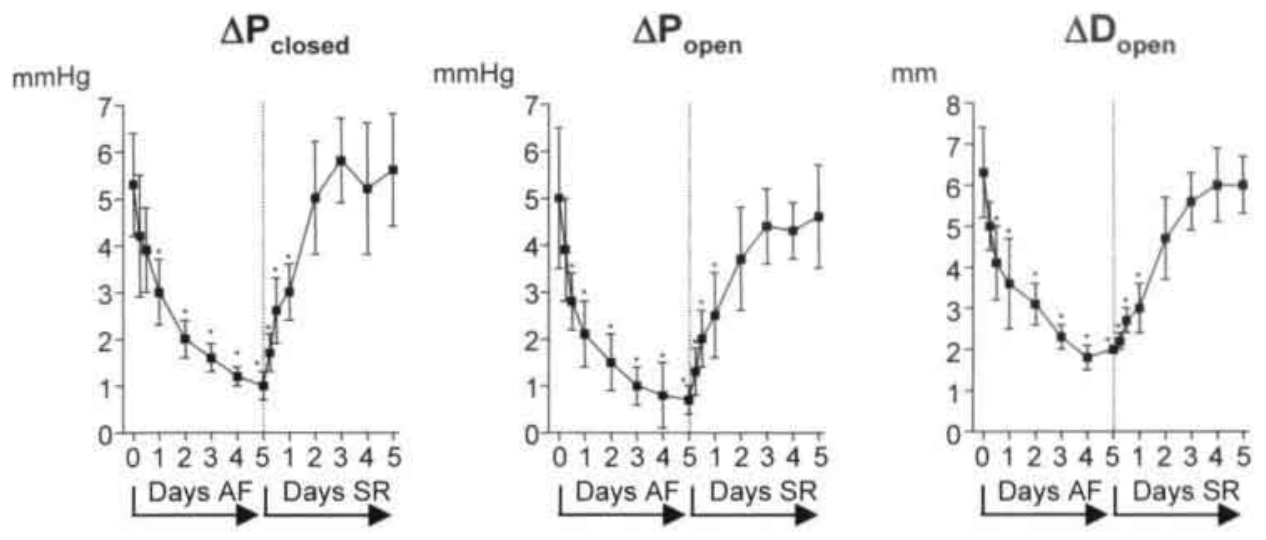

Figure 6

Time course of contractile remodeling assessed during $A F . n=8$ goats. $\because p<0.05$ versus baseline.

\section{Changes in Atrial Pressure, Compliance and Size}

Figure 7 shows the changes in right atrial compliance during the first days of AF. The atrial pressure and diameter were recorded during control, $30 \mathrm{~min}$ after administration of $125 \mathrm{mg}$ furosemide, and after infusion of $1 \mathrm{~L}$ saline within $10 \mathrm{~min}$ (left panels). Both at baseline and after 5 days of AF furosemide mainly reduced atrial diameter whereas the atrial pressure was less affected. In contrast, infusion of $1 \mathrm{~L}$ saline mainly increased the atrial pressure while the effect on atrial diameter was less pronounced. The corresponding pressure-diameter loops and the compliance curves are shown in the right panels. After 5 days of AF the pressure-diameter loops points are shifted to the right. At low atrial diameters the compliance curve is flattened but at high atrial diameters it is steeper than during baseline.

Quantitative analysis revealed that during the first 5 days of AF the stiffness constant increased $\sim 2.5$ fold, whereas the elasticity decreased to less than $10 \%$ of the baseline value. These changes were completely reversible within 2 days after cardioversion of AF (figure 8). The offset of the monoexponential compliance curve did not change throughout the experiment. In figure 9, representative compliances curves during baseline (acute AF), and after AF lasting 2 and 5 days are depicted. The dotted lines indicate the mean atrial pressure $\left(\mathrm{P}_{\text {mean }}\right)$ and the mean atrial diameter $\left(\mathrm{D}_{\text {mean }}\right)$ and cross the compliance curve at the 'working point' (gray dot). Whereas $\mathrm{P}_{\text {mean }}$ did not change, the compliance curve became flatter at low atrial diameters, i.e. atrial compliance increased. This caused a rightward shift of the working point on the atrial compliance curve and $\mathrm{D}_{\text {mean }}$ increased from 21.8 to $24.8 \mathrm{~mm}$. Figure 10 shows the changes in atrial compliance at the baseline atrial diameter (compliance hase ), the atrial compliance at the working point (compliance ${ }_{\text {work }}$ ), $\mathrm{P}_{\text {mean }}$ and atrial diameters during 5 days of $\mathrm{AF}$. Compliance $_{\text {base }}$ increased 4 fold reflecting the progressive flattening of the compliance curve at low atrial diameters. At the working point of the compliance curve, however, the compliance (compliance ${ }_{\text {work }}$ ) did not significantly change. The increase of $D_{\text {mean }}$ by $\sim 11.8 \pm 4.7 \%$ within 5 days of AF was mainly caused by an increase of $D_{\min }$ $(+23.7 \pm 5.1 \%$ after 5 days of $A F)$. In contrast, $D_{\max }$ only slightly increased $(+4.5 \pm 1.9 \%$ after 5 days of AF). All changes were reversible within two days of SR. 


\section{Baseline}
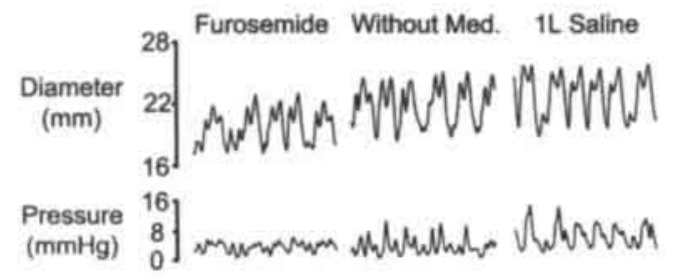

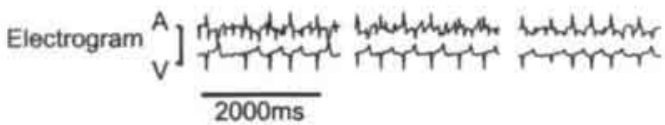

Atrial Pressure $(\mathrm{mmHg})$

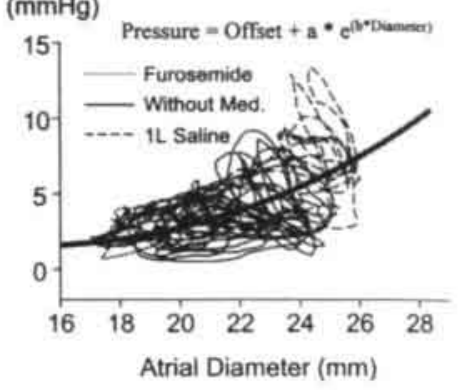

\section{After 5 days AF}

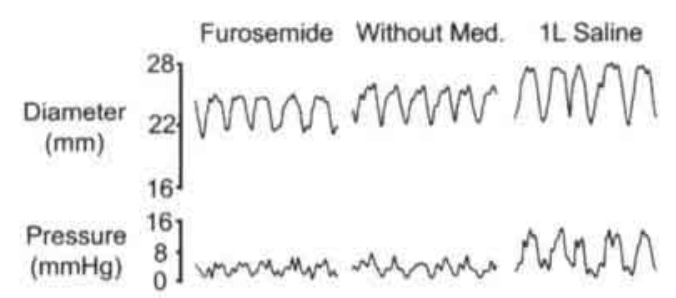

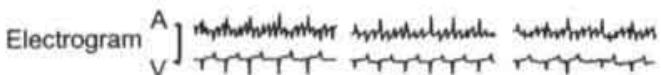

Figure 7

Effect of contractile remodeling on the compliance curve of the fibrillating atrium.

Upper panels: Right atrial pressure and diameter at baseline without medication, $30 \mathrm{~min}$ after administration of furosemide and after infusion of IL saline within $10 \mathrm{~min}$ (left). The merged pressure diameter data are shown on the right. The compliance curve (thick line) was fitted to the equation: pressure $=$ offset $+a e^{\text {halumint. }}$, where $a$ is the elastic constant and b the stiffness constant of the fibrillating atrium.

Lower panels: Right atrial pressure and diameter recordings after 3 days of AF (left) and respective pressurediameter diagram (right).
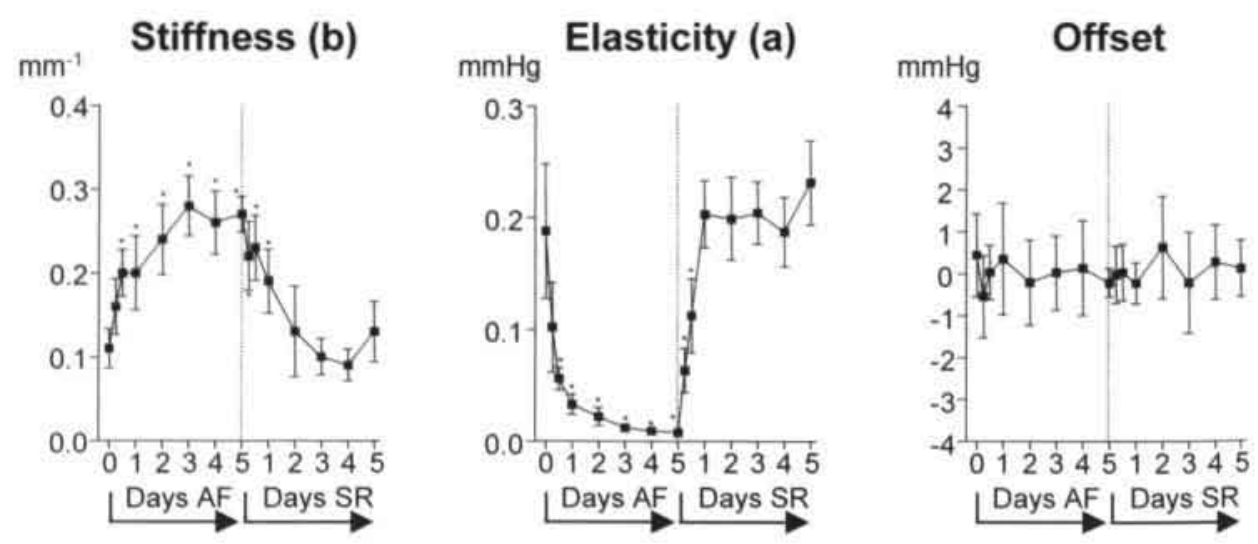

Figure 8

Changes of stiffness, elasticity, and offset constant during the first 5 davs of $A F$ and during recovery. $n=8$ goats. * $p<0.05$ versus baseline. 


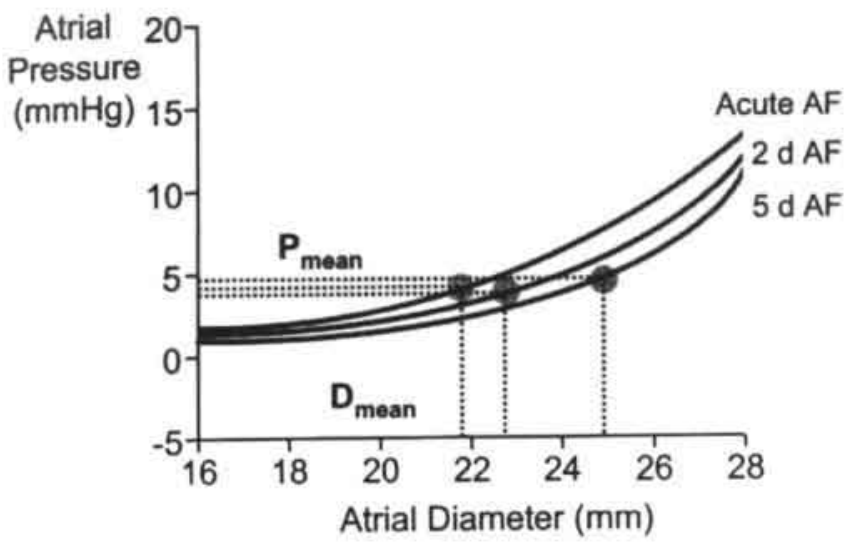

Figure 9

Representative right atrial compliance curves during acute $A F$, after 2 days, and after 5 days of AF. Due to an increase in atrial compliance at low atrial diameters flattening of the compliance curve) the working point (gray) during $A F$ shifted to the right, $P_{\operatorname{man}}=$ mean atrial pressure. $D_{\text {mian }}=$ mean atrial diameter.
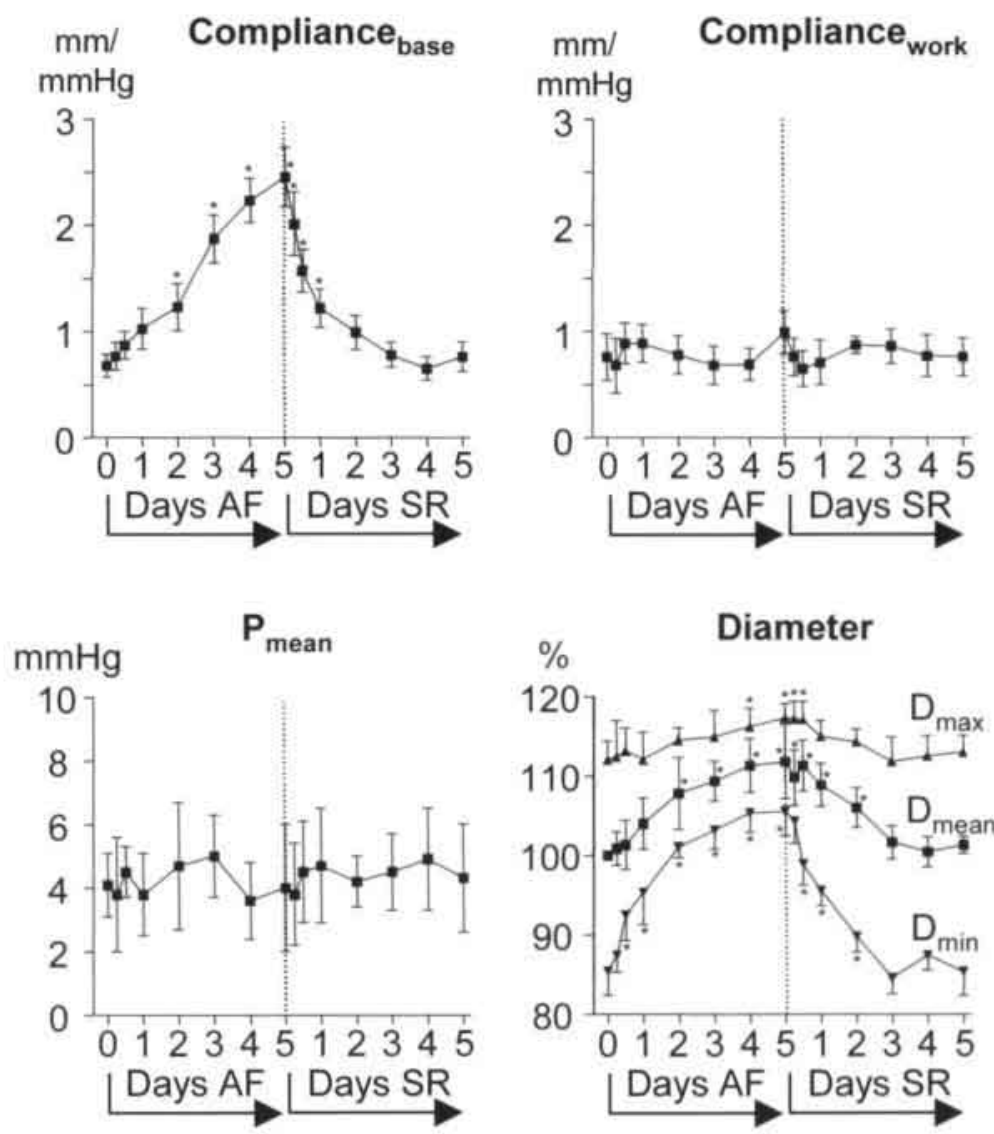

Figure 10

Changes of the atrial compliance at the baseline atrial diameter (compiance), the atrial compliance at the working point (compliance $\left.{ }_{\text {wark }}\right)$, the mean atrial pressure $\left(P_{\text {minn }}\right)$, and the atrial diameter during 5 days of $A F$ and during recovery. Maximal $\left(D_{\text {mid }}\right)$, mean $\left(D_{\text {mant }}\right)$, and minimal $\left(D_{\text {min }}\right)$ atrial diameters are normalized to the mean atrial diameter at baseline, $n=8$ goats. $* p<0.05$ versus baseline. 


\section{Discussion}

In the present study we describe the effects of atrial contractile remodeling on atrial pressure, compliance and size during the first days of AF. The progressive loss of atrial contractility causes a flattening of the atrial compliance curve at low atrial diameters during $\mathrm{AF}$. Since the right atrial pressure did not change during the first days of $\mathrm{AF}$, the working point on the atrial compliance curve shifted to the right. Thus, atrial dilatation during the first days of $\mathrm{AF}$ is a direct consequence of the loss of atrial contractility. All changes in contractility, compliance, and size were completely reversed during the first 2 to 3 days of SR.

\section{Atrial Wall Excursions during Sinus Rhythm, Atrial Pacing and AF}

The atrial PV-loop during sinus rhythm consists of an 'a-loop' representing the active atrial contraction and a ' $\mathrm{v}$-loop' which is due to passive filling and emptying of the atria during ventricular contraction and early relaxation. The latter reflects the 'reservoir function' of the atria. ${ }^{19}$ During atrial pacing the phase of passive atrial emptying becomes shorter and fuses with the active atrial shortening. Although less clearly distinguishable, also under these conditions both the atrial pump function and the reservoir function are still present. This becomes obvious when atrial contraction is abolished after 3 days of AF. At that time AWI is reduced to less than $10 \%$ of control. However, still significant wall excursions of the atria occur due to passive filling and emptying during ventricular contraction and relaxation.

During rapid atrial pacing $(160 \mathrm{~ms})$ and 2:1 or 3:1 AV-block, shape and strength of atrial contractions depend on the timing between atrial and ventricular contraction. During ventricular diastole a simultaneous increase in atrial pressure and decrease in diameter indicate an active atrial contraction ejecting blood into the ventricle. In this case both the pressure amplitude and the shortening of the atrial diameter should be used for quantification of atrial contractility. When the AV-valve is closed, no blood is ejected into the ventricles and atrial contraction only results in an increase in atrial pressure. A small decrease in atrial diameter during these contractions is likely due to regurgitation of blood into the caval veins.

Due to the random nature of $\mathrm{AF}$ the contraction pattern of the fibrillating atrium is chaotic. Shape and strength of the contractions depend on variations in preload, afterload, and frequency of AF. Nevertheless, as like during rapid atrial pacing, two types of contractions can be distinguished. When the AV-valve is open, blood is ejected from the atria into the ventricles and the atrial diameter shortens during the atrial pressure wave. In contrast, when the AV-valves are closed, no blood is ejected into the ventricles and atrial contraction only results in an increase in atrial pressure.

Atrial contractility measured either during rapid atrial pacing or AF markedly declined during the first days of AF. After 5 days of AF pressure and shortening amplitude of the atria were decreased to less than $20 \%$. However, this might not only reflect a decrease in intrinsic atrial contractility during AF. Mapping studies in the goat have shown that during acute AF single propagation wavefronts spread over the right atrial wall. ${ }^{20}$ This observation is in line with our finding that each atrial activation during $\mathrm{AF}$ is followed by one single pressure wave in the right atrium. After several days of $\mathrm{AF}$ the shortening in $\mathrm{AFCl}$ from $152 \pm 13 \mathrm{~ms}$ to $85 \pm 10 \mathrm{~ms}$ results in a pronounced decrease of the pathlength of the atrial reentry circuits thereby allowing 4 to 6 circuits to coexist in the right 
atrium..$^{20}$ Under these circumstances some parts of the right atrium will contract while other parts are relaxing. Changes in atrial pressure and diameter are no longer expected to occur as single contractions of the fibrillating atrium. To study time course and extent of atrial contractile remodeling of rapidly activated atrial myocardium, atrial contractility was also measured during rapid atrial pacing at a cycle length of $160 \mathrm{~ms}$. Under these conditions the atria are activated in a coordinated manner with a frequency only slightly below the frequency of AF. Atrial contractility measured during rapid atrial pacing clearly declined during the first days of AF exactly to the same extent as the contractility measured during AF (to $\sim 20 \%$ of baseline). This observation suggests that the decrease of pressure and shortening amplitude of the fibrillating atrium during the first days of AF is mainly due to the loss of intrinsic atrial contractility. Thus, after a couple of days in AF, the atrial wall excursions are mainly caused by the passive filling and emptying of the atria due to the repetitive opening and closing of the AV-valve.

\section{Time Course of Contractile Remodeling}

In a previous study we investigated the time course of atrial contractile remodeling during AF in the same model. ${ }^{11}$ It turned out that within 2 to 3 days of AF the atrial PVloop recorded during SR or slow atrial pacing was almost completely closed. At that time the atrial work index was reduced to less than $10 \%$ of the normal value. This loss of atrial contractility was present both during sinus rhythm, and during right atrial pacing with a cycle length ranging from 450 to $250 \mathrm{~ms}$. The present study extends this finding to higher atrial frequencies. Time course and extent of atrial contractile remodeling assessed during $\mathrm{AF}$ or rapid atrial pacing were roughly the same as when atrial contractile function was measured during SR or slow atrial pacing ( 300 or $400 \mathrm{~ms}$ ). The recovery of the contractile function was complete after 2 days of SR indicating that contractile remodeling recovers approximately as quickly as it develops.

\section{Effect of Contractile Remodeling on Atrial Compliance and Size}

As a result of the progressive loss of atrial contractility during AF the pressure-diameter diagram of the fibrillating atrium becomes narrower and the curvature of the compliance curve increases. This change in shape of the compliance curve reflects the decrease of the elasticity constant of the fibrillating atria while the stiffness constant increases. As result of contractile remodeling the atrial wall becomes stiffer and less elastic because atrial stretch is no longer damped by the muscle bundles but directly transferred to the more rigid strands of connective tissue. At low atrial diameters increasing stiffness of the atrial wall leads to flattening of the compliance curve causing the rightward shift of the working point and thus an increase in atrial size. After cardioversion atrial size normalizes as contractility recovers. The changes in atrial contractility and size follow exactly the same time course suggesting that during the first days of $\mathrm{AF}$ atrial dilatation is mainly related to loss of atrial contractility. This hypothesis is also supported by the observation that right atrial maximal diameters increase by only $\sim 4.5 \%$ during 5 days of AF. In contrast, the minimal atrial diameters which are more dependent on atrial contractile function increase by $\sim 24 \%$.

\section{Limitations and Clinical Relevance}

Echocardiographic studies have shown that atrial dilatation during prolonged $\mathrm{AF}$ is a progressive process which may continue for months to years. ${ }^{8}$ In contrast, atrial contractile function is already abolished after a couple of days of AF. This discrepancy strongly suggests that besides the loss of atrial contractility additional mechanisms 
contribute to atrial dilatation during prolonged AF. Elongation and new synthesis of connective tissue fibres and cellular hypertrophy might certainly contribute to the longterm increase in atrial dimensions. Due to the loss of atrial contractility atrial stretch will be transferred to the passive filaments of the atrial wall and thereby enhance elongation of collagen fibres.

During AF the atrial refractory period progressively shortens (electrical remodeling) which significantly contributes to increasing stability of AF with time. Electrical remodeling is mainly a consequence of downregulation of the $\mathrm{L}$-type $\mathrm{Ca}^{2+}$ inward current in atrial cardiomyocytes. ${ }^{21}$ In a recent study we demonstrated that electrical remodeling follows the same time course as the decrease in atrial contractility. This suggests that - like electrical remodeling - also contractile remodeling is a consequence of the reduction of the L-type $\mathrm{Ca}^{2+}$ current. ${ }^{1+}$ The present study therefore suggests that electrical remodeling is not only proarrhythmic due to the shortening of atrial refractoriness with a reduction of the reentrant circuit size. The reduction of the L-type $\mathrm{Ca}^{2+}$ current might also decrease the contractility of the fibrillating atrium resulting in an increase in atrial compliance and atrial dilatation. Atrial dilatation in turn might promote AF.

\section{$\underline{\text { Reference List }}$}

I. Fraser HRL, Turner RWD. Auricuiar fibriflation with special reference to theumatic heart disease. British Medical Journal 1955: 2:1414-1418.

2. Henry WL, Morganroth J, Pearlman AS, Clark CE, Redwood DR, Itscoitz SB, Epstein SE, Relation between echocardiographically determined left atrial size and atrial fibrillation. Circulation 1976; 53:273-279.

3. Vasan RS, Larson MG, Levy D, Evans JC, Benjamin EJ. Distribution and categorization of echocardiographic measurements in relation to reference limits: the Framingham Heart Study: formulation of a height- and sex-specific classification and its prospective validation. Circulation 1997; 96:1863-1873.

4. Vaziri SM, Larson MG, Benjamin EJ. Levy D. Echocardiographic predictors of nonrheumatic atrial fibrillation. The Framingham Heart Study. Circulation 1994; 89:724-730.

5. Boyden PA, Tilley LP, Pham TD, Liu SK, Fenoglic JJJ, Wit AL. Effects of left atrial enlargement on atrial transmembrane potentials and structure in dogs with mitral valve fibrosis. Am J Cardiol 1982; 49:1896-1908.

6. Ravelli F, Allessie M. Effects of atrial dilatation on refractory period and vulnerability to atrial fibrillation in the isolated Langendorff-perfused rabbit heart. Circulation 1997; 96:1686-1695.

7. Eijsbouts S, Majidi M, von Zandvoort M. Allessie M. The effects of acute atrial dilatation on heterogeneity in conduction in the isolated rabbit heart. J Cardiovasc Electrophysiol 2003 ; in press.

8. Sanfilippo AJ, Abascal VM. Sheehan M, Oertel LB, Harrigan P, Hughes RA, Weyman AE. Atrial enlargement as a consequence of atrial fibrillation. A prospective echocardiographic study. Circulation 1990: 82:792-797.

9. Logan W, Rowlands D. Howitt G, Holmes A. Left atrial activity following cardioversion. Lancet 1965: 2:471-473.

10. Manning WJ, Leeman DE, Gotch PJ, Come PC. Pulsed Doppler evaluation of atrial mechanical function after electrical cardioversion of atrial fibrillation. J Am Coll Cardiol 1989; 13:617-623.

11. Schotten U. Duytschaever M. Ausma J. Eijsbouts S. Neuberger HR. Allessie M. Electrical and contractile remodeling during the first days of atrial fibrillation go hand-in-hand. Circulation 2003:107:1433-1439.

12. Little R. Effect of atrial fibrillation on left atrial pressure and distensibility of pulmonary-left heart vascular segment. Proc Soc Exp Biol Med 1960; 105:87-88.

13. White CW, Kerber RE. Weiss HR. Marcus ML. The effects of atrial fibrillation on atrial pressurevolume and flow relationships. Circ Res 1982; 51:205-215. 
14. Leistad E, Christensen G, llebekk A. Effects of atrial fibrillation on left and right atrial dimensions, pressures, and compliances. Am J Physiol 1993; 264:H1093-H1097.

15. Wijffels MC, Kirchhof CJ, Dorland R, Allessie MA. Atrial fibrillation begets atrial fibrillation. A study in awake chronically instrumented goats. Circulation 1995; 92:1954-1968.

16. Leistad E. Aksnes G, Verburg E, Christensen G. Atrial contractile dysfunction after short-term atrial fibrillation is reduced by verapamil but increased by BAY K8644. Circulation 1996; 93:1747-1754.

17. Kihara Y, Sasayama S, Miyazaki S, Onodera T, Susawa T, Nakamura Y, Fujiwara H, Kawai C. Role of the left atrium in adaptation of the heart to chronic mitral regurgitation in conscious dogs. Circ Res 1988; 62:543-553.

18. Nagano T, Arakawa M, Tanaka T, Yamaguchi M, Takaya T, Noda T, Miwa H, Kagawa K, Hirakawa S. Diastolic compliance of the left atrium in man: a determinant of preload of the left ventricle. Heart Vessels 1989; 5:25-32.

19. Stefanadis C, Dernellis J, Toutouzas P. A clinical appraisal of left atrial function. Eur Heart J 2001: 22:22-36.

20. Konings KT. Mapping of the right atrium during acute and chronic atrial fibrillation in the goat. Doctoral Thesis University Maastricht 1999.

21. Yue L, Feng J, Gaspo R, Li GR, Wang Z, Nattel S. lonic remodeling underlying action potential changes in a canine model of atrial fibrillation. Circ Res 1997; 81:512-525. 



\section{Chapter 7}

\section{The Role of Atrial Dilatation in the Domestication of Atrial Fibrillation}

Ulrich Schotten, Hans-Ruprecht Neuberger, Maurits Allessie

Progress in Biophysics \& Molecular Biology 2003;82:151-162 


\section{$\underline{\text { Abstract }}$}

Numerous clinical investigations as well as recent experimental studies have demonstrated that atrial fibrillation (AF) is a progressive arrhythmia. With time paroxysmal AF becomes persistent and the success rate of cardioversion of persistent AF declines. Electrical remodeling (shortening of atrial refractoriness) develops within the first days of AF and contributes to the increase in stability of the arrhythmia. However, 'domestication of AF' must also depend on other mechanisms since the persistence of AF continues to increase after electrical remodeling has been completed. During the first days of AF in the goat, electrical and contractile remodeling (loss of atrial contractility) followed exactly the same time course suggesting that they are due to the same underlying mechanism. Contractile remodeling not only enhances the risk of atrial thrombus formation, it also enhances atrial dilatation by increasing the compliance of the fibrillating atrium. In goats with chronic AV-block atrial dilatation increased the duration of artificially induced AF-episodes but did not change atrial refractoriness or the AF cycle length. When AF was maintained a couple of days in these animals, a shortening of the atrial refractory period did occur. However, the AF cycle length did not decrease. Long lasting episodes of AF with a long AF cycle length and a wide excitable gap suggest that in this model AF is mainly promoted by conduction disturbances. Chronic atrial stretch induces activation of numerous signaling pathways leading to cellular hypertrophy, fibroblast proliferation and tissue fibrosis. The resulting electroanatomical substrate in dilated atria is characterized by increased non-uniform anisotropy and macroscopic slowing of conduction, promoting reentrant circuits in the atria. Prevention of electroanatomical remodeling by blockade of pathways activated by chronic atrial stretch therefore provides a promising strategy for future treatment of AF.

\section{$\underline{\text { Atrial Dilatation as a Risk Factor for Atrial Fibrillation }}$}

A relationship between atrial size and atrial fibrillation (AF) has been established already 50 years ago. In 1955 Fraser and Turner showed that left and right atrial enlargement correlated with the incidence of AF in patients with mitral valve disease.' Two decades later Henry et al. reported that in patients with valve disease or asymmetric septal hypertrophy AF was rare $(3 \%)$ when the left atrial diameter was less than $40 \mathrm{~mm}$, but common (54\%) when it exceeded $40 \mathrm{~mm}$. Furthermore, they found that a left atrial diameter of more than $45 \mathrm{~mm}$ predicts a high likelihood of $\mathrm{AF}$ recurrence within 6 months after cardioversion. They hypothesized that in these patients a chronic haemodynamic burden resulted in atrial dilatation which in turn increased the propensity to $\mathrm{AF}^{2}$ Two further decades later, large prospective trials established left atrial enlargement as an independent risk factor for the development of $\mathrm{AF}^{3: 4}$ In the Cardiovascular Health Study Psaty et al. included about 5000 participants who were all in sinus rhythm. ${ }^{5}$ Left atrial size at baseline was strongly and independently associated with the incidence of AF during the follow-up of 3 years. In a very recent study left 
atrial size was (apart from age) even the only predictive parameter for the occurrence of $\mathrm{AF}$ in patients with mitral regurgitation. Left ventricular ejection fraction and severity of the regurgitation were not independently associated with $\mathrm{AF}^{6}$. According to these data atrial dilatation may be a cause of $\mathrm{AF}$, and it was suggested that "interventions that maintain left atrial size may be important in the prevention of AF". 5

On the other hand, several studies imply that atrial enlargement is also a consequence of AF. In 1949 Phillips and Levine reported a series of patients with AF as a cause of reversible heart failure and cardiac dilatation. ${ }^{7}$ Probst et al. proposed in 1973 that "gross atriomegaly is an effect rather than a cause of AF in most patients" with mitral stenosis, because a high incidence of left atrial enlargement was seen only in patients with chronic AF but not in patients with intermittent $\mathrm{AF}$ or sinus rhythm. ${ }^{8}$ Keren et al. showed in 1987 that patients with mitral stenosis and sinus rhythm had normal right atrial dimensions but an increased left atrial size. ${ }^{9}$ In contrast, patients with mitral stenosis and $\mathrm{AF}$ as well as patients with lone $\mathrm{AF}$ showed significantly enlarged right and left atria. Sanfilippo et al. performed in 1990 a small but prospective echocardiographic study in patients with AF, a normal atrial size at baseline and no evidence of other cardiac abnormalities. After an average time of 20.6 months left and right atrial volume was significantly increased. ${ }^{10}$ Recently the investigators of the Stroke Prevention in Atrial Fibrillation (SPAF) trials estimated that the independent contribution of $\mathrm{AF}$ ( $>1$ year) to the increase in left atrial diameter is about $2.5 \mathrm{~mm}$. $^{\prime \prime}$ It should be noted, that none of the above-mentioned studies established a causal relationship between atrial dilatation and AF. Both could be surrogates for one and the same underlying condition. Nevertheless, these studies suggest that atrial dilatation and $\mathrm{AF}$ are mutually dependent.

\section{$\underline{\text { Positive Feedback Loops during Atrial Fibrillation }}$}

In the 90 s several experimental investigations addressed the self-perpetuating and progressive nature of AF. In a dog model of prolonged rapid atrial pacing Morillo et al. found that the atrial refractory period was reduced by about $15 \% .^{12}$ In the goat, Wijffels et al. maintained AF by a fibrillation pacemaker automatically delivering bursts of stimuli ( 1 second, $50 \mathrm{~Hz}$ ) as soon as sinus rhythm occurred. ${ }^{13}$ This resulted in a marked shortening of atrial refractoriness from $\sim 150$ to $\sim 80 \mathrm{~ms}(-45 \%)$. More importantly, these studies showed that long-term rapid atrial pacing or maintenance of AF led to a progressive increase in the stability of AF. After 6 weeks of rapid atrial pacing, in $82 \%$ of the dogs episodes of AF lasting $>15$ minutes could be induced. ${ }^{12}$ In the goat, initially only short paroxysms of AF were induced by burst pacing (mean $6 \pm 3$ seconds) but after 2 days of AF the paroxysms lasted more than 4 hours and by that time in 2 of 12 animals AF had become sustained ( $>24$ hours). After $2-3$ weeks in $90 \%$ of the goats AF was persistent. This observation of tachycardia-induced electrical remodeling creating a substrate for persistent AF, led to the concept that 'Atrial Fibrillation Begets Atrial Fibrillation'. ${ }^{13}$ The longer duration of the AF episodes was explained by a shortening of the wavelength of the atrial impulse. ${ }^{14: 15}$ When the wavelength is short, small regions of intra-atrial conduction block may already serve as a site for initiation of reentry, thus increasing the vulnerability for AF. A short wavelength is also expected to increase the 
stability of AF because it allows more reentering wavelets to coexist on the available surface area of the atria.

However, there are reasons to believe that besides the shortening of refractoriness also other factors play a role in the development of chronic AF. Already in the initial study in the goat model of AF it was noted that the time course of the changes in atrial refractoriness did not run parallel with the increase in persistence of $\mathrm{AF}$. Whereas the AF cycle length reached a new steady state within 3-5 days, it took an additional 1-2 weeks before AF became persistent. ${ }^{13}$ This led to the hypothesis that a so-called 'second factor' was involved in the development of persistent AF.

Therefore, we recently suggested the existence of additional positive feedback loops in AF (figure 1). ${ }^{16}$ While the positive feedback between electrical remodeling and AF is well established, the proposed cascades of contractile and structural remodeling are still partly hypothetical. Structural remodeling has been demonstrated to occur as a consequence of AF but is also believed to promote the arrhythmia. Also, changes of the mechanical properties of the atria might contribute to the domestication of AF. AF induces a pronounced contractile dysfunction of the atria ${ }^{17: 18}$ which might increase atrial compliance and size. As explained above clinical observations suggest that increased atrial size might in turn promote AF. Recently, we tried to verify this hypothetical contractile feedback loop in the goat model of AF. The following two paragraphs will describe time course and extent of the AF-induced atrial contractile dysfunction in these animals, the subsequent changes in atrial compliance and size, and the effect of chronic atrial dilatation on the electrophysiological properties of the atria and the stability of AF.

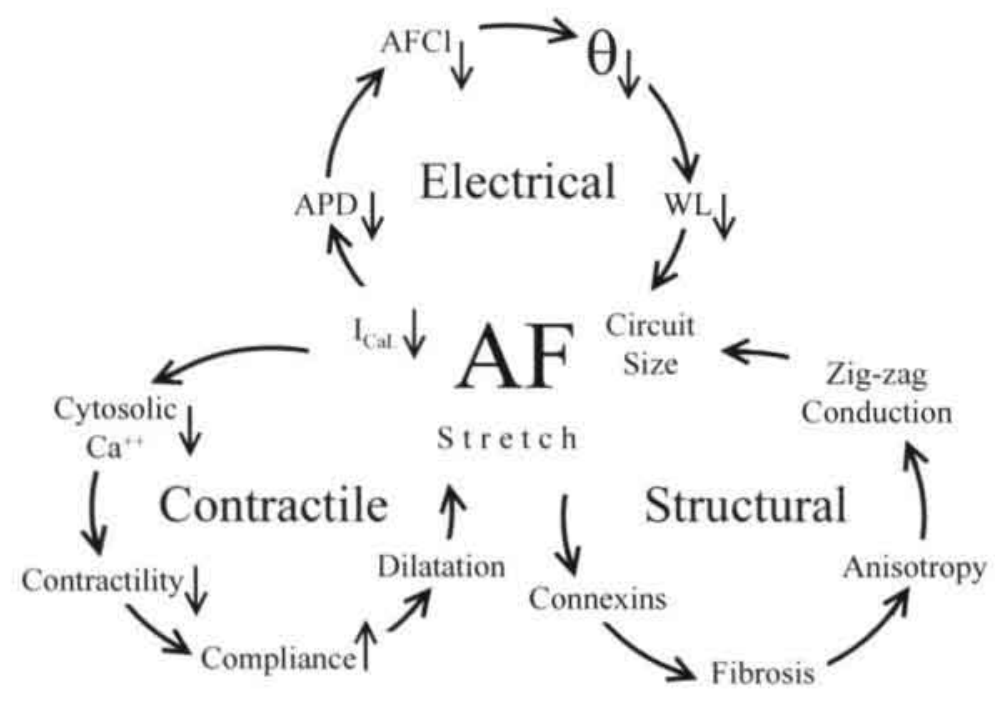

Figure 1

Three proposed positive feedback-loops of atrial remodeling on AF. Reduction of the L-type Ca' inward current is considered to be the primary cause for electrical and contractile remodeling. The loss of atrial contractility leads to an increase in compliance of the fibrillating atria which in furn facilitates atrial dilatation. The resulting stretch acts as a stimulus for structural remodeling of the enlarged atria. The combination of electrical and structural remodeling allows intra-atrial reentrant circuits of a smaller size, due to a reduction in wavelength (shortening of refractoriness and slowing of conduction) and increased non-uniform tissue anisotropy (zig-zag conduction). Modified from Allessie, 2002. 


\section{Atrial Dilatation as a Consequence of Atrial Fibrillation}

We recently evaluated the effects of AF on atrial contractility, compliance, and size in the goat model of $\mathrm{AF} .{ }^{19}$ The animals were instrumented with epicardial electrodes and ultrasonic piezoelectric crystals to measure the medio-lateral diameter of the atrium. A tip pressure transducer was implanted in the right atrium via the right jugular vein. $\mathrm{AF}$ was induced by burst pacing as soon as sinus rhythm (SR) was detected. ${ }^{13}$ During 5 days of artificially maintained AF changes in atrial pressure, contractility, compliance and size were followed. After spontaneous cardioversion the recovery of atrial contractility and dimensions was studied for 5 days in SR.

Right atrial pressure diameter loops were obtained by plotting right atrial pressure against its medio-lateral diameter. The area enclosed by these surrogate PV-loops reflects the work performed by the atrium and is referenced to as the atrial work index (AWI). Figure 2 shows right atrial PV-loops recorded during slow atrial pacing at a cycle length of $400 \mathrm{~ms}$. During the 5 days of AF the area enclosed by the loop (=AWI) progressively declined. After 2 days of AF AWI was reduced by $~ 75 \%$ and after 5 days the loop was almost closed indicating that the atrial contractile function was nearly completely abolished. After resumption of SR atrial contractile function completely recovered within 5 days. As expected, $\mathrm{AF}$ also shortened the atrial effective refractory period (AERP). The AERP declined from $\sim 140 \mathrm{~ms}$ before the induction of AF to $\sim 85 \mathrm{~ms}$ after 5 days of AF. Interestingly, contractile remodeling (reduction of the atrial work index) and electrical remodeling (shortening of AERP) followed exactly the same time course. Since the main cellular mechanism responsible for electrical remodeling is the reduction of the L-type $\mathrm{Ca}^{2+}$ inward current $\left(\mathrm{I}_{\mathrm{Cat}}\right)^{20}$ it is likely that atrial contractile dysfunction during the first 5 days of $\mathrm{AF}$ is also due the reduction of $\mathrm{I}_{\mathrm{Cal}}$.

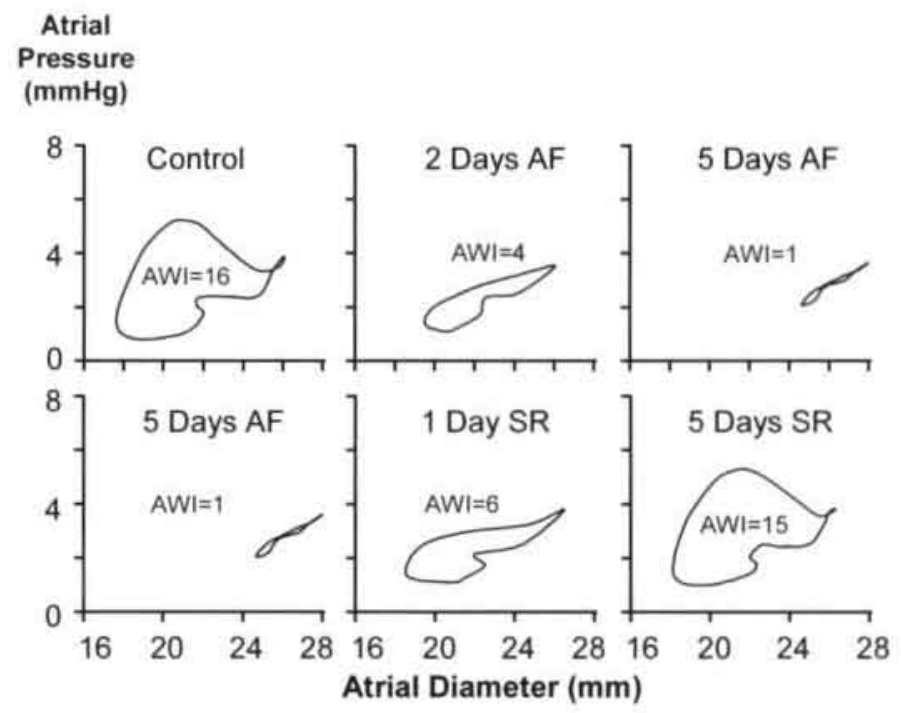

Figure 2

Contractile remodeling of the atria during the first 5 days of AF. Pressure-diameter loops and atrial electrograms of a goat during slow atrial pacing at a cycle length of $400 \mathrm{~ms}$. The atrial work index (AWI) decreased from $16 \mathrm{~mm}^{*} \mathrm{mmHg}$ to $1 \mathrm{~mm} * \mathrm{mmHg}$ within 5 days of AF. The atrial contractile function was completely restored within 5 days after cardioversion. Modified from Schotten, 2001. 
To quantify atrial contractility during AF the amplitude of the right atrial pressure waves during AF was measured. After 5 days of AF the amplitude of the pressure waves and the atrial wall excursions during AF were reduced to less than $15 \%$. This clearly indicates that the loss of atrial contractility is not only present when assessed during SR or slow atrial pacing. Also, the contractility of the fibrillating atrium is markedly reduced after a couple of days in AF. After resumption of SR, also the atrial contractility during brief episodes of AF also recovered completely within 3 days of SR. To study the effect of the loss of atrial contractility on the compliance of the fibrillating atrium, pressure and diameter were measured after unloading the atria with a fast acting loop diuretic and after loading the atria with $1 \mathrm{~L}$ saline infused within $10 \mathrm{~min}^{21}$ In figure 3 representative compliance curves during baseline (acute AF), after 3 days, and after 5 days of AF are given. The mean atrial pressure $\left(\mathrm{P}_{\text {mean }}\right)$ did not change throughout the experiment. During the first days of $\mathrm{AF}$ the compliance curve flattened indicating that the compliance of the atrium increased. This caused a rightward shift of the working point (gray) and the mean atrial diameter $\left(D_{\text {mean }}\right)$ increased from 24.2 to $26.3 \mathrm{~mm}$. The changes in atrial compliance and size followed the same time course as the loss of contractility of the fibrillating atria and were fully reversible within two days of SR. Administration of the $\mathrm{Ca}^{2+}$-sensitizer EMD 57033 significantly increased the contractility of the fibrillating atria leading to a decrease in atrial compliance and size. This suggests that the increase in atrial size during the first days of AF is mainly due to a loss of contractility of the fibrillating atrium resulting in an increase in atrial compliance.

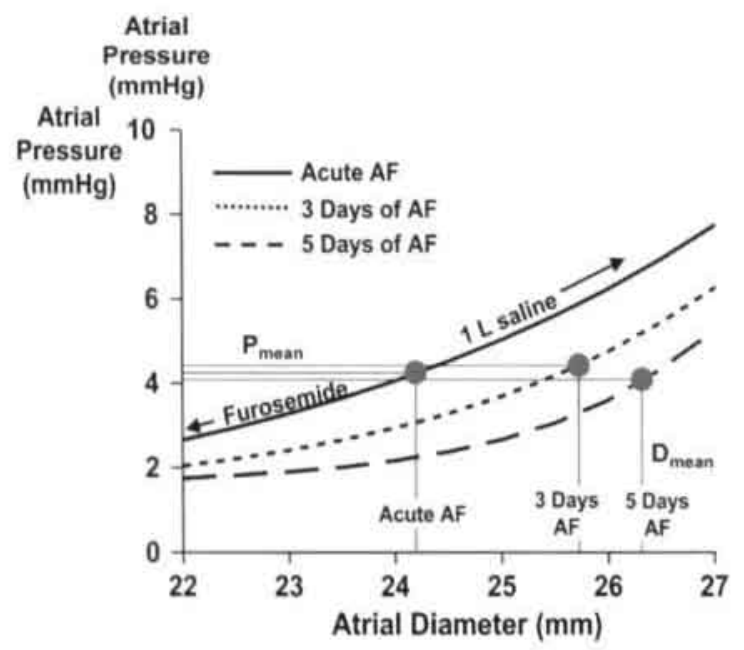

\begin{abstract}
Figure 3
Representative right atrial compliance curves during acute $A F$ and after 3 or 5 days of $A F$. The compliance was measured by unloading the atria with a rapidly acting loop-diuretic and loading by infusion of $1 \mathrm{~L}$ saline in $10 \mathrm{~min}$. Due to an increase in atrial compliance at low atrial diameters flattening of the compliance curve) the working point during $A F$ shifted to the right. $P_{\text {mon }}=$ mean atrial pressure. $D_{\text {mon }}=$ mean atrial diameter, Modified from Schotten, 2002.
\end{abstract}

Echocardiographic studies have shown that atrial dilatation during AF is a progressive process which may continue for months to years. ${ }^{10}$ In contrast, in our experimental studies atrial contractile function was almost completely abolished after a couple of days of AF. Obviously, apart from the loss of atrial contractility, additional mechanisms are operative which cause the atria to dilate during prolonged AF. The loss of atrial contractility will transfer the atrial stretch more to the passive elements of the atrial wall which might lead to elongation of collagen fibres. Synthesis of connective tissue fibres and cellular hypertrophy could also result in a slow increase in atrial dimensions. 
Our results emphasize the role of atrial contractile dysfunction for dilatation of the atria. Prevention of the atrial contractile dysfunction during AF thus might be able to delay or even prevent atrial dilatation. Verapamil ${ }^{22 ; 23}$ and the $\mathrm{Na}^{+} / \mathrm{H}^{+}$-exchange inhibitor $\mathrm{HOE}$ $642^{24}$ have been shown to prevent atrial hypocontractility following short-lasting $\mathrm{AF}$. However, prevention of the atrial contractile dysfunction during prolonged $\mathrm{AF}$ has not been reported yet. Nevertheless, since atrial enlargement decreases the success rate of pharmacological and electrical cardioversion, treatment of contractile remodeling might be a worthwhile therapeutic goal in itself.

\section{Atrial Dilatation as a Cause of Atrial Fibrillation}

The effect of atrial enlargement on atrial electrophysiology was repeatedly addressed during the past two decades. Mostly, the effect of acute atrial dilatation on atrial refractoriness and conduction was investigated. These studies, however, revealed conflicting results. Acute atrial dilatation in isolated rabbit hearts or in open-chest dogs resulted in a shortening of atrial refractoriness. ${ }^{25: 26}$ Others described no change ${ }^{27}$ or even a prolongation of the refractory period during acute stretch. ${ }^{28: 29}$ The only common finding was an increase in the inducibility and persistence of AF.

The first experiments on chronic enlargement of the atria were performed in the early 1980 s by Boyden et al. In 8 dogs with tricuspid regurgitation and stenosis of the pulmonary artery the right atrial volume increased by $40 \%$ during -100 days of followup. Atrial arrhythmias did not occur spontaneously. However, the inducibility and the duration of artificially induced atrial tachyarrhythmias significantly increased. Atrial refractoriness was not measured, but the duration of action potentials recorded in vitro were not different compared to control. Histological and ultrastructural analysis revealed cardiac hypertrophy and an increase in connective tissue content. ${ }^{30}$ In another study in dogs with spontaneous mitral valve fibrosis (MVF) and left atrial enlargement also no change in transmembrane potentials was found. ${ }^{31}$ In MVF dogs left atrial volume was six to eight times the left atrial volume of control dogs. In-between the greatly hypertrophied atrial myocytes (17 vs. $10 \mu \mathrm{m}$ in diameter) a large amount of connective tissue was present. Most MVF animals had spontaneous atrial arrhythmias, but the underlying mechanism could not be defined. The authors speculated that atrial conduction could be impaired. An alternative explanation for the increased stability of AF in chronically dilated atria was provided by Le Grand et al. They demonstrated that in trabeculae from human dilated atria the action potential was shortened and the plateau was markedly depressed. In isolated cells of dilated atria the $\mathrm{Ca}^{2+}$ inward current was reduced. ${ }^{32}$

To describe the chronological sequence of progressive atrial dilatation and its correlation with alterations in atrial electrophysiology, we studied goats with chronic complete AV block. ${ }^{33}$ Six goats were instrumented with modified screw-in leads with two sonomicrometer crystals attached to the tip. Two of these modified leads were placed in the right atrium, one in the anterolateral and one in the posteroseptal wall. With the ultrasound crystals the distance between the lead tips could be measured as an index of the atrial diameter. Two weeks after instrumentation the mean atrial diameter and the atrial effective refractory period (AERP) were measured. AF was induced by 
$50 \mathrm{~Hz}$ burst pacing and both, the duration of AF episodes (AFD) and the AF interval (AFCL) were determined. After these control measurements the His bundle was ablated and the goats were left in a slow idioventricular rhythm. The atrial diameter, AERP, AFD and AFCL were determined weekly during 4 weeks.

Figure 4A (left panel) shows an atrial electrogram together with the changes in atrial diameter during normal sinus rhythm (Control). The atrial diameter is maximal at the end of the ventricular contraction, followed first by passive and then by active atrial emptying. After His bundle ablation the ventricular heart rate decreased from about 120 to $50 \mathrm{bpm}$. Mean atrial and enddiastolic ventricular pressures acutely increased by $\sim 5 \mathrm{mmHg}$ but remained constant during 4 weeks of AV block. Within the first days in AV block the atrial diameter did not change (Figure $4 \mathrm{~A}$, mid panel). However 4 weeks after the ablation the atrial diameter was increased by $\sim 12 \%$. Together with atrial dilatation the duration of $\mathrm{AF}$ paroxysms increased from a few seconds during control to several hours (Figure 4B). Since the AERP and AFCL kept constant throughout 4 weeks of complete AV block, the increased persistence of AF could not be explained by a shortening of AERP. Studies in humans with biatrial dilatation even showed a longer AERP compared to control, ${ }^{34: 35}$ and animal models of rapid pacing induced heart failure and atrial dilatation demonstrated either a prolongation of the AERP ${ }^{36: 37}$ or no change. ${ }^{38}$ Possibly, the enlarged atria simply allow more re-entrant circuits to coexist, which increases the stability of AF.

A

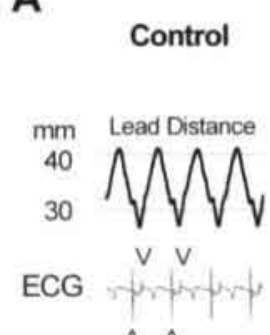

\section{AV block} 2 days

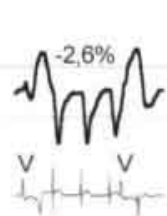

A A A A A

\section{AV block 4 weeks}

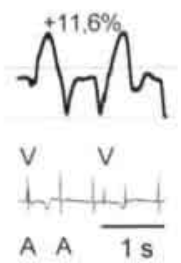

\section{[\%]}

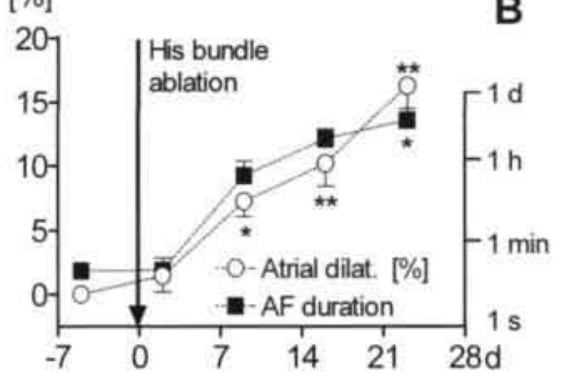

Figure 4

A: A representative example of traces obtained from goats endocardially instrumented with modified atrial leads. Upper trace: Distance between the antero-lateral and the posteroseptal lead in the right atrium measured by ultrasound crystals attached to the lead tip. Lower trace: Unipolar atrial electrogram. Both during control and AV-block the atrial diameter reaches a maximum at the end of the ventricular systole $(T$ wave) followed by passive and then active atrial emptying. During AV-block single isolated atrial contractions can be recognized during the long diastolic pause. Two days after His bundle ablation the mean diameter is not increased, whereas 4 weeks of $A V$-block result in a relative dilatation of about $12 \%$ in one dimension

B: Relative atrial dilatation and duration of induced AF episodes during control and 4 weeks of chronic complete AV block in 6 goats. From Neuberger. 2002.

An interesting finding in the goats with chronic $\mathrm{AV}$ block was that $\mathrm{AF}$-induced electrical remodeling (shortening of AERP) was not associated with a shortening of the mean AFCL (Fig. 5, left panel). First, this demonstrates that electrical remodeling still occurs in dilated atria. Unlike recent reports in a dog model of heart failure, ${ }^{39}$ the time course and the extent of tachycardia induced electrical remodeling in AV block goats were similar to control suggesting that the same mechanisms are also operating in dilated atria. Secondly, a shortening of the AERP without a concomitant shortening of AFCL means that the excitable gap during AF becomes wider. This observation may be 
explained by lines of conduction block resulting in macroreentrant circuits during $\mathrm{AF}$ as described in a dog model of mitral regurgitation. ${ }^{40}$ In dogs with cardiomyopathy and pronounced atrial dilatation, a prolonged AFD and discrete regions of slow atrial conduction were found (Figure 5, right panel). Atrial myofibres were separated by thick layers of connective tissue which may cause local conduction block during $\mathrm{AF}^{38}{ }^{38}$

Although the causal relationship has not been established yet, all these experimental results indicate that impairment of atrial wavefront propagation can be a consequence of atrial dilatation and thereby stabilises AF.

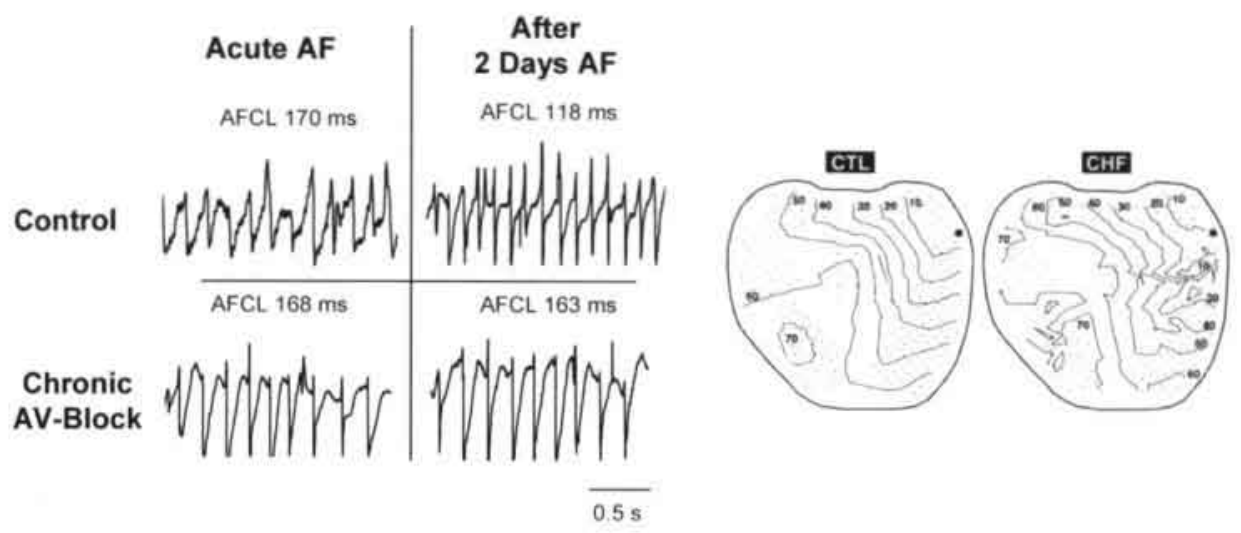

Figure 5

Left panel: A representative example of unipolar endocardial atrial electrograms obtained from a goat after induction of $A F$ by burst pacing. Under control conditions (conducting $A V$ node, upper panels) the median $A F$ interval and the AERP shorten during 2 days of $A F$. During chronic complete AV block (lower panels) $A F$ maintenance during 2 days still reduces AERP. but AFCL keeps constant. This indicates a widening of the excitable gap during electrical remodeling in the AV block goat.

Right panel: Activation map of the left and right atrium in a dog with tachycardiomyopathy. Left: Control. Right: Dog with heart failure (rapid ventricular pacing for 6 weeks). Crowding of isochrones indicates local slowing of conduction. Modified from Li, 1999.

\section{The Role of Mechanoelectric Feedback in the Generation of the Substrate of AF}

The original concept of mechanoelectrical feedback described electrophysiological changes induced by acute stretch. These alterations included changes of the action potential duration, a decrease in the resting diastolic potential, the occurrence of early afterdepolarisations and the generation of ectopic beats. ${ }^{4 t}$ They are mediated by the activation of mechano-sensitive channels and might provoke stretch-induced arrhythmias by changes in excitability and refractoriness or the occurrence of ectopic activity.

A different kind of mechano-electric feedback may be induced by chronic stretch. Chronic stretch has been demonstrated to activate numerous intracellular signaling pathways including the mitogen-activated protein kinase pathway (MAPK), the janus 


\section{8 | Chapter 7}

kinase/signal transducers and activators of transcription pathway (JAK/STAT) as well as $\mathrm{Ca}^{2+} /$ calmodulin dependent pathways. ${ }^{42}$ Stretch also stimulates local secretion of angiotensin II, which together with other growth factors, causes activation of various second messengers systems. ${ }^{43}$ These signaling pathways are known to promote cellular hypertrophy, to stimulate fibroblast proliferation, and to activate matrix protein synthesis leading to tissue fibrosis. ${ }^{44}$ In fibrotic myocardium conduction velocity is slowed by microscopic zigzagging circuits or depressed propagation in branching muscle bundles. ${ }^{45}$ Such an electroanatomical substrate will allow multiple small reentrant circuits which will stabilize the arrhythmia. ${ }^{46}$ Multiple entry and exit points and multiple sites at which unidirectional block occurs will shift the balance between generation and extinction of wavelets more to the favor of generation of new wavefronts. Also, tissue fibrosis will tend to increase electrophysiological dispersion. ${ }^{47}$ While the scarred matrix will transfer stretch primarily to the adjacent atrial myocardium, other regions might even become shielded by surrounding strands of connective tissue. Unequal atrial stretch has been shown to affect the local refractory period differentially depending on the degree of elongation of the atrial muscle fibers. ${ }^{28}$ Therefore, tissue fibrosis will not only increase anisotropy in conduction but also dispersion in refractoriness. Cellular hypertrophy increases the complexity of the substrate even more since in hypertrophied myocytes smaller mechanical stimuli are sufficient to activate stretch-activated channels. ${ }^{48}$

Finally, the development of such an electroanatomical substrate would also explain the loss of efficacy of drugs to cardiovert AF. In discontinuous tissue the safety-factor for conduction is higher than in normal tissue. ${ }^{49}$ Thus, a higher degree of $\mathrm{I}_{\mathrm{Na}}$-blockade is required to terminate AF. Anatomical obstacles might widen the excitable gap during $\mathrm{AF}$ making drugs that prolong atrial refractoriness less effective ${ }^{50}$ Also, multiple sites at which unidirectional block occurs might facilitate reinduction of $\mathrm{AF}$ immediately after cardioversion by early premature beats.

Therefore, new experimental strategies more focus on the prevention of structural remodeling. Recently, the ACE-inhibitor enalapril has been shown to attenuate atrial fibrosis and conduction disturbances in dogs with rapid pacing-induced heart failure. ${ }^{51}$ This observation supports the hypothesis that the activation of the renin-angiotensin system is involved in the signalling cascade leading to atrial cell growth, proliferation of fibroblasts and atrial fibrosis. Also, in clinical trials ACE-inhibitors proved to be effective against $\mathrm{AF}$ in patients with heart failure ${ }^{52}$ or left ventricular dysfunction after myocardial infarction. ${ }^{53}$ While this effect might be explained by an improvement of the patients hemodynamics a recent trial with the angiotensin receptor blocker irbesartan showed that blockade of the renin-angiotensin system can reduce the recurrence rate of $\mathrm{AF}$ in a heterogeneous patient population with less diseased hearts. ${ }^{54}$ However, since in structurally remodeled atria mechanical strain is heterogeneously transferred to the atrial myocytes, more detailed studies on the role of mechano-sensitive channels for the perpetuation of AF would certainly be worthwhile. 


\section{Reference List}

1. Fraser HRL, Turner RWD. Auricular fibrillation with special reference to rheumatic heart disease. British Medical Journal 1955; 2:1414-1418.

2. Henry WL, Morganroth J, Pearlman AS, Clark CE, Redwood DR, Itscoitz SB, Epstein SE. Relation between echocardiographically determined left atrial size and atrial fibrillation. Circulation 1976; $53: 273-279$.

3. Vasan RS, Larson MG. Levy D, Evans JC, Benjamin EJ. Distribution and categorization of echocardiographic measurements in relation to reference limits: the Framingham Heart Study: formulation of a height- and sex-specific classification and its prospective validation. Circulation 1997: 96:1863-1873.

4. Vaziri SM, Larson MG, Benjamin EJ, Levy D. Echocardiographic predictors of nonrheumatic atrial fibrillation. The Framingham Heart Study. Circulation 1994; 89:724-730.

5. Psaty BM, Manolio TA, Kuller LH, Kronmal RA, Cushman M, Fried LP, White R, Furberg CD, Rautaharju PM. Incidence of and risk factors for atrial fibrillation in older adults. Circulation 1997; 96:2455-2461.

6. Grigioni F, Avierinos JF, Ling LH, Scott CG, Bailey KR, Tajik AJ, Frye RL, Enriquez-Sarano M. Atrial fibrillation complicating the course of degenerative mitral regurgitation: determinants and longterm outcome. J Am Coll Cardiol 2002; 40:84-92.

7. Phillips E, Levy D. Auricular fibrillation without other evidence of heart disease. A cause of reversible heart failure. Am J Med 1949; 7:478-489.

8. Probst P, Goldschlager N, Selzer A. Left atrial size and atrial fibrillation in mitral stenosis. Factors influencing their relationship. Circulation 1973; 48:1282-1287.

9. Keren G, Etzion T, Sherez J, Zelcer AA, Megidish R, Miller HI, Laniado S. Atrial fibrillation and atrial enlargement in patients with mitral stenosis. Am Heart J 1987; 114:1146-1155.

10. Sanfilippo AJ, Abascal VM, Sheehan M, Oertel LB, Harrigan P. Hughes RA, Weyman AE. Atrial enlargement as a consequence of atrial fibrillation. A prospective echocardiographic study. Circulation 1990: 82:792-797.

11. Dittrich HC, Pearce LA, Asinger RW, McBride R, Webel R, Zabalgoitia M, Pennock GD, Safford RE, Rothbart RM. Halperin JL, Hart RG. Left atrial diameter in nonvalvular atrial fibrillation: An echocardiographic study. Stroke Prevention in Atrial Fibrillation Investigators. Am Heart J 1999: 137:494-499.

12. Morillo CA, Klein GJ, Jones DL, Guiraudon CM. Chronic rapid atrial pacing. Structural, functional, and electrophysiological characteristics of a new model of sustained atrial fibrillation. Circulation 1995; 91:1588-1595.

13. Wijffels MC, Kirchhof CJ, Dorland R, Allessie MA. Atrial fibrillation begets atrial fibrillation. A study in awake chronically instrumented goats. Circulation 1995; 92:1954-1968.

14. Allessie MA. Atrial electrophysiologic remodeling: another vicious circle? J Cardiovasc Electrophysiol 1998: 9:1378-1393.

15. Rensma PL. Allessie MA. Lammers WJ. Bonke FI, Schalij MJ. Length of excitation wave and susceptibility to reentrant atrial arrhythmias in normal conscious dogs. Circ Res 1988; 62:395-410.

16. Allessie MA, Ausma J. Schotten U. Electrical, contractile and structural remodeling during atrial fibrillation. Cardiovasc Res 2002; 54:230-246.

17. Logan W. Rowlands D. Howitt G, Holmes A. Left atrial activity following cardioversion. Lancet $1965 ; 2: 471-473$.

18. Manning WJ, Leeman DE, Gotch PJ, Come PC. Pulsed Doppler evaluation of atrial mechanical function after electrical cardioversion of atrial fibrillation. J Am Coll Cardiol 1989; 13:61 7-623.

19. Schotten U, Allessie MA. Electrical and mechanical remodeling of the atria: what are the underlying mechanisms, the time course and clinical relevance? In: A Raviele: Cardiac Arrhythmias 2001; Springer:345-352.

20. Yue L, Feng J, Gaspo R, Li GR, Wang Z, Nattel S. Ionic remodeling underlying action potential changes in a canine model of atrial fibrillation. Circ Res 1997; 81:512-525.

21. Schotten U, Allessie MA. Atrial size, pressure, and compliance during the first 5 days of atrial fibrillation in the goat. Z Kardiol 2002; $91: 1171$.

22. Leistad E, Aksnes G, Verburg E. Christensen G. Atrial contractile dysfunction after short-term atrial fibrillation is reduced by verapamil but increased by BAY K8644. Circulation 1996; 93:1747-1754.

23. Daoud EG, Marcovitz P. Knight BP, Goyal R, Man KC, Strickberger SA. Armstrong WF. Morady F. Short-term effect of atrial fibrillation on atrial contractile function in humans. Circulation 1999; 99-3024-3027. 
24. Altemose GT, Zipes DP, Weksler J, Miller JM, Olgin JE. Inhibition of the $\mathrm{Na}(+) / \mathrm{H}(+)$ exchanger delays the development of rapid pacing-induced atrial contractile dysfunction. Circulation 2001; 103:762-768.

25. Ravelli F. Allessie M. Effects of atrial dilatation on refractory period and vulnerability to atrial fibrillation in the isolated Langendorff-perfused rabbit heart. Circulation 1997; 96:1686-1695.

26. Solti F, Vecsey T, Kekesi V, Juhasz-Nagy A. The effect of atrial dilatation on the genesis of atrial arthythmias. Cardiovasc Res 1989;23:882-886.

27. Wijffels MCEF, Kirchhof CJHJ, Dorland R, Power J, Allessie MA. Electrical remodeling due to atrial fibrillation in chronically instrumented conscious goats: roles of neurohumoral changes, ischemia, atrial stretch and high rate of electrical activation. Circulation 1997; 96:3710-3720.

28. Satoh T, Zipes DP. Unequal atrial stretch in dogs increases dispersion of refractoriness conducive to developing atrial fibrillation. J Cardiovasc Electrophysiol 1996; 7:833-842.

29. Sideris DA, Toumanidis ST, Thodorakis M. Kostopoulos K, Tselepatiotis E, Langoura C, Stringli T, Moulopoulos SD. Some observations on the mechanism of pressure related atrial fibrillation. Eur Heart J 1994: 15:1585-1589.

30. Boyden PA, Hoffman BF. The effects on atrial electrophysiology and structure of surgically induced right atrial enlargement in dogs. Circ Res 1981; 49:1319-1331.

31. Boyden PA, Tilley LP, Pham TD, Liu SK, Fenoglic JJ, Wit AL. Effects of left atrial enlargement on atrial transmembrane potentials and structure in dogs with mitral valve fibrosis. Am J Cardiol 1982; 49:1896-1908.

32. Le Grand BL, Hatem S, Deroubaix E, Couetil JP, Coraboeuf E. Depressed transient outward and calcium currents in dilated human atria. Cardiovasc Res 1994; 28:548-556.

33. Neuberger HR, Schotten U, Ausma J, Blaauw Y, Eijsbouts S, van Hunnik A, Allessie M. Atrial remodeling in the goat due to chronic complete atrioventricular block. European Heart Journal 2002;23:138.

34. Sparks PB, Mond HG, Vohra JK. Jayaprakash S, Kalman JM. Electrical remodeling of the atria following loss of atrioventricular synchrony: a long-term study in humans. Circulation 1999; 100:1894-1900.

35. Chen YJ, Chen SA, Tai CT, Yu WC, Feng AN, Ding YA, Chang MS. Electrophysiologic characteristics of a dilated atrium in patients with paroxysmal atrial fibrillation and atrial flutter. $\mathrm{J}$ Interv Card Electrophysiol 1998; 2:181-186.

36. Power JM, Beacom GA, Alferness CA, Raman J, Farish SJ. Tonkin AM. Effects of left atrial dilatation on the endocardial atrial defibrillation threshold: a study in an ovine model of pacing induced dilated cardiomyopathy. Pacing Clin Electrophysiol 1998; 21:1595-1600.

37. Power JM, Beacom GA. Alferness CA, Raman J. Wijffels M. Farish SJ, Burrell LM, Tonkin AM. Susceptibility to atrial fibrillation: a study in an ovine model of pacing-induced early heart failure. J Cardiovasc Electrophysiol 1998; 9:423-435.

38. Li D, Fareh S, Leung TK, Nattel S. Promotion of atrial fibrillation by heart failure in dogs: atrial remodeling of a different sort. Circulation 1999; 100:87-95.

39. Shinagawa K, Li D, Leung TK, Nattel S. Consequences of atrial tachycardia-induced remodeling depend on the preexisting atrial substrate. Circulation 2002; 105:251-257.

40. Cox JL, Canavan TE, Schuessler RB. Cain ME, Lindsay BD, Stone C, Smith PK. Corr PB, Boineau JP. The surgical treatment of atrial fibrillation. II. Intraoperative electrophysiologic mapping and description of the electrophysiologic basis of atrial flutter and atrial fibrillation. J Thorac Cardiovasc Surg 1991: 101:406-426.

41. Franz MR. Mechano-electrical feedback. Cardiovasc Res 2000; 45:263-266.

42. Ruwhof C, van der LA. Mechanical stress-induced cardiac hypertrophy: mechanisms and signal transduction pathways. Cardiovase Res 2000; 47:23-37.

43. Sadoshima J, Izumo $\mathrm{S}$. The cellular and molecular response of cardiac myocytes to mechanical stress. Annu Rev Physiol 1997: 59:551-71.

44. Goette A, Lendeckel U, Klein HU. Signal transduction systems and atrial fibrillation. Cardiovasc Res 2002: 54:247-258.

45. de Bakker JM, van Capelle FJ, Janse MJ, Tasseron S, Vermeulen JT, de Jonge N. Lahpor JR. Slow conduction in the infarcted human heart. 'Zigzag' course of activation. Circulation 1993; 88:915-926,

46. Spach MS, Josephson ME. Initiating reentry: the role of nonuniform anisotropy in small circuits. J Cardiovase Electrophysiol 1994; 5:182-209.

47. Allessie MA, Boyden PA. Camm AJ. Kleber AG, Lab MJ, Legato MJ, Rosen MR, Schwartz PJ, Spooner PM, Van Wagoner DR. Waldo AL. Pathophysiology and prevention of atrial fibrillation. Circulation 2001; 103:769-777.

48. Kamkin A, Kiseleva I, Isenberg G. Stretch-activated currents in ventricular myocytes: amplitude and arrhythmogenic effects increase with hypertrophy. Cardiovase Res 2000; 48:409-420. 
49. Shaw RM, Rudy Y. Ionic mechanisms of propagation in cardiac tissue. Roles of the sodium and Ltype calcium currents during reduced excitability and decreased gap junction coupling. Circ Res 1997: 81:727-741.

50. Girouard SD, Pastore JM, Laurita KR, Gregory KW, Rosenbaum DS. Optical mapping in a new guinea pig model of ventricular tachycardia reveals mechanisms for multiple wavelengths in a single reentrant circuit. Circulation 1996; 93:603-613.

51. Li D, Shinagawa K, Pang L, Leung TK, Cardin S, Wang Z, Nattel S. Effects of Angiotensinconverting enzyme inhibition on the development of the atrial fibrillation substrate in dogs with ventricular tachypacing-induced congestive heart failure. Circulation 2001; 104:2608-2614.

52. Gurlek A, Erol C, Basesme E. Antiarrhythmic effect of converting enzyme inhibitors in congestive heart failure. Int J Cardiol 1994; 43:315-318.

53. Pedersen OD, Bagger H, Kober L, Torp-Pedersen C. Trandolapril reduces the incidence of atrial fibrillation after acute myocardial infarction in patients with left ventricular dysfunction. Circulation 1999; 100:376-380.

54. Madrid AH, Bueno MG, Rebollo JM, Marin I, Pena G, Bernal E, Rodriguez A, Cano L, Cano JM, Cabeza P. Moro C. Use of irbesartan to maintain sinus rhythm in patients with long-lasting persistent atrial fibrillation: a prospective and randomized study. Circulation 2002; 106:331-336. 



\section{Chapter 8}

\section{General Discussion}

\section{Electrical, Contractile and Structural Remodeling during Atrial Fibrillation}

Maurits Allessie, Jannie Ausma, Ulrich Schotten 


\section{$\underline{\text { Abstract }}$}

The natural history of atrial fibrillation (AF) is characterized by a gradual worsening with time. The recent finding that $\mathrm{AF}$ itself produces changes in atrial function and structure has provided a possible explanation for the progressive nature of this arrhythmia. Electrical remodeling (shortening of atrial refractoriness) develops within the first days of AF and contributes to an increase in stability of AF. However, 'domestication of AF' must also depend on a 'second factor' since the persistence of AF continues to increase after electrical remodeling has been completed. Atrial contractile remodeling (loss of contractility) leads to a reduced atrial transport function after cardioversion of AF. An important clinical consequence is that during several days after restoration of sinus rhythm, the risk of atrial thrombus formation is still high. In addition, the reduction of atrial contractility during AF may enhance atrial dilatation which may add to the persistence of AF. Tachycardia-induced structural remodeling takes place in a different time domain (weeks to months). Myolysis probably contributes to the loss of atrial contractile force. Although it might explain the loss of efficacy of pharmacological cardioversion and the development of permanent AF, the role of structural remodeling in the progression of $\mathrm{AF}$ is still unclear. Atrial structural remodeling also occurs as a result of heart failure and other underlying cardiovascular diseases. The associated atrial fibrosis might explain intra-atrial conduction disturbances and the susceptibility for AF. Thus, both AF itself and the underlying heart disease are responsible for the development of the arrhythmogenic substrate. New strategies for prevention and termination of AF should be build on our knowledge of the mechanisms and time course of AF-induced atrial remodeling.

\section{Electrical Remodeling}

The concept of tachycardia-induced electrical remodeling of the atria was introduced in 1995 by two independent experimental studies. ${ }^{1: 2}$ In a dog model of prolonged rapid atrial pacing $(400 / \mathrm{min})$ Morillo et al. found that the atrial refractory period was reduced by about $15 \%$. In the goat, Wijffels et al. maintained AF by a fibrillation pacemaker automatically delivering bursts of stimuli (1 second, $50 \mathrm{~Hz})$ as soon as sinus rhythm occurred. This resulted in an even more marked shortening in atrial refractoriness from $146 \pm 19$ to $81 \pm 22 \mathrm{~ms}(-45 \%)$ and a loss (or even inversion) of the normal rate adaptation of the refractory period. Given its long-term nature (days to weeks) these tachycardiainduced changes in atrial refractoriness were thought to be due to alterations in the expression of ion channels and were referred to as 'electrical remodeling'.' More importantly, these studies showed that long-term rapid atrial pacing or maintenance of AF led to a progressive increase in the susceptibility to atrial fibrillation (AF). After 6 weeks of rapid atrial pacing, in $82 \%$ of the dogs episodes of AF lasting $>15$ minutes could be induced. ${ }^{2}$ In the goat this effect was even more striking. Whereas during control, only short paroxysms of AF were induced by burst pacing (mean $6 \pm 3$ seconds), 
after 2 days of AF the paroxysms lasted 7.8 \pm 9.7 minutes and by that time in 2 of 12 animals AF had become sustained ( $>24$ hours). After $2-3$ weeks in $90 \%$ of the goats AF was persistent (Figure 1). This observation of tachycardia-induced electrical remodeling creating a substrate for persistent AF, led to the concept that 'Atrial Fibrillation Begets Atrial Fibrillation'.'

The higher susceptibility to AF was explained by a shortening of the wavelength of the atrial impulse. ${ }^{3: 4}$ When the wavelength is short, small regions of intra-atrial conduction block may already serve as a site for initiation of reentry, thus increasing the vulnerability for AF. A short wavelength is also expected to increase the stability of AF because it allows more reentering wavelets to coexist in the available surface area of the atria. This is illustrated in the right part of Figure 1, showing high density maps (diameter $4 \mathrm{~cm}, 240$ electrodes) from the free wall of the right atrium during paroxysmal (type I) and persistent AF (type III). Whereas during control (no remodeling) the right atrium was activated by broad fibrillation waves (type I AF), after electrical remodeling the fibrillation waves were much more disorganized (type III AF). ${ }^{6}$ These different types of AF were first distinguished by Wells et al. ${ }^{7}$ based on difference in morphology of bipolar fibrilation electrograms and later by Konings et al. by different degrees of complexities in high density maps of $\mathrm{AF}^{8}$ Due to the shortening in wavelength, now multiple wavelets were wandering under the mapping electrode (type III AF). This higher degree of spatial dissociation lowers the chance that the fibrillation waves will all die out, making it less likely that AF will self-terminate.
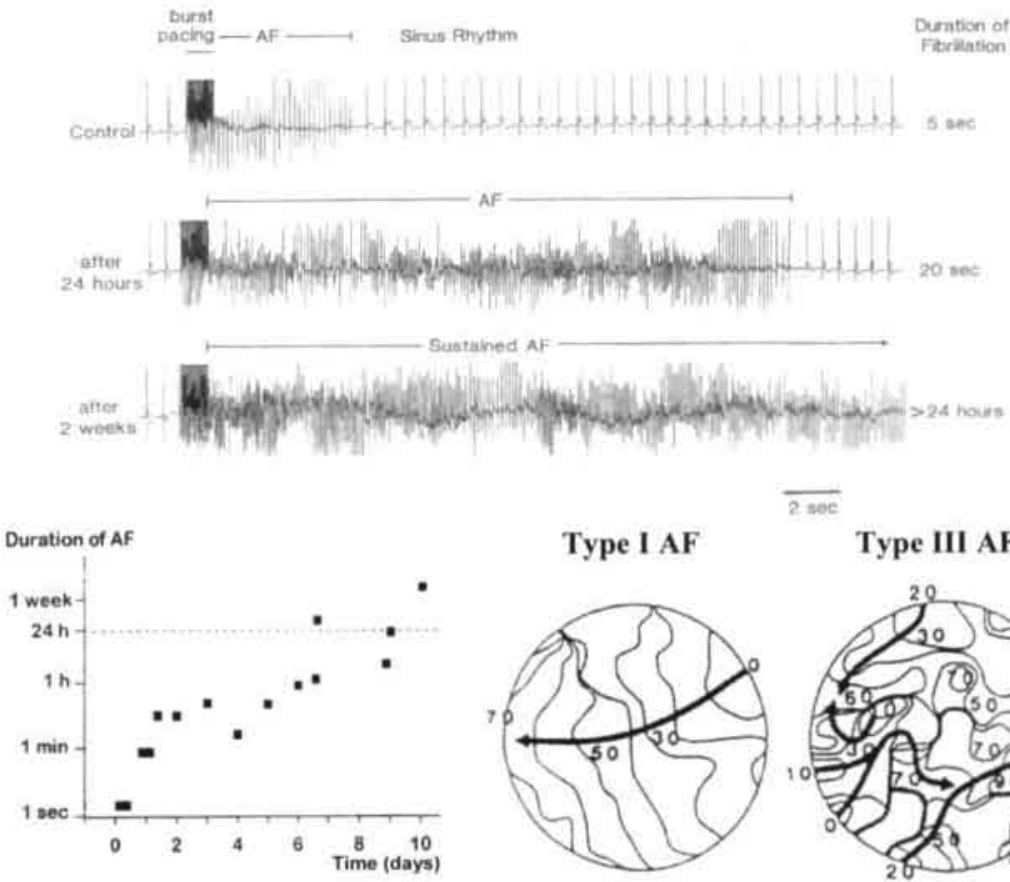

Type III AF

Figure 1

Upper and left lower panels: Prolongation of the duration of episodes of electrically induced AF in the goat as a result of electrical remodeling (from Wiiffels et al. 1995).

Right lower panels: High density mapping of the free wall of the right atrium of a goat during acutely induced (left) and persistent AF (right). The mapping array (diameter $4 \mathrm{~cm}$ ) contained 240 electrodes with an interelectrode distance of $2.25 \mathrm{~mm}$. Isochrones are drawn every $10 \mathrm{~ms}$. The direction of propagation is indicated by arrows (from Konings et al. 1999). 
Shortly after the demonstration of tachycardia-induced electrical remodeling, the ionic mechanisms underlying this arrhythmogenic process have been elucidated by a number of elegant and convincing studies. ${ }^{9.13}$ Action potential recordings and patch clamp experiments in isolated atrial cells from animal models and patients in chronic AF showed a consistent pattern. The most important impact of $\mathrm{AF}$ on the ion channels was a marked reduction in the L-type $\mathrm{Ca}^{2+}$ current. This explains the shortening of the atrial action potential and the loss of the physiological rate adaptation of the duration of the action potential. ${ }^{10}$ Unexpectedly, also the transient outward current $\left(\mathrm{I}_{\mathrm{to}}\right)$ and the sustained component of the ultra-rapid delayed rectifier $\left(\mathrm{Ik}_{\text {sus }}\right)$ were reduced. ${ }^{10: 12}$ In another study in patients with chronic AF downregulation of $\mathrm{Ik}_{\text {sus }}$ was not found. ${ }^{14}$ Pharmacological probes by which a reduction in $\mathrm{I}_{\mathrm{Ca}}$ and $\mathrm{I}_{\mathrm{to}}$ can be mimicked showed that in atrial myocardium $\mathrm{I}_{\mathrm{to}}$ is of much less importance for the duration of the action potential than $\mathrm{I}_{\mathrm{Ca}}{ }^{10}{ }^{10}$ In Figure 2 the cellular mechanisms of tachycardia-induced electrical remodeling are summarized. The upper panels show the characteristics of changes in refractory period and action potential in the goat model of AF. ${ }^{1: 15}$ Already during the first 24 hours a dramatic shortening and loss of rate adaptation of the refractory period occurred (panel A). The complete time course of electrical remodeling of the atrial refractory period is plotted in panel B. It took place during the first days of $\mathrm{AF}$ and the refractory period reached a new steady state after about 2-3 days.

A

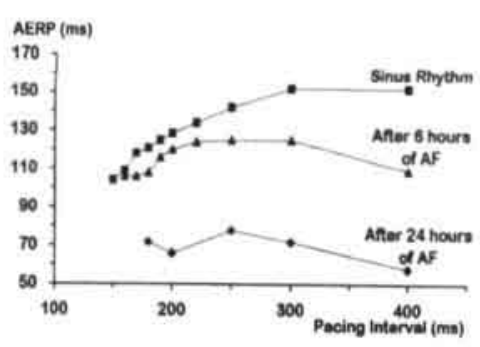

C

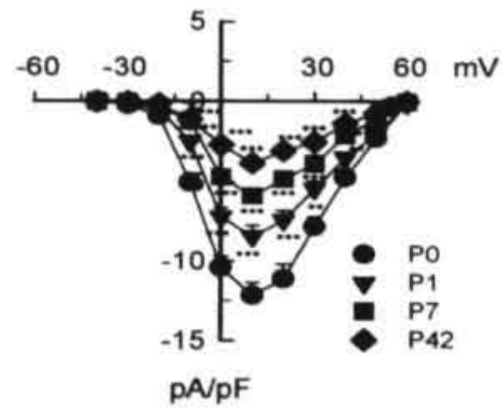

B

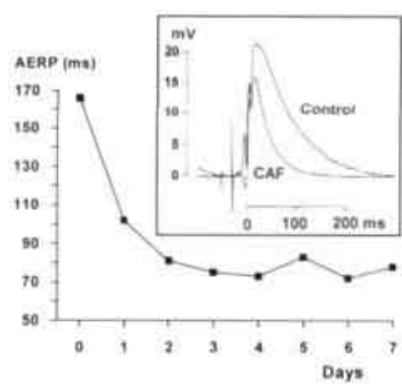

D
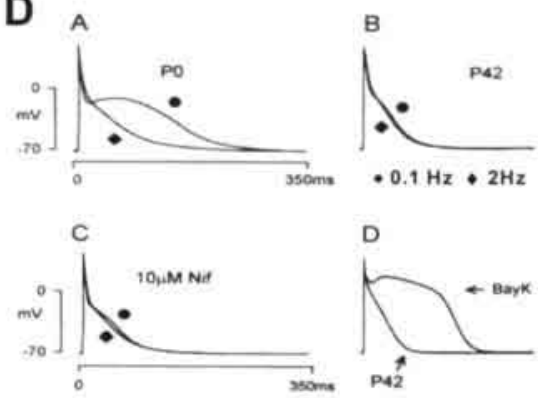

Figure 2

Panel A: Shortening of the atrial effective refractory period (AERP) and loss of rate adaptation during 24 hours of $A F$ in the goat. Panel B: Time course of shortening of the AERP by AF (pacing interval 400ms) (from Wiiffels et al. 1995). In the inset monophasic action potentials are superimposed recorded from the free wall of the right atrium during control and after cardioversion of chronic $A F(C A F)$. Note that the duration of the MAP is reduced by about $50 \%$. (from Van der Velden et al. 2000). Panel C: Voltage current relationships of $I_{c a t}$ during control $(P 0)$ and after 1,7 and 42 days of rapid atrial pacing in the dog. The density of Iciat was progressively reduced with the duration of rapid pacing. Panel D: Action potentials recorded at $0.1(\bullet)$ and $2 \mathrm{~Hz}(\bullet)$ in control atrial cells $(P 0)$ and after 42 days of rapid atrial pacing (P42). Addition of nifedipine (C) mimicked the effects of electrical remodeling, whereas the Ca-agonist BayK 8644 restored the plateau phase of the action potential (D) (from Yue et al 1997). 
Monophasic action potentials recorded from the free wall of the right atrium before and after chronic AF also clearly demonstrated a shortening of the atrial action potential (inset panel B). The two lower panels show the changes in atrial action potentials and Ltype $\mathrm{Ca}^{2+}$ currents in the dog. ${ }^{10}$ During 42 days of rapid atrial pacing a progressive reduction in inward $\mathrm{I}_{\mathrm{Ca}}$ occurred (panel $\mathrm{C}$ ). The voltage, time and frequency characteristics of the L-type $\mathrm{Ca}^{2+}$ current remained unchanged. Administration of nifedipine $(10 \mu \mathrm{M})$ to atrial cells from animals in sinus rhythm mimicked the shortening and loss of rate adaptation due to rapid pacing. Vice versa, adding the $\mathrm{Ca}^{2+}$-channel agonist BayK to a large extent could 'undo' the effects of electrical remodeling (panel D).

Some important steps in our knowledge of AF-induced electrical remodeling in humans are depicted in Figure 3. The earliest clinical observations that abnormalities in rate adaptation of the refractory period were related to AF were made by Attuel et al.. ${ }^{16}$ In 1982 they measured the atrial refractory period in 39 patients and noticed that atrial tachyarrhythmias preferentially occurred in patients in whom the atrial refractory period failed to adapt to changes in pacing rate (Figure 3A). They suggested that a poor or absent rate adaptation of the atrial refractory period was a marker of some 'cryptic' atrial pathology which caused AF. They further suggested that maladaptation of the atrial refractory period and a propensity to AF together 'constituted a clinical entity'. ${ }^{16}$ In 1986, loss of rate adaptation of the refractory period and action potential duration was confirmed in isolated right atrial tissue of patients with chronic AF. ${ }^{17}$ The first clinical study demonstrating electrical remodeling in human atria after prolonged tachyarrhythmias was done by Franz et al.. ${ }^{18}$ In control patients, the $\mathrm{APD}_{90}$ of the monophasic action potential of the right atrium was compared with the $\mathrm{APD}_{90}$ in patients with chronic atrial flutter or fibrillation. In patients with $\mathrm{AF}$ or atrial flutter, the $\mathrm{APD}_{90}$ measured during slow pacing 15 to $30 \mathrm{~min}$ after electrical cardioversion was $130-150 \mathrm{~ms}$ shorter than in the control group. The curve describing the relation between the $\mathrm{APD}_{90}$ and the steady state cycle length was shifted downward and flattened in the range between 400 and $800 \mathrm{~ms}$ (Figure 3B). In humans the adaptation of atrial refractoriness and APD duration to changes in heart rate is more pronounced than in dog and goat. ${ }^{1: 19}$ Also the degree of loss of rate adaptation might be different in different patient populations. ${ }^{16: 18}$ This might explain why in electrically remodeled human atria still some rate adaptation exists at high pacing rates. ${ }^{18}$ The association between a short monophasic action potential and the difficulty to maintain sinus rhythm in patients had already been noted earlier by Olsson et al.. ${ }^{20: 21}$

Also on the cellular level the changes in repolarization and ionic mechanisms have shown to be similar as in animal models. ${ }^{11-13: 22}$ Human AF was associated with a marked shortening in action potential duration and blunting of its rate adaptation (Figure $3 \mathrm{C}$ ). As in animal studies, both the transient outward current and the L-type $\mathrm{Ca}^{2+}$ current were reduced by about $70 \%$ (Figure $3 \mathrm{D}$ ). In addition, the recovery from inactivation of the $\mathrm{I}_{\mathrm{Ca}, \mathrm{L}}$ current was slower in cells from AF patients, which contributes to a decreased $\mathrm{Ca}^{2+}$ influx at high rates. ${ }^{12}$ Van Wagoner et al. showed that, like in the dog model of rapid atrial pacing, the loss of rate adaptation of the action potential could be mimicked by administration of $10 \mu \mathrm{M}$ of nifedipine. ${ }^{13}$ The question whether the reduction in $\mathrm{Ca}^{2+}$ influx is solely the result of a reduction of the ion-channel proteins in the cell membrane is not completely settled. In animal models of AF or rapid atrial pacing the mRNA-level of the $\alpha_{1 \mathrm{c}}$-subunit of the L-type $\mathrm{Ca}^{2+}$ channel was reduced. ${ }^{15: 23} \mathrm{~A}$ reduced mRNA content of the $\alpha_{1 C}$-subunit in humans with AF was found in some studies ${ }^{24: 25}$ but were 
not confirmed in others. ${ }^{26}$ On the protein level, the expression of the $\alpha_{1 \mathrm{c}}$ subunit was found to be reduced in one study ${ }^{25}$ but not in another. ${ }^{27}$
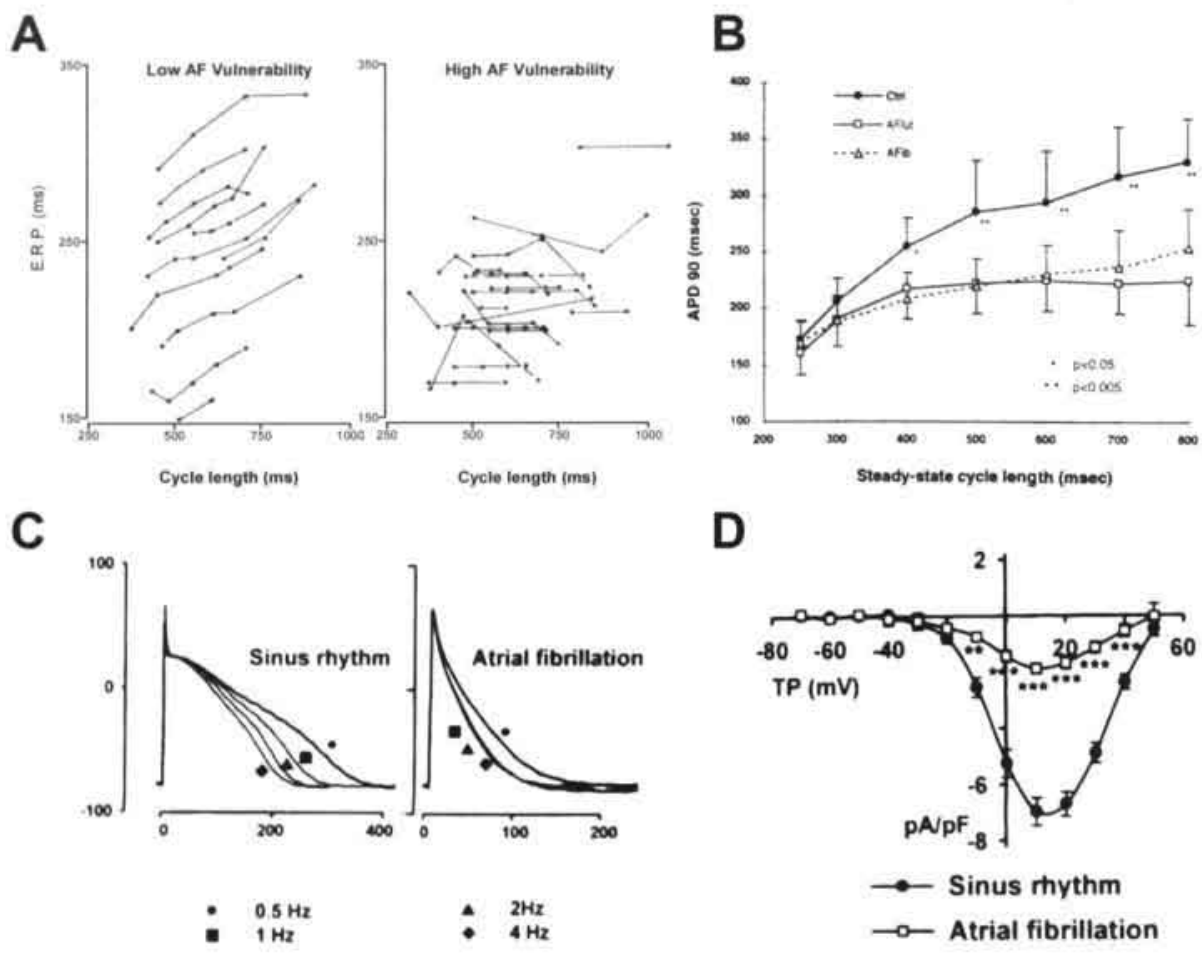

Figure 3

Panel A: Physiological rate adaptation of the effective refractory period in II control patients (left) and nonadaptation of the ERP in 17 patients with a high vulnerability for atrial fibrillation (right) (from Attuel et al. 1982). Panel B: Average APD90 duration \pm SD plotted as a function of steady state cycle length. Asterisks denote significant differences in average APD90 of patients with atrial fibrillation (Afib) or flutter (Aflut). (from Franz et al. 1997). Panels C and D: Action potentials and L-type Ca ${ }^{2}$ current in atrial cells from humans in simus rhythm and atrial fibrillation (from Bosch et al. 1999).

The time course of reverse electrical remodeling after restoration of sinus rhythm has been studied both in goats and humans. ${ }^{1: 28}$ Even after prolonged periods of $\mathrm{AF}$ (months to years), the shortening of the atrial refractory period and diminished rate adaptation are still completely reversible (Figure 4 ). The fact that atrial refractoriness becomes normal again within only a few days of sinus rhythm has important clinical implications. It means that recurrences of $\mathrm{AF}$ occurring more than 1 week after cardioversion, can not be explained on the basis of abnormalities in atrial repolarization due to electrical remodeling.

It is not yet clear whether prolonged rapid atrial rates also lead to slowing in atrial conduction. Whereas in the dog, after 42 days of rapid pacing a decrease in atrial conduction velocity of $25 \%$ was reported, ${ }^{19}$ mapping of the right atrium in the goat showed no slowing in atrial conduction even after several months of $\mathrm{AF}^{1,15}$ At all voltage ranges $\mathrm{I}_{\mathrm{Na}}$ was significantly reduced in the chronic dog model of $\mathrm{AF}$ and its inactivation kinetics were slowed. ${ }^{9}$ In contrast, in isolated cells from fibrillating human 

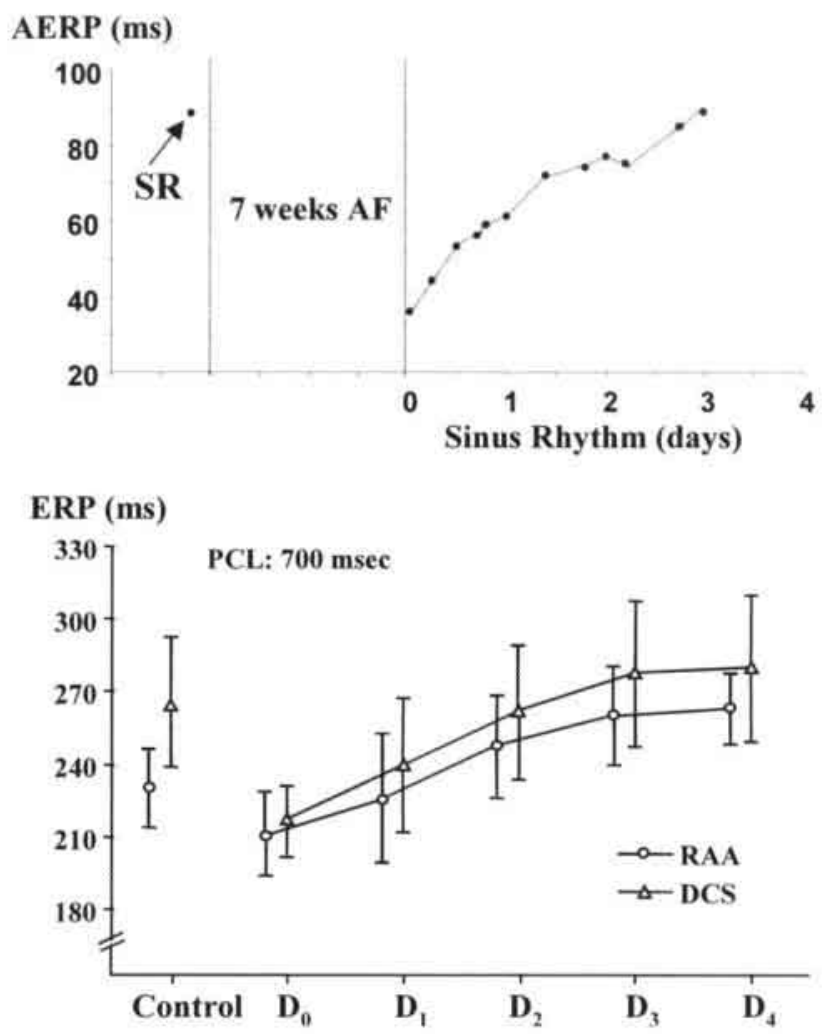

Figure 4

Top: An example of reverse remodeling of the atrial effective refractory period (AERP) after comversion of 7 weeks of $A F$. Within 3 days of simus rhythm the AERP returned to its control value (modified from Wijffels et al. 1995). Bottom: Reversal of atrial electrical remodeling after cardioversion of long-term $A F$ in man. Both in the right atrial appendage (RAA) and the distal coronary simus (DCS) the refractory period gradually prolonged and reached control steady state values within 3 days of sinus rhythm. PCL: pacing cycle length. (from Yu et al. 1997).

atria neither the current density nor the voltage dependence of the rapid sodium channels were altered. ${ }^{12}$ The voltage-dependent inactivation of $\mathrm{I}_{\mathrm{Na}}$ was shifted to more positive voltages, which increases rather than decreases the availabitity of these channels. It is equally unclear whether changes in atrial gap junctions may cause slowing of atrial conduction. First of all, the data on remodeling of the atrial connexins are not consistent. Elvan et al. ${ }^{29}$ reported an increase in expression of connexin 43 in dogs, whereas in humans a decrease in connexin 43 was found. ${ }^{30}$ In the goat model of AF Van der Velden et al. reported no change in connexin 43 but instead a decrease and more heterogeneous distribution of connexin $40 .^{31}$ Second, although the gap junctions play a major role in conduction, the speed of propagation of the atrial impulse is only affected when the connexins are down-regulated by more than $40 \%{ }^{32}$ Spatial heterogeneities in connexins might create microscopic obstacles for conduction which not necessarily disturb the conduction of a broad wavefront, but may serve as turning points or areas of zig zag conduction when the wavefront becomes fragmented. It therefore remains a possibility that gap junctional remodeling is involved in the creation of a substrate for persistent AF. Indeed, there are good reasons to believe that shortening of the atrial action potential is not the only factor involved in the development of permanent AF. The longer time course of the development of sustained AF and the cumulative effects of repetitive 1-month episodes of AF, strongly suggest that a much slower so-called 'second factor' is involved. ${ }^{1: 33}$ A good candidate for such a second factor is an increased tissue anisotropy due to changes in local expression of gap junctional proteins or tissue fibrosis as demonstrated in a canine model of heart 
failure. ${ }^{34}$ In this model of heart failure induced by 5 weeks of rapid ventricular pacing, the atrial refractory period and spatial dispersion of refractoriness were not altered. Instead, discrete regions of slow conduction were the cause of the increased stability of AF. Such atrial remodeling of a 'different sort' could explain the development of a substrate for $\mathrm{AF}$ in old age, rheumatic valve disease and heart failure.

\section{Contractile Remodeling}

Already more than 30 years ago Logan et al. documented that after cardioversion of AF the a-wave in the atrial pressure curve was lost (Figure 5A). ${ }^{35}$ Using echocardiographic techniques, later studies revealed that this atrial contractile dysfunction correlated with the duration of $\mathrm{AF}$ and that it could take months before the atrial transport function was fully recovered ${ }^{36: 37}$ Manning at al. showed that after 2 weeks of AF, recovery of atrial contractile function was complete within $24 \mathrm{~h}$ of sinus rhythm, whereas it took more than one month to recover from AF lasting more than 6 weeks. ${ }^{36}$ Harjai et al. showed that patients undergoing electrical cardioversion displayed a greater degree of atrial dysfunction than those who were converted pharmacologically. ${ }^{38}$ However, such a relationship between mode of cardioversion and atrial stunning was not confirmed by other studies. Even after spontaneous termination of AF a similar degree of atrial contractile dysfunction was demonstrated. ${ }^{39: 40}$ Although thromboembolic events often occur shortly after cardioversion they also may occur several days or weeks later. ${ }^{41}$ Transesophageal echocardiography has shown that new atrial thrombi can be formed after cardioversion. ${ }^{42}$ Thus, the depressed and slow recovery of atrial contraction after restoration of sinus rhythm may play a role in the occurrence of thromboembolic events, even when at the time of cardioversion atrial thrombi were not present. ${ }^{43}$

The mechanisms responsible for the postfibrillatory contractile dysfunction are not completely understood. Originally it was thought that the electrical shock itself caused 'atrial stunning', ${ }^{42}$ but soon it became clear that also after pharmacological and spontaneous cardioversion the contractile atrial function was depressed. ${ }^{39}$ In experimental and clinical studies verapamil was able to largely prevent the atrial dysfunction after short periods of AF, indicating that atrial stunning is mediated by $\mathrm{Ca}^{2+}$-overload. ${ }^{44: 45}$ While the altered atrial function after short paroxysms of AF is likely to be the result of changes in cellular metabolism, long-lasting atrial tachyarrhythmias may induce additional changes causing a more persistent atrial contractile dysfunction. In dogs with sustained atrial tachycardia (6 weeks) the degree of shortening of isolated atrial myocytes was shown to be reduced and associated with a pronounced reduction of the $\mathrm{Ca}^{2+}$-transient. ${ }^{46}$ In the same model the $\mathrm{L}$-type $\mathrm{Ca}^{2+}$ current $\left(\mathrm{I}_{\mathrm{Cal}}\right)$ was down regulated by $70 \%{ }^{10}$ Since the $\mathrm{I}_{\mathrm{Cat}}$ is a main factor in determining both the $\mathrm{Ca}^{2+}$ content and release from the sarcoplasmic reticulum, the down-regulation of $\mathrm{I}_{\mathrm{Cal}}$ is likely to be the main mechanism responsible for the AF-induced contractile dysfunction.

Presently, we are evaluating the development of atrial tachycardiomyopathy in the goat model of chronic $\mathrm{AF}^{47}$ Already after 3 days the atrial peak Doppler flow velocity was largely reduced during atrial systole, showing that atrial contractility was severely depressed (Figure 5B). In Figure 5C the changes in atrial pressure-diameter loops during the first 48 hours of $\mathrm{AF}$ are shown. Already after 12 hours the atrial work index 
was reduced by $\sim 50 \%$. After 2 days the atrial pressure-diameter loop became almost completely closed, indicating that during sinus rhythm or slow overdrive pacing the atrial contractions were nearly completely abolished. In two recent human studies we compared the force of contraction of small bundles of the right atrial appendage of patients undergoing mitral valve repair with and without long-standing $\mathrm{AF}^{48: 49}$ In patients with chronic AF the contractile force was reduced by $\sim 75 \%$ (Figure $5 D$ ). Since the post-rest potentiation was fully maintained and also the relaxation velocity was still normal, a disturbance in $\mathrm{Ca}^{2+}$ reuptake by the sarcoplasmic reticulum could be excluded. In contrast, the positive inotropic effect of isoproterenol was markedly impaired although the density of the $\beta$-adrenoceptors and the expression of the inhibitory and stimulatory $\mathrm{G}$ proteins were unaltered. Also the catecholamine-stimulated adenylyl cyclase activity was not impaired showing that the $\beta$-adrenergic signal transduction was not desensitized. ${ }^{49}$ Whereas in SR patients, the L-type $\mathrm{Ca}^{2+}$ agonist

A
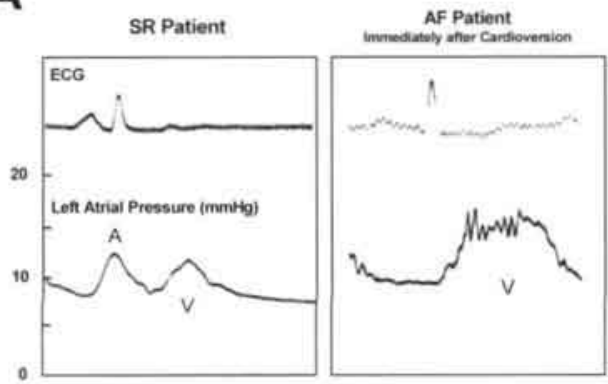

C

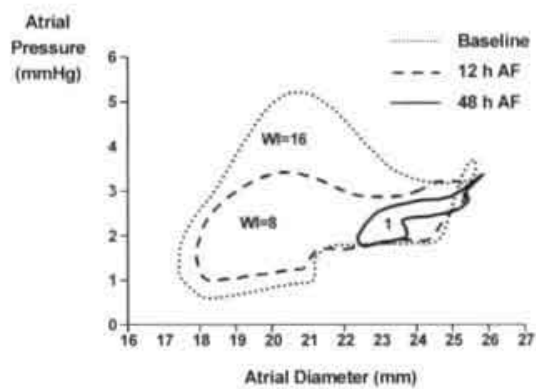

B

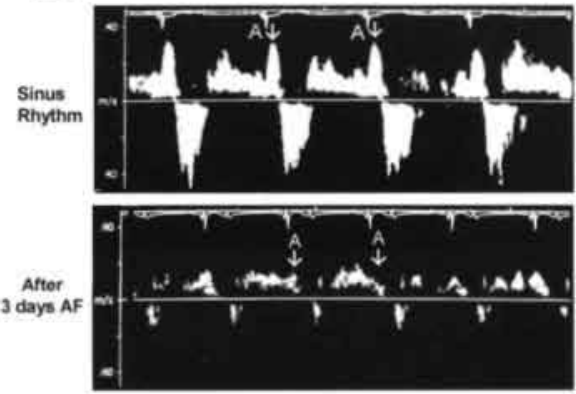

D
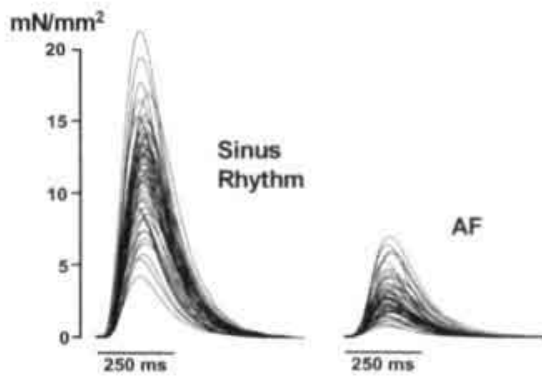

Figure 5

A: Left atrial pressure recordings of a control patient in SR and a patient immediately after cardioversion of chronic $A F$. The a-wave is completely abolished in the AF patient (modified from Logan et al. 1965). B: Using a $7.5 \mathrm{MHz}$ intravascular ultrasound probe (AcuNav@. Acuson Sequoia(B) right atrial appendage Doppler flow velocities were measured before and after 3 days of lone $A F$ in the goat. The white arrows point to the peak emptying flow during atrial systole $(A)$. The peak emptying velocity of the right atrial appendage during atrial systole is clearly reduced after 3 days of $A F$. C: Atrial pressure-diameter loops during atrial pacing at a cycle length of $400 \mathrm{~ms}$. During the first 48 hours of $A F$, the atrial work index (surface area of the pressure-diameter loop) diminished from 16 to $1 \mathrm{mmHg}^{*} \mathrm{~mm}$. The almost completely closed loop after 2 days of $A F$ indicates a virtually complete loss of atrial contractility. D: Superimposed recordings of the force of contraction of small isolated right atrial trabeculae from 47 patients undergoing mitral valve surgery. In AF patients the average force of atrial contraction was reduced by about $75 \%$ (from Schotten et al. 2001). 
Bay K8644 exerted a pronounced positive inotropic effect, in AF patients this stimulatory effect was only minor. Thus, in contrast to ventricular tachycardiomyopathy, which is due to a dysfunction of the sarcoplasmic reticulum and $\beta$-adrenergic desensitization, the atrial contractile dysfunction after prolonged fibrillation seems mainly to be due to a depressed L-type $\mathrm{Ca}^{2+}$ current.

\section{Structural Remodeling}

The first study showing that AF causes alterations in the ultrastructure of atrial myocytes was that of Morillo et al. in $1995 .^{2}$ In dogs subjected to prolonged periods of rapid atrial pacing ( 6 weeks), both light- and electronmicroscopic changes were found in the atria. Several later studies confirmed this important observation both in dogs and goats. ${ }^{29 ; 50-54}$ The alterations in atrial myocytes after sustained AF closely resemble the changes in ventricular myocytes due to chronic low flow ischemia (hibernation). ${ }^{55}$ Both in chronic hibernating ventricular myocardium and in fibrillating atria a phenotypic adaptation occurs towards a more fetal stage of development (dedifferentiation). The AF-induced structural changes in atrial myocytes include: 1) increase in cell size, 2) perinuclear accumulation of glycogen, 3) central loss of sarcomeres (myolysis), 4) alterations in connexin expression, 5) changes in mitochondrial shape, 6) fragmentation of sarcoplasmic reticulum, 7) homogeneous distribution of nuclear chromatin, and 8) changes in quantity and localization of structural cellular proteins (Figure 6). Most prominent is an increase in atrial cell size associated with myolysis and perinuclear accumulation of glycogen. This hibernation of fibrillating atrial myocardium is heterogeneously distributed, with some cells strongly affected next to virtually normal cells. The dedifferentiation to a more fetal stage of development is evident from the reexpression of $\alpha$-smooth muscle actin and the loss of desmin. In the goat, gap-junctional remodeling consists of a loss and heterogeneous distribution of connexin 40 . At an electron microscopic level changes in subcellular structures can be seen. In fibrillating myocardium nuclear chromatin is more homogeneously distributed and the mitochondria are smaller with longitudinally oriented cristae.

Although in general the different animal models show similar structural changes, some differences exist between different species and different models of atrial tachyarrhythmias. In the dog, a high atrial rate is associated with an increase in size of mitochondria, ${ }^{2}$ whereas in the goat model of AF numerous small mitochondria with longitudinally oriented cristae were found. ${ }^{50}$ Whereas in models with pure atrial tachyarrhythmias the extracellular matrix was not changed ${ }^{2: 50}$, in canine atria subjected to a combination of rapid atrial pacing and mitral regurgitation, the volume of the intercellular space was increased. ${ }^{54}$ The effects of structural remodeling on gap junctions also differ in different species. ${ }^{29: 51}$

These structural changes caused by AF should not be regarded as degenerative, since signs of irreversible changes leading to cell death (disruption of mitochondrial cristae, abnormal secondary lysosomes, cytosolic blebs, lipid droplets, discontinuities of the sarcolemma) and markers of apoptosis (bcl-2, P53, proliferating nuclear antigen, TUNEL reactivity) are all absent in chronic lone AF. ${ }^{52}$ Instead, the structural changes in response to $\mathrm{AF}$ might be considered as the consequence of a physiological adaptation to 
chronic $\mathrm{Ca}^{2+}$ overload and metabolic stress. This is supported by the fact that after longterm AF the expression of heat-shock-proteins (HSP70, GRP94) is upregulated. ${ }^{56}$ In patients, data about structural remodeling as a consequence of AF are still limited. ${ }^{4: 57-59}$ Only one study investigated the structural changes associated with lone $\mathrm{AF}^{58}$ Similar signs of dedifferentiation of human atrial myocardium were found as in various animal models. However, in patients with $\mathrm{AF}$ and atrial dilatation also degenerative changes were observed. Some nuclei of atrial myocytes showed a strong TUNEL reactivity indicative for DNA cleavage and programmed cell death. ${ }^{60}$ Furthermore, the degree of interstitial fibrosis, both between individual myocytes (endomysial) and atrial bundles (perimysial) is increased in patients with chronic $\mathrm{AF}^{57: 59}$ Compared to animal models, the more extensive structural changes found in patients might be related to the older age and/or associated heart diseases. ${ }^{48 ; 61-66}$
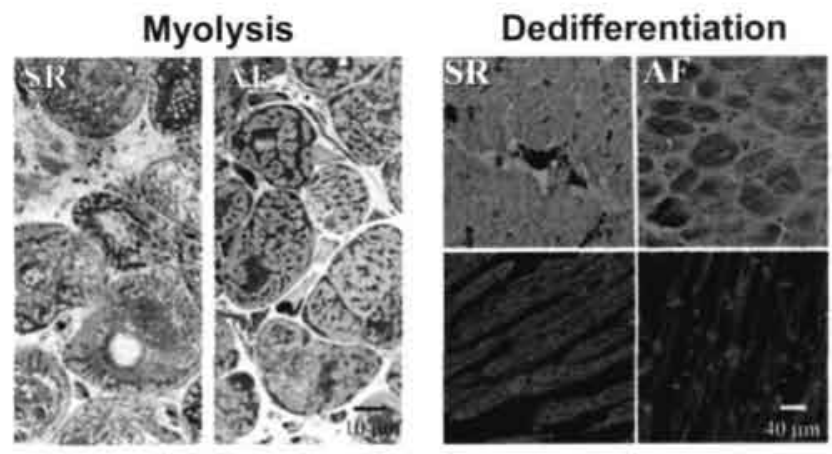

\section{Connexins}
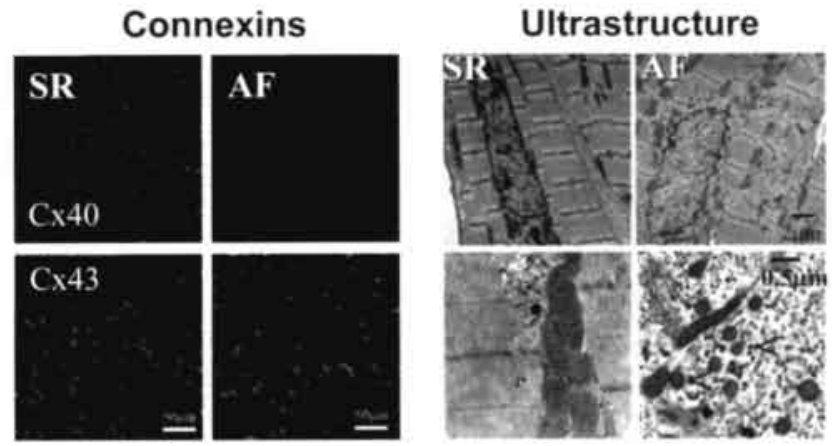

Figure 6

Structural remodeling of atrial myocytes after 4 months of AF in the goat. The left pictures are taken from goats in sinus rhythm, the right photographs are from goats in chronic AF. Light microscopy (upper left panel) shows cells with severe myolysis (loss of sarcomeres: blue staining) and accumulation of glycogen (red). Immunostaining of structural proteins (right upper panel) demonstrates the dedifferentiation of the atrial myocardium by a clear increase in fetal $\alpha$-smooth muscle actin (red staining in upper pictures). In the lower pictures of this panel the myocytes are stained for desmin (red). The nuclei are stained by blue DAPI. During AF desmin looses its cross-striated pattern in the cytoplasm and at the intercalated disks the intensified desmin staining is no longer present. In the lower left panel changes in gap-junctions are shown. Labeling of Cx40 (green) and Cx43 (red) revealed a clear reduction in Cx40 and no change in Cx43 expression. Electron microscopy (lower right) shows changes in the subcellular organization of the atrial myocytes. During AF the atrial nuclei get a more homogeneous distribution of chromatin. For comparison the normal clustering of chromatin at the nuclear membrane is indicated by arrows in the upper left panel. During AF many small domut shaped mitochondria can be found (arrowheads right lower panel) (from Ausma et al. 1997a,b and Van der Velden et al. 2000). 


\section{Relation between Electrical, Contractile, and Structural Remodeling}

To study the relationship between electrical remodeling and loss of atrial contractility, goats were instrumented with epicardial electrodes and sonomicrometer crystals together with a right atrial pressure catheter. ${ }^{47}$ During the first 5 days of $\mathrm{AF}$, the atrial refractory period and work index were measured 30 minutes after spontaneous conversion of $\mathrm{AF}$ during regular atrial pacing. As expected, the refractory period shortened considerably from $\sim 130$ to $\sim 80 \mathrm{~ms}$ (Figure 7). Also the strength of the atrial contractions diminished and the atrial work index decreased from 16 to less than 2 $\mathrm{mmHg}^{*} \mathrm{~mm}$. After restoration of sinus rhythm this loss of atrial contractility completely recovered following the same time course as reverse electrical remodeling. After 2 days of SR both the atrial work index and the refractory period were back at control values. The fact that electrical and contractile remodeling go 'hand in hand', strongly suggests that they are the result of a common mechanism. Since electrical remodeling is known to be mainly due to a reduction of $I_{\text {Cat }}$, also atrial contractile remodeling is probably directly related to a reduction in $\mathrm{Ca}^{2+}$ inward current. However, so far the time course of $\mathrm{AF}$-induced down-regulation of the $\mathrm{I}_{\mathrm{Cat}}$. channels has not been directly compared with the time course of shortening of the atrial action potential and loss of contractility.

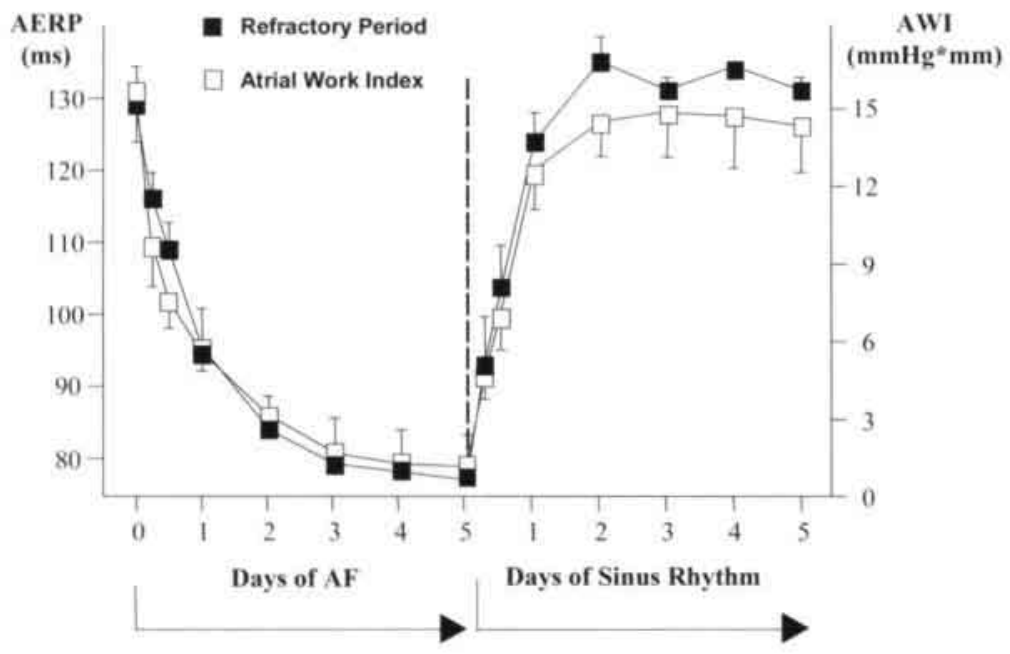

Figure 7

Changes in atrial effective refractory period (AERP) and atrial work index (AWI) during 5 days of AF followed by 5 days of sinus rhythm in 5 chronically instrumented goats. During electrical remodeling and its reversal after cardioversion of $A F$, the changes in atrial work index followed the exact same time course as the changes in AERP (modified from Schotten et al, 2001).

In humans, even after prolonged $\mathrm{AF}$ (months to years) electrical remodeling is completely reversible within a few days. ${ }^{2 \times, 67}$ In contrast, depending on the duration of AF the recovery of the atrial transport function may take several months. ${ }^{36: 37}$ This delayed recovery of contractile remodeling suggests that, in addition to the down- 
regulation of $\mathrm{I}_{\mathrm{Cal}}$, in long-term $\mathrm{AF}$ additional mechanisms are operative. One possibility is that the slow component of the recovery of atrial contractility reflects the slow resynthesis of sarcomeres which have been lost during $\mathrm{AF}$ (myolysis). ${ }^{4850}$ In a recent study we investigated the contribution of myolysis to the loss of atrial contraction in patients with and without chronic $\mathrm{AF}^{48}$ In patients with $\mathrm{AF}$ the contractile force of isolated right atrial trabeculae was reduced by $75 \%$ (Figure 8 ). However, after increasing the $\mathrm{Ca}^{2+}$ concentration the maximal force of contraction was reduced by only $15 \%$. Histological quantification of the degree of myolysis revealed a total reduction of sarcomeres of $14 \%$ (Figure $8 \mathrm{~B}$ ). Thus, post-AF atrial stunning seems to be the result of two different mechanisms. The first and most important component is a functional loss of contraction due to decreased activation of the contractile apparatus due to the reduction of $\mathrm{I}_{\mathrm{Cal}}$. AF-induced atrial myolysis causes an additional $15 \%$ reduction in force of contraction. The functional part of atrial stunning recovers quickly (a matter of days), ${ }^{47}$ whereas complete restoration of the atrial transport function in patients with chronic AF may take much longer (up to several months). ${ }^{36}$ Since the contribution of myolysis to the AF-induced atrial dysfunction is limited, most probably other, so far unidentified mechanisms are responsible for the delayed recovery of the atrial contractile function after cardioversion of prolonged $\mathrm{AF}$.

In the $80 \mathrm{~s}$ Boyden et al. studied the relationship between atrial enlargement and electrophysiological properties in dogs and cats with mitral valve disease and ventricular cardiomyopathy. ${ }^{68-70}$ In dilated atria increased amounts of connective tissue were found between enlarged myocytes. Also signs of degeneration and a loss of myofilaments were observed. These dilated atria had a high susceptibility for initiation and perpetuation of atrial arrhythmias. Transmembrane action potentials were not found to be significantly different from non-dilated atria. In a canine model of heart failure AF could be easily induced and was of long duration. ${ }^{34}$ Also in these animals an increase in atrial size and extensive interstitial fibrosis was found. The main electrophysiological changes consisted of a marked increase in spatial heterogeneity in atrial conduction velocity. The susceptibility to AF in these models was explained by the increased interstitial fibrosis and a higher likelihood of local intra-atrial conduction block leading to smaller and more numerous reentrant circuits. Thus, both electrical and structural remodeling can either create a substrate for $\mathrm{AF}$. The dimensions of intra-atrial circuits can become smaller either by shortening of the action potential (electrical remodeling) or by local conduction delay (enhanced nonuniform anisotropy). While electrical remodeling occurs in a couple of days, structural remodeling is a much slower process which may continue for several months. In Figure 9 the three cascades of electrical, contractile and structural remodeling are depicted. The positive feed back between electrical remodeling and $\mathrm{AF}$ is well established, whereas the proposed cascades of contractile and structural remodeling are still partly hypothetical. The electroanatomical substrate of AF may consist of dilated atria with small local intra-atrial circuits, both due to shortening of refractoriness and increased non-uniform anisotropy. Increased non-uniform anisotropy may result from alterations in expression of connexins or atrial architecture (dissociation of atrial bundles, endo- and perimysial fibrosis). 

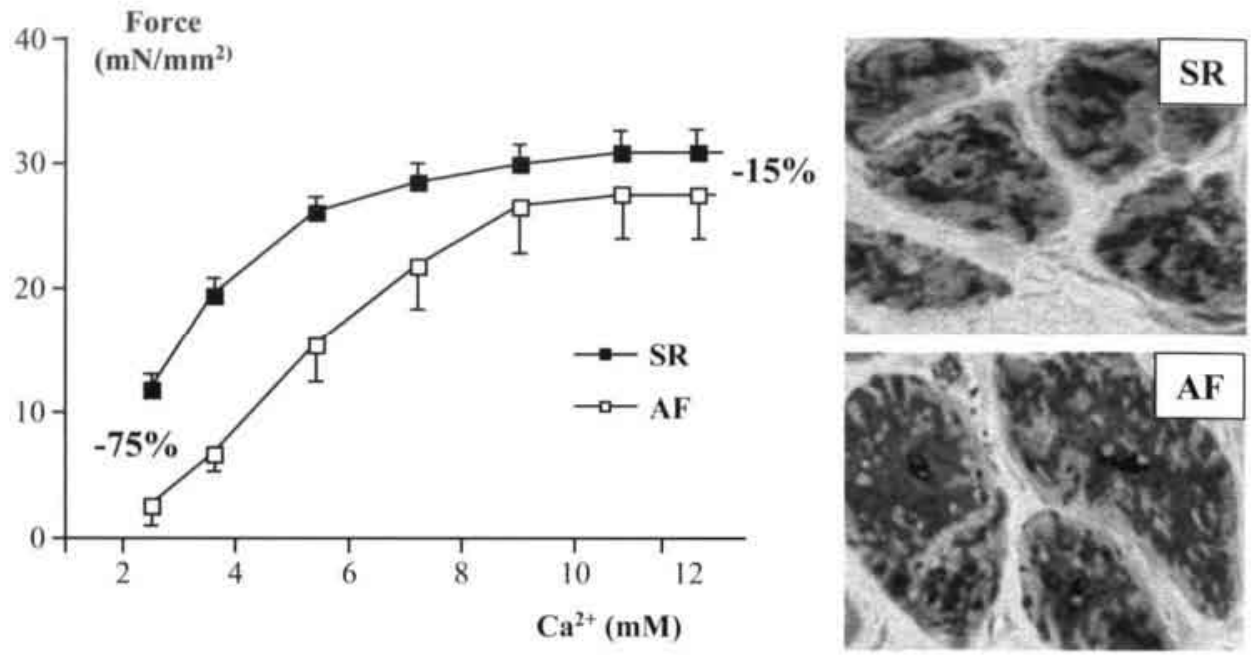

Figure 8

The effects of extracellular $\mathrm{Ca}^{2}$ concentration on force of contraction in isolated right atrial bundles from patients in simus rhythm and chronic AF. At a physiological $\mathrm{Ca}^{2 *}$ concentration of $2.5 \mathrm{mM}$, the force of contraction was $75 \%$ less in AF patients compared to SR patients. However, in both groups elevation of the extracellular $\mathrm{Ca}^{2 *}$ concentration elicited a strong positive inotropic effect. This resulted in only $15 \%$ less contractile force at maximal activation by high $\mathrm{Ca}^{*}$ in AF patients. The sarcomere content of the atrial myocytes (blue staining) was reduced to a similar extent $(-14 \%)$. The red staining in the myolytic cells is due to glycogen accumulation (modified from Schotten et al. 2001).

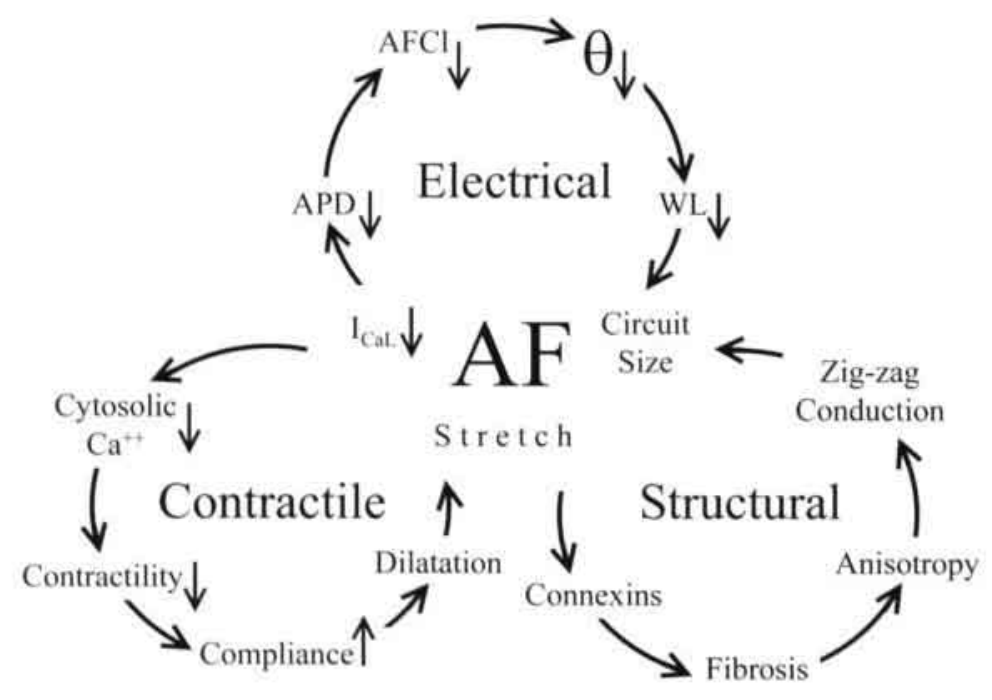

Figure 9

Three proposed positive feedback-loops of atrial remodeling on $A F$. Reduction of the L-type $\mathrm{Ca}^{2}$ inward current is considered to be the primary cause for electrical and contractile remodeling. Stretch of the atrial myocardium, which is the result of loss of contractility and increase in compliance of the fibrillating atria, is hypothesized to act as a stimulus for structural remodeling of the atria. The resulting electro-anatomical substrate of $A F$ consists of enlarged atria allowing intra-atrial circuits of small size, due to a reduction in wavelength (shortening of refractoriness and slowing of conduction) and increased non-uniform tissue anisotropy (zig-zag conduction). (Modified). 


\section{$\underline{\text { Different Time Domains }}$}

\section{The First Minutes}

Within the first minutes of AF, both the oxygen consumption and coronary flow of the atria increases nearly threefold. ${ }^{71}$ Profound changes in atrial metabolism occur, which is expressed by a reduction in atrial creatine phosphate. ${ }^{45}$ Due to the high rate, the cytosolic $\mathrm{Na}^{+}$and $\mathrm{Ca}^{2+}$ concentrations increase, the $\mathrm{Ca}^{2+}$ load of the sarcoplasmic reticulum rises ${ }^{72}$ and moderate cellular acidosis develops. The increase in $\mathrm{Ca}^{2+}$ concentration contributes to the rate dependent shortening of the action potential by inactivation of the L-type $\mathrm{Ca}^{2+}$ channel. Also changes in the intracellular redox potential can inhibit the L-type $\mathrm{Ca}^{2+}$ channels. ${ }^{73}$ After the onset of $\mathrm{AF}$ it takes several minutes before a new steady state in atrial refractory period, conduction velocity and ion concentrations is reached. Similarly, when AF terminates the action potential will only return gradually to its original shape, explaining why the refractory period is still short during the first minutes after conversion to sinus rhythm. ${ }^{74}$ The changes in atrial contractility after termination of short-lasting AF are more complex. The first contractions are stronger than during steady state sinus rhythm due to the high intracellular $\mathrm{Ca}^{2+}$ concentration build up during the preceding $\mathrm{AF}$ episode. ${ }^{45}$ However, already after a couple of seconds atrial contractility declines indicating that the $\mathrm{Ca}^{2+}$ overload disappears rapidly. Actually, the atrial contractions temporarily become $50 \%$ weaker than during steady state sinus rhythm (undershoot). Thereafter, the force of contraction gradually increases to its baseline value with a similar time course as the prolongation of the action potential. ${ }^{45 ; 74}$ Also in isolated atrial myocytes short-term rapid stimulation ( 3 minutes) results in a short period of hypercontractility, followed by a phase of hypocontractility before gradual recovery. ${ }^{72}$ The major mechanism of the depressed cellular contractile function was a lowering of $\mathrm{Ca}^{2+}$ available for release from the sarcoplasmic reticulum.

Thus, after cardioversion of AF the early electrical and contractile changes of the atria have short on- and offset kinetics. As emphasized by Pandozi \& Santini, these changes should be clearly distinguished from 'true' electrical and contractile remodeling which are based on alterations in gene expression with far slower kinetics. In this respect, the recently introduced terms "short-term remodeling" somewhat confusing, since they actually have nothing to do with remodeling. The metabolic shortening of the atrial refractory period during AF may explain the higher vulnerability of the atria briefly after conversion to sinus rhythm. ${ }^{77}$ In electrically remodeled atria, this transient metabolic shortening of the refractory period causes an additional shortening of the atrial action potential immediately after cardioversion of AF. The resulting temporary ultra-short refractory period provides a good explanation for immediate recurrences of AF (IRAF) frequently seen after electrical cardioversion. $^{78 ; 79}$

\section{The First Days}

During the first days of $\mathrm{AF}$ a progressive reduction in refractory period and atrial contractility occurs until after 3-5 days a new steady state is reached. Also reversal of this AF-induced electrical and contractile remodeling takes a couple of days. ${ }^{1: 47}$ This slower time course compared to the more rapid metabolically mediated changes, suggests that different mechanisms are involved. At present it is still uncertain whether 
the reduction in $\mathrm{I}_{\text {Cal }}$ is due to a decrease in the actual number of channels in the atrial cell membrane or to changes in channel properties. Also insufficient knowledge exists about the exact time course in reduction of the $\mathrm{I}_{\mathrm{CaL}}$ and the related AF-induced electrical and contractile remodeling. A direct correlation between the density of the L-type $\mathrm{Ca}^{2+}$ channels, the calcium inward current and atrial refractoriness was found by Gaspo et al.. ${ }^{80}$ However, in this study it took several weeks of rapid atrial pacing for the atria to remodel, whereas in the goat model of AF electrical remodeling is complete within 3-5 days.'

During the first days of AF the refractory period shortens considerably $(20-40 \%)$, whereas after 6 weeks of rapid atrial pacing in the dog atrial conduction velocity was found to be moderately decreased. ${ }^{19}$ Thus, as a result of electrical remodeling the wavelength of the atrial impulse shortens by a shortening in refractoriness and possibly also by slowing in atrial conduction. This shortening of the wavelength during $\mathrm{AF}$ allows more wavelets to coexist in the atria which can at least partly explain the increased stability of $\mathrm{AF}$ with time. Also, recurrences of $\mathrm{AF}$ are facilitated by electrical remodeling. In patients with chronic AF a positive correlation between the shortest coupling interval of premature atrial beats and early recurrence of the arrhythmia was found. ${ }^{81}$ In humans with chronic AF it has been shown that the electrical remodeling of the atria (shortening of refractoriness) is completely reversible within 3 days of sinus rhythm. ${ }^{28}$ This means that recurrences of AF occurring later than 3-5 days after cardioversion can not be due to electrical remodeling. Recent experiments in goats have shown that also the contractility of the atria largely diminishes during the first days of AF. As a result, the compliance of the fibrillating atria will increase and the atria will dilate even when the mean atrial pressure does not increase. ${ }^{82}$

\section{The First Months}

There are reasons to believe that, besides the shortening of refractoriness also other factors play a role in the development of chronic AF. In the first study of Wijffels et al. in the goat in which 'AF begets AF' was demonstrated, it was already noted that the time course of the changes in atrial refractoriness did not run parallel with the increase in persistence of AF. Whereas the AF cycle length already reached a new steady state after 3-5 days, it took an additional 1-2 weeks before AF became persistent.' This led to the hypothesis that a so-called 'second factor' was involved in the development of persistent AF.

The time course of AF-induced structural changes in atrial myocytes has been extensively studied (Table 1). ${ }^{83}$ The first sign of structural remodeling is a more homogeneous distribution of nuclear chromatin resembling nuclei of embryonic myocytes and a decrease in the myocardial protein cardiotin. Both phenomena occurring after 1 week of AF are general signs of dedifferentiation and are not very likely to play a role in the stabilization of AF. In the time between 1 and 4 weeks of AF several additional changes occur such as a decrease and heterogeneous distribution of connexin 40 (gap-junctional remodeling), ${ }^{31}$ an increase in size of the atrial myocytes, loss of sarcomeres (myolysis) and perinuclear accumulation of glycogen. When AF continues for longer than I month a further increase in cell size, myolysis, glycogen accumulation and dedifferentiation occur. In addition, the sarcoplasmic reticulum became fragmented and the number of small mitochondria increase. After 4 months of AF the total amount of atrial connective tissue was not changed. However, because the atrial cells have become larger the amount of connective tissue per myocyte was increased. 


\begin{tabular}{|c|c|c|c|c|c|}
\hline & $I W A F$ & $2 W A F$ & $4 W A F$ & $8 \sim A F$ & $16 \times A F$ \\
\hline Nuclear Chromatin & + & + & + & + & + \\
\hline Downregulation of $\mathrm{C} \times 40$ & + & ++ & ++ & ++ & ++ \\
\hline Cell swelling/Myolysis & + & + & ++ & $+1+$ & $+1+$ \\
\hline a-Smooth muscle actin & + & + & ++ & ++ & $+t+$ \\
\hline Loss of Cardiotin & + & + & ++ & $++t$ & ++ \\
\hline Small Mitochondriae & & & + & ++ & ++ \\
\hline Remnants of SR & & & + & ++ & ++ \\
\hline Loss of Titin & & & + & ++ & $++t$ \\
\hline Loss of Desmin & & & & + & ++ \\
\hline
\end{tabular}

Table I: Time Course of AF-induced Structural Remodeling

The question whether the structural changes caused by prolonged AF are reversible or not, was addressed by two recent studies. ${ }^{54: 84}$ In the dog, 2 weeks after cardioversion of 8 weeks of AF combined with mitral regurgitation, no regression of the structural changes was yet observed. This was true despite the fact that by that time the AFinduced electrical remodeling was completely reversed. ${ }^{54}$ From this study it is not clear whether absence of recovery of structural remodeling was due to the short time window studied or to the still existing mitral regurgitation, which in itself may cause tissue fibrosis. In the goat model of 16 weeks of lone AF, 8 or 16 weeks after cardioversion reversion of structural remodeling was still far from complete. Recovery of gap junctions occurred relatively rapid and the expression of connexin 40 was normalized within 8 weeks of sinus rhythm. ${ }^{84}$ However, even after 16 weeks of sinus rhythm, many atrial myocytes were still myolytic and showed perinuclear glycogen accumulation.

The hypothesis that a 'second factor' is involved in the development of persistent AF was recently tested by two studies (Figure 10). ${ }^{33: 85}$ In the first study, three successive 5day periods of AF were maintained by burst pacing, each interrupted by two days of sinus rhythm. During these two days the electrical remodeling was completely reversed and the atrial refractory period returned to normal. It was hypothesized that, in case a 'second factor', repetitive AF episodes would exert a cumulative effect on the stability of $\mathrm{AF}$. However, no significant differences were found in the time required for $\mathrm{AF}$ to become sustained during the second or third 5-days episode of AF. In a second study this protocol was repeated, but now the duration of the consecutive AF episodes was prolonged to 1 month. Following each month, AF was cardioverted electrically and the atrial refractory period was allowed to return to control before the next episode of $\mathrm{AF}$. Although the time course of electrical remodeling was the same, the time required for development of persistent AF became shorter after each AF episode. ${ }^{33}$ This evidence suggests that indeed a second factor is involved in the transition from paroxysmal to persistent AF. More evidence for the presence of a slow second factor was recently obtained by serial pharmacological cardioversion of lone AF. In goats without any underlying heart disease, the efficacy of cardioversion by class Ic drugs progressively reduced from $78 \%$ after one month to $30 \%$ after 4 months of $\mathrm{AF}^{86}$ Pharmacological cardioversion failed despite the fact that higher dosages of the drug were administered. Whereas a reduced efficacy of pharmacological cardioversion during the first days of $\mathrm{AF}$ is readily explained by electrical remodeling, failure in the course of several months of AF might be due to the much slower structural remodeling of the atria. 
Repetitive 5-days periods of AF in the Goat

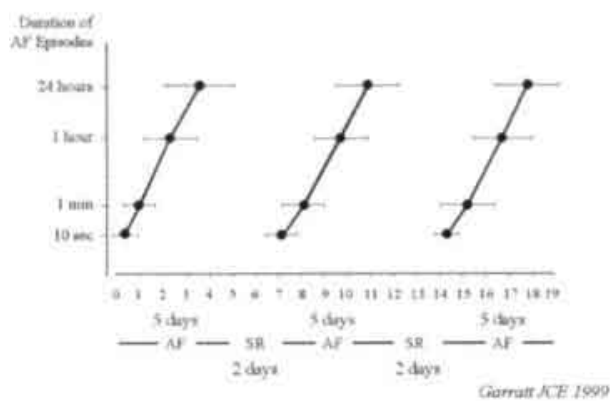

Repetitive One-Month Periods of AF

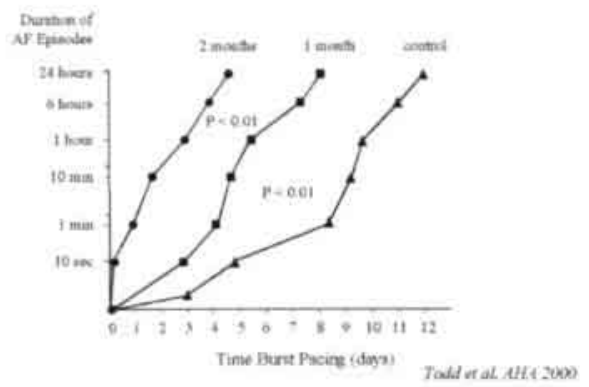

Figure 10

Repetitive electrical remodeling by 5 days of $A F$ interrupted by two days of simus rhythm had no cumulative effect in the goat. In contrast, three consecutive 1-month episodes of AF resulted in a progressive shortening of the time required for the development of persistent atrial fibrillation. This strongly supports the hypothesis that a 'second factor' other than the atrial refractory period is involved in the remodeling process which creates a substrate for self-perpetuation of AF (from Garatt et al. 1999 and Todd et al. 2001).

In patients $\mathrm{AF}$ has been related to the extent of structural changes ${ }^{62}$ which were found to be a predictor for failure of cardioversion. ${ }^{61}$ However, it is not easy to understand how certain changes in cellular structure like increased cell size, glycogen accumulation and different expression of structural proteins could play a role in perpetuation of $\mathrm{AF}$. On the other hand structural changes in gap junctions and interstitial fibrosis might result in inhomogeneities in conduction. The enhanced nonuniform tissue anisotropy might be responsible for slow conduction and reentry which stabilize AF. The increase in atrial size due to loss of contractility will also increase the number of wavelets. Some studies showed that atrial enlargement was positively correlated to the recurrence of AF after conversion to sinus rhythm ${ }^{87: 88}$ and very recently, a significant correlation between atrial dimensions and the stability of AF was demonstrated in dogs with heart failure. ${ }^{89}$ Regional differences in wall thickness resulting in inhomogeneous wall stress will further add to the increased heterogeneity in conduction. However, at the present time the exact nature of the 'second factor' involved in development of permanent AF is still unknown.

\section{Future Perspectives}

New strategies for the management of AF, amongst other things, will depend on a better understanding of the mechanisms underlying atrial remodeling. In humans with chronic AF atrial electrical remodeling has been shown to be completely reversible within 3-4 days after cardioversion of $\mathrm{AF}^{28}$ Recurrences of $\mathrm{AF}$ are frequent during the first week after cardioversion and may be related to the process of reverse electrical remodeling. ${ }^{78,81}$ Because of the short time course of AF-induced electrical remodeling and its complete and rapid reversibility, AF-recurrences occurring after one week can 
not be explained on this basis. A persisting high susceptibility to AF might be due to structural remodeling of the atria as a result of prolonged AF. The reversibility of AFinduced structural changes has proven to be a very slow process which takes at least several months. Some structural changes may be even irreversible. ${ }^{84}$ Thus the prevention of structural remodeling by $\mathrm{AF}$ might be an important new element in $\mathrm{AF}$ management. Recently, the ACE-inhibitor enalapril was shown to attenuate atrial fibrosis and conduction abnormalities in a canine model of heart failure. ${ }^{90}$ Activation of the Renin-Angiotensin system causes atrial cell growth, proliferation of fibroblasts and atrial fibrosis. This might explain why ACE-inhibitors are effective to prevent $\mathrm{AF}$ in patients with heart failure $e^{91}$ and left ventricular dysfunction after myocardial infarction. ${ }^{92}$ Thus, whereas electrical remodeling is 'forgiving' and only plays a shortlasting role in the occurrence and perpetuation of AF, structural atrial remodeling may be less reversible. Thus, conservation of the normal atrial size and architecture by preventing structural atrial remodeling due to $\mathrm{AF}$ and ventricular dysfunction seems of prime importance for the future management of AF.

\section{$\underline{\text { References }}$}

1. Wijffels MC, Kirchhof CJ, Dorland R, Allessie MA. Atrial fibrillation begets atrial fibrillation. A study in awake chronically instrumented goats. Circulation 1995; 92:1954-1968.

2. Morillo CA, Klein GJ, Jones DL. Guiraudon CM. Chronic rapid atrial pacing. Structural. functional, and electrophysiological characteristics of a new model of sustained atrial fibrillation. Circulation 1995: 91:1588-1595.

3. Rensma PL, Allessie MA, Lammers WJ, Bonke FI, Schalij MJ. Length of excitation wave and susceptibility to reentrant atrial arrhythmias in normal conscious dogs. Circ Res 1988: 62:395-410.

4. Allessie MA. Atrial electrophysiologic remodeling: another vicious circle? J Cardiovasc Electrophysiol 1998; 9:1378-1393.

5. Konings KT, Wijffels M, Dorland R, Mast F. Allessie M. High-density mapping of the right atrium during acute and chronic atrial fibrillation in the goat. Pacing Clin Electrophysiol 1999; 22:727.

6. Konings KT. Kirchhof CJ. Smeets JR, Wellens HJ, Penn OC, Allessie MA. High-density mapping of electrically induced atrial fibrillation in humans. Circulation 1994; 89:1665-1680.

7. Wells JL, Jr., Karp RB, Kouchoukos NT, MacLean WA, James TN, Waldo AL. Characterization of atrial fibrillation in man: studies following open heart surgery. Pacing Clin Electrophysiol 1978: 1:426-438.

8. Konings KT. Mapping of electrically induced atrial fibrillation in humans. Thesis Maastricht University 1999.

9. Gaspo R, Bosch RF. Bou-Abboud E, Nattel S. Tachycardia-induced changes in Na+ current in a chronic dog model of atrial fibrillation. Circ Res 1997; 81:1045-1052.

10. Yue L, Feng J, Gaspo R, Li GR, Wang Z, Nattel S. Ionic remodeling underlying action potential changes in a canine model of atrial fibrillation. Circ Res 1997; 81:512-525.

11. Van Wagoner DR, Pond AL, McCarthy PM, Trimmer JS, Nerbonne JM. Outward K+ current densities and Kv1.5 expression are reduced in chronic human atrial fibrillation. Circ Res 1997. 80:772-781.

12. Bosch RF, Zeng X. Grammer JB. Popovic K, Mewis C, Kuhlkamp V. Ionic mechanisms of electrical remodeling in human atrial fibrillation. Cardiovasc Res 1999; 44:121-131.

13. Van Wagoner DR. Pond AL, Lamorgese M, Rossie SS, McCarthy PM, Nerbonne JM. Atrial Ltype $\mathrm{Ca}^{2+}$ currents and human atrial fibrillation. Circ Res 1999; 85:428-436.

14. Grammer JB, Bosch RF, Kuhlkamp V, Seipel L. Molecular remodeling of Kv4.3 potassium channels in human atrial fibrillation. J Cardiovasc Electrophysiol 2000; 11:626-633.

15. van der Velden HMW, van der ZL, Wijffels MC, van Leuven C. Dorland R. Vos MA. Jongsma HJ. Allessie MA. Atrial fibrillation in the goat induces changes in monophasic action potential and 
mRNA expression of ion channels involved in repolarization. I Cardiovasc Electrophysiol 2000; 11:1262-1269.

16. Attuel P, Childers R, Cauchemez B, Poveda J. Mugica J, Coumel P. Failure in the rate adaptation of the atrial refractory period: its relationship to vulnerability. Int J Cardiol 1982; 2:179-197.

17. Boutjdir M, Le Heuzey JY, Lavergne T, Chauvaud S, Guize L, Carpentier A, Peronneau P. Inhomogeneity of cellular refractoriness in human atrium: factor of arrhythmia? Pacing Clin Electrophysiol 1986; 9:1095-1100.

18. Franz MR, Karasik PL, Li C, Moubarak J, Chavez M. Electrical remodeling of the human atrium: similar effects in patients with chronic atrial fibrillation and atrial flutter. J Am Coll Cardiol 1997; 30:1785-1792.

19. Gaspo R, Bosch RF, Talajic M, Nattel S. Functional mechanisms underlying tachycardia-induced sustained atrial fibrillation in a chronic dog model. Circulation 1997; 96:4027-4035.

20. Olsson SB. Chronic atrial fibrillation - what is wrong with the atrium? Eur Heart $J 1999$; 20:856857.

21. Olsson SB, Cotoi S, Varnauskas E. Monophasic action potential and sinus rhythm stability after conversion of atrial fibrillation. Acta Med Scand 1971; 190:381-387.

22. Skasa M, Jungling E, Picht E, Schondube F, Luckhoff A. L-type calcium currents in atrial myocytes from patients with persistent and non-persistent atrial fibrillation. Basic Res Cardiol 2001; $96: 151-159$.

23. Yue L, Melnyk P. Gaspo R, Wang Z, Nattel S. Molecular mechanisms underlying ionic remodeling in a dog model of atrial fibrillation. Circ Res 1999; 84:776-784.

24. Lai LP, Su MJ, Lin JL, Lin FY, Tsai CH, Chen YS, Huang SK, Tseng YZ, Lien WP. Downregulation of L-type calcium channel and sarcoplasmic reticular $\mathrm{Ca}(2+)$-ATPase mRNA in human atrial fibrillation without significant change in the mRNA of ryanodine receptor, calsequestrin and phospholamban: an insight into the mechanism of atrial electrical remodeling. J Am Coll Cardiol 1999:33:1231-1237.

25. Brundel BJ, Van Gelder IC, Henning RH. Tieleman RG. Tuinenburg AE, Wietses M, Grandjean JG, Van Gilst WH, Crijns HJ. Ion channel remodeling is related to intraoperative atrial effective refractory periods in patients with paroxysmal and persistent atrial fibrillation. Circulation 2001; 103:684-690.

26. Grammer JB, Zeng X. Bosch RF. Kuhlkamp V. Atrial L-type Ca2+-channel, beta-adrenorecptor, and 5-hydroxytryptamine type 4 receptor mRNAs in human atrial fibrillation. Basic Res Cardiol 2001: 96:82-90.

27. Schotten U., Haase H. Frechen D, Greiser M, Stellbrink C, Vazquez-Jimenez JF. Morano I. Allessie M, Hanrath P. The L-Type Ca ${ }^{2 \cdot}$ Channel Subunits $\alpha_{1 \mathrm{C}}$ and $\beta_{2}$ are not Downregulated in Atrial Myocardium of Patients with Chronic Atrial Fibrillation. J Mol Cell Cardiol 2003, 35;437. 443.

28. Yu WC, Lee SH. Tai CT. Tsai CF. Hsieh MH, Chen CC, Ding YA. Chang MS, Chen SA. Reversal of atrial electrical remodeling following cardioversion of long-standing atrial fibrillation in man. Cardiovase Res 1999: 42:470-476.

29. Elvan A, Huang XD, Pressler ML, Zipes DP. Radiofrequency catheter ablation of the atria eliminates pacing-induced sustained atrial fibrillation and reduces connexin 43 in dogs. Circulation 1997: 96:1675-1685.

30. Patel P. Jones D. Dupont E. Remodeling of human connexin 43 expression in human atrial fibrillation. Eur Heart J 2001; 19:465.

31. van der Velden HM, Ausma J, Rook MB, Hellemons AJ, van Veen TA, Allessie MA, Jongsma HJ. Gap junctional remodeling in relation to stabilization of atrial fibrillation in the goat. Cardiovasc Res 2000:46:476-486.

32. Jongsma HJ, Wilders R. Gap junctions in cardiovascular disease. Circ Res 2000; 86:1193-1197.

33. Todd DM, Walden AP. Fynn SP, Hobbs WJ, Garratt CJ. Repetitive one-month periods of atrial electrical remodeling promote stability of atrial fibrillation. Circulation 2000; 102:154-155.

34. Li D, Fareh S, Leung TK. Nattel S. Promotion of atrial fibrillation by heart failure in dogs: atrial remodeling of a different sort. Circulation 1999; 100:87-95.

35. Logan W, Rowlands D, Howitt G, Holmes A. Left atrial activity following cardioversion. Lancet $1965: 2: 471-473$.

36. Manning WJ, Silverman DI, Katz SE, Riley MF, Come PC, Doherty RM, Munson JT, Douglas PS. Impaired left atrial mechanical function after cardioversion: relation to the duration of atrial fibrillation. J Am Coll Cardiol 1994: 23:1535-1540.

37. Manning WJ, Silverman DI, Katz SE, Riley MF. Doherty RM. Munson JT, Douglas PS. Temporal dependence of the return of atrial mechanical function on the mode of cardioversion of atrial fibrillation to sinus rhythm. Am J Cardiol 1995; 75:624-626. 
38. Harjai KJ, Mobarek SK, Cheirif J, Boulos LM, Murgo JP, Abi-Samra F. Clinical variables affecting recovery of left atrial mechanical function after cardioversion from atrial fibrillation. J Am Coll Cardiol 1997: 30:481-486.

39. Grimm RA, Leung DY, Black IW, Stewart WJ, Thomas JD, Klein AL. Left atrial appendage "stunning" after spotaneous conversion of atrial fibrillation demonstrated by transesophageal Doppler echocardiography. Am Heart J 1995; 130:174-176.

40. Falk RH, Decara J, Abascal V. Is pharmacologic cardioversion of atrial fibrillation really preferable to electrical cardioversion? J Am Coll Cardiol 1998; 31:1446-1447.

41. Resnekov L, McDonald L. Complications in 220 patients with cardiac dysrhythmias treated by phased direct current shock, and indications for electroconversion. Br Heart J 1967; 29:926-936.

42. Fatkin D, Kuchar DL, Thorburn CW. Feneley MP. Transesophageal echocardiography before and during direct current cardioversion of atrial fibrillation: evidence for "atrial stunning" as a mechanism of thromboembolic complications. J Am Coll Cardiol 1994; 23:307-316.

43. Black IW, Fatkin D, Sagar KB, Khandheria BK, Leung DY, Galloway JM, Feneley MP, Walsh WF, Grimm RA. Stollberger C. Exclusion of atrial thrombus by transesophageal echocardiography does not preclude embolism after cardioversion of atrial fibrillation. A multicenter study. Circulation 1994; 89:2509-2513.

44. Daoud EG, Marcovitz P. Knight BP, Goyal R, Man KC, Strickberger SA, Armstrong WF, Morady F. Short-term effect of atrial fibrillation on atrial contractile function in humans. Circulation 1999; 99:3024-3027.

45. Leistad E, Aksnes G, Verburg E, Christensen G. Atrial contractile dysfunction after short-term atrial fibrillation is reduced by verapamil but increased by BAY K8644. Circulation 1996; 93:1747-1754.

46. Sun H, Gaspo R, Leblanc N, Nattel S. Cellular mechanisms of atrial contractile dysfunction caused by sustained atrial tachycardia. Circulation 1998; 98:719-727.

47. Schotten U, Duytschaever M, Ausma J, Eijsbouts S, Neuberger HR, Allessie M. Electrical and Contractile Remodeling during the First Days of Atrial Fibrillation go Hand-in-Hand. Circulation 2003, 107:1433-1439.

48. Schotten U. Ausma J, Stellbrink C, Sabatschus I, Vogel M. Frechen D, Schoendube F, Hanrath P. Allessie MA. Cellular mechanisms of depressed atrial contractility in patients with chronic atrial fibrillation. Circulation 2001: 103:691-698.

49. Schotten U, Greiser M, Benke D. Buerkel K, Ehrenteidt B, Stellbrink C, Vazquez-Jimenez JF, Schoendube F, Hanrath P. Allessie M. Atrial fibrillation-induced atrial contractile dysfunction: a tachycardiomyopathy of a different sort. Cardiovasc Res 2002; 53:192-201.

50. Ausma J, Wijffels M. Thone F, Wouters L, Allessie M. Borgers M. Structural changes of atrial myocardium due to sustained atrial fibrillation in the goat. Circulation 1997:96:3157-3163.

51. van der Velden HM, van Kempen MJ, Wijffels MC, van Zijverden M. Groenewegen WA, Allessie MA, Jongsma HJ. Altered pattern of connexin 40 distribution in persistent atrial fibrillation in the goat. J Cardiovasc Electrophysiol 1998; 9:596-607.

52. Dispersyn GD. Ausma J. Thone F. Flameng W, Vanoverschelde JL, Allessie MA, Ramaekers FC. Borgers M. Cardiomyocyte remodelling during myocardial hibernation and atrial fibrillation: prelude to apoptosis. Cardiovasc Res 1999; 43:947-957.

53. Ausma J. Dispersyn GD. Duimel H. Thone F. Ver DL, Allessie MA. Borgers M. Changes in ultrastructural calcium distribution in goat atria during atrial fibrillation. J Mol Cell Cardiol 2000; 32:355-364.

54. Everett TH, Li H, Mangrum JM, McRury ID, Mitchell MA, Redick JA, Haines DE. Electrical. morphological, and ultrastructural remodeling and reverse remodeling in a canine model of chronic atrial fibrillation. Circulation 2000: 102:1454-1460.

55. Borgers M. Thone F, Wouters L, Ausma J, Shivalkar B, Flameng W. Structural correlates of regional myocardial dysfunction in patients with critically coronary artery stenosis:Chronic hibernation? Cardiovasc Pathol 1993: 2:237-245.

56. Vitadello M. Ausma J. Borgers M. Gambino A. Casarotto DC. Gorza L. Increased myocardial GRP94 amounts during sustained atrial fibrillation: a protective response? Circulation 2001: 103:2201-2206.

57. Thiedemann K-U. Ferrans VJ. Left atrial ultrastructure in mitral valvular disease. Am J Pathol 1977: 89:575-594.

58. Frustaci A, Chimenti C, Bellocei F. Morgante E, Russo MA, Maseri A. Histological substrate of atrial biopsies in patients with lone atrial fibrillation. Circulation 1997; 96:1180-1184.

59. Wouters L, Liu GS, Flameng W. Thijssen VL. Thone F, Borgers M. Structural remodeling of atrial myocardium in patients with cardiac valve disease and atrial fibrillation. Exp Clin Cardiol 2001; 5:158-163. 
60. Aimé-Sempé C, Folliguet T, Rucker-Martin C. Krajewska M, Krajewska S. Heimburger M, Aubier M, Mercadier JJ, Reed JC, Hatem SN. Myocardial cell death in fibrillating and dilated human right atria. J Am Coll Cardiol 1999; 34:1577-1586.

61. Bailey GW, Braniff BA. Hancock EW. Cohn KE. Relation of left atrial pathology to atrial fibrillation in mitral valvular disease. Ann Intern Med 1968; 69:13-20.

62. Fenoglio JJ. Jr., Wagner BM. Studies in rheumatic fever. VI. Ultrastructure of chronic rheumatic heart disease. Am J Pathol 1973; 73:623-640.

63. Pham TD, Wit AL, Hordof AJ, Malm JR. Fenoglio JJ, Jr, Right atrial ultrastructure in congenital heart disease. I. Comparison of ventricular septal defect and endocardial cushion defect. Am J Cardiol 1978; 42:973-982.

64. Fenoglio JJ, Jr., Pham TD, Hordof A, Edie RN, Wit AL. Right atrial ultrastructure in congenital heart disease. II. Atrial septal defect: effects of volume overload. Am J Cardiol 1979; 43:820-827.

65. Mary RL, Albert A, Pham TD, Hordof A, Fenoglio-JJ J, Malm JR, Rosen MR. The relationship of human atrial cellular electrophysiology to clinical function and ultrastructure. Circ Res 1983; 52:188-199.

66. Kitzman DW, Edwards WD. Age-related changes in the anatomy of the normal human heart. J Gerontol 1990; 45:M33-M39.

67. Hobbs WJ. Fynn S, Todd DM, Wolfson P. Galloway M, Garratt CJ. Reversal of atrial electrical remodeling after cardioversion of persistent atrial fibrillation in humans. Circulation 2000; 101:1145-1151.

68. Boyden PA, Tilley LP. Pham TD. Liu SK, Fenoglic JJJ. Wit AL. Effects of left atrial enlargement on atrial transmembrane potentials and structure in dogs with mitral valve fibrosis. Am J Cardiol $1982 ; 49: 1896-1908$.

69. Boyden PA, Tilley LP, Albala A. Liu SK, Fenoglio JJ, Jr., Wit AL. Mechanisms for atrial arrhythmias associated with cardiomyopathy: a study of feline hearts with primary myocardial disease. Circulation 1984; 69:1036-1047.

70. Boyden PA, Hoffman BF. The effects on atrial electrophysiology and structure of surgically induced right atrial enlargement in dogs. Circ Res 1981; 49:1319-1331.

71. White CW, Kerber RE, Weiss HR, Marcus ML. The effects of atrial fibrillation on atrial pressurevolume and flow relationships. Cire Res 1982; 51:205-215.

72. Sun H. Chartier D. Leblanc N, Nattel S. Intracellular calcium changes and tachycardia-induced contractile dysfunction in canine atrial myocytes. Cardiovasc Res 2001; 49:751-761.

73. Fearon IM, Varadi G, Koch S. Isaacsohn I, Ball SG. Peers C. Splice variants reveal the region involved in oxygen sensing by recombinant human L-type $\mathrm{Ca}(2+)$ channels. Circ Res 2000: 87:537-539.

74. Duytschaever M, Danse P, Allessie M. Supervulnerable phase immediately after termination of atrial fibrillation. J Cardiovasc Electrophysiol. 2002 Mar:13:267-275.

75. Jayachandran JV, Zipes DP, Weksler J, Olgin JE. Role of the $\mathrm{Na}(+) / \mathrm{H}(+)$ exchanger in short-term atrial electrophysiological remodeling. Circulation 2000; 101:1861-1866.

76. Pandozi C, Santini M. Update on atrial remodelling owing to rate; does atrial fibrillation always 'beget' atrial fibrillation? Eur Heart J 2001; 22:541-553.

77. Daoud EG, Bogun F, Goyal R, Harvey M. Man KC. Strickberger SA, Morady F. Effect of atrial fibrillation on atrial refractoriness in humans. Circulation 1996; 94:1600-1606.

78. Van Noord T, Van Gelder IC, Schoonderwoerd BA, Crijns HJ. Immediate reinitiation of atrial fibrillation after electrical cardioversion predicts subsequent pharmacologic and electrical conversion to sinus rhythm and amiodarone. Am J Cardiol 2000; 86:1384-5.

79. Timmermans C, Rodriguez LM, Smeets JL, Wellens HJ. Immediate reinitiation of atrial fibrillation following internal atrial defibrillation. J Cardiovasc Electrophysiol 1998; 9:122-128.

80. Gaspo R, Sun H, Fareh S, Levi M, Yue L, Allen BG, Hebert TE, Nattel S. Dihydropyridine and beta adrenergic receptor binding in dogs with tachycardia-induced atrial fibrillation. Cardiovasc Res 1999: 42:434-442.

81. Tieleman RG, Van Gelder IC, Crijns HJ, de Kam PJ. Van Den Berg MP, Haaksma J, Van Der Woude HJ, Allessie MA. Early recurrences of atrial fibrillation after electrical cardioversion: a result of fibrillation-induced electrical remodeling of the atria? J Am Coll Cardiol 1998; 31:167173.

82. Sanfilippo AJ, Abascal VM, Sheehan M, Oertel LB, Harrigan P, Hughes RA, Weyman AE. Atrial enlargement as a consequence of atrial fibrillation. A prospective echocardiographic study [see comments]. Circulation 1990: 82:792-797.

83. Ausma J, Litjens N, Lenders M-H, Duimel H, Mast F, Wouters L, Ramaekers F, Allessie M, Borgers M. Time course of atrial fibrillation-induced cellular structural remodeling in atria of the goat. J Mol Cell Cardiol 2001: 33:2083-2094. 
84. Ausma J, van der Velden HMW, Lenders M-H, van Ankeren EP, Jongsma HJ, Raemakers FC, Borgers M. Allessie M. Reverse structural and gap-junctional remodeling after prolonged atrial fibrillation in the goat. Circulation 2003; 107:2051-2058.

85. Garratt CJ. Duytschaever M, Killian M, Dorland R. Mast F, Allessie MA. Repetitive electrical remodeling by paroxysms of atrial fibrillation in the goat: no cumulative effect on inducibility or stability of atrial fibrillation. J Cardiovase Electrophysiol 1999; 10:1101-1108.

86. Ausma J, Duytschaever M, Wijffels M, Borgers M. Allessie M. Loss of efficacy of cardioversion by class Ic drugs after long term atrial fibrillation in the goat. Eur Heart J 2001; 21:543.

87. Brodsky MA, Allen BJ, Capparelli EV, Luckett CR, Morton R, Henry WL. Factors determining maintenance of sinus rhythm after chronic atrial fibrillation with left atrial dilatation. Am J Cardiol 1989; 63:1065-1068.

88. Verhorst PM. Kamp O, Welling RC, Van Eenige MJ, Visser CA. Transesophageal echocardiographic predictors for maintenance of sinus rhythm after electrical cardioversion of atrial fibrillation. Am J Cardiol 1997; 79:1355-1359.

89. Shi Y, Ducharme A. Li D. Gaspo R, Nattel S, Tardif JC. Remodeling of atrial dimensions and emptying function in canine models of atrial fibrillation. Cardiovasc Res 2001; 52:217-225.

90. Li D, Shinagawa K. Pang L, Leung TK. Cardin S, Wang Z, Nattel S. Effects of Angiotensinconverting enzyme inhibition on the development of the atrial fibrillation substrate in dogs with ventricular tachypacing-induced congestive heart failure. Circulation 2001; 104:2608-2614.

91. Gurlek A, Erol C, Basesme E. Antiarrhythmic effect of converting enzyme inhibitors in congestive heart failure. Int J Cardiol 1994; 43:315-318.

92. Pedersen OD, Bagger H, Kober L. Torp-Pedersen C. Trandolapril reduces the incidence of atrial fibrillation after acute myocardial infarction in patients with left ventricular dysfunction. Circulation 1999; 100:376-380. 

In the present study we investigated some of the mechanisms underlying atrial contractile dysfunction induced by atrial fibrillation. It was also studied whether loss of atrial contractility during $\mathrm{AF}$ results in dilatation of fibrillating atria.

Chapter 2 to 4 focus on the mechanisms of atrial contractile dysfunction in patients with chronic $\mathrm{AF}$. In $\mathrm{AF}$ patients contractile force of isolated right atrial trabeculae was reduced by $\sim 75 \%$ (chapter 2 and 3 ). The most relevant result of the fist study was, that against our expectations contractile reserve of the isolated atrial myocardium from patients with chronic AF was only slightly reduced (-15\%) (chapter 2 ). Light microscopy of the same muscle preparations revealed that indeed the degree of myolysis attributable to AF was very limited and that there was a strong correlation between contractile reserve and sarcomere content of the muscle bundles. Thus, besides moderate myolysis there must be other mechanisms contributing to atrial contractile dysfunction. The L-type $\mathrm{Ca}^{2+}$ channel agonist BayK8644 could not restore contraction suggesting that downregulation and/or functional alterations of the L-type $\mathrm{Ca}^{2+}$ channel might contribute to atrial dysfunction in $\mathrm{AF}$ patients.

In the second study (chapter 3) we tested the hypothesis that atrial contractile dysfunction may be regarded as the atrial version of classical ventricular tachycardiainduced cardiomyopathy. We found that the positive inotropic response to isoprenaline was reduced, but $\beta$-adrenoceptor density and expression of $\mathrm{G}$ proteins involved in $\beta$ adrenergic signalling were unchanged. Baseline and isoprenaline-stimulated adenylyl cyclase activity were also not altered indicating that the $\beta$-adrenergic signal transduction pathway per se is not affected in atrial myocardium of $\mathrm{AF}$ patients. Also, we found no impairment of relaxation properties, force-frequency relation, or post-rest potentiation of isolated myocardium of AF patients. The expression of the most relevant $\mathrm{Ca}^{2+}$ transport proteins of the sarcoplasmic reticulum was not altered. Thus, two key alterations present in classical ventricular tachycardiomyopathy - $\beta$-adrenergic desensitisation and dysfunction of the sarcoplasmic reticulum - are missing in AFinduced atrial contractile dysfunction indicating that adaptation processes to the same stimulus (e.g. tachycardia) may be different in atria and ventricles.

Downregulation of the L-type $\mathrm{Ca}^{2+}$-inward current $\left(\mathrm{I}_{\mathrm{Cat}}\right)$ was reported to underlie electrical remodeling but might also contribute to $\mathrm{AF}$-induced atrial contractile dysfunction. Studies on gene expression of the L-type $\mathrm{Ca}^{2+}$ channel reported that $\alpha_{\mathrm{IC}}$ subunit mRNA was reduced in animal models and human $\mathrm{AF}$. We quantified the protein expression of the L-type $\mathrm{Ca}^{2+}$ channel subunits $\alpha_{\mathrm{IC}}$ and $\beta_{2}$ in atrial myocardium of AF patients (Western blot) and compared them to the density of dihydropyridine binding sites in the same tissue (chapter 4). Much to our surprise, we found that neither $\alpha_{1 \mathrm{C}}$ or $\beta_{2}$ protein expression nor the density of dihydropyridine binding sites was reduced in $\mathrm{AF}$ patients. Thus, reduced $\mathrm{I}_{\mathrm{Cat}}$ in human $\mathrm{AF}$ might be due to downregulation of other accessory subunits $\left(\alpha_{2} \delta\right)$, changes in channel trafficking or alterations in channel function.

The following two chapters focus on atrial paralysis induced by several days of $\mathrm{AF}$ in the goat. First, we determined the time course of atrial contractile dysfunction (chapter 5). We found that already after two to three days of $\mathrm{AF}$ atrial contractile function was completely abolished. Interestingly, contractile remodeling followed exactly the same 
time course as the shortening of the refractory period (electrical remodeling) suggesting and electrical and contractile remodeling during the first days of $\mathrm{AF}$ are due to the same cellular mechanisms. Since electrical remodeling is due to a reduction of $I_{\text {CaL }}$ it is reasonable to believe that during the first days of $\mathrm{AF}$ atrial contractile dysfunction is also mainly related to downregulation of this current.

In theory, loss of atrial contractile function during $\mathrm{AF}$ might contribute to progressive atrial dilatation. In chapter 6 we describe the effect of atrial contractile remodeling on compliance and size of fibrillating atria. With loss of atrial contractility the atrial compliance curve shifted to the right and compliance increased. Although mean atrial pressure did not change during 5 days of $\mathrm{AF}$ the rightward shift and the flattening of the compliance curve resulted in an increase in atrial size. As atrial contractility recovered after cardioversion, baseline atrial diameter was restored. The results indicate that atrial dilatation during the first days of $\mathrm{AF}$ is a direct consequence of the loss of atrial contractile function.

In chapter 7 a new hypothetical positive feedback loop of $\mathrm{AF}$ is suggested. According to this 'contractile feedback loop' AF results in loss of atrial contractility which increases atrial compliance thereby facilitating atrial dilatation. Using goats with chronic AV block we demonstrate that atrial dilatation in turn promotes AF. The increased propensity to AF in this model could not be explained by a shortening of refractory period or AF cycle length. Rather, the stability of AF correlated with the increase in atrial size. Thus, AF-induced atrial contractile remodeling might indirectly contribute to the self-perpetuating nature of the arrhythmia.

In chapter $\mathbf{8}$ the relation between electrical, contractile, and structural remodeling is discussed. Special attention is paid to the different time domains of the complex remodeling process. During the first minutes of $\mathrm{AF}$ changes in cellular ion concentrations and ion pump activities cause a moderate 'metabolic' hypocontractility which recovers within minutes. During the first days of $\mathrm{AF} \mathrm{I}_{\mathrm{Cat}}$ is downregulated which explains the shortening of the refractory period and the pronounced loss of atrial contractility. These changes take a couple of days to recover. After several months of $\mathrm{AF}$, apart from a reduction of $\mathrm{I}_{\text {Cat }}$ moderate myolysis, upregulation of the $\mathrm{Na}^{+} / \mathrm{Ca}^{2+}$ exchanger, and possibly an impaired release of $\mathrm{Ca}^{2+}$ from the sarcoplasmic reticulum contribute to atrial contractile dysfunction. Delayed reversal of these changes after cardioversion of AF might explain the slow recovery of atrial contractility. 


\section{Samenvatting}

Boezemfibrilleren is de meest voorkomende vorm van hartritmestoornissen bij volwassenen. $\mathrm{Na}$ het opheffen van boezemfibrilleren blijkt de contractiekracht van de boezemspier aangetast. Hierdoor wordt de boezem niet goed leeggepompt en de verminderde doorstroom kan leiden tot de vorming van bloedstolsels, die als ze in de bloedbaan terechtkomen embolieën kunnen veroorzaken (thromboembolie). Deze studie is bedoeld om te achterhalen welke mechanismen verantwoordelijk zijn voor de verminderde contractiekracht na boezemfibrilleren.

In de hoofdstukken $2 \mathrm{t} / \mathrm{m} 4$ worden de mechanismen van de contractiele disfunctie van de boezems in patiënten met langdurig boezemfibrilleren beschreven. Lange tijd is de hypothese geweest dat in deze patiënten de hypocontractiliteit werd veroorzaakt door myolyse, het verdwijnen of 'lyseren' van spiereiwitten. Inderdaad vonden wij in geïsoleerde spierbundels van de rechter boezem van patiënten met boezemfibrilleren een lagere contractiekracht dan bij patiënten met sinusritme. De maximale door een hoge calciumconcentratie opwekbare contractiekracht was echter nauwelijks verminderd. Daarom is na langdurig boezemfibrilleren de verlaagde contractiliteit van de boezems slechts in beperkte mate toe te schrijven aan myolyse (hoofdstuk 2). Ook de $\beta$-adrenerge signaaltransductie en de functie van het sarcoplasmatische reticulum blijken niet aangetast te zijn (hoofdstuk 3). Een alternatieve verklaring voor de verstoorde atriale contractiliteit zou de vermindering van de calcium-instroom in atriale myocyten kunnen zijn, die de laatste jaren door verschillende groepen werd aangetoond. Wij vermoedden daarom dat de hoeveelheid van de kanaaleiwitten in het atriale weefsel van patienten met boezemfibrilleren verlaagd zou zijn. Tot onze verbazing vonden wij dat de expressie van de $\mathrm{Ca}^{2+}$-kanaal subunits $\alpha_{1 \mathrm{c}}$ en $\beta_{2}$ in het atriale weefsel van patiënten met boezemfibrilleren niet verminderd is (hoofdstuk 4). Blijkbaar berust de verlaging van de calcium-stroom op een functionele verandering van de calcium kanalen.

De volgende twee hoofdstukken ( 5 en 6 ) zijn gewijd aan de vermindering van de atriale contractiekracht in de geit. Met behulp van een atriale fibrillator hebben wij in deze dieren boezemfibrilleren opgewekt. De atriale grootte werd gemeten met geïmplanteerde ultrageluid kristallen. De contractie van de atria werd bepaald met drukvolume lussen opgenomen met een geïmplanteerde druk-catheter. Al na twee dagen boezemfibrilleren was de contractiliteit van de boezem bijna volledig opgeheven. Het tijdsverloop van elektrische remodellering (verkorting van de refractaire periode) en contractiele remodellering (verlaging van de atriale contractiliteit) waren vrijwel identiek wat betekent dat de cellulaire oorzaken van deze twee processen nauw gerelateerd zijn (hoofdstuk 5). De hypocontractiliteit van de boezem heeft ook consequenties voor de grootte van de boezems. De rekbaarheid van de boezem neemt door het verlies van de contractiliteit toe en de boezems dilateren (hoofdstuk 6). Dilatatie van de boezems verhoogt wederom de stabiliteit van boezemfibrilleren zoals wij hebben aangetoond in geiten met een chronische blokkering van de atrioventriculaire geleiding. Er is dus sprake van een vicieuze cirkel (hoofdstuk 7).

Afgerond wordt dit proefschrift door een beschrijving van het verband tussen elektrische, contractiele en structurele remodellering in de atria van patiënten met boezemfibrilleren (hoofdstuk 8). Hierbij wordt de nadruk op verschillende tijdsdomeinen gelegd. Kortdurende fibrillatie, tot enkele dagen, leidt tot verminderde instroom van calcium-ionen door de L-type calcium kanalen. De calcium-stroom 
herstelt binnen enkele dagen na het stoppen van de boezemfibrillatie. Tegelijkertijd herstelt ook de contractiekracht, wat het aannemelijk maakt dat de veranderde calciumstroom verantwoordelijk is voor de veranderde contractiekracht. $\mathrm{Na}$ chronische fibrillatie echter, fibrillatie die maanden tot jaren aanhoudt, duurt het ook maanden voordat de contractiekracht weer hersteld is. Dit wijst erop dat er meer mechanismen aan het werk zijn dan alleen de reductie van de calcium-stroom. Mogelijke alternatieve oorzaken van de atriale disfunctie zouden een verhoogde expressie van de $\mathrm{Na}^{+} / \mathrm{Ca}^{2+}$ uitwisselaar, het verstoorde vrijmaken van calcium uit het sarcoplasmatische reticulum of een veranderde functie van de spiereiwitten kunnen zijn. 


\section{Nawoord}

Alles begon op een mooie en hete dag in maart 1997 in Californië. Ik nam aan het ACC congres in Anaheim deel en sloeg, zittend in het zwembad, het abstractboek open. Toevallig stond juist op deze pagina een artikel over het effect van boezemfibrilleren op een bepaald ion-kanaal dat me destijds interesseerde. Volgens dit artikel zou boezemfibrilleren waarschijnlijk sterke veranderingen in de elektro-mechanische koppeling opwekken. Het verband tussen een ritmestoornis en de contractiele functie van het hart fascineerde mij meteen. Nog diezelfde maand begonnen wij in Aken met het systematische onderzoek naar de oorzaken van 'Atrial Stunning'. Al gauw kwam ik bij literatuuronderzoek de naam Maurits Allessie tegen, maar een eerste bijeenkomst met hem verliep behoorlijk stug. Ten eerste leek Maurits maar in een beperkte mate interesse in dit onderwerp te hebben en ten tweede mocht volgens hem mijn carrière absoluut niet van dit project afhangen. Het was meteen helder, Maurits Allessie is een heel bijzonder persoon. Het zou niet makkelijk zijn, zijn mening te beïnvloeden of hem zelfs van iets anders dan zijn eigen mening te overtuigen. Op mij had dit nooit een afschrikwekkend effect. Ik zag het eerder als een uitdaging. Tijdens de tweede bijeenkomst leerde ik dan ook andere eigenschappen van hem kennen: Niet alles wat hij zegt bedoelt hij serieus en, niet minder belangrijk, ook al lijkt het er tijdens de discussie niet op, hij blijft na de discussie over sommige dingen wel nadenken en is dan in staat zijn mening bij te stellen. Slechts af en toe gebeurt dit als een geleidelijk proces dat weken tot zelfs maanden kan duren. Meestal treedt de verandering plotseling op en dan altijd als totale ommekeer van zijn zienswijze ('eye-opener'). Hiervan getuigen talloze commentaren van promovendi over het keer op keer veranderen van protocollen, de experimentele opstelling of de opzet van een paper. Deze eigenaardigheden van Maurits' bewustzijn wekte bij meerdere tijdgenoten, onafhankelijk van elkaar, associaties met de Brownse moleculaire beweging op. Uiteraard wordt dit door Maurits als een inadequate vergelijking beschouwd, omdat de Brownse beweging geen voorkeursrichting zou hebben. De kunst als medewerker van Maurits is dus deze voorkeursrichting uit zijn fibrillerende gedachten en suggesties te filteren en ze naar hem weer terug te spiegelen. Zoals these en antithese in de synthese zijn opgeheven en bewaard op een hoger niveau, zo zal, volgens Maurits, de volgende totale ommekeer van iets hogere kwaliteit zijn en leiden tot groei van kennis. Hieruit blijkt nog een eigenschap van Maurits: hij is een echte wetenschapper.

Beste Maurits, om met jou samen te werken is een heel bijzondere ervaring. Het is een wetenschappelijk avontuur en een permanente intellectuele uitdaging. Ik heb er altijd heel erg van genoten. Je enthousiasme en je helderheid stimuleert de werkbesprekingen en bevordert het denkproces van iedereen in hoge mate. Nog meer stel ik echter je persoonlijke betrokkenheid met je medewerkers op prijs. Ik weet nog goed hoe je me uit de brand hielp toen ik eens je steun nodig had. Daarvoor en voor alles wat ik van jou geleerd heb, heel erg bedankt.

Het vertrouwen en de steun die ik van mijn tweede promotor Prof. Hanrath heb gekregen is voor mij evenzeer van onschatbare waarde geweest:

Lieber Herr Hanrath, Sie haben mir den nötigen Raum gegeben, mich zu entwickeln. Ohne Ihre großzügige Unterstützung in allen Phasen bis zum heutigen Tage, wäre diese Arbeit niemals möglich gewesen. Wir haben zusammen einige Höhen und Tiefen des Labors mitgemacht. Ich bedanke mich bei Ihnen vor allem für das große und keinesfalls selbstverständliche Vertrauen, daß Sie mir in dieser Zeit immer entgegen gebracht 
haben. Auch mein Wechsel nach Maastricht hat daran nichts geändert. Daß Sie der zweite Promoter dieser Arbeit sind und wir weiterhin intensiv zusammenarbeiten, erfüllt mich deshalb mit Dankbarkeit und Genugtuung.

Im elektrophysiologischen Ziegenlabor herrschte immer eine außerordentlich angenehme und konstruktive Atmosphäre, die zu zahllosen Diskussionen anregte:

Beste Jannie, Mattias, Peter, Sabine, Yuri, Hans N, Robert, Natasja, Paolo, Chan, Michiel, Sunniva, Els, Dirk, Jodil, Hans D, het was en is nog steeds een erg leuke tijd met jullie. Beste Jannie, jij hebt me in het begin geholpen de weg te vinden in mijn nieuwe universiteit met een ander onderwijssysteem. Je was altijd voor alle grote en kleine problemen aanspreekbaar. Daar zal ik je altijd dankbaar voor blijven. Bedankt ook voor het duizendvoudig corrigeren van mijn Nederlands in woord en geschrift. Mattias, bedankt voor al de geiten-trucjes die je me liet zien, voor je besmettelijke enthousiasme en de talloze discussies over de toekomst van het geitenonderzoek. Sabine, jij hebt altijd voor de nodige verbondenheid in de groep gezorgd. Zonder jou waren er geen borrels en gezellige avonden geweest, en vooral geen afscheidscadeaus. Beste Yuri, naast het fietsen is je tweede hobby vragen te stellen waarop niemand een antwoord weet; ik vond het altijd erg leuk met jou daarover te brainstormen. Beste Hans, ook al leek het er vaak niet op, ik stelde je kritische commentaren en je twijfels en bezwaren over dit en dat altijd heel erg op prijs. Beste Jan, de enige verklaring dat je nog steeds zo rustig kunt blijven als er weer een prikkelaar of een oscilloscoop is opgeblazen, is dat je in 't geheim ervan houdt de hele dag op je werkplek te zitten en weerstandjes of transistortjes op printkaartjes te solderen. Ruud, Theo en Arne met jullie kundige handen op de OK hebben jullie een heel belangrijke bijdrage geleverd aan de totstandkoming van dit proefschrift. Marion, Joyce, May, Frans en Monique, bedankt voor jullie deskundig advies en het verzorgen van de geiten.

Auch der Stammannschaft der Fachgruppe Physiologie möchte ich natürlich danken, daß sie mich so warmherzig (hartelijk) in ihre Mitte aufgenommen hat:

Beste Mirjam, Rob, Marc, Luc, Ger, Marc, Ferdi, Tammo, Jan, Frits en Maurits, bedankt dat jullie me op zo'n vriendelijke manier in de staf hebben opgenomen. Jullie hebben ervoor gezorgd dat ik me binnen zeer korte tijd thuis kon voelen in de vakgroep Fysiologie.

De leden van de beoordelingscommissie, prof. dr. U. Ravens, prof. dr. H.J.G.M. Crijns, prof. dr. H.A.J. Struijker Boudier, prof. dr. G.J. van der Vusse, dr. D. van Wagoner, bedankt voor het kritisch doorlezen van het manuscript en voor de deelname aan deze verdediging. I very much appreciate that Prof. Ravens and D. van Wagoner made the effort to travel to Maastricht to join the evaluation committee.

Ook in Aken zijn er een aantal mensen heel nauw bij dit onderzoek betrokken geweest: Liebe(r) Maura, Dirk, Irina, Eva, Eckard, Miriam, Ingo, Britta, Kai, Denniz und Dirk. Ich weiß wieviel Schweiß und Nerven euch das Warten im OP, das Besorgen der Akten und das Aufhängen unzähliger Muskelpräparate gekostet hat. Umso mehr freut es mich, daß es euch doch insgesamt Spaß gemacht hat und ihr eure Freude nicht verloren habt. Vielen Dank für euren unermüdlichen Einsatz und die vielen Anregungen, die ich von euch bekommen habe.

De allermeeste dank ben ik natuurlijk mijn lieve vrouw Andrea verschuldigd die jarenlang voor mij thuis de ballen in de lucht heeft gehouden: Liebe Andrea, du hast über Jahre alle Löcher gefüllt, die ich zu Hause hinterlassen habe. Ich bewundere immer wieder, mit wieviel Geduld du Tag ein und Tag aus für die Kinder sorgst. Tausend große und kleine Dinge hast du für mich getan, obwohl du selbst ja auch einiges um die 
Ohren hattest (het zeer druk hebben). Du hast mir immer das Gefühl gegeben, frei zu sein in meinen Entscheidungen.

Uiteraard was dit zonder de enorme inzet van de grootouders niet mogelijk geweest: Liebe Mama und Papa, Vasu und Masu, euer aller Einsatz für Anna Lotte und Felix ist mit Gold nicht aufzuwiegen (met geen goud te betalen). Wie schön, daß die Kinder immer ,Hurra' rufen wenn sie wiedereinmal bei Oma und Opa schlafen dürfen. Liebe Anna Lotte, lieber Felix, von Euch hat Papa in dieser Zeit am meisten gelernt. Abends im Bett bei einer Gute-Nacht-Geschichte zeigt Ihr mir immer wieder aufs neue, worum es im Leben wirklich geht. Und das kann man schon mal vergessen über all den Experimenten und Artikeln.

Sinds maart 1997 hebben 203 patiënten aan de universiteiten in Aken en Maastricht toestemming gegeven dat een biopt van het tijdens een hartoperatie verwijderde atriale weefsel voor dit onderzoek gebruikt mocht worden. Ze hebben er toe bijgedragen dat de data afkomstig van experimenten met 19 geiten (oktober $1999 \mathrm{t} / \mathrm{m}$ november 2002) beter in een wetenschappelijk kader kon worden geïntegreerd. 


\section{List of Publications}

\section{Original contributions:}

Schumacher C, Becker H, Conrads R, Schotten U, Pott S, Kellinghaus M, Sigmund M, Schöndube F, Preusse C, Schulte HG, Hanrath P: Hypertrophic cardiomyopathy: A desensitized cardiac $\beta$-adrenergic system in the presence of normal plasma catecholamine concentrations. Naunyn-Schmiedeberg's Arch Pharmacol 1995; $351: 398-407$

Schotten U, Schumacher C, Sigmund M, Karlein C, Rose H, Kammermeier H, Sivarajan M, Hanrath P: Halothane, but not isoflurane, desensitizes the $\beta$-adrenergic signal transduction pathway in rat myocardium. Anesthesiology 1998; 88:1330-1339

Schotten U, Voss S, Wiederin T, Voss M, Schoendube F, Hanrath P, Schumacher C: Altered force-frequency relation in hypertrophic obstructive cardiomyopathy. Basic Res Cardiol. 1999; 94:120-127

Schotten U, Schumacher C, Conrads V, Braun V, Schoendube F, Voss M, Hanrath P: Calcium-sensitivity of the SR calcium release channel in failing and nonfailing human myocardium. Basic Res Cardiol. 1999; 94: 145-151.

Schotten U, Koenigs B, Rueppel M, Schoendube F, Boknik P, Schmitz W, Hanrath P: Reduced myocardial SR $\mathrm{Ca}^{2+}$ ATPase expression in compensated primary and secondary human cardiac hypertrophy. J Mol Cell Cardiol 1999; 31:1483-1494.

Schotten U, Filzmaier K, Borghardt B, Kulka S, Schoendube F, Schumacher C, Hanrath $P$ : Changes of the $\beta$-adrenergic signal transduction in compensated human cardiac hypertrophy depend on the underlying disease. Am J Physiol. 2000; 278:H2076-H2083.

Schotten U, Greiser M, Braun V, Karlein C, Schoendube F, Hanrath P. Effect of volatile anesthetics on the force-frequency relation in human ventricular myocardium: the role of the sarcoplasmic reticulum calcium-release channel. Anesthesiology 2001; 95(5):1160-1168.

Zarse M, Stellbrink C, Athanatou E, Robert J, Schotten U, Hanrath P. Verapamil prevents stretch-induced shortening of atrial effective refractory period in langendorffperfused rabbit heart. J Cardiovasc Electrophysiol 2001; 12(1):85-92.

Schotten U, Ausma J, Stellbrink C, Sabatschus I, Vogel M, Frechen D, Schoendube F, Hanrath P, Allessie MA. Cellular mechanisms of depressed atrial contractility in patients with chronic atrial fibrillation. Circulation 2001; 103(5):691-698.

Schroth SC, Schotten U, Alkanoglu O, Reyle-Hahn MS, Hanrath P, Rossaint R. Xenon does not impair the responsiveness of cardiac muscle bundles to positive inotropic and chronotropic stimulation. Anesthesiology 2002; 96(2):422-427. 
Schotten U, Greiser M, Benke D, Buerkel K, Ehrenteidt B, Stellbrink C, VazquezJimenez JF, Schoendube F, Hanrath P, Allessie M. Atrial fibrillation-induced atrial contractile dysfunction: a tachycardiomyopathy of a different sort. Cardiovasc Res 2002; 53(1):192-201.

Schotten U, Duytschaever M, Ausma J, Eijsbouts S, Neuberger HR, Allessie M. Electrical and Contractile Remodeling during the First Days of Atrial Fibrillation go Hand-in-Hand. Circulation 2003, 107:1433-1439.

Schotten U, Haase H, Frechen D, Greiser M, Stellbrink C, Vazquez-Jimenez JF, Morano I, Allessie M, Hanrath P. The L-Type Ca ${ }^{2+}$ Channel Subunits $\alpha_{1 \mathrm{C}}$ and $\beta_{2}$ are not Downregulated in Atrial Myocardium of Patients with Chronic Atrial Fibrillation. J Mol Cell Cardiol 2003, 35:437-443.

\section{Review articles:}

Schotten U, Hanrath P: B-Rezeptorenblocker: Ein neues Prinzip zur Therapie bei Herzinsuffizienz? Dtsch med Wschr (1997) 122:387-390

vom Dahl J, Schotten U, Sasse A: Medikamentöse Therapie der chronischen Herzinsuffizienz: Wann sind $\beta$-Rezeptorenblocker indiziert? Dtsch med Wschr (1999) 124: S48-S53

Schotten U, Hanrath P: Treatment of chronic cardiac insufficiency with beta-blockers: results of the cardiac insufficiency Bisoprolol Study II (CIBIS II) J Clin Basic Cardiol (2000) 3: 11-13.

Allessie M, Ausma J, Schotten U. Electrical, contractile and structural remodeling during atrial fibrillation. Cardiovasc Res 2002; 54(2):230-246.

Schotten U, Neuberger HR, Allessie M. The role of atrial dilatation during the domestication of atrial fibrillation. Proc Biophys Mol Biol 2003,82:151-162.

\section{Book chapters}

Schotten U, Allessie M: Electrical and mechanical remodeling of the atria: What are the underlying mechanisms, the time course and clinical relevance? pp345-352. In: Raviele A: Cardiac Arrhythmias, 2001, Springer.

Schotten U, Allessie M: Pathophysiology of the atrial fibrillation electrogram. In: Malik M: Dynamics in Electrocardiography. 2003, Blackwell, in press. 


\section{Curriculum Vitae}

Ulrich Schotten

16.1.1968

13.6.1987

1988-1995

$1991-1996$

6.6.1995

$8 / 1995-8 / 1998$

4.9 .1996

9/1998-8/1999

1999-2002

1.9 .2002
Born in Aachen

Final school exam

Study of medicine, Technical University Aachen (RWTH)

Doctoral fellow at Dept. of Cardiology, RWTH

Aachen

Graduation as medical doctor „MD“

Resident of internal medicine, Cardiology, RWTH Aachen

Graduation to „Dr. med."

Scholar of the Academy of Sciences of North-Rhine Westfalia at the Dept. of Physiology, University Maastricht

Post-doc at the Dept. of Physiology, University Maastricht

Assistant Professor of Physiology 

